\title{
Genetic polymorphisms in genes regulating renal ion excretion and diuretic drug effects
}

\author{
Doctoral Thesis \\ In partial fulfillment of the requirements for the degree \\ "Doctor rerum naturalium (Dr. rer. nat.)" \\ in the Molecular Medicine Study Program \\ at the Georg-August University Göttingen
}

\author{
Submitted by \\ Nawar Dalila \\ Born 03.03.1982 \\ Lattakia, Syria
}

Göttingen 2014 
Members of the thesis committee:

Supervisor

Name, Institute: Prof. Dr. Med. Jürgen Brockmöller, Institute of Clinical Pharmacology, GeorgAugust University Göttingen

Second member of the thesis committee

Name, Institute: Prof. Dr. rer. nat. Hubertus Jarry, Department of Clinical and Experimental Endocrinology, Georg-August University Göttingen

Third member of the thesis committee

Name, Institute: Prof. Dr. Med. Dörthe M Katschinski, Department of Cardiovascular Physiology, Georg-August University Göttingen

Date of disputation: 
Dedicated to Syria... 


\section{Affidavit}

Here I declare that my doctoral thesis entitled "Genetic polymorphisms in genes regulating renal ion excretion and diuretic drug effects" has been written independently with no other sources and aids than quoted.

\section{Nawar Dalila}

Göttingen, May 2014 


\section{Table of Contents}

Affidavit

Table of Contents

Acknowledgments VI

Abstract VII

List of figures IX

List of tables ..X

Abbreviations XII

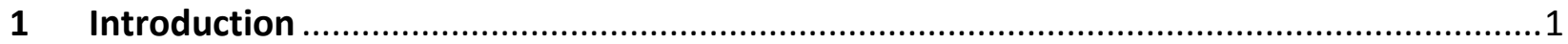

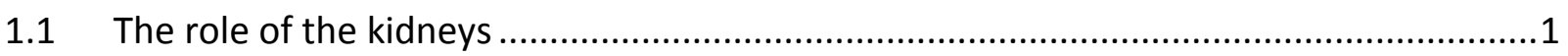

1.1.1 The nephron: Anatomy and function ..........................................................

1.2 Biomedical impact of renal salt and water regulation ..........................................

1.3 Major renal salt transporters and their regulatory networks ......................................

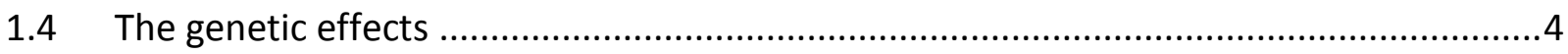

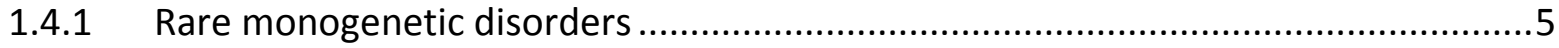

1.4.2 Common genetic variation (Frequent multi-allelic variation)..............................6

1.4.3 Ethnic differences....................................................................................

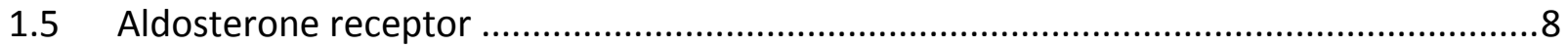

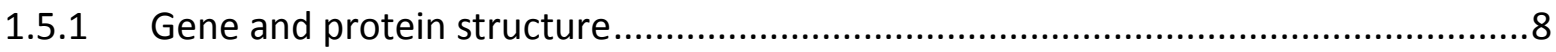

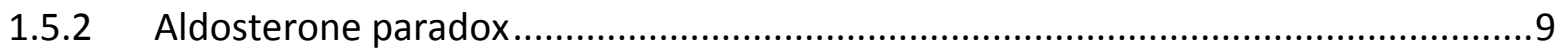

1.5.3 Aldosterone receptor polymorphisms ......................................................10

1.6 With-no-Lysine kinases (WNKs) ...................................................................... 11

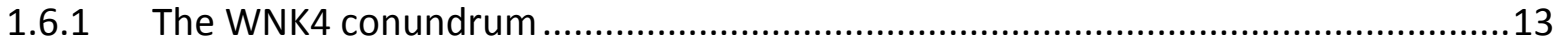

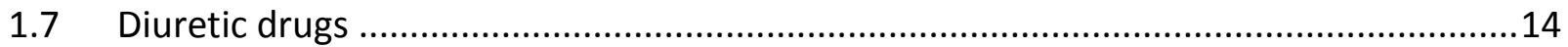

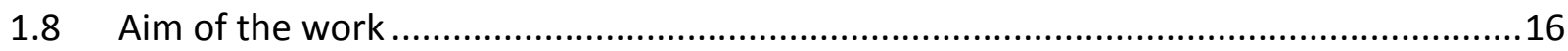

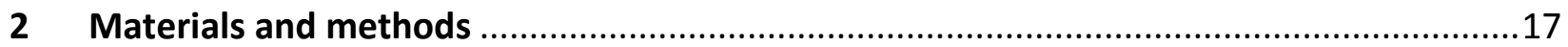

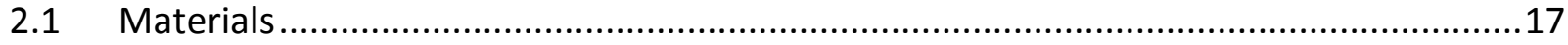

2.1.1 Reagents, kits, media and enzymes ...............................................................17 


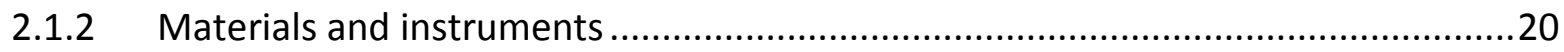

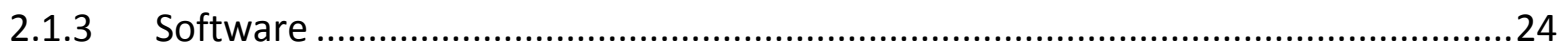

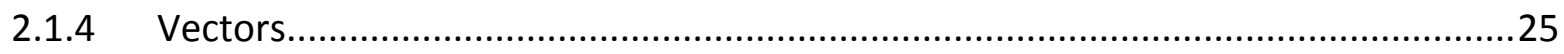

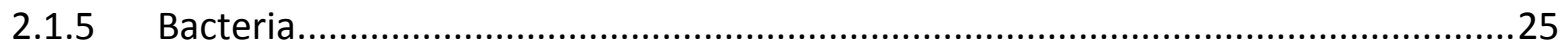

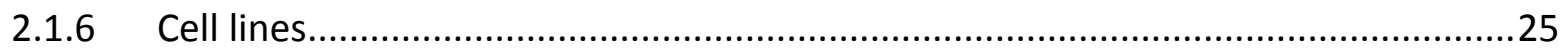

2.2 Summary of the clinical studies...........................................................................26

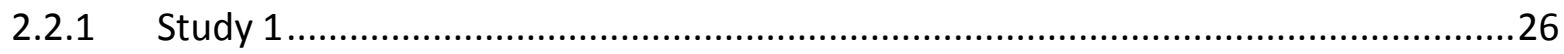

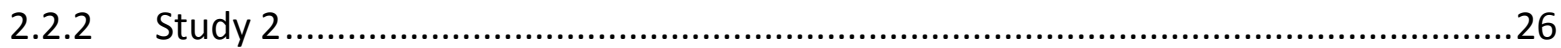

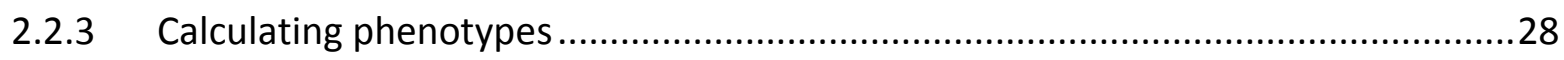

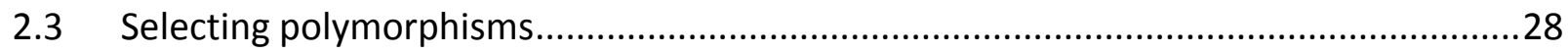

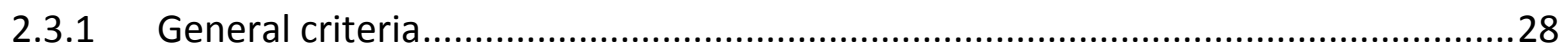

2.3.2 Aldosterone receptor polymorphisms ......................................................28

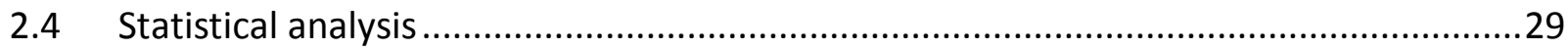

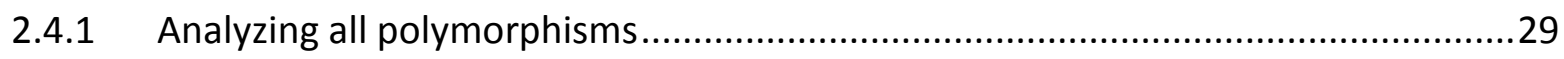

2.4.2 Aldosterone receptor polymorphisms analysis .........................................30

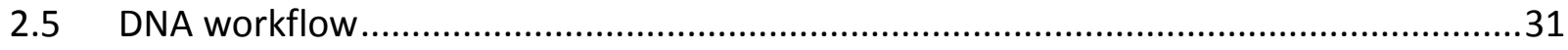

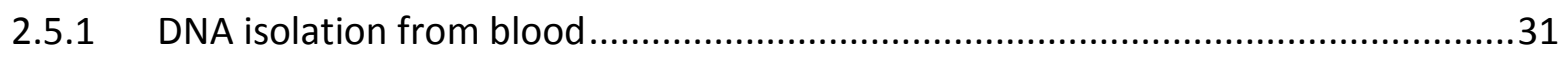

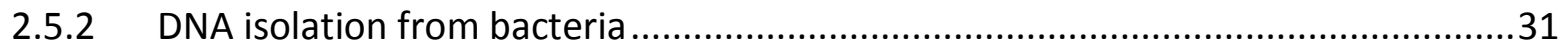

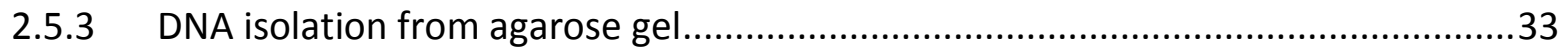

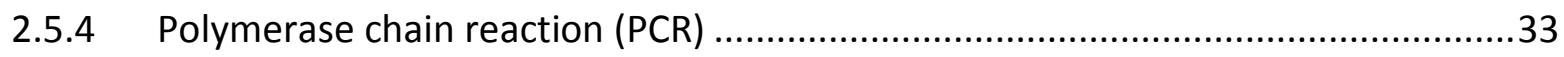

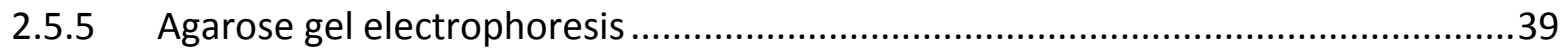

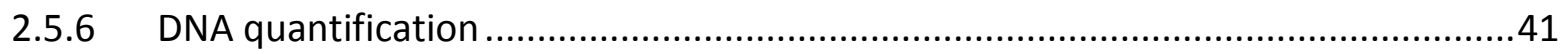

2.5.7 Exonuclease and endonuclease restriction digestion ....................................42

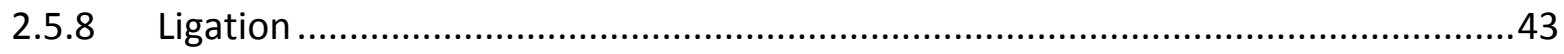

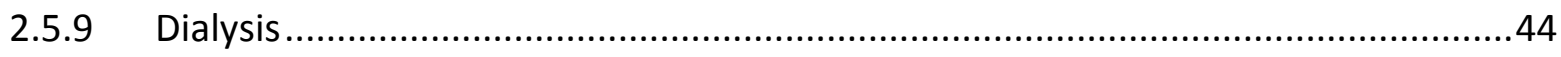




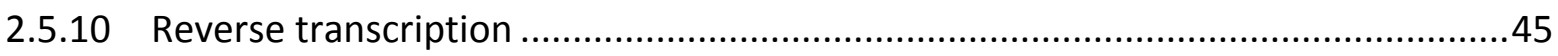

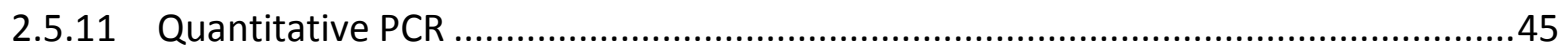

2.6 Sequencing and genotyping workflow ..........................................................47

2.6.1 Genotyping by the Single Nucleotide Primer Extension Method SNaPShot ${ }^{\mathrm{TM}}$........47

2.6.2 Dideoxy chain termination (Sanger) sequencing ...........................................51

2.6.3 Massive parallel sequencing (Next generation sequencing) ................................53

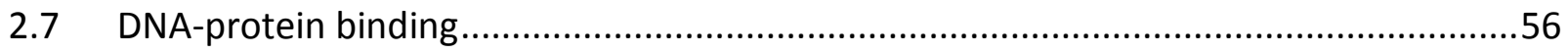

2.7.1 Electrophoretic mobility shift assay (EMSA) .................................................56

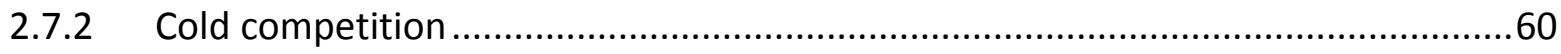

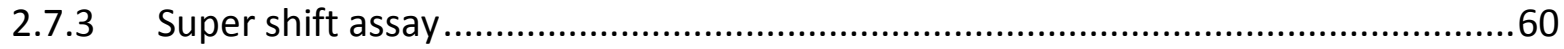

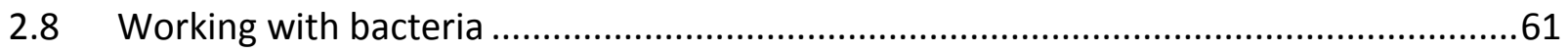

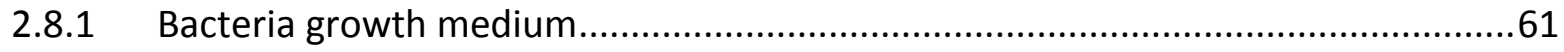

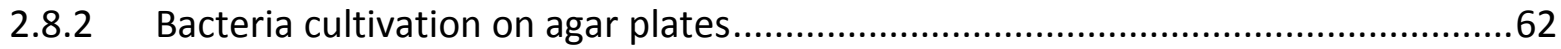

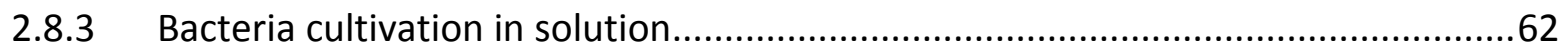

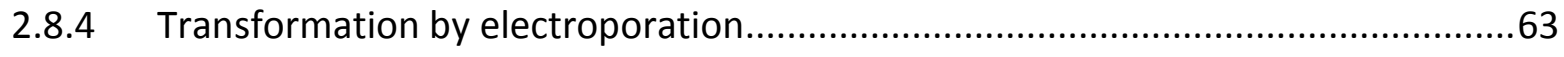

2.8.5 Making bacteria reservoir (Stock) ................................................................63

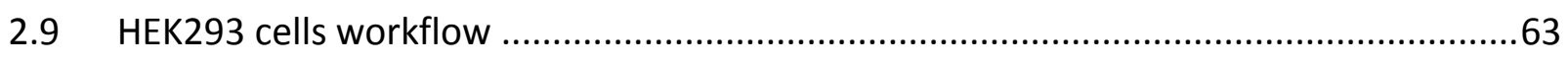

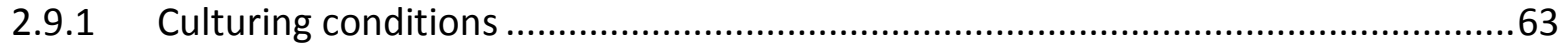

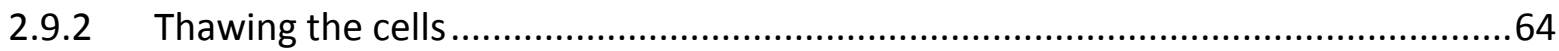

2.9.3 Counting the cells with Neubauer-cell chamber............................................64

2.9.4 Transient transfection and luciferase reporter gene assay ...............................65

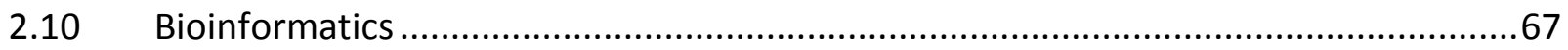

2.10.1 Calculating the linkage disequilibrium using HaploView ${ }^{\circledR}$ v4.2 ….......................67

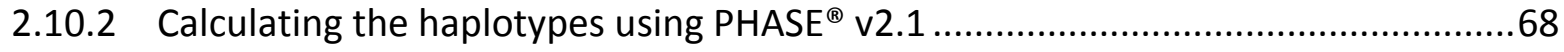

2.10.3 Protein function prediction tools ........................................................69 
2.10.4 Transcription factor prediction (TRANSFAC ${ }^{\circledR}$ ) ............................................. 70

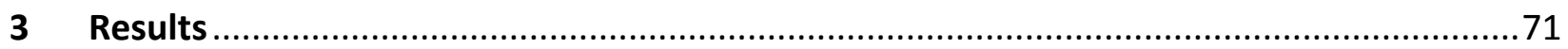

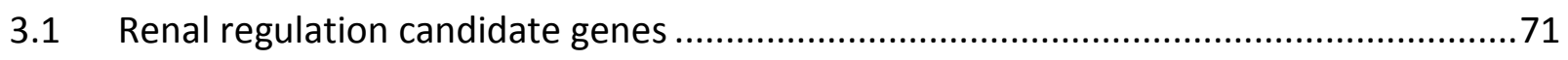

3.2 Selected and genotyped polymorphisms .......................................................... 72

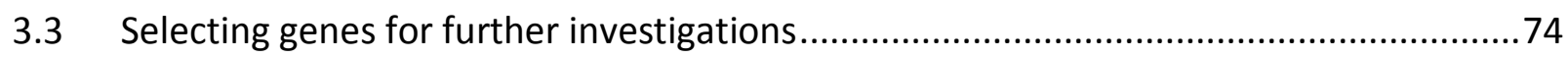

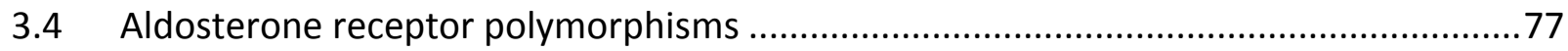

3.4.1 Phenotype-genotype association ............................................................. 77

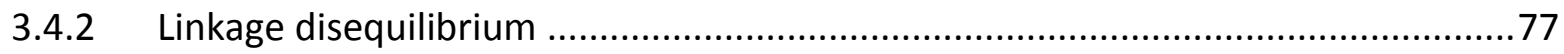

3.4.3 Effects on sodium and chloride excretion and potassium excretion.....................80

3.4.4 Comparing the effects of the polymorphisms with the pharmacokinetic effects...85

3.5 Functional study of the intron 3 polymorphism ( $r$ 3857080) in the aldosterone receptor

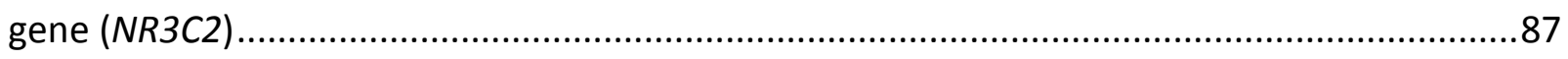

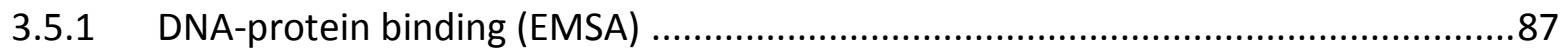

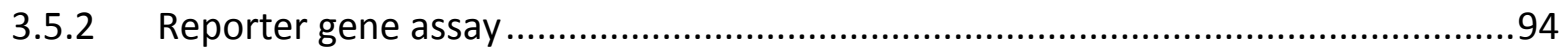

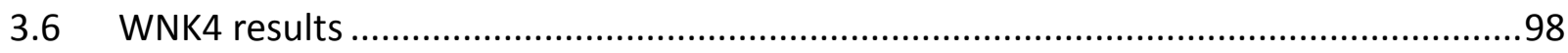

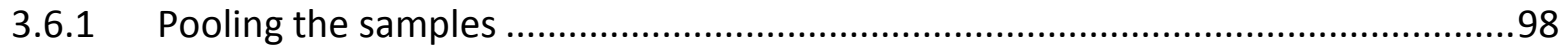

3.6.2 Confirming and validating the detected polymorphisms ...................................98

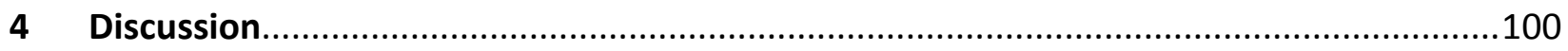

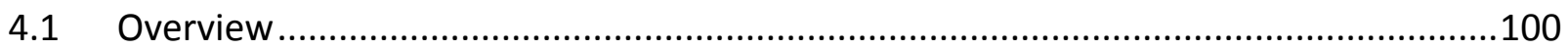

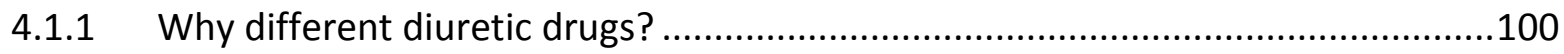

4.2 Phenotype-genotype analysis of the renal regulation candidate genes.....................101

4.3 Aldosterone receptor polymorphisms ........................................................... 102

4.3.1 Effects on ion excretion...........................................................................

4.3.2 Functional characterization of the intron 3 polymorphism ( $r s 3857080)$.............104

4.3.3 Possible clinical consequences of the minor A-allele carriers of the intron 3

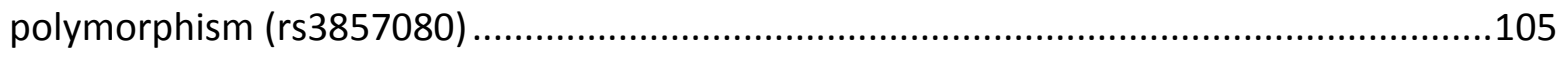

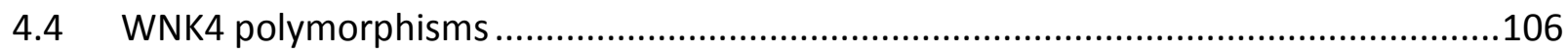




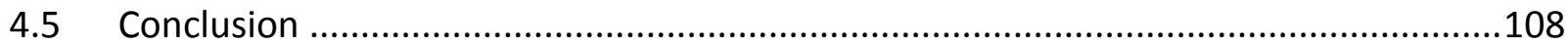

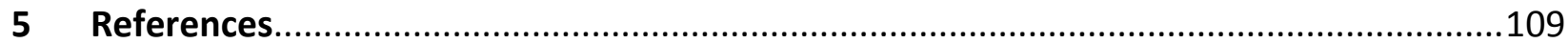

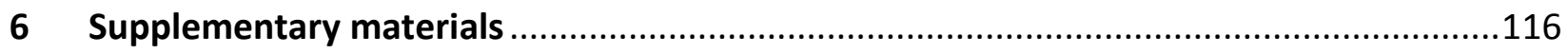

6.1.1 Genotyped polymorphisms, allele frequencies and Chi square calculations for

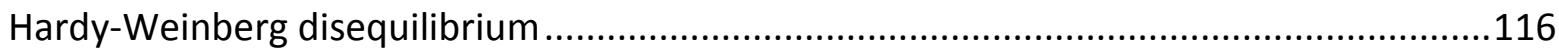

6.1.2 Effects of the twelve selected polymorphisms in $\mathrm{NR3C2}$ gene on $\mathrm{NaCl}$ and $\mathrm{K}^{+}$ excretion between 0 and $24 \mathrm{~h}$

6.1.3 Predicted transcription factors by TRANSFAC ${ }^{\circledR}$ 125

6.1.4 Validating WNK4 polymorphisms .128

6.1.5 Gene expression in 20 tissues panel (NR3C2 - WNK4) 


\section{Acknowledgments}

This research would have never seen the light without the support and guidance of my supervisor prof. Jürgen Brockmöller, to whom I am most thankful. My gratitude is for encouraging my research and for allowing me to grow as a research scientist.

I would like to thank my thesis committee members prof. Hubertus Jarry and prof. Dörthe Katschinski for letting our meetings be an enjoyable moment, and for your brilliant comments and suggestions.

My special thanks are for Dr. Stefan Viktor Vormfelde. You were tremendous mentor for me. Your words in our Tuesday morning meetings were priceless. Introducing me to your family pushed away a lot of the alienation sense and was not only of a big effect on my life, but also on my work.

In addition, I am grateful for Dr. Mladen Tzvetkov, Dr. Markus Schirmer who were always there to help and advise through the lab work. I learned a lot from you. Many thanks also to the bioinformatics department in the University of Göttingen for their valuable help, Mr. Martin Haubrock and Prof. Edgar Wingender.

I thank the technical assistant Mrs. Karoline Jobst and my fellow lab mates in the institute of clinical pharmacology and institute of pharmacology: Mohammad, Sina, Kate, Claudia, Kristin, Tina, Sebastian, Steffi, Manar, Joao, Robert, Jiayin, Konrad, Ali, PL, Sumon, Farah, Steffi, Anita and Simran. Thanks for all the stimulating discussions also through our "Kaffeepause", for the late nights we were working together before deadlines, and for all the fun we have had over the last three years.

To my family, words cannot express how grateful I am, for having you first and for your all sacrifices. My father Taufik, my mother Faten, my two brothers Zewar and Nawras and my little princess sister Raghdaa. I can simply say: You were always with me.

To my beloved wife Alak, my appreciations for your sleepless nights you spent with me, for all your support at the moments where nobody was there to answer. Your passion empowered me always through the way. I love you. 


\section{Abstract}

Regulation of human salt and fluid homeostasis is of basic biological importance. Kidney functions allow surviving under a wide variety of conditions with high or low salt diets and with high or low intake of fluids, even over long periods of times. Ion and water excretion is regulated by a complex network which responds to the internal and environmental conditions. The response to hypovolemia could lead to retaining sodium and excreting more potassium, while in hyperkalemia the excretion of potassium may not be accompanied with differences in the sodium chloride excretion. This controlling network consists mainly of the with-no-lysine kinases (WNKs) and the mineralocorticoid receptor (aldosterone receptor, MR) and their downstream effectors. Genetic polymorphisms in ion transporters were shown to affect the ionbalance excretion with and without diuretic drugs, but no comprehensive study has been performed to study the effects of the polymorphisms in the regulating genes.

229 Healthy Caucasian volunteers from two clinical studies under different diuretic drugs and under sodium chloride restriction days were genotyped for 39 polymorphisms in 11 genes. Two genes arose as candidates for further investigation, the aldosterone receptor gene NR3C2 and the with-no-lysine 4 kinase gene WNK4. Twelve polymorphisms in the NR3C2 gene were selected for further analysis. The association between ion excretion and the minor A-allele of the intron 3 polymorphism ( $r$ 3857080) was further investigated in silico and in vitro. The WNK4 exon regions were sequenced for all healthy volunteers in both clinical studies by massive parallel sequencing (Next generation sequencing).

The intron 3 polymorphism ( $r 33857080$ ) in the NR3C2 gene was of high impact mostly on potassium excretion in both clinical studies. The effect of this polymorphism was seen after the sodium chloride restriction days and after the different used diuretics, but it was not seen after torsemide which may have antialdosteronergic effect. In silico and in vitro studies showed that the intron 3 polymorphism region has a possible binding site for the transcription factor LHX4, with higher affinity to bind when the double-strand DNA corresponded to the minor A-allele. The same region had an activating effect in reporter gene assays, but there was no consistent difference between the two different alleles. The WNK4 gene appeared to be not very polymorphic. The massive parallel sequencing of the whole exon regions of the WNK4 gene in 
both clinical studies revealed only five non-synonymous polymorphisms which were confirmed by Sanger-sequencing. Two novel polymorphisms in the kinase region of the WNK4 (S239W and V358A) were predicted to have deleterious effect on the protein function.

Concerning the medical impact, carriers of the A-allele of rs3857080 may be more prone to hypokalemia from diuretic therapy and its devastating consequences than carriers of the major G-allele. The A-allele of the intron 3 polymorphism (rs3857080) may predict a sub-optimal outcome from diuretic therapy and heart diseases. More in vitro studies should follow, first to confirm the possible impact of the intron 3 polymorphism (rs3857080) in the NR3C2 gene, and second to confirm the consistency of the bioinformatics predictions on the WNK4 polymorphisms with the real effects. 


\section{List of figures}

Figure 1: The nephron and its subdivisions 1

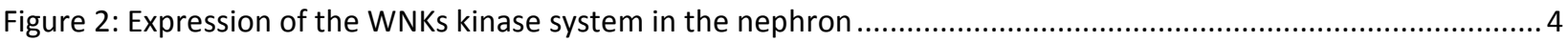

Figure 3: Transporters in the different nephron parts, diuretics and their targets ........................................... 6

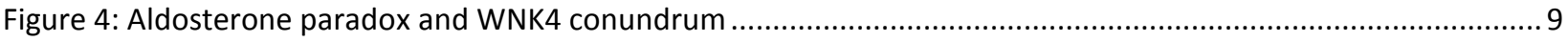

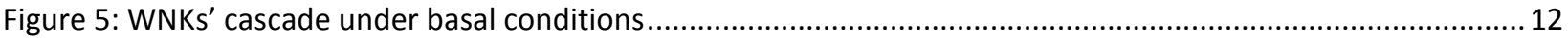

Figure 6: Aim of the work: Genetic polymorphisms in genes regulating renal ion excretion and diuretic drug effects

Figure 7: Schematic view of the two clinical studies performed by the institute of clinical pharmacology ............... 27

Figure 8: Agarose gel image of 5 PCR products, with and without Q-solution .................................................. 35

Figure 9: Analytical digestion for pOTB7+LHX4 plasmid DNA using Ecorl restriction enzyme..............................43

Figure 10: The two major steps for SNaPShot ${ }^{\mathrm{TM}}$ genotyping method ...........................................................48

Figure 11: WNK4 gene with the covered regions by the target enrichment. .....................................................5

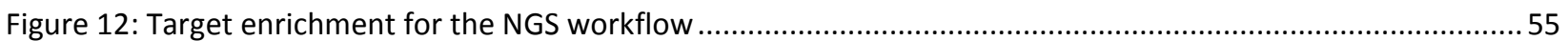

Figure 13: Preparing the (.ped) and (.info) files for HaploView ${ }^{\circledR}$ v4.2 ….....................................................67

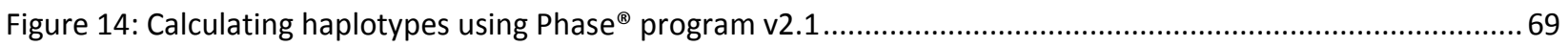

Figure 15: Linkage disequilibrium among the investigated polymorphisms..................................................... 79

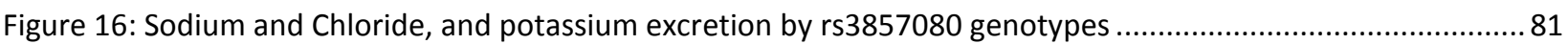

Figure 17: Differences in urinary sodium\&chloride, and potassium excretion with rs3857080 and Ile180Val (rs5522)

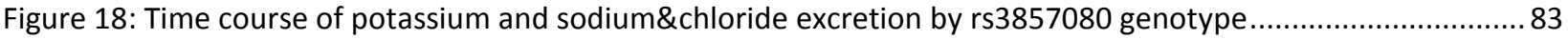

Figure 19: Variation in $24 \mathrm{~h}$ electrolyte excretion explained by ten genetic polymorphisms and urinary drug

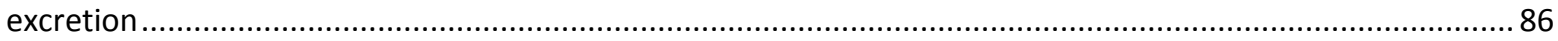

Figure 20: Electrophoretic mobility shift assay for minor-A and major-G alleles of rs3857080 ...........................8 88

Figure 21: Electrophoretic Mobility Shift Assay for rs3857080 with HEK293 nuclear cell extracts ..........................89

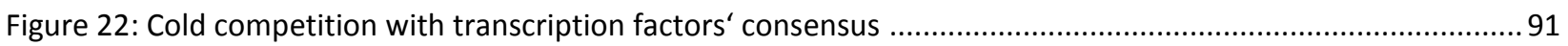

Figure 23: Aligned sequences of the rs3857080 region with LHX4 and Barx1 consensus. .................................... 91

Figure 24: EMSA for rs3857080 and LHX4 consensus and their mutated sequences..........................................93

Figure 25: rs3857080 region inserted in the pGL3-promoter vector ...........................................................94

Figure 26: Reporter gene assay for the rs3857080 major-G, minor-A and mutated alleles ................................95

Figure 27: re-cloning LHX4-ORF from pOTB7 into pcDNA3.1 vector. .........................................................96

Figure 28: Reporter gene assay for the rs3857080 major-G, minor-A and mutated alleles in the presence or absence

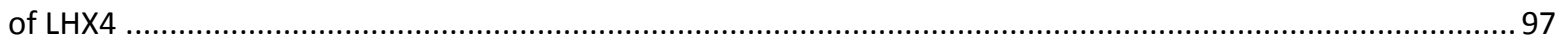

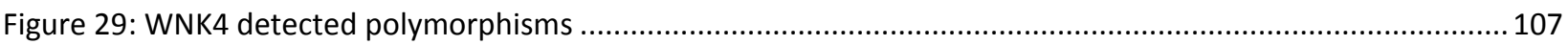




\section{List of tables}

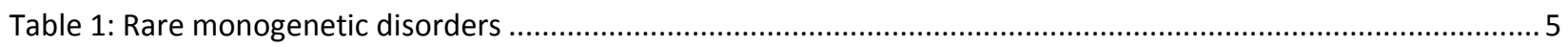

Table 2: Frequent genetic variations in major renal salt transporters and their regulatory proteins ........................ 7

Table 3: Known aldosterone receptor genotype-phenotype associations .......................................................... 10

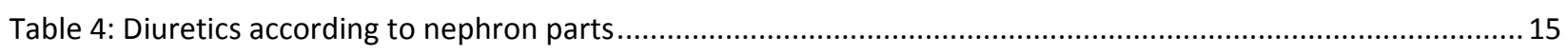

Table 5: Comparing different statistical models with different complexity .....................................................30

Table 6: Buffers used in DNA isolation from bacteria by chloroform extraction (Mini-Prep)................................. 31

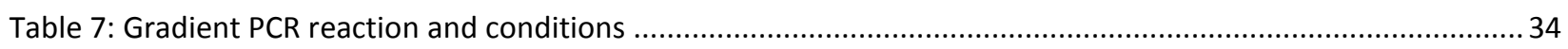

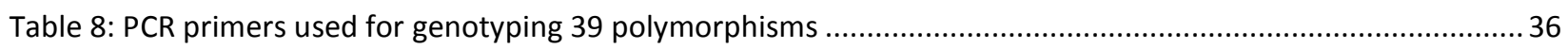

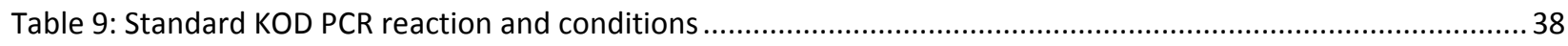

Table 10: Designed primers for amplifying the open reading frame of LHX4 from pOTB7 vector ..........................39

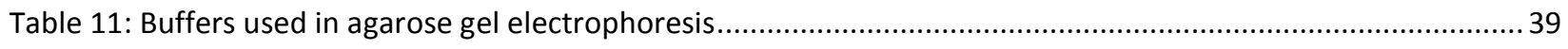

Table 12: Used gene expression assays (Applied Biosystems, Darmstadt) ...................................................46

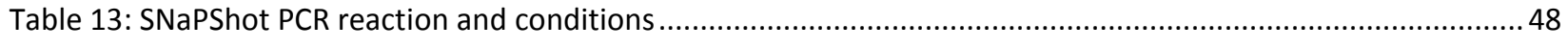

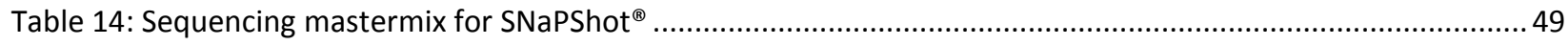

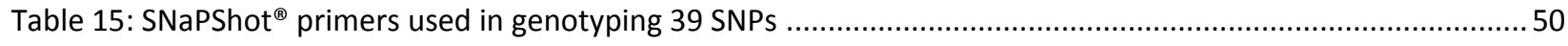

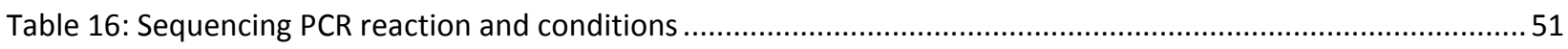

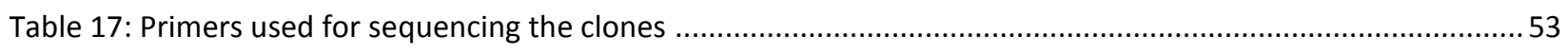

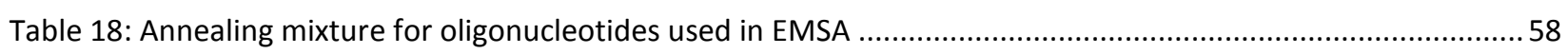

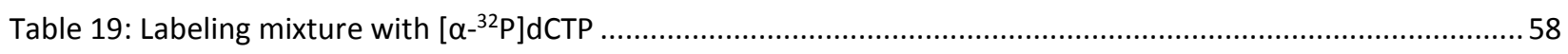

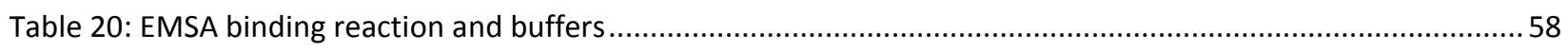

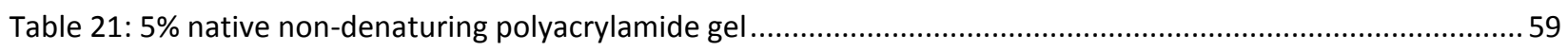

Table 22: Oligonucleotides used for electrophoretic mobility shift assays (EMSA) ...........................................60

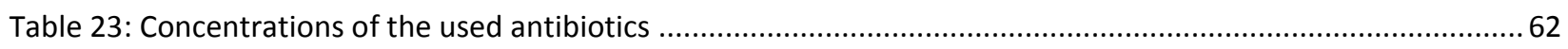

Table 24: Oligonucleotides used in the different cloning procedures and luciferase assay ..................................6 66

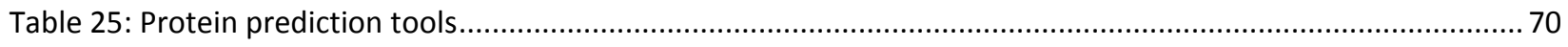

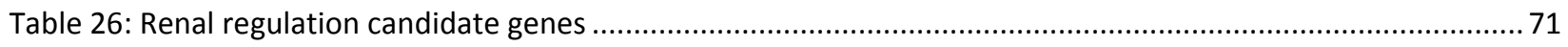

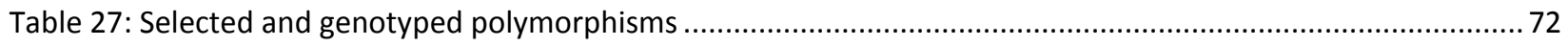

Table 28: P-values from repetitive analyze of covariance (RANCOVA) of studied polymorphisms and haplotypes ... 75

Table 29: P-values from analyze of covariance (ANCOVA) of studied polymorphisms and haplotypes in the

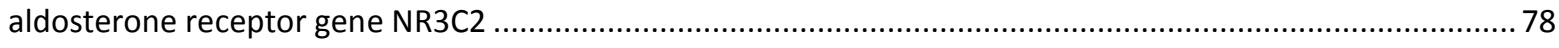

Table 30: Mean urinary $24 \mathrm{~h}$ excretion and differences in $24 \mathrm{~h}$ excretion of volume and electrolytes in relation to

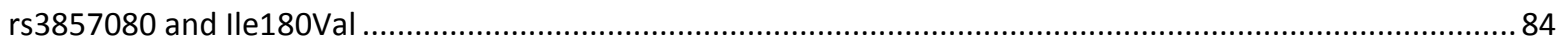

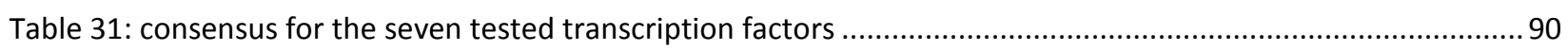


Table 32: Pooled DNA samples into four different groups from two clinical studies ............................................98

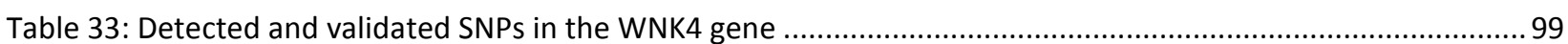

Table 34: protein function predictions for the five validated polymorphisms in the WNK4 gene ...........................99

Table 35: percentage of the polymorphisms through the studied genes ....................................................... 106 


\section{Abbreviations}

\begin{tabular}{|c|c|}
\hline ACE & Angiotensin converting enzyme \\
\hline ADD & Alpha-adducin \\
\hline $\mathrm{AF}$ & Allele frequency \\
\hline ANP & Atrial natriuretic peptide precursor \\
\hline APS & Ammonium persulfate \\
\hline BFT & Bumetanide, furosemide, torsemide \\
\hline bp & Base pair \\
\hline$C D$ & Collecting duct \\
\hline cDNA & Complimentary or copy DNA \\
\hline CT & Connecting tubule \\
\hline DCT & Distal convoluted tubule \\
\hline $\mathrm{dd} \mathrm{H}_{2} \mathrm{O}$ & bi-distilled Water \\
\hline ddNTP & Dideoxynucleoside triphosphates \\
\hline DMEM & Dulbecco's Modified Eagle Medium \\
\hline DMSO & Dimethylsulfoxide \\
\hline DNA & Desoxyribonucleic acid \\
\hline $\mathrm{dCTP}$ & Deoxycytidine triphosphate \\
\hline dNTP & Deoxynucleoside Triphosphate \\
\hline DTT & Dithiothreitol \\
\hline EDTA & Ethylene di-amine tetra-acetic acid \\
\hline $\mathrm{ENaC}$ & Epithelial sodium channel \\
\hline et al. & Et alii \\
\hline FAM & 6-Carboxyfluorescein \\
\hline g & Gravity acceleration $\left(9.81 \mathrm{~m} / \mathrm{s}^{2}\right)$ \\
\hline h & Hour \\
\hline $\mathrm{HCT}$ & Hydrochlorothiazide \\
\hline HEPES & 4-(2-hydroxyethyl)-1-piperazineethanesulfonic acid \\
\hline K & Potassium \\
\hline $\mathrm{kb}$ & Kilo base pairs \\
\hline KCNJ1 & Potassium inwardly-rectifying channel, subfamily J, member 1 \\
\hline kV & Kilo volt \\
\hline LB & Luria-Bertani medium \\
\hline M & Molarity \\
\hline $\mathrm{MR}$ & Mineralocorticoid receptor (Aldosterone receptor) \\
\hline mRNA & Messenger RNA \\
\hline $\mathrm{NaCl}$ & Sodium chloride \\
\hline NCC (TSC) & Sodium chloride co-transporter (Thiazide sensitive co-transporters) \\
\hline
\end{tabular}


NEDD4L

NGS

NKCC2

$N R 3 C 2$

OSR1

PCR

PHA1

PHA2 (FHHt)

ROMK

rpm

RT

SDS

SGK1

SLC12A3

SNP

SPAK

TAL

Taq

TBE-Buffer

TE-Buffer

TEMED

TRIA

Tris

$\mathrm{U}$

$\mathrm{v} / \mathrm{v}$

Vol

$w / v$

WNK
Neural precursor cell expressed, developmentally down-regulated 4-

like, E3 ubiquitin protein ligase

Next generation sequencer

Sodium potassium di-chloride co-transporter

Nuclear receptor subfamily 3, group C, member 2

Oxidative stress response kinase 1

Polymerase chain reaction

Pseudohypoaldosteronism type 1

Pseudohypoaldosteronism type 2 (Familial hyperkalemia and

hypertension type 2, Gordon syndrome)

Renal outer medullary potassium channel

Revolutions per minute

Room temperature

Sodium dodecyl sulfate

Serum/glucocorticoid regulated kinase 1

Solute carrier family 12 member 3

Single nucleotide polymorphism

STE20/SPS1-related proline/alanine-rich kinase

Thick ascending part of loop of Henle

Thermus aquaticus

Tris-Borat-EDTA-buffer

Tris-hydroxymethyl-aminomethan-EDTA-buffer

$\mathrm{N}, \mathrm{N}, \mathrm{N}^{\prime}, \mathrm{N}^{\prime}$-Tetramethylethylenediamine

Triamterene

Tris hydroxymethyl aminomethane

Unit

Volume per volume

Volume

Weight per volume

With-no-lysine 


\section{Introduction}

\subsection{The role of the kidneys}

The two kidneys in the human body are responsible for a number of major functions. These functions include activating or producing hormones, filtering and removing a number of toxins from the blood and keeping the salt and water homeostasis in the body. The kidneys can activate vitamin $D$ and produce erythropoietin. Removing some toxins involves metabolism within the kidneys and excretion, particularly of the hydrophilic metabolites in the urine. Contribution to homeostasis partially means regulation of the acid-base balance and the electrolyte balance, which could lead directly to the regulation of the blood pressure. The major functional unit in the kidneys is the nephron which is responsible for the filtering, secreting and reabsorbing functions (Figure 1). Each kidney has approximately one million nephrons. Each nephron is an independent unit, until it merges with one or more nephrons with the collecting duct (Boron and Boulpaep, 2012).

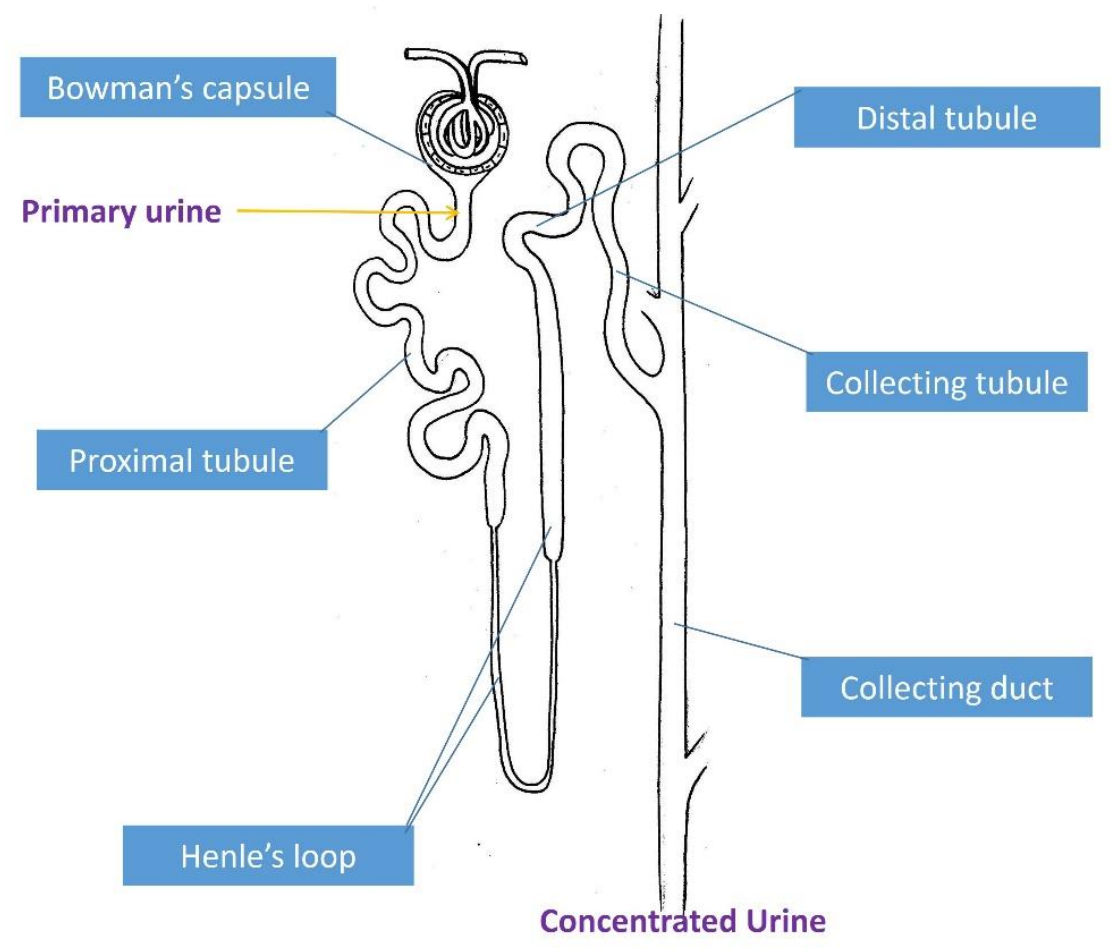

Figure 1: The nephron and its subdivisions 


\subsubsection{The nephron: Anatomy and function}

Each nephron is divided into several functional parts (Figure 1). These functional parts differ by their role which is directly related to the type of transporters, regulators and receptors that could be found in this exact part. The nephron starts with the Bowman's capsule followed by the proximal tubule, the loop of Henle (descending and ascending), the distal convoluted tubule (which is further divided to part 1 proximal and 2 distal depending on the sensitivity to the aldosterone), the collecting tubule and finally the collecting duct.

In the glomerular capillary loops, ultrafiltration of plasma fluid into the Bowman's capsule yields the primary urine. In the proximal tubules, approximately $70 \%$ of the ultrafiltrate is retrieved by isosmotic reabsorption of sodium and chloride and water. In the thick portion of the ascending limb of Henle's loop, sodium and chloride are absorbed unaccompanied with water. In the distal tubule, sodium and chloride and water are again jointly reabsorbed. At the end of the nephron, the process involves an aldosterone-controlled exchange of sodium against potassium or proton $\left[\mathrm{H}^{+}\right]$. In the collecting tubule, vasopressin increases the epithelial permeability for water, which is drawn into the hyperosmolar environment of the renal medulla and thus retained in the body. As a result, concentrated urine enters the renal pelvis.

\subsection{Biomedical impact of renal salt and water regulation}

Regulation of a single cell and total organism salt and fluid contents is of basic biological importance for any higher organism living outside the water. In humans, kidney functions allow to survive under a wide variety of conditions with high or low salt diets and with high or limited intake of fluids even over long periods of times.

There is strong evidence that reduced renal salt elimination may result in hypertension. For instance, treatment with glucocorticoids or aldosterone analogues increased blood pressure (both increase renal salt retention). There is also strong evidence that at least a subset of the human population, those who are salt sensitive (e.g. Elderly, African Americans, and obese individuals) may have a greater decrease in blood pressure with reduced salt intake due to a lower activation of the rennin-angiotensin-aldosterone system (Frisoli et al., 2012). Mechanisms in which salt retention affects blood pressure may still be incompletely understood, but include: 
1) inhibiting the sodium pump by high sodium and low potassium concentrations in the extracellular fluid leading to increased intracellular sodium, and driving calcium into cells, which induces smooth muscle contraction and thus increases peripheral vascular resistance (Adrogue and Madias, 2007). 2) Turning the excess sodium to an osmotically inactive form by storing it in the subcutaneous lymphatic system then acts as a fluid-buffering system to reduce the blood pressure increase during excessive salt intake (Machnik et al., 2009). And 3) it is suggested that many individual genes influence the body's handling of sodium to varying degrees (O'Shaughnessy and Karet, 2006).

\subsection{Major renal salt transporters and their regulatory networks}

A multi-gene network is essential to the regulation of renal sodium and potassium excretion. Alteration in the signaling through the network can yield in different handling of the renal sodium and potassium with different consequences including different types of hypertension. The network includes kinases like the with-no-lysine kinases (WNKs), the Ste20-related prolinealanine-rich kinase (SPAK), oxidative stress response kinase (OSR1), and receptors like the mineralocorticoids receptor (MR, aldosterone receptor), and their effectors like the thiazide sensitive sodium chloride co-transporter (NCC), sodium-potassium-di-chloride co-transporters 2 (NKCC2), epithelial sodium channel $(\mathrm{ENaC})$, and renal outer medullary potassium channel (ROMK). Some evidence indicates that the kinase network normally functions as a molecular switch to change the mineralocorticoid receptor response in the kidney to either conserve sodium or excrete potassium, depending on whether aldosterone is induced by a change in dietary sodium or potassium (Castaneda-Bueno et al., 2012; Hoorn et al., 2011; Seva Pessoa et al., 2013; Welling et al., 2010).

The expression of this regulating system can differ within the different functional parts of the nephron, as shown in Figure 2. 


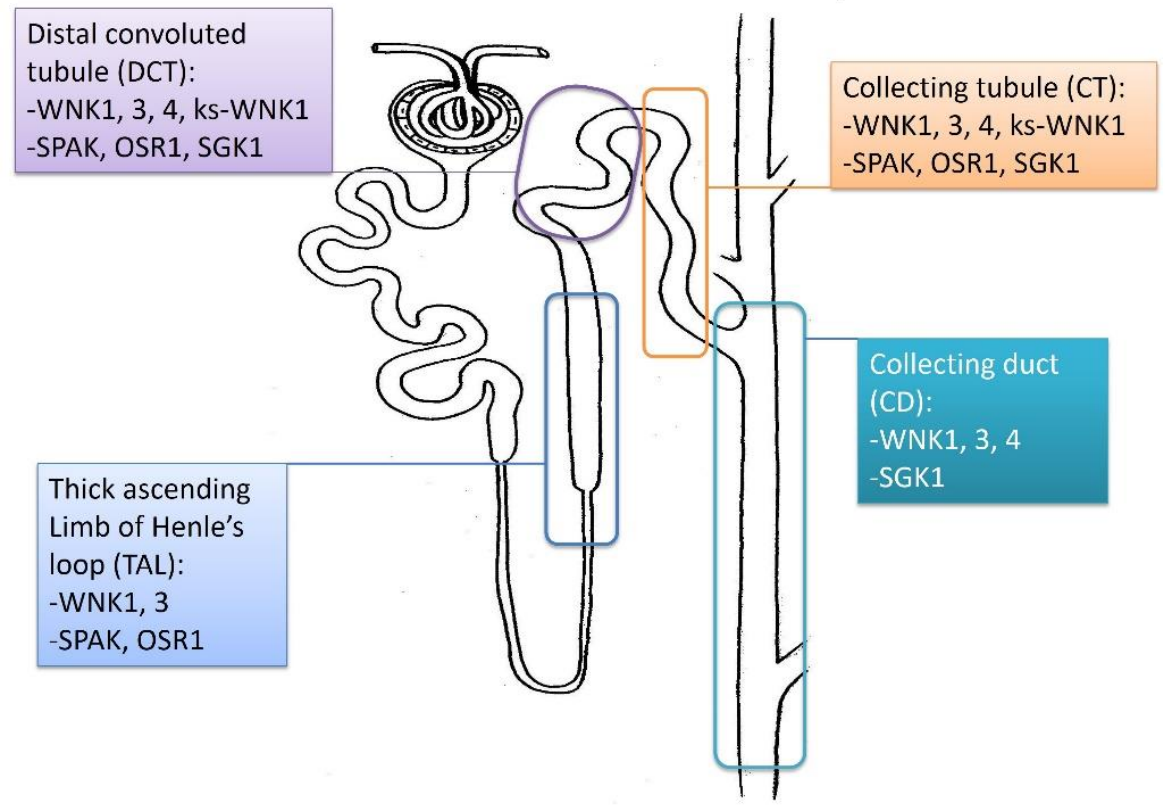

Figure 2: Expression of the WNKs kinase system in the nephron

\subsection{The genetic effects}

Genetic disorders usually involve the inheritance of a specific mutated disease-causing gene "Monogenetic disorders", such as sickle cell anemia. The mutated gene is passed down through a family, and each generation of children can inherit the gene that causes the disease. Rarely, one of these monogenic diseases can occur spontaneously in a child when parents do not have the disease gene, or there is no history of the disease in the family. This can result from a new mutation occurring in the egg or sperm that arise in that child.

Most genetic disorders are however "multifactorial inheritance disorders", meaning that they are caused by a combination of inherited mutations in multiple genes often acting together with environmental factors. Examples of such diseases include many commonly-occurring diseases, such as diabetes and hypertension, which are present in many people in different populations around the world.

Research on the human genome has shown that although many commonly occurring diseases are usually caused by inheritance of mutations in multiple genes at once, such common diseases can also be caused by rare hereditary mutations in a single gene. In these cases, gene mutations 
that cause or strongly predispose a person to these diseases run in a family, and can significantly increase each family member's risk of developing the disease. One example is hypertension, where inheritance of a mutated sodium-chloride co-transporter gene SLC12A3 leads to the risk of developing Gordon's syndrome.

\subsubsection{Rare monogenetic disorders}

Genetic variations in the genes coding networks mentioned above (Figure 2) seem to have a big role in salt homeostasis. A number of loss-of-function mutations may lead to hypotension like the loss of function mutations in NKCC2 causing Bartter's syndrome, loss of function mutations in NCC causing Gitelman's disease, loss of function mutations in ENaC that can cause the hypotension of pseudohypoaldosteronism type 1 (PHA1). While gain of function mutations may result in hypertension just like Gordon's syndrome and Liddle's syndrome (Table 1, Figure 3) (Lang et al., 2005).

Table 1: Rare monogenetic disorders

\begin{tabular}{|c|c|c|c|}
\hline Disease & Mutation & $\begin{array}{l}\text { Affected } \\
\text { transporter(s) }\end{array}$ & Symptoms \\
\hline Bartter's syndrome & Loss of function & NKCC2 & $\begin{array}{l}\text { Hypotension } \\
\text { Hypokalemic metabolic alkalosis }\end{array}$ \\
\hline Gitelman's syndrome & Loss of function & NCC & $\begin{array}{l}\text { Hypotension } \\
\text { Hypokalemic metabolic alkalosis }\end{array}$ \\
\hline $\begin{array}{l}\text { Pseudohypoaldosteronism Type } 1 \\
\text { (PHA I) }\end{array}$ & Loss of function & $\mathrm{ENaC}$ & $\begin{array}{l}\text { Hypotension } \\
\text { Hyperkalemia }\end{array}$ \\
\hline $\begin{array}{l}\text { Pseudohypoaldosteronism Type } 2 \\
\text { (PHA II, Gordon's syndrome) }\end{array}$ & (Gain) of function ${ }^{*}$ & NCC & $\begin{array}{l}\text { Hypertension } \\
\text { Hyperkalemia }\end{array}$ \\
\hline Liddle's syndrome & Gain of function & $\mathrm{ENaC}$ & $\begin{array}{l}\text { Hypertension } \\
\text { Hypokalemia }\end{array}$ \\
\hline
\end{tabular}

* There is no known gain of function mutation in the gene coding NCC (SLC12A3), but the regulators like WNK1 and WNK4. Deletion in large part of WNK1 gene can lead to excess in L-WNK1 protein and that may lead to pseudohypoaldosteronism type 2 (PHA II). Also a change in one specific amino acid (D561A) in WNK4 may lead to PHA II (Wilson et al., 2001). 


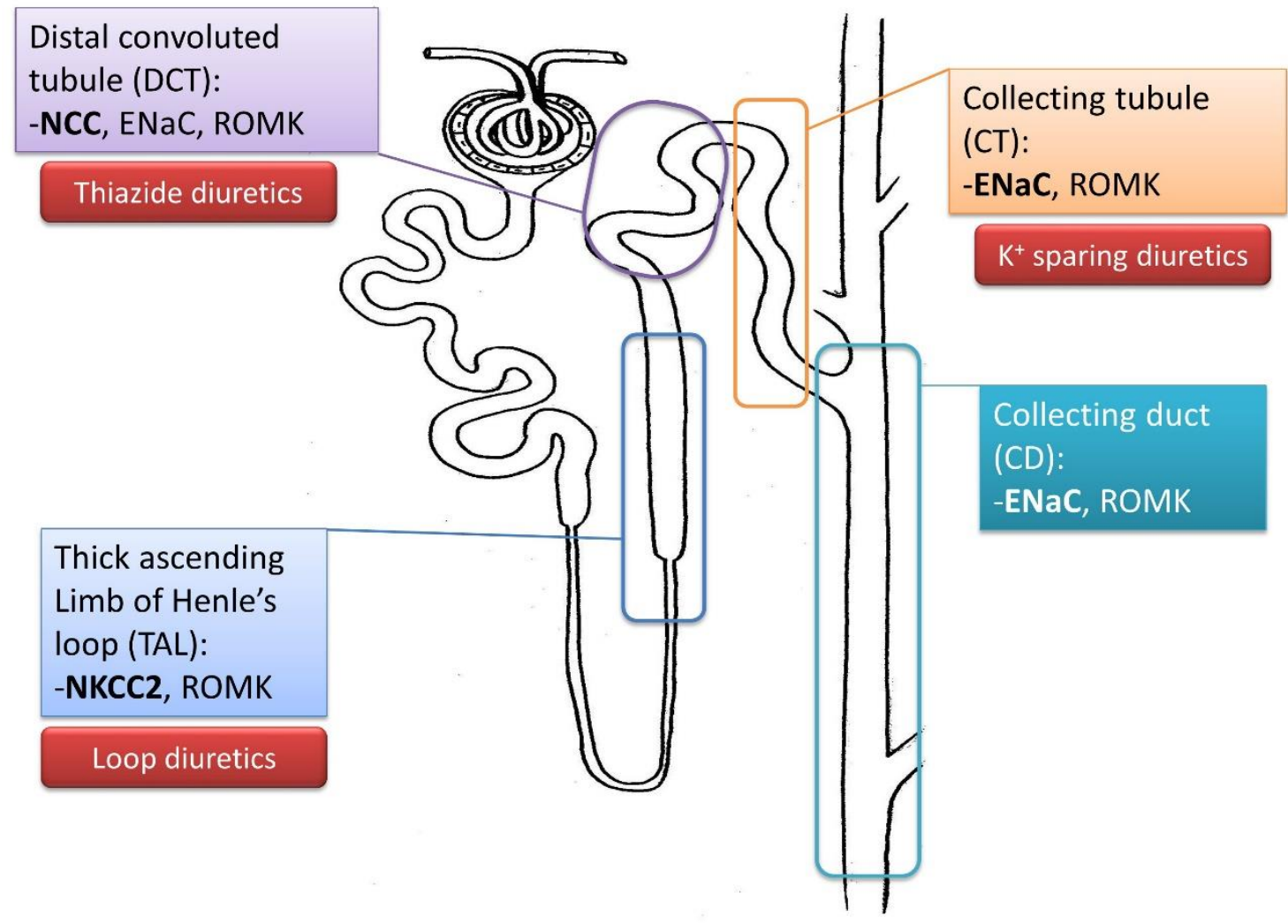

Figure 3: Transporters in the different nephron parts, diuretics and their targets

Diuretics are in the red boxes according to their targets (Marked in bold).

\subsubsection{Common genetic variation (Frequent multi-allelic variation)}

Many studies tried to elucidate the association between measurable renal-function related phenotypes and a number of frequent genetic variations. Table 2 summarizes some results about the association of some phenotypes with frequent genetic polymorphisms in the renal transporters, the kinase network and aldosterone receptor. 
Table 2: Frequent genetic variations in major renal salt transporters and their regulatory proteins

\begin{tabular}{|c|c|c|c|c|}
\hline Protein & Gene & Variation & Medical impact of polymorphism & Citation \\
\hline NKCC2 & SLC12A1 & rs2291340 & $\begin{array}{l}\text { Associated with HTN in Japanese } \\
\text { females even after Bonferroni } \\
\text { correction }\end{array}$ & $\begin{array}{l}\text { (lwai et al., } \\
\text { 2004) }\end{array}$ \\
\hline NCC & SLC12A3 & rs13306673 & $\begin{array}{l}\text { Associated with the response to } \\
\text { thiazide diuretics }\end{array}$ & $\begin{array}{l}\text { (Matayoshi et } \\
\text { al., 2004) }\end{array}$ \\
\hline $\mathrm{ENaC}$ & SCNN1 & $\begin{array}{l}\text { the most frequent } \\
\text { SCNN1B haplotype } \\
\text { (AAGT) }\end{array}$ & Stronger diuresis & $\begin{array}{l}\text { (Vormfelde et } \\
\text { al., 2007) }\end{array}$ \\
\hline ROMK & KCNJ1 & rs2846679 & Strong association with mean 24-h SBP & $\begin{array}{l}\text { (Tobin et al., } \\
\text { 2008) }\end{array}$ \\
\hline ClC-Ka & CLCNKa & rs1010069 & $\begin{array}{l}\text { Significantly associated with BP change } \\
\text { after Na-load in Hypertension patients }\end{array}$ & $\begin{array}{l}\text { (Barlassina et al., } \\
\text { 2007) }\end{array}$ \\
\hline NEDD4L & NEDD4L & rs4149601 & $\begin{array}{l}\text { Influences the efficacy of } \beta \text {-blocker and } \\
\text { diuretic-based antihypertensive } \\
\text { treatment both in terms of blood } \\
\text { pressure reduction and cardiovascular } \\
\text { disease protection }\end{array}$ & $\begin{array}{l}\text { (Svensson- } \\
\text { Farbom et al., } \\
\text { 2011) }\end{array}$ \\
\hline WNK1 & WNK1 & rs765250 & $\begin{array}{l}\text { Significant association with mean } 24- \\
\text { hour and nighttime SBP and with mean } \\
\text { nighttime DBP }\end{array}$ & $\begin{array}{l}\text { (Tobin et al., } \\
\text { 2005) }\end{array}$ \\
\hline WNK4 & WNK4 & agactttaga(G/A)gtggggtcta & $\begin{array}{l}\text { The frequency of the rare allele differed } \\
\text { significantly between hypertensive and } \\
\text { normotensive whites }\end{array}$ & $\begin{array}{l}\text { (Erlich et al., } \\
\text { 2003) }\end{array}$ \\
\hline $\begin{array}{l}\text { Aldosterone } \\
\text { receptor }\end{array}$ & NR3C2 & rs11099681, rs4835493 & $\begin{array}{l}\text { These two SNPs were significantly } \\
\text { associated with SBP }\end{array}$ & $\begin{array}{l}\text { (Montasser et } \\
\text { al., 2011) }\end{array}$ \\
\hline
\end{tabular}

HTN: Hypertension, SBP: Systolic blood pressure, DBP: Diastolic blood pressure.

\subsubsection{Ethnic differences}

A major topic in genomic variation of renal salt transport is related to ethnic differences. Such differences may have appeared through different environmental conditions during evolution and it is interesting in terms of basic biosciences to understand these relationships. In medicine, 
these ethnic differences are relevant concerning disease susceptibility, drug effects and side effects like the difference in response to furosemide between black and white populations due to the difference in active NKCC2 co-transporters (Chun et al., 2008). For reasons of feasibility we did not study ethnic differences in this work (The volunteers of our two clinical studies had German family origins).

\subsection{Aldosterone receptor}

The aldosterone receptor, also called the mineralocorticoid receptor (MR), is a nuclear hormone receptor which plays an important role in sodium reabsorption and potassium excretion. The major role of the aldosterone receptor in keeping the sodium homeostasis was identified in MRknockout mice model by the massive salt-waste phenotype (Berger et al., 1998). The functional role of the MR is partially mediated by transcriptional regulation of ENaC (Lifton et al., 2001; Mick et al., 2001; Pearce and Kleyman, 2007). Modulation of the renal outer medullary potassium channel (ROMK) mediated by the aldosterone receptor has also been suggested but less investigated (Arroyo et al., 2011; Fodstad et al., 2009).

\subsubsection{Gene and protein structure}

The assignment of the gene coding for the aldosterone receptor has been done almost 25 years ago (Morrison et al., 1990). The gene coding the aldosterone receptor is called NR3C2 (nuclear receptor subfamily 3, group $C$, member 2 ) and is located on chromosome 4 (q31.1 region). The gene spans almost $370 \mathrm{~kb}$ and is composed of nine exons. The first exon is untranslated, while the eight following exons are encoding the aldosterone receptor protein which consists of 984 amino acids.

The protein has three main regions, the N-terminal domain NTD (encoded by exon 2), the DNAbinding domain DBD (exon 3 and exon 4 are encoding the two zinc fingers in this domain) and finally the C-terminal ligand-binding domain LBD (encoded by the last five exons) (Viengchareun et al., 2007). The aldosterone receptor is located in the cytoplasm under the free-ligand-binding status. It translocates to the nucleus after the activation by aldosterone binding (Binart et al., 1991; Lombes et al., 1994). The aldosterone receptor could be phosphorylated in minutes also after activation by aldosterone (Le Moellic et al., 2004). The two activation types correspond to 
the slow genomic effects of MR and the fast non-genomic effects (Funder, 2005), but the fast non-genomic effects are still controversial.

\subsubsection{Aldosterone paradox}

The renal regulation of sodium and potassium balance have been shown to be independent (Castaneda-Bueno et al., 2012). This observation may lead to a better understanding of the different response from the aldosterone receptor to either hypovolemia or hyperkalemia. The major response to hypovolemia would be more sodium reabsorption without affecting potassium excretion, while in hyperkalemia, the sodium chloride is not affected but potassium excretion is elevated in the distal nephron. These two different responses term what is now known as "aldosterone paradox" (Halperin et al., 2006). The key point in these two different responses is believed to be the interaction between effects of the aldosterone and Angiotensin II (Figure 4) (Arroyo et al., 2011; Hoorn et al., 2011; Seva Pessoa et al., 2013).

A. Hypovolemia

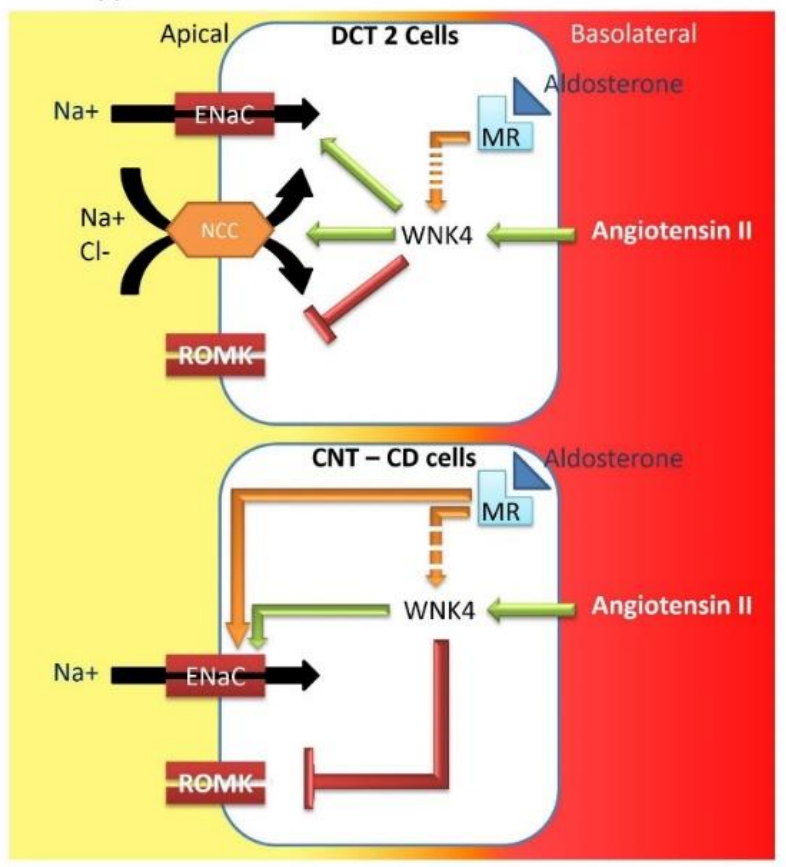

B. Hyperkalemia

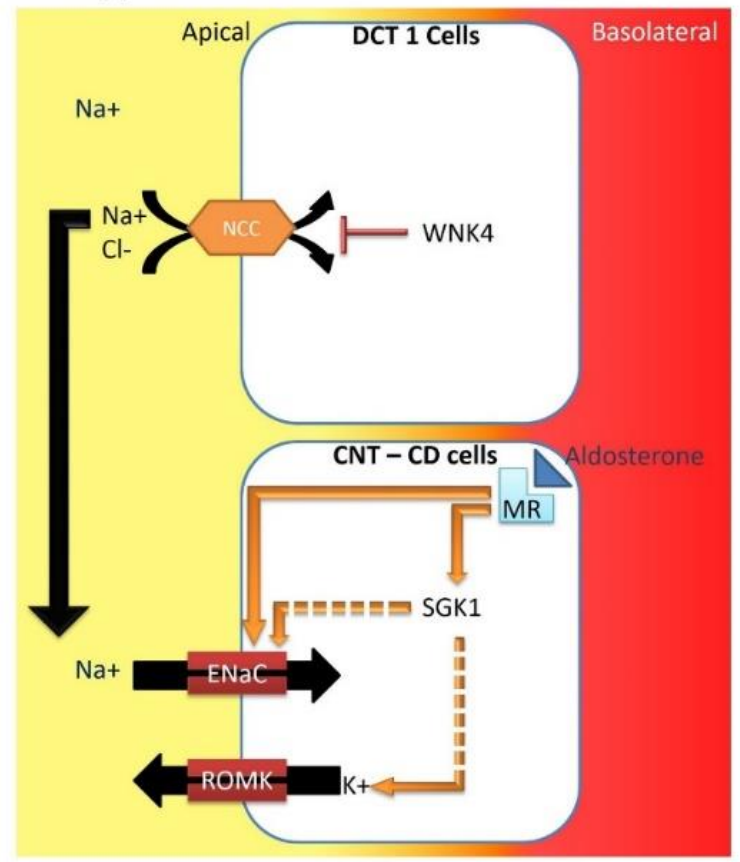

Figure 4: Aldosterone paradox and WNK4 conundrum

In hypovolemia (Part A), Angiotensin II leads to more aldosterone production and both will recruit WNKs-SPAK/OSR1 or SGK1 pathways to give the end effects of activating ENaC and NCC while blocking ROMK through WNK4. In hyperkalemia (Part B), WNK4 is blocking NCC in the DCT 1 part of the nephron leading to more sodium delivered to the last parts of the nephron in the CNT and $C D$ where the $\mathrm{Na}+\mathrm{K}+$ indirect driven exchange takes place 


\subsubsection{Aldosterone receptor polymorphisms}

A number of polymorphisms in the aldosterone receptor gene, $N R 3 C 2$, have been implicated with in vivo phenotypes. Table 3 shows the twelve polymorphisms which had been associated with specific biological or medical phenotypes. The lle180Val amino acid substitution (rs5522) has been especially implicated with neuropsychiatric phenotypes (DeRijk et al., 2006; Kortmann et al., 2013; Rovaris et al., 2013) however, diuretic drug effects have been poorly investigated in relation to these polymorphisms.

Table 3: Known aldosterone receptor genotype-phenotype associations

\begin{tabular}{|c|c|c|c|c|c|c|c|c|c|c|c|c|c|}
\hline Citation & $\begin{array}{l}\text { Affected } \\
\text { phenotype }\end{array}$ & 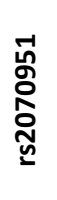 & 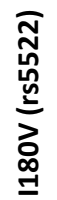 & 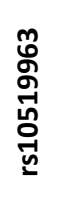 & 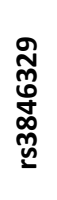 & 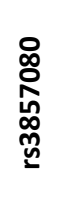 & 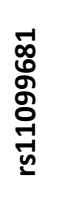 & 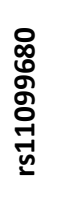 & 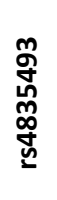 & 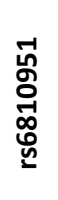 & 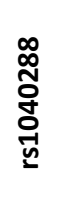 & 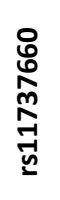 & 芯 \\
\hline (Song et al., 2011) & Blood pressure & & & $\uparrow$ & & & & & & $\uparrow$ & & $\uparrow$ & \\
\hline (Martinez et al., 2009) & Blood pressure & & $\downarrow$ & & & & & & & & & & \\
\hline (van Leeuwen et al., 2010) & Blood pressure & $\downarrow$ & & & & & & & & & & & \\
\hline $\begin{array}{l}\text { (Morales-Suarez-Varela et } \\
\text { al., 2011) }\end{array}$ & $\begin{array}{l}\text { Uncontrolled blood } \\
\text { pressure }\end{array}$ & & & & & & & $\uparrow$ & & & $\uparrow$ & & \\
\hline (Tobin et al., 2008) & $\begin{array}{l}\text { Night time systolic blood } \\
\text { pressure }\end{array}$ & & & & & $\downarrow$ & & & & & & & \\
\hline (Montasser et al., 2011) & $\begin{array}{l}\text { Blood pressure in } \\
\text { physically active subjects }\end{array}$ & & & & & & $\downarrow$ & & $\downarrow$ & & & & \\
\hline (van Leeuwen et al., 2011) & NR3C2 expression & $\uparrow$ & - & & & & & & & & & & \\
\hline (Derijk et al., 2008) & $\begin{array}{l}\text { Cortisol blood } \\
\text { concentrations with } \\
\text { rs2070951; heart rate with } \\
\text { Ile180Val }\end{array}$ & $\downarrow$ & $\uparrow$ & & & & & & & & & & \\
\hline (Klok et al., 2011) & $\begin{array}{l}\text { Morning cortisol in } \\
\text { depression }\end{array}$ & $\uparrow$ & - & & & & & & & & & & \\
\hline (Nossent et al., 2011) & Myocardial infarction & & & & & & & & & & & & $\uparrow$ \\
\hline (Pan et al., 2011) & Intelligence quotient & & & & $\uparrow$ & & & & & & & & \\
\hline
\end{tabular}




\subsection{With-no-Lysine kinases (WNKs)}

Protein kinases are important mediators in many cell processes. After their activation, they regulate downstream proteins by phosphorylation. Protein kinases have usually a conserved core (Hanks et al., 1988), they have usually a conserved lysine located in the subdomain II (Knighton et al., 1991). A novel class of protein kinases was discovered fourteen years ago where the conserved lysine was surprisingly located in the Subdomain I rather than subdomain II (Verissimo and Jordan, 2001; Xu et al., 2000). These kinases were termed as the

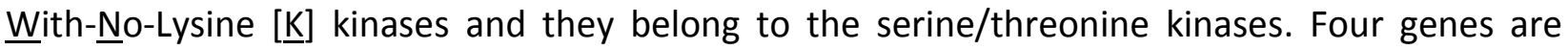
encoding the human WNKs, located in chromosomes 12, 9, $\mathrm{X}$ and 17 for the WNK1-4 respectively. WNKs are widely expressed, with high levels of WNK1 in the testis, heart and kidneys (O'Reilly et al., 2003). WNK2 is not expressed in the kidneys but in the heart, brain and colon (Verissimo and Jordan, 2001). WNK3 is expressed with low levels in brain, lung, kidneys, liver and pancreas and some fetal tissues (Holden et al., 2004; Verissimo and Jordan, 2001). WNK4 is found in tissues with secretory epithelia like kidneys, colon and blood brain barrier (Kahle et al., 2004; Verissimo and Jordan, 2001). There is also a truncated isoform of WNK1 lacking most of the kinase domain which is expressed only in the kidneys and called kidneyspecific WNK1 (ks-WNK1) (Xu et al., 2002).

WNKs contain multiple domains for protein-protein interactions other than the Kinase domain. For that, many studies have divided the WNKs' pathways into two categories: Catalytic way when it is contributing phosphorylation by the kinase domain (Figure $5 \mathrm{~A}$ ), and Non-catalytic way as the non-kinase dependent pathway (Figure 5 B) (Flatman, 2007; Hoorn et al., 2011; Huang et al., 2008; Richardson and Alessi, 2008). 
A. Catalytic way

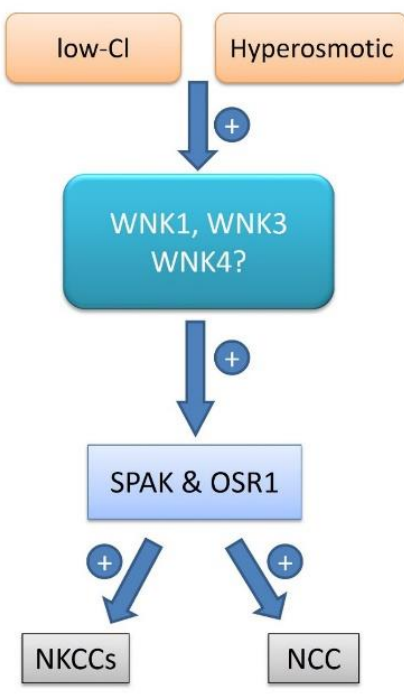

B. Non catalytic way

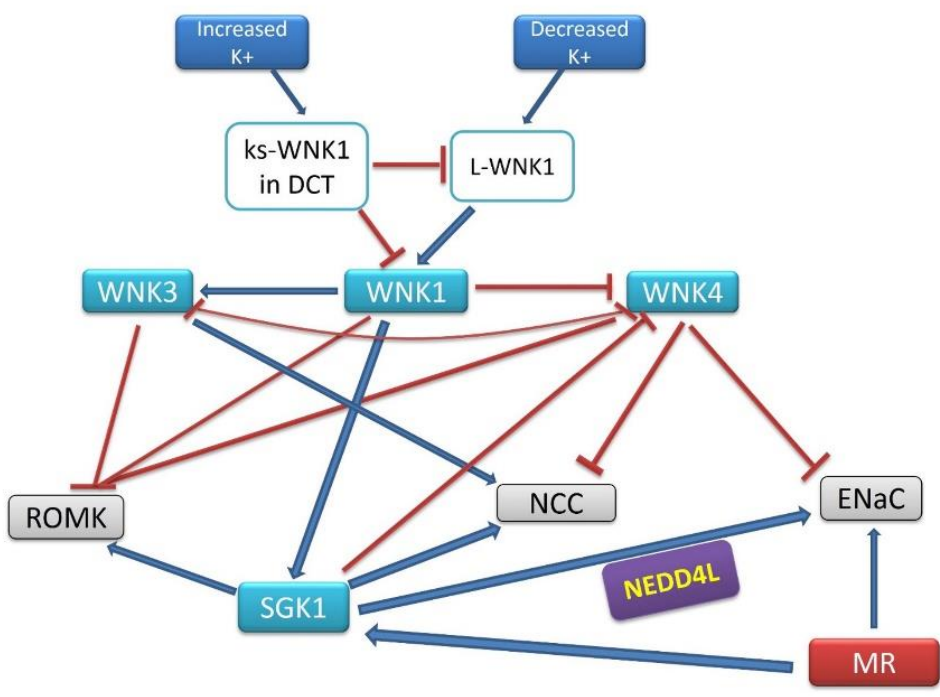

Figure 5: WNKs' cascade under basal conditions

DCT: Distal Convoluted Tubule. ks-WNK: Kidney Specific WNK1, L-WNK: Full-length transcript of WNK1. WNKs, SGK1, SPAK, OSR1: Kinases. NEDD4L: Phosphatase. NKCCS, NCC, ENaC, ROMK: transporters. MR: mineralocorticoid receptor (Aldosterone receptor). Figure 2 is described in details under Aldosterone paradox [1.5.2], the With-no-lysine kinases [1.6] and the WNK4 conundrum [1.6.1] paragraphs.

For the catalytic way and in cultured cells, the hyperosmolar conditions as well as low chloride conditions were the triggers to activate WNKs (WNK1 and 3) (Richardson and Alessi, 2008) which in turn phosphorylate SPAK/OSR1 kinases which also phosphorylate and activate NKCC2 and NCC (Flatman, 2007; Hoorn et al., 2011). The exact role of WNK4 in this catalytic way has not yet exactly clarified as the wt-WNK4 inhibits the NCC (see [1.6.1]).

In the non-catalytic way, potassium concentration in the outer media seems to have the big role to activate either L-WNK1 (full length isoform of WNK1) or ks-WNK1. Ks-WNK1 inhibits the activity of L-WNK1 which in turn inhibits the activity of WNK4. WNK3 and WNK4 inhibit each other's effects (Hoorn et al., 2011).

The regulation mechanisms of the ion transporters by the WNKs under kinase-dependent or independent ways usually include the effects on the cell surface expression or the activity of the ion transporters (Huang et al., 2008). 
Analysis of the physiological and pathophysiological roles of the WNKs is still in the very beginning step, but hypertension seems to be an obvious therapeutic target for WNK-specific inhibitors (more specifically WNK1 and WNK3). While a better understanding of WNKs action in vivo is required (especially WNK4), the development of specific inhibitors of the WNKs is already under construction as structural analysis suggested that specific WNK1 inhibitors could be designed in principle (McCormick and Ellison, 2011).

\subsubsection{The WNK4 conundrum}

The term conundrum was introduced to refer to the still incompletely understood functions of WNK4 (Arroyo et al., 2011). This kinase could have three major (known or expected) functional states under different conditions to activate or inhibit the same ion transporter or channel (Figure 4, Figure 5). The first state is under the basal conditions when WNK4 has inhibitory effects on NCC, ENaC and ROMK (wt-WNK4). The second state is under hypovolemia conditions when the inhibition of NCC and ENaC is lost but not the inhibition of ROMK (PHA II-type-WNK4). The third state is observed under hyperkalemia when the inhibition of NCC stays in the nonaldosterone-sensitive parts of the nephron (DCT1) while the inhibition of ENaC and ROMK is lost, most likely because of the phosphorylation of WNK4 at position S1169 by SGK1 which is induced be the aldosterone. The effects on NCC in the DCT2 part of the nephron in the third state, which is aldosterone sensitive, needs to be clarified, but the net effect on NCC would be expected to be as with low activity due to the high expressed amount of NCC in DCT1 compared with DCT2 (Arroyo et al., 2011). In one study (Lalioti et al., 2006), two different mice models were generated, each of them has four copies of the WNK4. The first model has four wt-WNK4 while the second model has two wt-WNK4 and two PHA II-type-WNK4. The mice from the first model developed symptoms like Gitelman's syndrome while the second mice model developed PHA II like symptoms. These results suggest that the PHA II-type-WNK4 is an autosomal dominant type which results in gain of function of WNK4 regarding the regulation of the NCC. 


\subsection{Diuretic drugs}

Diuretic drugs control salt, water excretion and blood pressure and are the most important drugs in hypertension and heart failure (Chobanian et al., 2003; Mancia et al., 2013; McMurray et al., 2012; Yancy et al., 2013).

Some of the diuretics were used successfully to treat diseases from genetic origins like pseudohypoaldosteronism Type 2 (Gordon's syndrome) like thiazides (Mayan et al., 2002).

Diuretic drugs are divided into many groups according to their physiological actions. They include carbonic anhydrase inhibitors, osmotic diuretics, loop diuretics, thiazides and potassium-sparing diuretics.

Carbonic anhydrase inhibitors (e.g. acetazolamide) have a weak diuresis effects and are rarely used other than an eye drops against glaucoma. Osmotic diuretics (e.g. mannitol) are used to treat cerebral edema and raised intra-ocular pressure. Loop diuretics (e.g. furosemide) are the most effective drugs among the diuretics and they are acting by blocking the NKCC2 activity in the thick ascending limb of Henle (TAL). Loop diuretics are used as antihypertensive treatment to control blood pressure in patients with resistant hypertension, or in patients with impaired renal function or heart failure. Loop diuretics can be used intravenously in pulmonary edema due to left ventricular failure. Thiazides (e.g. hydrochlorothiazide) are the moderate diuretics and their effect is coming from blocking the NCC in the distal convoluted tubule (DCT). The thiazides are used widely in the management of hypertension. Potassium-sparing diuretics can be divided into two groups: The $\mathrm{ENaC}$ inhibitors (e.g. triamterene) and the aldosterone antagonists (e.g. spironolactone). They are also weak diuretics and used usually in combination with the thiazide diuretic to antagonize the potassium sparing effects (Committee, 2013). Table 4 is summarizing the most common diuretics according to their part of effects in the nephron. 
Table 4: Diuretics according to nephron parts

\begin{tabular}{|c|c|c|c|c|c|c|c|}
\hline Nephron part & Relevant drugs & Major transporters & Major regulators & Potency & Primary effects & $\begin{array}{l}\text { Secondary } \\
\text { effects }\end{array}$ & Side effects \\
\hline \multirow{4}{*}{ Loop of Henle } & Loop diuretics & & WNK1 & \multirow{4}{*}{ +++ } & \multirow{4}{*}{$\begin{array}{l}\downarrow \mathrm{Na}^{+} / \mathrm{K}^{+} / 2 \mathrm{Cl}^{-} \\
\text {absorption }\end{array}$} & & \multirow{4}{*}{$\begin{array}{l}\text { Hypokalemic } \\
\text { alkalosis }\end{array}$} \\
\hline & (Bumetanide, & NKCC2 & WNK3 & & & $\uparrow \mathrm{K}^{+}$loss & \\
\hline & Furosemide, & \multirow[t]{2}{*}{ ROMK } & SPAK & & & $\uparrow \mathrm{H}^{+}$secretion & \\
\hline & Turosemide) & & OSR1 & & & & \\
\hline \multirow{8}{*}{ Distal Tubule } & \multirow{8}{*}{$\begin{array}{l}\text { Thiazide } \\
\text { (Hydrochlorothiazide, } \\
\text { Chlorthalidone) }\end{array}$} & \multirow{8}{*}{$\begin{array}{l}\text { NCC } \\
\text { ENaC } \\
\text { ROMK }\end{array}$} & WNK1 & & \multirow{8}{*}{$\begin{array}{l}\downarrow \mathrm{Na}^{+} / \mathrm{Cl}^{-} \\
\text {absorption }\end{array}$} & \multirow{8}{*}{$\begin{array}{l}\uparrow \mathrm{K}^{+} \text {loss } \\
\uparrow \mathrm{H}^{+} \text {secretion }\end{array}$} & \multirow{8}{*}{$\begin{array}{l}\text { Hypokalemic } \\
\text { alkalosis }\end{array}$} \\
\hline & & & ks-WNK & & & & \\
\hline & & & WNK3 & & & & \\
\hline & & & WNK4 & & & & \\
\hline & & & SPAK & & & & \\
\hline & & & OSR1 & & & & \\
\hline & & & SGK1 & & & & \\
\hline & & & MR & & & & \\
\hline \multirow{5}{*}{ Collecting Duct } & Potassium sparing & \multirow{5}{*}{$\begin{array}{l}\mathrm{ENaC} \\
\text { ROMK }\end{array}$} & WNK1 & \multirow{5}{*}{+} & \multirow{5}{*}{$\begin{array}{l}\downarrow \mathrm{Na}^{+} \\
\text {absorption }\end{array}$} & \multirow{5}{*}{$\begin{array}{l}\downarrow \mathrm{K}^{+} \text {loss } \\
\downarrow \mathrm{H}^{+} \text {secretion }\end{array}$} & \multirow{5}{*}{$\begin{array}{l}\text { Hyperkalemic } \\
\text { acidosis }\end{array}$} \\
\hline & diuretics (Amiloride, & & WNK3 & & & & \\
\hline & Triamterene, & & WNK4 & & & & \\
\hline & Spironolactone, & & SGK1 & & & & \\
\hline & Eplerenon) & & $\mathrm{MR}$ & & & & \\
\hline
\end{tabular}




\subsection{Aim of the work}

Rare genetic variants and frequent polymorphisms in the sodium-potassium-dichloride cotransporters (NKCC2), the sodium-chloride co-transporters (NCC) and the epithelial sodium channels $(\mathrm{ENaC})$ have been reported to affect electrolyte excretion when diuretics are applied (Vormfelde et al., 2007). Little has been studied thus far regarding the functional effects of the regulatory pathways regulating short and long term activity of the renal ion transporters. This project should contribute to a better understanding of variation in renal functions concerning electrolyte excretion.

Major focus of this study is the impact of genomic variations in the renal salt transporters and their regulatory pathways on the effects and side effects of diuretic drugs (Figure 6). More concretely, we wanted to identify inherited genetic polymorphisms which explain a significant part of variation in renal elimination of sodium, chloride, potassium and urine volume. We wanted to do this using the so-called candidate-gene approach focusing on genes coding for the ion transporters and the proteins regulating the activity of the ion transporters.

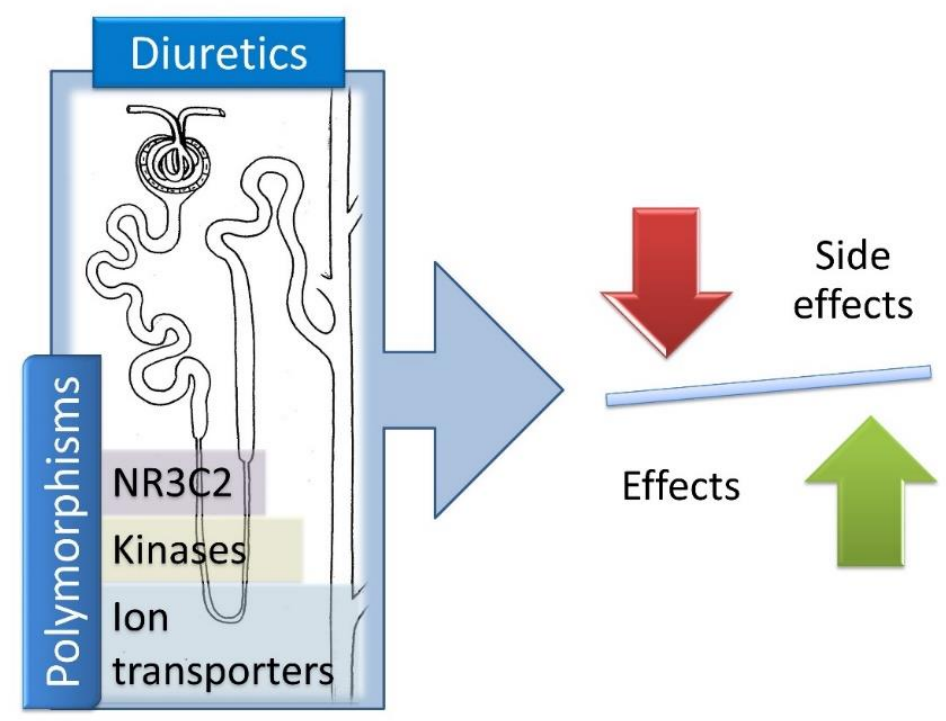

Figure 6: Aim of the work: Genetic polymorphisms in genes regulating renal ion excretion and diuretic drug effects

Medically, this project might contribute to a better understanding of both rare monogenetic renal disorders on one side and multifactorial inheritance disorders such as hypertension, diabetes and osteoporosis on the other side. 


\section{Materials and methods}

\subsection{Materials}

\subsubsection{Reagents, kits, media and enzymes}

Reagents, kits, media and enzymes

$\left[\alpha-{ }^{32} \mathrm{P}\right]-d C T P($ for EMSA)

$1 \mathrm{~kb}$ Size standard ladder for agarose gel

$100 \mathrm{bp}$ Size standard ladder for agarose gel 40\% (w/v) Acrylamide:Bis-acrylamide / Mix

$37.5: 1$

4326322E (RT-assay, TBP gene)

Agar (for bacteriology)

Agarose Ultra Pure (for sequencing)

All oligonucleotides for PCR or EMSA

Ammonium persulfate $\geq 98 \%$

Ampicillin min. 99\%

AmpliSeq $^{\text {TM }}$ Library Kit 2.0 (for target

enrichment)

Anti-BARX1 antibody (rabbit)

Anti-LHX4 antibody (rabbit)

Aquasafe 500 Plus (safety scintillator

solution)

Bg/ll

Bicinchoninic Acid Solution

BigDye $^{\circledR}$ v1.1 Sequencing Kit (fluorescence

based Sanger sequencing)

Boric acid $100 \%$

Bovine serum albumin (BSA)

\section{Distributer / Manufacturer*}

Hartmann Analytic $\mathrm{GmbH}$, Braunschweig

ABgene, Fermentas, St. Leon-Rot

ABgene, Fermentas, St. Leon-Rot

Biomol, Hamburg

Applied Biosystems, Darmstadt

AppliChem, Darmstadt

Invitrogen, Karlsruhe

Eurofins MWG synthesis GmbH, Ebersberg

Sigma-Aldrich, Deisenhofen

AppliChem, Darmstadt

Life technologies, Darmstadt

Sigma-Aldrich, St. Louis, USA

Sigma-Aldrich, St. Louis, USA

Zinser Analytic, Berkshire

Fermentas, St. Leon-Roth

Sigma-Aldrich, Deisenhofen

Applied Biosystems, Darmstadt

Merck, Darmstadt

Sigma-Aldrich, Deisenhofen 
Bromphenol blue Na-Salt (for

electrophoresis)

Chloroform $\geq 99.8 \%$

Compactprep kit (for midi-prep)

X-ray developer G150

Dimethyl sulfoxide (DMSO)

Dithiothreitol $\geq 99.5 \%$ (for Molecular

biology)

DNeasy Blood \& Tissue Kit (For DNA

extraction)

dNTP Set

Dual-Luciferase ${ }^{\circledR}$ Reporter Assay System

Dulbecco's Modified Eagle Medium (DMEM)

ECORI

EDTA $0.5 \mathrm{M}$ in water solution

EDTA pure

Ethanol 96\%

Ethanol denatured 99\% (Disinfection

reagent)

Ethidium bromide $1 \%$ in $\mathrm{H} 2 \mathrm{O}$ (for

electrophoresis)

Exonuclease I E.coli (Exol; $20 \mathrm{u} / \mu \mathrm{l})$

EZ1 DNA Blood Kit

X-ray fixer G354

FuGene 6 (Transfection reagent)

GeneScanLIZ120 (Size standard ladder for SNaPshot ${ }^{\mathrm{TM}}$ )

Glycerol 85\%
Roth, Karlsruhe

J.T. Baker, Phillipsburg, USA

Qiagen, Hilden

AGFA, Leverkusen

AppliChem, Darmstadt

AppliChem, Darmstadt

Qiagen, Hilden

ABgene, Hamburg

Promega, Mannheim

Gibco/Invitrogen, Karlsruhe

Fermentas, St. Leon-Roth

Sigma-Aldrich, Deisenhofen

Merck, Darmstadt

Merck, Darmstadt

Chemie-Vertrieb Hannover

Merck, Darmstadt

ABgene, Fermentas, St. Leon-Rot

Qiagen, Hilden

AGFA, Leverkusen

Roche, Mannheim

Applied Biosystems, Darmstadt

Central pharmacy - University medical center, Göttingen 


\begin{tabular}{|c|c|}
\hline Helipur ${ }^{\circledR}$ H plus N (Disinfection reagent) & Braun, Melsungen \\
\hline HEPES 99.5\% & AppliChem, Darmstadt \\
\hline HindIII & ABgene, Fermentas, St. Leon-Rot \\
\hline HotStarTaq Master Mix Kit (250 units) & Qiagen, Hilden \\
\hline HS00260769_m1 (RT-assay, WNK4 gene) & Applied Biosystems, Darmstadt \\
\hline HS01031809_m1 (RT-assay, NR3C2 gene) & Applied Biosystems, Darmstadt \\
\hline $\begin{array}{l}\text { Ion OneTouch }{ }^{\mathrm{TM}} 200 \text { Template Kit v2 } \\
\text { (Template preparation for the NGS) }\end{array}$ & Life technologies, Darmstadt \\
\hline Ion library quantitation kit & Life technologies, Darmstadt \\
\hline Ion PGM ${ }^{T M} 200$ Sequencing kit & Life technologies, Darmstadt \\
\hline Isoamyl alcohol 98\% & Schuchardt, Hohenbrunn \\
\hline Isopropanol $\geq 99.9 \%$ & Merck, Darmstadt \\
\hline Klenow-Fragment (For EMSA) & ABgene, Fermentas, St. Leon-Rot \\
\hline KOD HotStart DNA Polymerase & Novagen Merck, Darmstadt \\
\hline Ligate-ITTM Rapid Ligation Kit & USB europe GmbH, Staufen \\
\hline Magnesium chloride $\geq 99 \%$ & Riedel-De Haën AG, Seelze \\
\hline Magnesium sulfate $\geq 99.5 \%$ & Merck, Darmstadt \\
\hline Mini Quick Spin Oligo Columns & Roche, Mannheim \\
\hline Multiplex PCR Kit & Qiagen, Hilden \\
\hline Neodisher ${ }^{\circledR}$ A 8 (Cleaning powder) & Chem. Fabrik Dr. Weigert, Mühlenhagen \\
\hline Normal rabbit antibody IgG (sc-2027) & Santa cruz Biotechnology, Heidelberg \\
\hline PBS powder (Dulbecco's 10X for cell culture) & AppliChem, Darmstadt \\
\hline Penicillin/Streptomycin solution & Invitrogen, Karlsruhe \\
\hline Poly (deoxyinosinic-deoxycytidylic) (EMSA) & Sigma-Aldrich, Deisenhofen \\
\hline $\begin{array}{l}\text { Poly-d-lysine hydrobromide (For cell } \\
\text { culture) }\end{array}$ & Sigma-Aldrich, Deisenhofen \\
\hline Polymer POP6 for sequencer & Applied Biosystems, Darmstadt \\
\hline Potassium chloride $\geq 99.5 \%$ & Riedel-De Haën AG, Seelze \\
\hline QIAquick Gel Extraction Kit & Qiagen, Hilden \\
\hline
\end{tabular}


QIAquick PCR Purification Kit

qRT-PCR Mastermix

Random Hexanucleotide Primer dN6

RNAse A 70\%

Sephadex ${ }^{\mathrm{TM}}$ G-50 Superfine

Shrimp Alkaline Phosphatase $(1 \mathrm{u} / \mu \mathrm{l})$

SnapShot ${ }^{\mathrm{TM}}$ Multiplex Kit

Sodium chloride

Super Script II Reverse Transcriptase

Taq DNA Polymerase

TEMED $\geq 99 \%\left(N, N, N^{\prime}, N^{\prime}-\right.$

Tetramethylethylenediamine)

Tris $100 \%$ (Tris hydroxymethyl

aminomethane)

Trypan blue solution (0.4 \%)

Tryptone

Xylene cyanol FF (for molecular biology)

Yeast extract
Qiagen, Hilden

PrimerDesign Ltd Precision OneStepTM,

Southampton, United Kingdom

Roche, Mannheim

AppliChem, Darmstadt

Amersham Bioscience, Freiburg

Affymetrix, High Wycombe, United Kingdom

Applied Biosystems, Darmstadt

Merck, Darmstadt

Invitrogen, Karlsruhe

Qiagen, Hilden

Sigma-Aldrich, Deisenhofen

Roth, Karlsruhe

Sigma-Aldrich, Deisenhofen

AppliChem, Darmstadt

AppliChem, Darmstadt

AppliChem, Darmstadt

${ }^{*}$ Country was not mentioned for Germany.

\subsubsection{Materials and instruments}

\section{Materials and instruments}

12-Well plate (for Cell culturing)

3130xl Genetic Analyser (Capillary sequencer)

384-well plate (FrameStar ${ }^{\circledR}$ )

$50 \mathrm{ml}$ Centrifuge tube

96 Millipore MAHV N45 Plate

96er PCR-Plate

\section{Distributer / Manufacturer*}

Greiner, Frickenhausen

Applied Biosystems, Darmstadt

4titude, Dorking, United Kingdom

Beckman, München

Millipore, Schwalbach

ABgene, Epsom, United Kingdom 
96-wells Microtiter plate (Cat No 3603)

Absolute QPCR Seal (Optical Foil for Taqman)

Adhesive PCR Foil Seals

Bacteria Incubator-Incudrive

Biofuge fresco

Biofuge pico

BioPhotometer

BioRobot ${ }^{\circledR}$ EZ1

Centrifuge $5810 \mathrm{R}$

Centrifuge JA-20 Rotor

CO2-Incubator BBD 6220

ComPhor L Mini Gel-chamber

Concentrator 5301

Culture flask $25 \mathrm{~cm}^{2}$ and $75 \mathrm{~cm}^{2}$

Cuvette (UVetten) 50-1000 $\mu \mathrm{l}$

Dialyse filter VSWP01300

Electroporation cuvette $2 \mathrm{~mm}$

Electroporator Gene Pulser II

Fine weight machine

Flat cap strips, $12 \mathrm{er}$

Flat cap strips, 8er

Fluor-S ${ }^{\text {TM }}$ Multilmager

gel-drying-system (DrygelSr)

Glass Pasteur pipette $230 \mathrm{~mm}$

GloMax ${ }^{\circledR}$ Luminometer

Ion $316^{\mathrm{TM}}$ sequencing chip

Labofuge 400R
Corning ${ }^{\circledR}$ Microtest, North Yorkshire, United

Kingdom

Thermo Scientific, Schwerte

ABgene, Epsom, United Kingdom

Schütt, Göttingen

Heraeus, Hanau

Heraeus, Hanau

Eppendorf, Hamburg

Qiagen, Hilden

Eppendorf, Hamburg

Beckman, München

Heraeus, Hanau

Biozym, Hessisch Oldendorf

Eppendorf; Hamburg

Sarstedt, Nümbrecht

Eppendorf, Hamburg

Millipore, Schwalbach

PeqLab, Erlangen

BioRad, Hercules, USA

Sartorius, Göttingen

ABgene, Epsom, United Kingdom

ABgene, Epsom, United Kingdom

BioRad, Hercules, USA

Hoffer scientific instruments, San Francisco, USA

WU, Mainz

Turner BioSystems, Sunnyvale, USA

Life technologies, Darmstadt

Heraeus, Hanau 


\begin{tabular}{|c|c|}
\hline Magnetic stirrer & Ika, Staufen \\
\hline Mastercycler gradient & Eppendorf, Hamburg \\
\hline Microscope Axiovert 40 CFL & Zeiss, Jena \\
\hline MS 2 Mini shaker-Vortexer & Ika, Staufen \\
\hline Nanodrop cuvette & Implen, München \\
\hline Neubauer-Cell chamber & Schütt, Göttingen \\
\hline OneTouch ${ }^{\mathrm{TM}}$ & Life technologies, Darmstadt \\
\hline OneTouch ${ }^{\mathrm{TM}} \mathrm{ES}$ & Life technologies, Darmstadt \\
\hline Parafilm $^{\circledR}$ & Brand, Wertheim \\
\hline PerfectBlue Gelsystem & Peqlab, Erlangen \\
\hline Petri Dish & Sarstedt, Nümbrecht \\
\hline $\begin{array}{l}\mathrm{PGM}^{\mathrm{TM}} \text { (Personal Genome Machine) } \\
\text { sequencer }\end{array}$ & Life technologies, Darmstadt \\
\hline Phosphor Imager & Raytest, Sprockhövel \\
\hline Pipette Tips $(10,100,1000 \mu \mathrm{ll})$ & Sarstedt, Nümbrecht \\
\hline Plate loader for Sephadex & Millipore, Schwalbach \\
\hline Plate Retainer for Sequencing & Applied Biosystems, Darmstadt \\
\hline QiaCube & Qiagen, Hilden \\
\hline QIAgility (pipetting robot) & Qiagen, Hilden \\
\hline Quali-Filterpipett tip sterile & Kisker, Steinfurt \\
\hline Qubit $^{\circledR} 2.0$ fluorometer & Life technologies, Darmstadt \\
\hline Scintillation instrument LS1801 & Beckman, München \\
\hline Shaker for Bacteria K2 260 basic & Ika, Staufen \\
\hline Sterile Bench-Clean Air type DFL/REC4 KL2A & Mahl, Trendelburg \\
\hline Sterile Pipette $(5,10,25 \mathrm{ml})$ & Sarstedt, Nümbrecht \\
\hline Sterile Polypropylen-tube 15 ml & Greiner, Frickenhausen \\
\hline Sterile Polypropylen-tube $50 \mathrm{ml}$ & Sarstedt, Nümbrecht \\
\hline TaqMan $7900 \mathrm{HT}$ & Applied Biosystems, Darmstadt \\
\hline
\end{tabular}


Thermal Gradient Cycler PTC-200 Peltier

Thermo-Fast 384-well Plate (PCR-Plates for Taqman)

Thermo-Fast 96-well Plate

Thermomixer 5436

Transilluminator TI 2

Vertical-Autoclave KSG 40/60

Vertical-Autoclave: FV

Water bath GFL 1083

Whatman papers (Filter paper Nr. 2668)
MJ Research/BioRad, Hercules, USA

ABgene Epsom, United Kingdom

ABgene Epsom, United Kingdom

Eppendorf, Hamburg

Biometra, Göttingen

KSG, Olching

Tecnorama, Fernwald

Schütt, Göttingen

Schleicher und Schüll, Dassel

${ }^{*}$ Country was not mentioned for Germany. 


\subsubsection{Software}

\begin{tabular}{|c|c|}
\hline Software & Distributer / Manufacturer* \\
\hline 3100 Data Collection Software & Applied Biosystems, Darmstadt \\
\hline Adobe Photoshop ${ }^{\circledR}$ CS4 EXTENDED v11.0.2 & Adobe systems, München \\
\hline BASreader and AIDA Version 4.15.025 & Raytest, Sprockhövel \\
\hline BVTech plasmid v5.1 & BV Tech \\
\hline Clone Manager Suite v6.0 & Sci-Ed Software, Cary NC, USA \\
\hline CorelDRAW X3 & Corel corporation, Ontario, Canada \\
\hline DNA Sequencing Analysis & Applied Biosystems, Darmstadt \\
\hline DNASTAR $^{\circledR} \mathrm{v} 11.2$ & DNASTAR, Madison WI, USA \\
\hline EndNote $\mathrm{X7}$ & Thomson Reuters, Philadelphia PA, USA \\
\hline Gene mapper v3.7 software ${ }^{\circledR}$ & Applied Biosystems, Darmstadt \\
\hline HaploView $^{\circledR}$ v4.2 & Broad institute, Cambridge MA, USA \\
\hline IBMC SPSS ${ }^{\circledR}$ STATISTICS v20.0 and v21.0 & IBM Corp, Ehningen \\
\hline Integrative Genomics Viewer (IGV) v3.4.51874 & Broad institute, Cambridge MA, USA \\
\hline MS Office 2007 / 2013 & Microsoft, Unterschleißheim \\
\hline Oligo $^{\circledR}$ v6.58 & Molecular Biology Insights, Cascade CO, USA \\
\hline $\mathrm{PHASE}^{\circledR}$ V2.1 & $\begin{array}{l}\text { Department of Statistics, University of } \\
\text { Washington, Seattle, USA }\end{array}$ \\
\hline Quantity One S & BioRad, München \\
\hline SDS v2.1 & Applied Biosystems, Darmstadt \\
\hline SigmaPlot for windows v11.0 & Systat software, Erkrath \\
\hline Staden Package & $\begin{array}{l}\text { Medical research council laboratory of } \\
\text { molecular Biology, Cambridge, UK }\end{array}$ \\
\hline XFluor4 Software & Tecan, Crailsheim \\
\hline
\end{tabular}

\footnotetext{
${ }^{*}$ Country was not mentioned for Germany.
} 


\subsubsection{Vectors}

\begin{tabular}{lll}
\hline Vector & Resistance & Distributer / manufacturer $^{*}$ \\
\hline pOTB7::LHX4 & & Source BioScience \\
(Image ID 3529089/IRAU61 & Chloramphenicol & Lifesciences, Nottingham, \\
F08) & & United Kingdom \\
pcDNA3.1 & Ampicillin & Invitrogen, Karlsruhe \\
pGL3-promoter & Ampicillin & Promega, Mannheim \\
pCMV & Ampicillin & Invitrogen, Karlsruhe
\end{tabular}

${ }^{*}$ Country was not mentioned for Germany.

\subsubsection{Bacteria}

\begin{tabular}{|c|c|c|c|}
\hline Strain & Origin & Application & $\begin{array}{l}\text { Distributer / } \\
\text { manufacturer* }\end{array}$ \\
\hline $\begin{array}{l}\text { Top10 } \\
\text { (One shot TOP10 } \\
\text { Electro-comp. E.coli) }\end{array}$ & Escherichia coli & Electro-competent & $\begin{array}{l}\text { Invitrogen, } \\
\text { Karlsruhe }\end{array}$ \\
\hline $\begin{array}{l}{ }^{*} \text { Country was not me } \\
2.1 .6 \text { Cell lines }\end{array}$ & ntioned for Germ & & \\
\hline Cell line & Origin & Characteristic & $\begin{array}{l}\text { Distributer / } \\
\text { manufacturer }\end{array}$ \\
\hline HEK-293 & Human & $\begin{array}{l}\text { Embryonic kidney } \\
\text { cell line }\end{array}$ & DMSZ, Braunschweig \\
\hline
\end{tabular}

\footnotetext{
${ }^{*}$ Country was not mentioned for Germany.
} 


\subsection{Summary of the clinical studies}

The urinary electrolyte excretion was investigated in two single-dose cross-over studies in healthy, male Caucasian volunteers (Vormfelde et al., 2006; Vormfelde et al., 2007). The first study was on the loop diuretics bumetanide, furosemide and torsemide. The second study was on two doses of hydrochlorothiazide, on triamterene, and on moderate sodium chloride restriction. The studies were designed similarly but performed separately. The populations were unrelated to each other. Both studies were randomized, single-blind, three-arm, triple-crossover studies. Both studies were approved by the ethics committee of the University Medical Center Göttingen. All volunteers provided written informed consent before they were included into the studies. To avoid hypovolemia, the participants were repetitively encouraged to drink water or caffeine-free tea in both studies.

\subsubsection{Study 1}

The first study consisted of three periods separated by at least one week. Each period consisted of two days: A run-in day and a drug day. The participants were asked to stick to a salt-restricted diet from $48 \mathrm{~h}$ prior to drug administration until $24 \mathrm{~h}$ after drug intake. Participants were advised to restrict salt intake, but no strict salt-controlled diet was administered at the days before the study. On the drug days, the participants ingested single oral doses of $2 \mathrm{mg}$ bumetanide, $80 \mathrm{mg}$ furosemide and $10 \mathrm{mg}$ torsemide. Blood and urine were collected in intervals over $24 \mathrm{~h}$ after drug intake.

112 Caucasian men were recruited. 110 donated blood. 96 participants completed at least one study period: 95 the bumetanide period, 93 the furosemide period and 92 the torsemide period. The 96 participants were on average 28 years old (mean, range 19-50 years), weighed $78 \mathrm{~kg}$ (57-93 kg) and were $182 \mathrm{~cm}$ tall $(170-198 \mathrm{~cm})$.

\subsubsection{Study 2}

The second study also consisted of three periods. These periods were also separated by at least one week. Each period consisted of three days: A run-in day, a moderate sodium chloride restriction day and a drug day. On the sodium chloride restriction days, a placebo drug was taken single-blind. A drug was taken single-blind on the drug days, which were otherwise performed identically to the sodium chloride restriction days. Drugs were $25 \mathrm{mg}$ 
hydrochlorothiazide, $100 \mathrm{mg}$ hydrochlorothiazide and $200 \mathrm{mg}$ triamterene. Drugs were given in randomized order as single oral doses. Blood and urine were collected in intervals over $24 \mathrm{~h}$. The participants were taught and asked to restrict sodium chloride intake on all three day. Diet was not controlled on run-in days. Diet was partially controlled on the sodium chloride restriction days and drug days. We served low-sodium breakfast, lunch and water (the meals were prepared in the special gastronomy kitchen in UMG-klinikum Göttingen).

For the second study, we recruited 120 Caucasian men, which were unrelated to those of the first study. 119 donated blood. 107 participants completed at least one study period: 99 the 25 $\mathrm{mg}$ hydrochlorothiazide period, 99 the $100 \mathrm{mg}$ hydrochlorothiazide period and 101 the triamterene period. The 107 participants were on average 28 years old (mean, range 18-49 years), weighed $78 \mathrm{~kg}(58-100 \mathrm{~kg})$, and were $183 \mathrm{~cm}$ tall $(167-201 \mathrm{~cm})$.

Figure 7 gives an overview of the study design of both clinical studies.
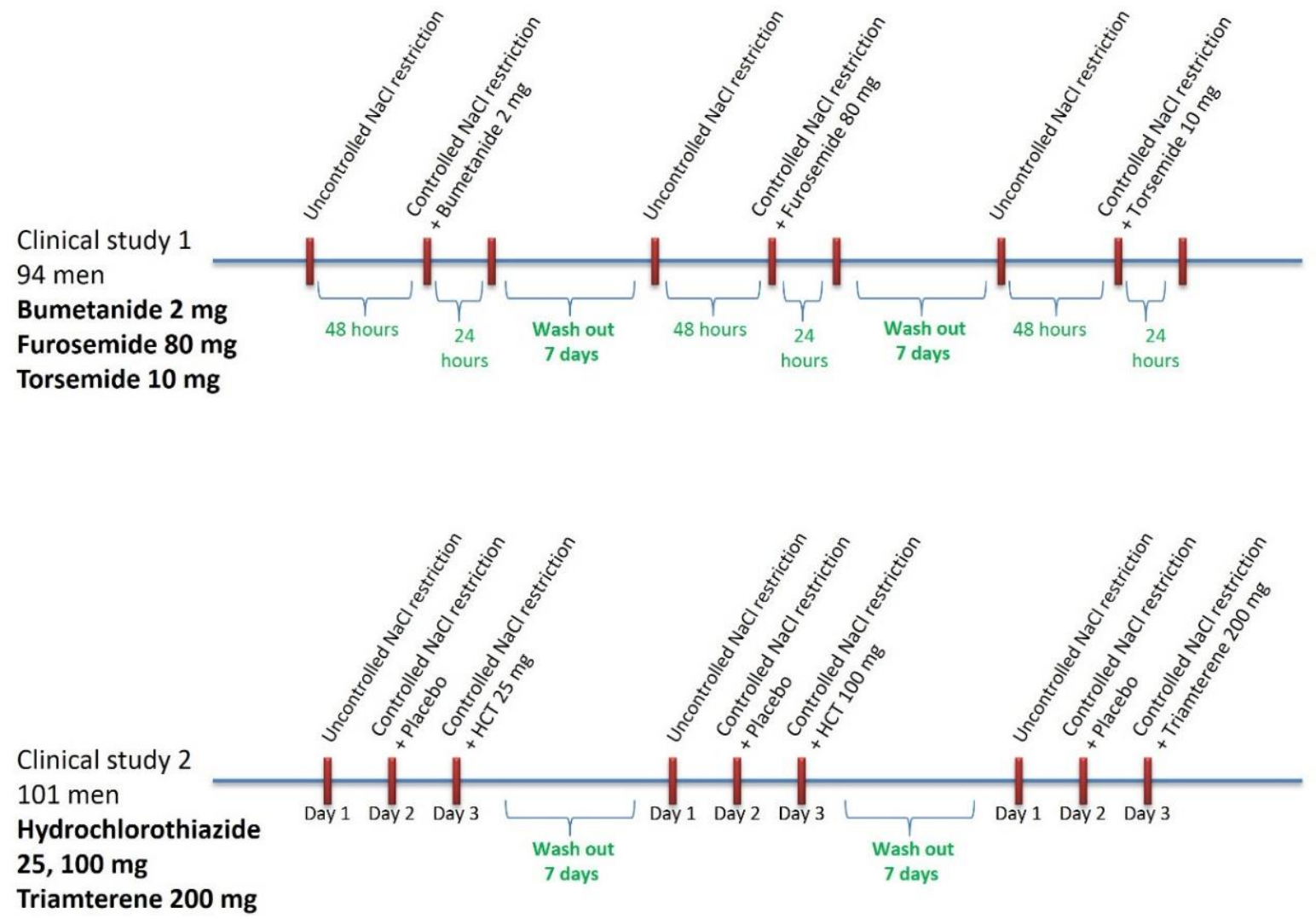

Figure 7: Schematic view of the two clinical studies performed by the institute of clinical pharmacology 


\subsubsection{Calculating phenotypes}

To describe the urinary excretion of electrolytes, volume and drugs, we calculated their "fraction excreted" $\left(f_{e}\right)$. $F_{e}$ is preferred to describe the urinary excretion when investigating diuretic effects (Rudy et al., 1994; Vargo et al., 1995). $F_{e}$ is calculated as percent denoting amounts excreted in the urine in relation to amounts filtered through the glomeruli (fraction excreted). $F_{e}$ is calculated by dividing electrolyte clearance, volume excretion rate or drug

clearance by the respective creatinine clearance $\left(\mathrm{f}_{\mathrm{e}}=\frac{C l_{i o n}}{C l_{C r}}, \mathrm{Cl}_{\text {ion }}\right.$ is the clearance of the respected ion, $\mathrm{Cl}_{\mathrm{cr}}$ is the clearance of the creatinine).

Secondly, we transformed $\mathrm{f}_{\mathrm{e}}$-percentages to gram amounts, which are better comprehensible: We multiplied the $\mathrm{f}_{\mathrm{e}}$-percentage with the standard glomerular filtration rate of $7.2 \mathrm{l} / \mathrm{h}$ $(=120 \mathrm{ml} / \mathrm{min})$, the respective time interval $(\mathrm{h})$, mean serum concentration $(\mathrm{mol} / \mathrm{l})$ and molar weight $(\mathrm{g} / \mathrm{mol})$. The equation below depicts all what was explained above:

Amount excreted (g)

$$
=\mathrm{f}_{\mathrm{e}} \times 7.2(\mathrm{l} / \mathrm{h}) \times \text { Time interval }(\mathrm{h})
$$

$\times$ Mean serum concentration of the respected ion $(\mathrm{mol} / \mathrm{l}) \times$ Molecular weight $(\mathrm{g} / \mathrm{mol})$

\subsection{Selecting polymorphisms}

\subsubsection{General criteria}

General criteria were applied for selecting the polymorphisms. There were several major approaches applied when possible. The polymorphism was selected when a functional association was generally known or reported in previous studies. Because frequencies of many polymorphisms depend on ethnicity, we focused on the Caucasian population (CEU). Tagging SNPs which have been defined automatically by the software HaploView 4.2 were selected also. The priority was always for the coding SNPs in the exon regions of the genes, then for the nonsynonymous ones considering the minor allele frequency (MAF) to be higher than $1 \%$ when possible.

\subsubsection{Aldosterone receptor polymorphisms}

The aldosterone receptor gene polymorphisms were selected through a literature search. In April 2013, 117 papers were identified after searching PubMed database for [polymorphism and ("mineralocorticoid" OR "NR3C2" OR "Aldosterone receptor")] with the filters [Human and 
English]. Two contributors (ND, SV) screened these papers by hand and identified twelve polymorphisms with significant phenotype associations (Table 3).

\subsection{Statistical analysis}

\subsubsection{Analyzing all polymorphisms}

For scanning or exploratory purposes, it was considered appropriate to analyze all possible predictors in the studied network. The studied network has a number of interacting genes, each with different possible roles. It was not enough from this point of view to start the scanning step with a fixed statistical model. The use of three statistical models gave broader scope through the screening procedure.

The first statistical model has the diuretic drug excretion as a covariate, and was performed to comply with the theory of the relation between the excretion of the diuretic drugs and their effects.

The second statistical model also had the excretion of the diuretic drugs and it had all previously known affecting polymorphisms in the studied network and allowed to compare the explained variation in the ion excretion that may be resulted from either pharmacogenetic or pharmacokinetic factors. The results coming from the second statistical model played also a checkpoint role for the previous results of the known affecting polymorphisms when other possible factors were included.

The third statistical model, which did not include any predictors other than the studied polymorphism, made it possible to observe the main effect of the genotype groups as a result of the polymorphism itself without any other factors.

The data for the genotype-phenotype association were analyzed by the repetitive analyze of covariance using SPSS ${ }^{\circledR}$ v20.0. The three models were performed using the SPSS Syntax (Table 5). 
Table 5: Comparing different statistical models with different complexity

\begin{tabular}{|c|c|c|c|}
\hline Model & Type & Covariates & SPSS syntax ${ }^{*}$ \\
\hline \multirow[t]{4}{*}{1} & Intermediate & - Studied Polymorphisms & GLM Vol_0_24 BY DIU WITH BFT_0_24 \\
\hline & & - Diuretic drug excretion & rs3857080_A \\
\hline & & & /INTERCEPT=EXCLUDE/DESIGN= DIU \\
\hline & & & BFT_0_24*DIU rs3857080_A. \\
\hline \multirow[t]{6}{*}{2} & Most complex & - Studied Polymorphisms & GLM Vol_0_24 BY DIU WITH BFT_0_24 ACE \\
\hline & & - Diuretic drug excretion & ADD GNB ANP1 ANP2 NCC ENaCb ENaCg \\
\hline & & - 8 Polymorphisms reported & rs3857080_A \\
\hline & & earlier to predict renal functions & /INTERCEPT=EXCLUDE/DESIGN= DIU \\
\hline & & & BFT_0_24*DIU ACE ADD GNB ANP1 ANP2 \\
\hline & & & NCC ENaCb ENaCg rs3857080_A. \\
\hline \multirow[t]{3}{*}{3} & Simple & - Studied Polymorphisms & GLM Vol_0_24 BY DIU WITH rs3857080_A \\
\hline & & & /INTERCEPT=EXCLUDE/DESIGN= DIU \\
\hline & & & rs3857080_A. \\
\hline \multicolumn{4}{|c|}{$\begin{array}{l}\text { * GLM is the general linear model function in SPSS, } \mathrm{Vol} 024 \text { is the volume excreted between } 0 \text { and } 24 \text { hours (as an example of } \\
\text { the studied phenotype), By DIU is referring to the way of stratifying the data (DIU was the study day), WITH followed by all the } \\
\text { predictors including the new potential studied polymorphism, /INTERCEPT=EXCLUDE/DESIGN= is the model design where the } \\
\text { interaction between the study days and the excreted drug amount was included in addition to all other old and new potential } \\
\text { polymorphisms. In each model the data were copied in a number of lines as many as the studied polymorphisms and haplotypes }\end{array}$} \\
\hline
\end{tabular}

\subsubsection{Aldosterone receptor polymorphisms analysis}

The associations of the electrolyte excretions with the polymorphisms were analyzed by covariance analysis (ANCOVA) using the general linear model function of the software package SPSS $^{\circledR}$ v21.0. Sodium and chloride excretion were analyzed as a composite endpoint termed sodium\&chloride ( $\mathrm{Na \& Cl})$; the separately analyzed results with sodium and chloride were comparable. For single regression analyses without further predictors in the model, polymorphisms were included solely as covariate. Secondly, in another statistical model, additional predictors were included as covariates: rs3857080 and lle180Val together, the excreted amount of study drug and eight polymorphisms formerly reported to be implicated with diuretic effects in the two clinical studies (Vormfelde and Brockmoller, 2012; Vormfelde et al., 2006; Vormfelde et al., 2007; Vormfelde et al., 2010). The $25 \mathrm{mg}$ and $100 \mathrm{mg}$ hydrochlorothiazide days were pooled together, and the bumetanide with the furosemide days also for the analyses of explained fractions. Then, the study days were included as fixed factors. In the "models" option of the software, the terms of study days with amounts of study drugs excreted were added as interaction. P-values were presented unadjusted for the number of tests. 


\subsection{DNA workflow}

\subsubsection{DNA isolation from blood}

DNA was automatically extracted and purified from whole blood using the BioRobot ${ }^{\circledR}$ EZ1 and EZ1 DNA Blood $200 \mu /$ kit (Qiagen, Hilden) according to the manufacturer instructions. In principle, the kit involves magnetic particles. The DNA binds to the magnetic particles which would be separated by a magnet in the robot.

\subsubsection{DNA isolation from bacteria}

\subsubsection{By chloroform extraction (Mini-prep)}

The used buffers for this DNA extraction are: buffer 1 (re-suspending buffer), buffer 2 (lysis buffer), buffer 3 (neutralizing buffer) and TE buffer (Table 6).

Table 6: Buffers used in DNA isolation from bacteria by chloroform extraction (Mini-Prep)

\section{Buffer 1 (re-suspending buffer) $\mathrm{pH} 8.0$}

Store at $4^{\circ} \mathrm{C}$

Tris- $\mathrm{HCl}$

$50 \mathrm{mM}$

EDTA

$10 \mathrm{mM}$

RNAse A (added after autoclaving the previous mixture)

Buffer 2 (lysis buffer)

Store at room temperature

$\mathrm{NaOH}$

$200 \mathrm{mM}$

SDS $1 \%(w / v)$

Buffer 3 (neutralizing buffer) $\mathrm{pH} 5.5$

Store at room temperature 
TE buffer $\mathrm{pH} 7.5$

Store at room temperature

After performing electroporation to the bacteria cells [2.8.4], the bacteria were cultured on agar plate with the corresponding antibiotic [2.8.2]. Successful clones were picked up and cultured again over night with $5 \mathrm{ml} \mathrm{LB}$ medium [2.8.3] with the corresponding antibiotic. On the next day, $5 \mu \mathrm{l}$ of each cultured clone was re-cultured on $1 / 4$ to $1 / 8$ agar plate with the same antibiotic for further experiments like DNA isolation by solid phase extraction (Midi-prep) [2.5.2.2] or Making bacteria reservoir [2.8.5]. All cultured tubes were centrifuged at $4000 \mathrm{rpm}$ with brake 9 and accelerating 9 (Centrifuge 5810R; Eppendorf, Hamburg) for 10 minutes at room temperature. Supernatant was discarded and pellets were re-suspended in $250 \mu \mathrm{l}$ buffer 1 and transferred into $1.5 \mathrm{ml}$ Eppendorf reaction tubes. Cells were lysed by adding $250 \mu \mathrm{l}$ buffer 2 and shaking well. The reaction was neutralized by adding $350 \mu \mathrm{l}$ of buffer 3 and inverting 4-6 times. At this point, the denatured proteins and genomic DNA could be seen as white flakes. To purify the DNA from this mixture, several steps have been performed; the mixtures were centrifuged at $13000 \mathrm{rpm}$ for 10 minutes (Biofuge pico; Heraeus, Hanau) at room temperature. The supernatant was transferred into new $1.5 \mathrm{ml}$ Eppendorf reaction tubes and $500 \mu \mathrm{l}$ of chloroform/isoamylalchohol (24:1 v/v) mixture was added to each tube with well shaking. The tubes were centrifuged at $13000 \mathrm{rpm}$ for 5 minutes (Biofuge pico) at room temperature. The higher phase was transferred to a final well labeled $1.5 \mathrm{ml}$ Eppendorf reaction tubes. To get plasmid DNA as pellets, $650 \mu$ of pre-cooled isopropanol (at $-20^{\circ} \mathrm{C}$ ) was added with very well shaking. Tubes were centrifuged again at $13000 \mathrm{rpm}$ for 15 minutes (Biofuge fresco; Heraeus, Hanau) at $4^{\circ} \mathrm{C}$. The supernatant was discarded and the pellets washed with $500 \mu$ l pre-cooled ($20^{\circ} \mathrm{C}$ ) Ethanol $70 \%$, then centrifuged at $13000 \mathrm{rpm}$ for 8 minutes (Biofuge fresco) at $4^{\circ} \mathrm{C}$. The supernatant was discarded and the pellets were left to dry at $37^{\circ} \mathrm{C}$, then resolved in $50 \mu \mathrm{TE}$ buffer. The DNA extraction was qualified by running the samples on $0.8 \%$ agarose gel 
(1 $\mu$ l plasmid DNA, $9 \mu \mathrm{lddH_{2 }}$ O, $2 \mu$ l loading dye 6X) and quantified using the photometric method [2.5.6.1].

\subsubsection{By solid phase extraction (Midi-prep)}

To get a higher amount and more pure extracted DNA plasmid for transfection purposes into eukaryotic cells (e.g. HEK293), The Compact Prep Plasmid Kit (Qiagen, Hilden) was used according to the manufacturer instructions. The protocol is based on a modified alkaline lysis procedure. A binding buffer is added to the cleared lysate to optimize the plasmid DNA binding to the provided column. Vacuuming is used to draw the cleared lysate and subsequent wash buffer through the column. The plasmid DNA is eluted again in small volumes (100 to $200 \mu \mathrm{l})$ by centrifuging.

\subsubsection{DNA isolation from agarose gel}

The QIAquick Gel Extraction Kit (Qiagen, Hilden) was used with the QiaCube robot (Qiagen, Hilden) according to manufacturer instructions. To recognize the pieces of the gel that contain the DNA, the agarose gel was placed on UV-light using transilluminator TI2 (Biometra, Göttingen), then sliced as wanted. The slices should not exceed $400 \mathrm{mg}$ weight of $2 \%$ agarose gel.

\subsubsection{Polymerase chain reaction (PCR)}

Polymerase chain reaction is a process of DNA amplification under cell-free conditions using special oligonucleotides as primers. It consists of three major steps taking place one after each other several times in the same order (cycles). Each cycle consists of denaturation, annealing and an elongation step. In the denaturation step the temperature is increased till the two strands of DNA are separating from each other. In the annealing phase, each primer will bind selectively to one DNA strand. The polymerase, which should be in the reaction mix, will start making a new copy of the DNA in the elongation step. Repeating the cycles will lead to an increase in the number of the copied DNA in an exponential way. A final elongation step depending on the DNA fragment length is usually required. All the PCR reactions were 
performed using either the thermal gradient cycler (BioRad, Hercules, USA) or the thermal mastercycler (Eppendorf, Hamburg).

\subsubsection{Gradient PCR}

Each pair of primers has an optimal annealing temperature. For determination of the best annealing temperature, the gradient PCR procedure was performed. In general, PCR reaction under different annealing temperatures was performed for the same reaction mix at the same time, then the samples were run on $7 \%$ agarose gel to define the best conditions for the reaction. The same reaction was performed twice, one with Q-solution (comes with QIAGEN $^{\circledR}$ Taq Polymerase Kit or with QIAGEN ${ }^{\circledR}$ Multiplex PCR kit), and the second without Q-solution. Qsolution could help separating the two strands in a DNA fragment when it has a high GC content (guanine, cytosine content). The gradient PCR could be of special interest when making a multiplex PCR to amplify different fragments of the DNA using different primers in one reaction mix (Figure 8). An example of a gradient PCR reaction and program conditions is presented in Table 7.

Table 7: Gradient PCR reaction and conditions

\section{Multiplex Mastermix}

Without Q-solution

2x QIAGEN Mastermix (Including

Taq Polymerase, dNTP mix and

magnesium chloride)

10x Primer mix ( $2 \mu \mathrm{M}$ each primer)

$\mathrm{H}_{2} \mathrm{O}$

Total

DNA

\begin{tabular}{|c|c|c|}
\hline \multirow[b]{2}{*}{ Volume $[\mu \mathrm{l}]$} & \multicolumn{2}{|l|}{ Multiplex Mastermix } \\
\hline & $\begin{array}{l}\text { With Q-solution } \\
\text { 2x QIAGEN Mastermix (Including }\end{array}$ & Volume $[\mu \mathrm{l}]$ \\
\hline 5,5 & $\begin{array}{l}\text { Taq Polymerase, dNTP mix and } \\
\text { magnesium chloride) }\end{array}$ & 5,5 \\
\hline 1,1 & Q-solution & 2,2 \\
\hline 3,4 & $\begin{array}{l}\text { 10x Primer Mix ( } 2 \mu \mathrm{M} \text { each } \\
\text { primer) }\end{array}$ & 1,1 \\
\hline & $\mathrm{H}_{2} \mathrm{O}$ & 1,2 \\
\hline 10 & Total & 10 \\
\hline 1 & DNA & 1 \\
\hline
\end{tabular}




\section{PCR conditions}

\begin{tabular}{llc|c} 
Denaturation & $95^{\circ} \mathrm{C}$ & $15 \mathrm{~min}$ & \\
Denaturation & $94^{\circ} \mathrm{C}$ & $30 \mathrm{sec}$ & $35 \mathrm{Cycles}$ \\
Primers annealing & Gradient $50-70^{\circ} \mathrm{C}$ & $1 \mathrm{~min} 30 \mathrm{sec}$ & \\
Elongation & $72^{\circ} \mathrm{C}$ & $2 \mathrm{~min}$ & $10 \mathrm{~min}$ \\
Final Elongation & $72^{\circ} \mathrm{C}$ & Forever \\
Cooling down & $8^{\circ} \mathrm{C}$ &
\end{tabular}

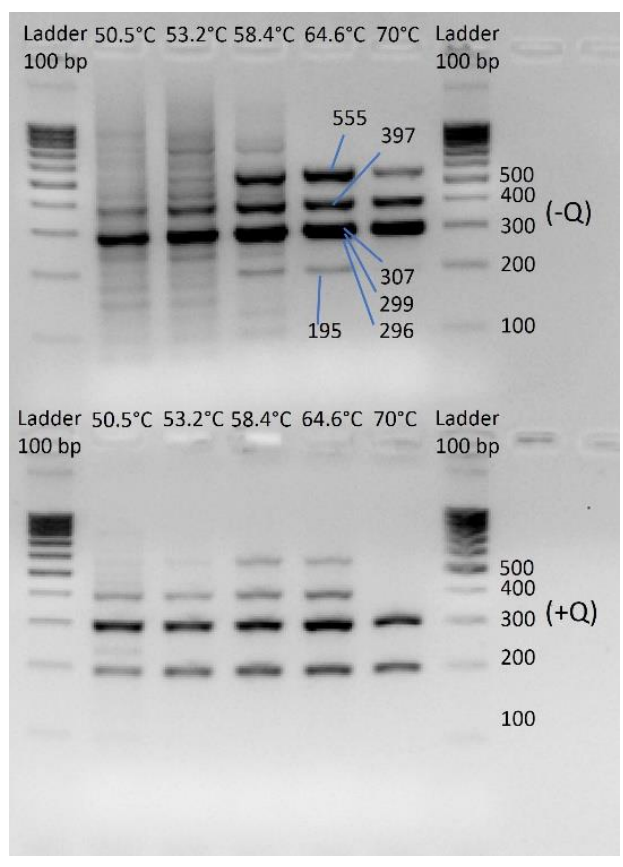

Figure 8: Agarose gel image of 5 PCR products, with and without Q-solution

The optimal condition was defined as the condition with only those bands strongly appearing which were expected from the bioinformatics analysis. In this exact case, 6 DNA fragments were expected and they were all generated under $64.6^{\circ} \mathrm{C}$ annealing temperature.

\subsubsection{Using Taq polymerase}

Taq polymerase was used for genotyping purposes when amplifying several DNA fragments in one multiplex reaction, prior to the SNaPshot ${ }^{\mathrm{TM}}$ [2.6.1] or sequencing [2.6.2]. QIAGEN ${ }^{\circledR}$ Multiplex PCR kit which contains this polymerase was used always. Table 8 shows all the PCR primers used in this research for genotyping 39 polymorphisms in 9 different genes distributed to four batches. The oligo name is referring to the polymorphism of interest in the amplified 
DNA fragment. All oligonucleotides were designed using Oligo ${ }^{\circledR}$ v6.58 software (Molecular Biology Insights, Cascade CO, USA).

Table 8: PCR primers used for genotyping 39 polymorphisms

\begin{tabular}{|c|c|c|c|c|c|c|}
\hline Oligo name & $\begin{array}{l}\text { Forward primer } \\
5^{\prime} \rightarrow 3^{\prime}\end{array}$ & $\begin{array}{l}\text { Reverse primer } \\
5^{\prime} \rightarrow 3^{\prime}\end{array}$ & $\begin{array}{l}\text { Amplicon } \\
\text { length }\end{array}$ & Gene & Protein & $\begin{array}{c}\text { Batch } \\
\text { No. }\end{array}$ \\
\hline rs2107614 & $\begin{array}{l}\text { TGTCTGGCCCTGAGACA } \\
\text { GAACACTG }\end{array}$ & $\begin{array}{l}\text { CCCAAAACGGGAAACAAC } \\
\text { ACAAATG }\end{array}$ & 555 & WNK1 & WNK1 & 1 \\
\hline rs765250 & $\begin{array}{l}\text { СААССТТССССССGТСC } \\
\text { ССААСТАС }\end{array}$ & $\begin{array}{l}\text { TGGGCAGCCTGGGAAAC } \\
\text { AGGGTAAA }\end{array}$ & 307 & WNK1 & WNK1 & 1 \\
\hline rs1159744 & $\begin{array}{l}\text { GCAGGAAACAGTGACA } \\
\text { GCCAAATGT }\end{array}$ & $\begin{array}{l}\text { GGGGATTGAGTTCCAATG } \\
\text { CCTATTT }\end{array}$ & 299 & WNK1 & WNK1 & 1 \\
\hline rs2277869 & $\begin{array}{l}\text { CTGAAAGAGGCCCCTGC } \\
\text { CTGTGTAC }\end{array}$ & $\begin{array}{l}\text { ATGTGCCCTTCCTGCTGG } \\
\text { ACGTCAT }\end{array}$ & 359 & WNK1 & WNK1 & 1 \\
\hline rs3021285 & $\begin{array}{l}\text { ACTGCTGGGCCAAGAG } \\
\text { GTGGAGAGT }\end{array}$ & $\begin{array}{l}\text { CTGGCTGGGGACCCCTAG } \\
\text { GACTTGA }\end{array}$ & 296 & WNK3 & WNK3 & 1 \\
\hline rs7880501 & $\begin{array}{l}\text { GGCATCTAGGGCAGCA } \\
\text { TTTTGAGAA }\end{array}$ & $\begin{array}{l}\text { TGTCAGCCATGGAGCTTT } \\
\text { TTTCATC }\end{array}$ & 397 & WNK3 & WNK3 & 1 \\
\hline rs61755606 & $\begin{array}{l}\text { CAAGAGGCGGCCAGTC } \\
\text { TGGTTTCTA }\end{array}$ & $\begin{array}{l}\text { TCCGGGCTGTCCCCATCC } \\
\text { AGATCAA }\end{array}$ & 258 & WNK4 & WNK4 & 1 \\
\hline rs1057293 & $\begin{array}{l}\text { GTGCCAAGGGGGAACC } \\
\text { AGCCAAGTA }\end{array}$ & $\begin{array}{l}\text { GCCTACCTCCGGCGTGCC } \\
\text { ACAGAAG }\end{array}$ & 327 & SGK1 & SGK1 & 1 \\
\hline rs3088353 & $\begin{array}{l}\text { TTGCGGCTTGTCGGTGC } \\
\text { TGAGTGAG }\end{array}$ & $\begin{array}{l}\text { CCGGGAGTGCTGCTCTGC } \\
\text { TTCTCTG }\end{array}$ & 195 & WNK1 & WNK1 & 2 \\
\hline rs77879367 & $\begin{array}{l}\text { AGGGGGGTAAGCCGGA } \\
\text { TGTGGACTT }\end{array}$ & $\begin{array}{l}\text { CCCCAGGCCGAACGGAG } \\
\text { AGGTCAGT }\end{array}$ & 254 & WNK4 & WNK4 & 2 \\
\hline rs75596106 & $\begin{array}{l}\text { TGGGTGTCCTGGGCCTG } \\
\text { ACATGACA }\end{array}$ & $\begin{array}{l}\text { TGAGCGTGCCCGAGGTCA } \\
\text { TGAGTTC }\end{array}$ & 213 & WNK4 & WNK4 & 2 \\
\hline rs77012584 & $\begin{array}{l}\text { GCCAGGCTGGCGCCCA } \\
\text { TCTCTGAAG }\end{array}$ & $\begin{array}{l}\text { GGGGATGTTGGCTGCAA } \\
\text { GGGAAGAG }\end{array}$ & 213 & WNK4 & WNK4 & 2 \\
\hline rs457661 & $\begin{array}{l}\text { GCGGCGAGGAGACGAG } \\
\text { CGAGGTCAG }\end{array}$ & $\begin{array}{l}\text { CCCCCTCCGCAGCGCCTG } \\
\text { СТСТСАС }\end{array}$ & 157 & OXSR1 & OSR1 & 2 \\
\hline rs113919536 & $\begin{array}{l}\text { TCAGCCAGCTGGGCAG } \\
\text { ATTGCTACA }\end{array}$ & $\begin{array}{l}\text { CATGAAACCATATCCCCG } \\
\text { GCTTTAC }\end{array}$ & 104 & OXSR1 & OSR1 & 2 \\
\hline rs4149601 & $\begin{array}{l}\text { CTGGGAGAGGCTGGAC } \\
\text { CTTGGTGTC }\end{array}$ & $\begin{array}{l}\text { TGGGTGGATGTGGAGAG } \\
\text { CTTCAGAA }\end{array}$ & 388 & $N E D D 4 L$ & NEDD4L & 2 \\
\hline
\end{tabular}




\begin{tabular}{|c|c|c|c|c|c|c|}
\hline rs2288774 & $\begin{array}{l}\text { CGTGCTGGGGGCGGGG } \\
\text { GTTTCTAAT }\end{array}$ & $\begin{array}{l}\text { GCGCACGACTCAGGCACC } \\
\text { CTTGACT }\end{array}$ & 191 & $N E D D 4 L$ & NEDD4L & 2 \\
\hline rs2846679 & $\begin{array}{l}\text { AGGGCACGCAGGGAAG } \\
\text { GGAGGTGAG }\end{array}$ & $\begin{array}{l}\text { CCGAGCCACCGCTCCCGG } \\
\text { ACAGAAC }\end{array}$ & 177 & KCNJ1 & ROMK & 2 \\
\hline rs1010069 & $\begin{array}{l}\text { CCCTGGCCACCGGCAGC } \\
\text { АСССТGTT }\end{array}$ & $\begin{array}{l}\text { AGAGGGAAGGGTGGGCC } \\
\text { CAGGTGAG }\end{array}$ & 322 & CLCNKA & ClC-Ka & 2 \\
\hline rs2495801 & $\begin{array}{l}\text { CAGCCTGGGCAACAGA } \\
\text { GCGAGAATC }\end{array}$ & $\begin{array}{l}\text { GGTCGGGGAAAGAAAGG } \\
\text { ATCATTCA }\end{array}$ & 218 & $\begin{array}{c}\text { FAM120C } \\
==> \\
\text { WNK3 } \\
\text { promoter }\end{array}$ & WNK3 & 3 \\
\hline rs3021280 & $\begin{array}{l}\text { CCCGGCCCCTACCCAGA } \\
\text { CTTTTGTG }\end{array}$ & $\begin{array}{l}\text { GTGGGGGCTGGTCACAG } \\
\text { AGAGATTG }\end{array}$ & 418 & WNK3 & WNK3 & 3 \\
\hline rs3021284 & $\begin{array}{l}\text { GATGCGCCAGAGGATA } \\
\text { TTGCAGACT }\end{array}$ & $\begin{array}{l}\text { GAAACCGGAGGAGATGC } \\
\text { AGTGACTT }\end{array}$ & 205 & WNK3 & WNK3 & 3 \\
\hline rs78645838 & $\begin{array}{l}\text { TCCCTGGCAGTGCTTGG } \\
\text { CACATAGT }\end{array}$ & $\begin{array}{l}\text { AGCCGCAAGCTTTGCTGA } \\
\text { ATGAGTA }\end{array}$ & 282 & WNK4 & WNK4 & 3 \\
\hline rs9493857 & $\begin{array}{l}\text { TGGGCAACAAAGCGAG } \\
\text { АСТССАТСТ }\end{array}$ & $\begin{array}{l}\text { CTGCACTCTAGCCTGGAC } \\
\text { GACAAAG }\end{array}$ & 326 & SGK1 & SGK1 & 3 \\
\hline rs6599079 & $\begin{array}{l}\text { TCTGCCTCAATTTATGA } \\
\text { AACTGTGG }\end{array}$ & $\begin{array}{l}\text { CCAAGGCATATGGTAGAC } \\
\text { CAAAGAT }\end{array}$ & 435 & OXSR1 & OSR1 & 3 \\
\hline rs35295772 & $\begin{array}{l}\text { AGAGGGGAACAGGGGT } \\
\text { CTCAGAAAT }\end{array}$ & $\begin{array}{l}\text { TGCAGGTCCTCACACTGT } \\
\text { TGCTATT }\end{array}$ & 536 & OXSR1 & OSR1 & 3 \\
\hline rs76640813 & $\begin{array}{l}\text { GACCTCCCGGAATTCCA } \\
\text { TCСTTCTG }\end{array}$ & $\begin{array}{l}\text { ATCTTGGCTAAGATGGCC } \\
\text { CCACACA }\end{array}$ & 224 & KCNJ1 & ROMK & 3 \\
\hline rs76937254 & $\begin{array}{l}\text { CGGGGAGGGAAGCTTT } \\
\text { GССТССТAA }\end{array}$ & $\begin{array}{l}\text { GGAGAAGGGTCTCCGCT } \\
\text { GCCATGTG }\end{array}$ & 256 & KCNJ1 & ROMK & 3 \\
\hline rs2070951 & $\begin{array}{l}\text { GGCAAGCCACCCACTTC } \\
\text { ACTAAGTC }\end{array}$ & $\begin{array}{l}\text { CTTGACCCCACCGTCTTTC } \\
\text { CATATC }\end{array}$ & 451 & $N R 3 C 2$ & $\mathrm{MR}$ & 3 \\
\hline rs5522 & $\begin{array}{l}\text { ATCGGCCTGGGATTTTA } \\
\text { АСАTCTGA }\end{array}$ & $\begin{array}{l}\text { GGGCTGCAAACCGAAGA } \\
\text { TGTCATGT }\end{array}$ & 385 & $N R 3 C 2$ & $\mathrm{MR}$ & 3 \\
\hline rs3857080 & $\begin{array}{l}\text { AACGCCTCAAGGGCATT } \\
\text { TAATAACA }\end{array}$ & $\begin{array}{l}\text { CTGGAAGCTGGCATTCGG } \\
\text { ATAAATA }\end{array}$ & 243 & $N R 3 C 2$ & $\mathrm{MR}$ & 3 \\
\hline rs10519963 & $\begin{array}{l}\text { TGCCAAACATCATGCTT } \\
\text { AAGCTTTT }\end{array}$ & $\begin{array}{l}\text { GTTTTGCCCAACAGGAAG } \\
\text { AACAAAG }\end{array}$ & 302 & $N R 3 C 2$ & $\mathrm{MR}$ & 4 \\
\hline
\end{tabular}




\begin{tabular}{|c|c|c|c|c|c|c|}
\hline rs3846329 & $\begin{array}{l}\text { ACGGACGCTGCTGTTGT } \\
\text { GTTTGTAT }\end{array}$ & $\begin{array}{l}\text { CAGGTGCAGGATCAGAG } \\
\text { GAAAACAC }\end{array}$ & 323 & $N R 3 C 2$ & $\mathrm{MR}$ & 4 \\
\hline rs11099681 & $\begin{array}{l}\text { TCAAAAATGGGCAGAG } \\
\text { TGAAAACTG }\end{array}$ & $\begin{array}{l}\text { GCGGTGAGATCGAGACA } \\
\text { TGCATAAA }\end{array}$ & 312 & $N R 3 C 2$ & $\mathrm{MR}$ & 4 \\
\hline rs11099680 & $\begin{array}{l}\text { CCGCTGTTTTCTTAGCA } \\
\text { AAGCAAAG }\end{array}$ & $\begin{array}{l}\text { GAGGCCAGTTTGGGGAC } \\
\text { ATGATTAG }\end{array}$ & 225 & $N R 3 C 2$ & MR & 4 \\
\hline rs4835493 & $\begin{array}{l}\text { GCACTGACCCCAGGCCC } \\
\text { CAAGACTG }\end{array}$ & $\begin{array}{l}\text { GGCGGATGACACCAGTCA } \\
\text { АТTCTCA }\end{array}$ & 204 & $N R 3 C 2$ & $\mathrm{MR}$ & 4 \\
\hline rs6810951 & $\begin{array}{l}\text { GCTCCCCATGATTTAGC } \\
\text { CAATGTCT }\end{array}$ & $\begin{array}{l}\text { GGGCCCTGTCACTGTTGT } \\
\text { GCTGATA }\end{array}$ & 230 & $N R 3 C 2$ & MR & 4 \\
\hline rs1040288 & $\begin{array}{l}\text { TGGGGAGCAAAGAATA } \\
\text { AACAAATGA }\end{array}$ & $\begin{array}{l}\text { CCAGGATCCAAACCCAGG } \\
\text { TTTTTTA }\end{array}$ & 169 & $N R 3 C 2$ & $\mathrm{MR}$ & 4 \\
\hline rs11737660 & $\begin{array}{l}\text { TGGCTTTTGGGCCGTGA } \\
\text { GTCTACTG }\end{array}$ & $\begin{array}{l}\text { TTTTGGGTCGCAGCTAAG } \\
\text { CAGTCTT }\end{array}$ & 309 & $N R 3 C 2$ & MR & 4 \\
\hline rs5534 & $\begin{array}{l}\text { CTGCCTCGTTTCCCTTTT } \\
\text { ССTCTAG }\end{array}$ & $\begin{array}{l}\text { GGTCTCCATGCCATTCAG } \\
\text { ACTGAAC }\end{array}$ & 288 & $N R 3 C 2$ & $\mathrm{MR}$ & 4 \\
\hline
\end{tabular}

\subsubsection{Using Kod polymerase}

KOD HotStart DNA Polymerase (Novagen Merck, Darmstadt) was used for cloning purposes because of the high proofreading of this polymerase. PCR reactions using KOD polymerase were performed into the following reaction mix:

Table 9: Standard KOD PCR reaction and conditions

\section{Standard KOD PCR reaction}

10X Buffer

dNTPs (2 mM)

$\mathrm{MgSO}_{4}(25 \mathrm{mM})$

Q-solution (optional)

Forward primer $(100 \mu \mathrm{M})$

Reverse primer $(100 \mu \mathrm{M})$

DNA $(300 \mu \mathrm{g} / \mathrm{ml})$

KOD HotStart DNA Polymerase (1 u/ $\mu \mathrm{l})$

$\mathrm{ddH}_{2} \mathrm{O}$
Volume $[\mu l]$

10

10

4

20

1

1

2

2

to 100 


\section{PCR conditions}

Denaturation

Denaturation

Primers annealing

Elongation

Final Elongation

Cooling down $94^{\circ} \mathrm{C}$

$94^{\circ} \mathrm{C}$

$50-70^{\circ} \mathrm{C}$

$72^{\circ} \mathrm{C}$

$72^{\circ} \mathrm{C}$

$8^{\circ} \mathrm{C}$

$5 \mathrm{~min}$
$15 \mathrm{sec}$
$30 \mathrm{sec}$
$1 \mathrm{~min} 30 \mathrm{sec}$
$8 \mathrm{~min}$
Forever

Table 10 shows the two primers used to amplify the open reading frame of the transcription factor LHX4 from the pOTB7 vector (SourceBioscience Lifesciences, Nottingham, United Kingdom). The two primers were designed to have specific restriction sites for further ligation with the expression vector pcDNA3.1 (Invitrogen, Karlsruhe) [2.5.8] but still have the ATG in the forward primer as a starting codon and TTA in the reverse primer as a complimentary for the stop codon.

Table 10: Designed primers for amplifying the open reading frame of LHX4 from pOTB7 vector

\section{Oligo name}

LHX4_HindIII_f

LHX4_KpnI_r

\section{Sequence $5^{\prime} \rightarrow 3^{\prime}$}

GGCTTAAGCTTCCGAGATGATGCAGAGTGCG

TGGGGAGGTACCAAGTTTAAAAAGGAGGATGA

\subsubsection{Agarose gel electrophoresis}

The used buffers on the agarose gel electrophoresis are TBE buffer $(\mathrm{pH} 8.3$ ) and $5 \mathrm{X}$ loading buffer (Table 11).

Table 11: Buffers used in agarose gel electrophoresis

$\underline{\text { TBE buffer } \mathrm{pH} 8.3}$

Store at room temperature

Tris

Boric acid

EDTA
$100 \mathrm{mM}$

$100 \mathrm{mM}$

$3 \mathrm{mM}$ 
$\underline{5 X}$ loading buffer

Store at room temperature

Glycerol

EDTA

Bromphenol blue

Xylene cyanol
$30 \%(\mathrm{v} / \mathrm{v})$

$50 \mathrm{mM}$

$0.25 \%(\mathrm{v} / \mathrm{v})$

$0.25 \%(\mathrm{v} / \mathrm{v})$

Agarose gel electrophoresis is a technique used usually to separate DNA fragments by their sizes. Agarose is forming a net matrix that leads to size separation of DNA. Gel electrophoresis could be used in the same context to trap the required DNA size prior to extracting the DNA from the gel [2.5.3]. Agarose concentration is ranging usually between $0.7 \%-3 \%(w / v)$, depending on the DNA fragment size. To prepare the gel, the required agarose amount is weighed (Agarose Ultra Pure; Invitrogen, Karlsruhe) and dissolved into the TBE buffer using heating in the microwave. The gel would be cooled down for several minutes before adding $0.5 \mathrm{\mu g} / \mathrm{ml}$ ethidium bromide (Merck, Darmstadt) and distributing it using a magnet stirrer. The gel mixture was poured into a gel tray with the required numbers of combs and left in room temperature for 20 minutes till it became solid. The solid gel was placed in a TBE buffer containing ethidium bromide $(0.5 \mu \mathrm{g} / \mathrm{ml})$ into the suited gel chamber. DNA samples were loaded after mixing them with the loading buffer (final concentration 1X). DNA ladders with 100 bp or $1 \mathrm{~kb}$ (ABgene, Fermentas, St. Leon-Rot) were used as size standards. The electrophoresis was performed under 120 Volt using a ComPhor L Mini Gel chamber (Biozym, Hessisch Oldendorf), or under 150 Volt using PerfectBlue Gelsystem (PEQLAB, Erlangen). To visualize the electrophoretic results, Fluor-S $S^{\text {TM }}$ Multilmager (BioRad, Hercules, USA) was used with the software Quantity One ${ }^{\circledR}$ S Version 4.3.1 (Bio-rad). 


\subsubsection{DNA quantification}

\subsubsection{Photometric quantification}

This method of DNA quantification is based on Beer-Lambert law:

$$
A=\alpha \times l \times C
$$

Where $A$ is the absorbance at wavelength of $260 \mathrm{~nm}, \alpha$ is the absorption coefficient of the DNA $\left(\mathrm{cm}^{2} / \mu \mathrm{g}\right), \mathrm{L}$ is the distance the light travels through the material (i.e., the path length, $\mathrm{cm}$ ) and $\mathrm{C}$ is the solute concentration $(\mathrm{ng} / \mu \mathrm{l})$. To perform this measurement, $3 \mu \mathrm{l}$ of the sample was placed on nanodrop cuvette (Implen, München) and the concentration was measured using BioPhotometer (Eppendorf, Hamburg). Absorbance ratio at $260 / 280$ is giving a clue of the purity of the solution. All the samples with a ratio higher than 1.6 were considered pure enough for further experiments.

\subsubsection{Using PicoGreen ${ }^{\circledR}$ assay}

PicoGreen ${ }^{\circledR}$ assay is a very sensitive method of detecting double strand DNA (dsDNA) even in the presence of single strand DNA (ssDNA), RNA or free nucleotides. It can detect to as low as $25 \mathrm{pg} / \mathrm{ml}$ of dsDNA. This very sensitive detection of dsDNA is of high value when preparing for genotyping techniques like $\operatorname{TaqMan}^{\circledR}$ or for library and template preparation prior to the Massive parallel sequencing (Next generation sequencing). This assay is based on the fact that the free cyanine dye (PicoGreen) does not fluoresce, but when it binds to the dsDNA it exhibits a more than 1000-fold fluorescence enhancement $(485 / 535 \mathrm{~nm}$; Excitation/Emission respectively). To perform the measurement the color reagent should be freshly prepared and stored for maximum one day at $4^{\circ} \mathrm{C}$. The color reagent could be prepared by diluting PicoGreen dsDNA quantitation reagent (MoBiTec P-7589) 400 times into TE buffer (Table 6). $200 \mu$ of the color reagent was pipetted into 96-wells Microtiter plate (Cat No 3603, Corning ${ }^{\circledR}$ Microtest, North Yorkshire, UK). The appropriate diluted samples (containing less than $20 \mathrm{ng} / \mu \mathrm{l}$ ) were added to the wells in volume of $5 \mu \mathrm{l}$ each. Standard dsDNA should be made from a stock human genomic DNA solution (10 $\mathrm{ng} / \mu \mathrm{l}$ ) by adding $0,3,5,7,10 \mu \mathrm{l}$ from the stock solution in duplicates. The plate should be covered with an adhesive foil and the samples should be mixed by vortexing, then the plate was centrifuged and covered with aluminum foil to prevent the direct exposure to the light and incubated at room temperature for half an hour. The fluorescence was measured using Tecan Ultra ${ }^{\circledR}$ microplate reader and XFluor4 software. If any fluorescence value 
was not in the range between 150 and 32000 FUs, an appropriate dilution of the corresponding sample should be considered.

\subsubsection{Exonuclease and endonuclease restriction digestion}

\subsubsection{For purification after PCR}

To purify DNA from the unincorporated dNTPs (deoxyribonucleotide) in PCR products, the recombinant Shrimp alkaline phosphatase $1 \mathrm{u} / \mu \mathrm{l}$ (rSAP, Affymetrix) was used to remove 5'phosphates from the dNTPS. Exonuclease I $20 \mathrm{u} / \mu \mathrm{l}$ (Fermentas, Thermo Scientific) was used to degrade the used primers as it hydrolyzes single-stranded DNA in the $3^{\prime} \rightarrow 5^{\prime}$ direction, releasing 5'-mononucleotides. The following protocol was used:

\section{Reagent}

$\operatorname{rSAP}(1 \mathrm{u} / \mu \mathrm{l})$

Exol $(20 \mathrm{u} / \mu \mathrm{l})$

10X rSAP Puffer

PCR product

Total

$37^{\circ} \mathrm{C}$ (Incubation)

Deactivation step $80^{\circ} \mathrm{C}$ (In PCR machine)

$8^{\circ} \mathrm{C}$ (In PCR machine)

\section{For 1 Sample}

\section{[ul]}

2,5

0,2

0,9

10

3

1 hour

$15 \min$

forever

\subsubsection{Analytical digestion}

Analytical digestion was used to check the fragmentation pattern of a DNA piece or a plasmid when it was cut at one, two or more specific positions that could be recognized by a specific restriction endonuclease enzyme. As an Example, a pOTB7 plasmid DNA containing sequence of the gene coding the transcription factor LHX4 (Source BioScience Lifesciences, Nottingham, UK). This plasmid has the size of $3534 \mathrm{bp}$ and two cutting positions for Ecorl which could lead to two pieces of DNA after the digestion with the last enzyme. The digestion mixture is composed of

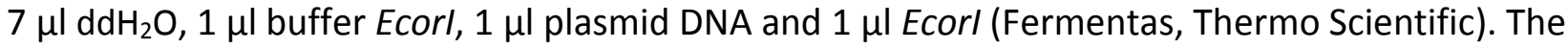
mixture was incubated in $37^{\circ} \mathrm{C}$ for one hour before running on $0.8 \%$ agarose gel (Figure 9 ). 


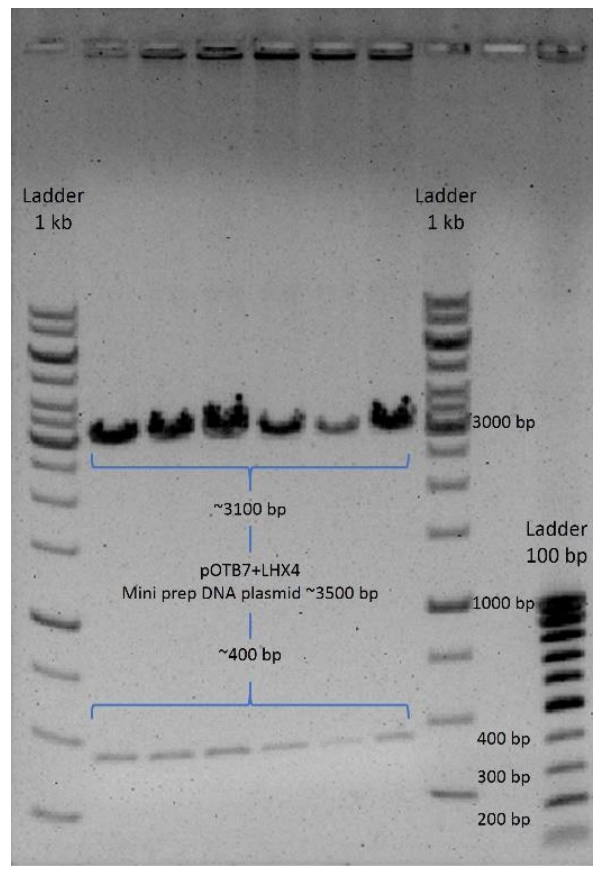

Figure 9: Analytical digestion for $\mathrm{POTB} 7+L H X 4$ plasmid DNA using Ecorl restriction enzyme

\subsubsection{Preparative digestion}

Many of the endonuclease restriction enzymes cut the DNA to have sticky ends. Using that feature, we can use the preparative digestion prior to the ligation step with a complementary construct to the cut ends of the plasmid. The preparative digestion mixture consisted of $5 \mu \mathrm{l}$ buffer according to the used restriction enzyme, $10 \mu \mathrm{l}$ mini prep plasmid DNA, $5 \mu$ ligesting enzyme. The volume was completed to $50 \mu \mathrm{l}$ with $\mathrm{ddH}_{2} \mathrm{O}$. The mixture was incubated in the optimal temperature for the enzyme either for 3 hours or overnight, then $1 \mu l$ from the enzyme was added again for one more hour before running the sample on $0.8 \%$ agarose gel and extract the DNA from the gel 2.5.3].

\subsubsection{Ligation}

This technique is usually used to insert a construct into the vector before performing electroporation to the bacteria cells. The idea is to bring the complimentary cut ends of the construct and the vector to each other. The complimentary ends could be generated either by preparative digestion [2.5.7.3] or synthetically. The ligation reaction is mediated by a DNA 
ligating enzyme (Ligate-ITTM Rapid Ligation Kit; USB, Staufen). The ligation mixture was prepared as the following protocol with a ratio insert:vector equal to 13:2 (v/v):

Reagent

$5 x$ ligase buffer

Plasmid vector

Inserted construct

Ligase

Total

Incubation (room temperature)

Incubation (on ice)

\section{For 1 Sample [ $\mu \mathrm{l}]$}

14

2

13

1

20

5-10 min

$5-10 \mathrm{~min}$

In order to test the ligation efficiency, the same reaction mixture should be prepared in parallel with $\mathrm{dd}_{2} \mathrm{O}$ instead of the inserted construct.

\subsubsection{Dialysis}

This procedure was done to remove trace of salts from the ligation solution [2.5.8] prior to the electroporation [2.8.4] to transfer the plasmid into the bacteria cells. For that, the $20 \mu$ ligation mixture was transferred carefully into the middle of a semipermeable membrane (Dialyse filter VSWP01300, Millipore, Schwalbach). The membrane should be placed already on the surface of $\mathrm{ddH}_{2} \mathrm{O}$ into a petri dish without covering upper face with the water. After $30-45$ minutes, the solution was removed and transferred to a new $1.5 \mathrm{ml}$ Eppendorf tube. The mixture was concentrated under vacuum and heat. For that, the Eppendorf tubes' caps were opened and placed in SpeedVav Plus ${ }^{\circledR}$ SC110A vacuum centrifuge (Schütt, Göttingen) after heating it. The centrifugation was started under vacuum (200 mbar, Membran-Vacuumpumpe, Vacuubrand, Wertheim) for 8 minutes. The remained DNA on the walls of the Eppendorf tubes should be reconstituted by pipetting and washing the tube's wall using the residual liquid. 


\subsubsection{Reverse transcription}

In order to assess the transcription level of any gene (e.g. quantitative PCR [2.5.11]), RNA should be reversely transcribed into cDNA (copy or complimentary DNA) for stability reasons and easiness of further amplification and other procedures. For that, all the RNA-containing samples were normalized to a concentration of $1 \mu \mathrm{g} / \mu \mathrm{l}$. Then $1 \mu \mathrm{l}$ of random hexanucleotide primers (dN6; Roche, Mannheim) were added to the $1 \mu \mathrm{g}$ RNA samples and incubated at $72^{\circ} \mathrm{C}$ for 10 minutes. The samples were left on room temperature to cool down slowly for one hour. Meanwhile, the reverse transcriptase mastermix (RT-Mastermix), which contains the Super Script ${ }^{\mathrm{TM}}$ II reverse transcriptase (Invitrogen, Karlsruhe), could be prepared as the following:

\section{$\underline{\text { RT-Mastermix }}$}

$5 x$ Superscript RT buffer

DTT (0.1 M)

dNTPs (10 mM)

RNase Inhibitor (USB)

Super Script ${ }^{\mathrm{TM}}$ II $(200 \mathrm{u} / \mu \mathrm{l})$

\section{Volume (per sample) [ul]}

6

3.5

1

0,5

0.25

Total volume

11.25

A total of $11.25 \mu \mathrm{l}$ from the RT-Mastermix was added to each samples and the reverse transcription was started by incubation at $42^{\circ} \mathrm{C}$ using either the thermal gradient cycler (BioRad, Hercules, USA) or the thermal mastercycler (Eppendorf, Germany) for one hour. An expected concentration of 2-10 ng/ $\mu \mathrm{l}$ of cDNA could be achieved by adding $70 \mu \mathrm{ddd} \mathrm{H}_{2} \mathrm{O}$ to each sample.

\subsubsection{Quantitative PCR}

The transcription levels of both aldosterone receptor gene (NR3C2) and with-no-Lysine 4 (WNK4) were evaluated using the quantitative PCR (real-time PCR). The housekeeping gene used as endogenous control (internal standard) was the Human TBP (TATA-box binding protein) (VIC/MGB Probe, Primer Limited; Applied Biosystems, Darmstadt). For that, $3 \mu$ of already prepared cDNA [2.5.10] were added to $15 \mu \mathrm{l}$ of the gene expression mastermix (per sample and well) in a 384-wells plate (Thermo Fast Plate 384 PCR, ABgene, Epsom, UK). The plate was 
covered with a special optical clear foil (Adhesive PCR foil seals; ABgene, Epsom, UK). The gene expression mastermix was prepared as the following:

Reagent (per sample)

2x qRT-PCR Mastermix (PrimerDesign Ltd Precision OneStep ${ }^{T M}$, United Kingdom) 20x Gene expression assay (Table 12)

dd $\mathrm{H}_{2} \mathrm{O}$

Total

Table 12: Used gene expression assays (Applied Biosystems, Darmstadt)

\begin{tabular}{cc}
\hline Gene & Assay number \\
\hline NR3C2 & HS01031809_m1 \\
WNK4 & HS00260769_m1 \\
TBP & $4326322 \mathrm{E}$ \\
\hline
\end{tabular}

Volume [ $\mu$ l]

9

0.9

5.1

15

The quantitative PCR was performed using Applied Biosystems 7900HT Fast Real-Time PCR System under the following conditions:

Phase

Activating uracil n-glycosylase

Activating Taq Polymerase

Denaturation

Primer annealing

\section{Duration Temperature}

2 Min

$50^{\circ} \mathrm{C}$

10 Min

$95^{\circ} \mathrm{C}$

$15 \mathrm{Sec}$

1 Min

$95^{\circ} \mathrm{C}$

$60^{\circ} \mathrm{C}$
40 Cycles

Data were analyzed by the software SDS 2.1. 
The relative expression of the studied genes was calculated using the equation:

$$
\begin{gathered}
\text { Relative expression }=2^{-d C t} \\
\text { Or } \\
\text { Relative expression }=2^{-(d C t-\text { Maximum } C t \text { between the samples })} \\
d C t=\left(C t_{\text {measured gene in the sample }}-C t_{\text {housekeeping }} \text { gene in the same sample }\right)
\end{gathered}
$$

Where $\mathrm{Ct}$ is the cycle number at which the fluorescence emission exceeds the fixed threshold level (defined automatically by the software) and is inversely proportional to the expression level of the target gene.

\subsection{Sequencing and genotyping workflow}

\subsubsection{Genotyping by the Single Nucleotide Primer Extension Method SNaPShot ${ }^{\mathrm{TM}}$}

SNaPShot ${ }^{T M}$ is a SNP genotyping method which refers to a single nucleotide extension at the position of the polymorphic base. To achieve a single nucleotide extension only, the use of fluorescently labeled dideoxyribonucleotide triphosphate (ddNTPs) is required in a SNaPShot PCR reaction (SNaPShot reaction mix: ABI PRISM ${ }^{\circledR}$ SNaPshot ${ }^{T M}$ Multiplex Kit, Applied Biosystems). ddNTPs are dNTPs lacking $(-\mathrm{OH})$ group at the 3 ' position which make them not suitable for further DNA extension. Two major steps are required for this method (Figure 10). The first is to amplify the DNA fragments that include the polymorphism(s) [2.5.4.2; Table 8]. The second is to design the SNaPShot primers that stop exactly one nucleotide before the genotyped polymorphism, where the complimentary fluorescent ddNTP could make a single nucleotide extension and could be detected by suitable laser detector after the electrophoresis. As the electrophoresis is separating the fragments depending on its length, it is possible to genotype up to 30 polymorphisms under optimal conditions with efficient results. 

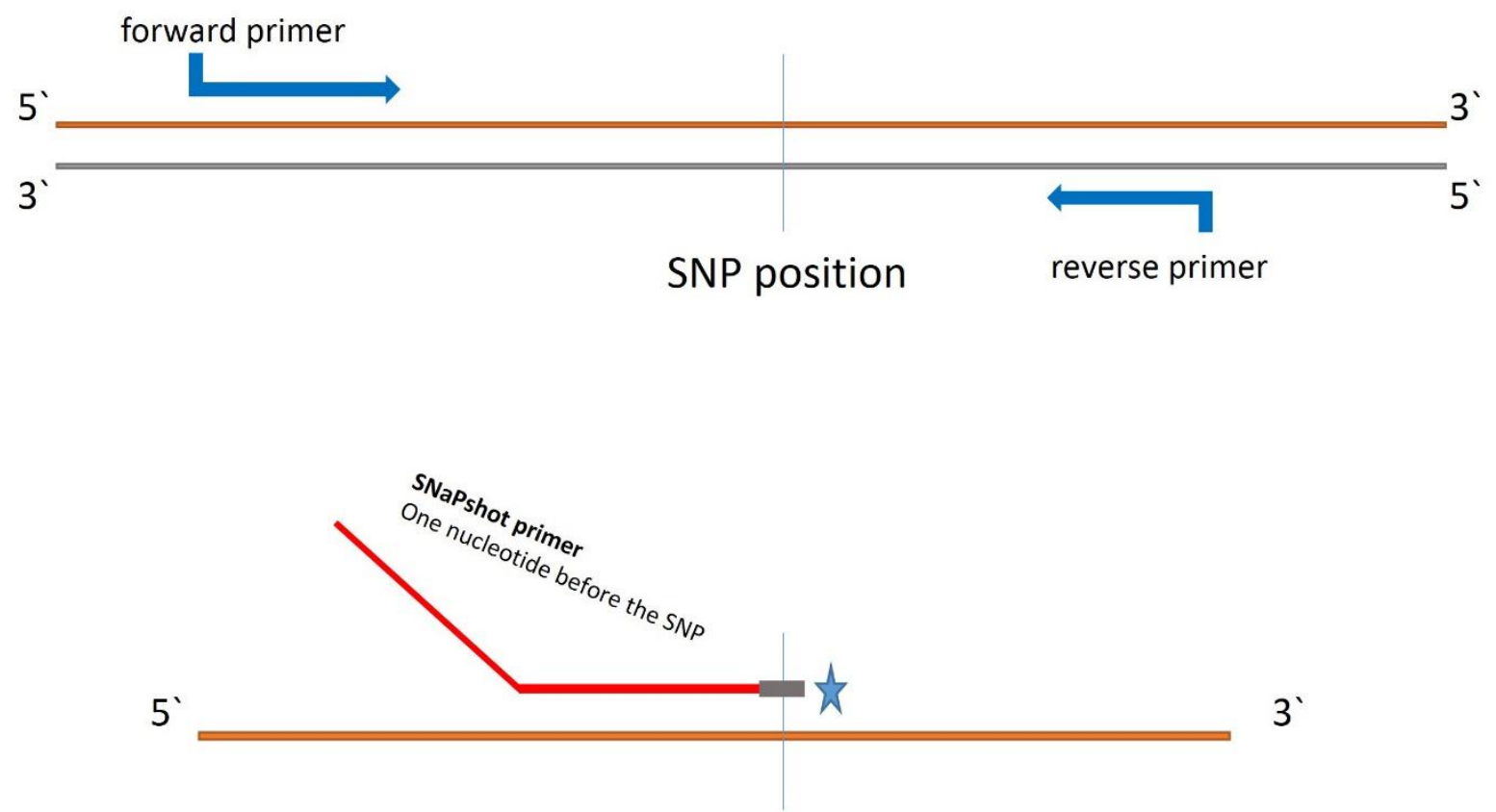

\section{SNP position}

Figure 10: The two major steps for SNaPShot ${ }^{T M}$ genotyping method

The upper part illustrates the PCR for amplification and the lower part shows the single nucleotide extension reaction ending with the incorporation of a fluorescently labelled ddNTP at the polymorphic base to be analyzed.

In details, after performing the purifying step [2.5.7.1] for the PCR products that include the polymorphisms [2.5.4.2], SNaPShot PCR reaction was performed under the following conditions in a 384-well PCR Plate (FrameStar ${ }^{\circledR}$; 4titude, Dorking, UK) (Table 13):

Table 13: SNaPShot PCR reaction and conditions

\section{Reagent}

SNaPShot reaction mix

Pooled primers mix (0.5-2 $\mu \mathrm{M}$ each)

$\mathrm{ddH}_{2} \mathrm{O}$

PCR products (DNA fragments)

\section{Volume per sample [ $\mu \mathrm{l}]$}

$0.5-2$

0.5

To 3

Total

\section{2}

5 


\section{SNaPShot PCR conditions}

Temperature Duration

Initial Denaturation

$96^{\circ} \mathrm{C}$

2 Min

Denaturation

$96^{\circ} \mathrm{C}$

$10 \mathrm{sec}$

Primers annealing

$50^{\circ} \mathrm{C}$

$5 \mathrm{sec}$

26 Cycles

Elongation

$60^{\circ} \mathrm{C}$

$30 \mathrm{sec}$

Cooling down

$8^{\circ} \mathrm{C}$

Forever

After the SNaPShot PCR, the samples underwent another purification step by incubating each with $1 \mu \mathrm{l}$ from a mixture 1:1 (v/v) of fast alkaline phosphatase and the respected-buffer (Fast$A P$; Fermentas, St. Leon-Roth) at $37^{\circ} \mathrm{C}$ for one hour to destroy the remaining unincorporated fluorescently labeled ddNTPs. The enzyme should be deactivated by incubating the samples at $75^{\circ} \mathrm{C}$ for 15 minutes. At this point, samples could be stored at $4^{\circ} \mathrm{C}$ or prepared for the sequencing and analysis. For that, $1 \mu \mathrm{l}$ from the samples is transferred to a 96 -well sequencing plate containing $10 \mu \mathrm{l}$ from the sequencing mastermix (Table 14). The plate was incubated at $95^{\circ} \mathrm{C}$ for 5 minutes then placed on ice immediately until cooling down. The plate was installed into its adapter for 3130xl Genetic Analyser (Applied Biosystems, Darmstadt) and data were analyzed using Gene mapper v3.7 software ${ }^{\circledR}$ (Applied Biosystems, Darmstadt).

Table 14: Sequencing mastermix for SNaPShot ${ }^{\circledR}$

\begin{tabular}{lc}
\hline Reagent & Volume per sample $[\mu \mathrm{l}]$ \\
\hline Formamid (Hi-DiTM Formamid, Applied Biosystems) & 10 \\
GeneScan $^{\mathrm{TM}}$ 120LIZ & 0.2 \\
\hline
\end{tabular}


Table 15: SNaPShot ${ }^{\circledast}$ primers used in genotyping 39 SNPS

\begin{tabular}{|c|c|c|c|c|c|c|}
\hline rs-number & Gene & SNaPshot Primer & $\begin{array}{l}\text { Primer } \\
\text { length }\end{array}$ & Allele1 & Allele2 & Batch No. \\
\hline rs765250 & WNK1 & AAGACATGCTCACCAAAACA & 20 & G & A & 1 \\
\hline rs1057293 & SGK1 & GGACACATTGTCCTTACTGA & 20 & C & $\mathbf{T}$ & 1 \\
\hline rs2277869 & WNK1 & gatcGGCTTCCCAGYTCATCCTCT & 24 & C & $\mathbf{T}$ & 1 \\
\hline rs7880501 & WNK3 & gatcgatcTTCAAATTTCTTGTACAGTA & 28 & C & $\mathbf{T}$ & 1 \\
\hline rs2107614 & WNK1 & gatcgatcgatcGAAGAGTTGAGGGGAAATGG & 32 & G & A & 1 \\
\hline rs3021285 & WNK3 & gatcgatcgatcgatcACTCTACTTACTGGTGGGGC & 36 & C & $\mathbf{T}$ & 1 \\
\hline rs1159744 & WNK1 & gatcgatcgatcgatcgCTTTACTGATATTCTCTATTTGTTGAG & 44 & G & C & 1 \\
\hline rs61755606 & WNK4 & gatcgatcgatcgatcgatcgatcgatcGTCTGGTTTCTAATACCAGACTTTAGA & 55 & G & A & 1 \\
\hline rs77012584 & WNK4 & AGGCCTCTGACCACTGACCT & 20 & C & $\mathbf{T}$ & 2 \\
\hline rs457661 & OXSR1 & GCTGCCGCCGTCATGTCCGA & 20 & G & A & 2 \\
\hline rs2846679 & KCNJ1 & gatcgaAGCCTTTCCCCCAGACCTTC & 26 & C & $\mathbf{T}$ & 2 \\
\hline rs1010069 & CLCNKA & gatcgaAGGACAGCCCTGGGGGTTGG & 26 & G & A & 2 \\
\hline rs113919536 & OXSR1 & gatcgatcgatcAGCTGTTTTTGCTGGCTCTG & 32 & C & A & 2 \\
\hline rs4149601 & NEDD4L & gatcgatcgatcgatcgaAAAGTCTTACCGAGTGTTAC & 38 & C & $\mathbf{T}$ & 2 \\
\hline rs3088353 & WNK1 & gatcgatcgatcgatcgatcgaCGAACCCGCCCGGCCGCGGT & 42 & G & $\mathbf{T}$ & 2 \\
\hline rs2288774 & NEDD4L & gatcgatcgatcgatcgatcgatcgatcgAAATGCCACTCTGAAAATAC & 49 & G & A & 2 \\
\hline rs77879367 & WNK4 & gatcgatcgatcgatcgatcgatcgatCGCAGCCTAACCCTGGCCAGAGTGGCTG & 55 & G & $\mathbf{T}$ & 2 \\
\hline rs75596106 & WNK4 & gatcgatcgatcgatcgatcgatcgatcgatcgatcgatcgaGACGATGTTGGGGTGCTGCA & 62 & G & C & 2 \\
\hline rs76937254 & KCNJ1 & gaGATCAATATCAACTTTGTAG & 22 & C & $\mathrm{T}$ & 3 \\
\hline rs2070951 & NR3C2 & gatcgaGGTAGCCTTTGGTCTCCATC & 26 & G & C & 3 \\
\hline rs35295772 & OXSR1 & gatcgatcCTTGGTTTCTTGTGAACCTG & 28 & A & T & 3 \\
\hline rs3021280 & WNK3 & gatcgatcgatcTCAGGGCACCGGCAGGGCTA & 32 & G & $\mathbf{T}$ & 3 \\
\hline \multirow[t]{2}{*}{ rs78645838 } & WNK4 & gatcgatcgCTGAGGTGGTTCAGATTTTAAATCAG & 35 & G & A & 3 \\
\hline & FAM120C & & & & & \\
\hline rs2495801 & $\begin{array}{l}==>\text { WNK3 } \\
\text { promoter }\end{array}$ & gatcgatcgatcgatcgatcgaAGATCCTTTCTCACAGCATG & 42 & C & $\mathbf{T}$ & 3 \\
\hline rs6599079 & OXSR1 & gatcgatcgatcgatcgatcgaTGGTTGGTGCTCTCTGCAAT & 42 & G & A & 3 \\
\hline rs9493857 & SGK1 & gatcgatcgatcgatcgatcgatcgatcgCTAAGTAGTTGATGAAACTA & 49 & C & $\mathbf{T}$ & 3 \\
\hline rs76640813 & KCNJ1 & gatcgatcgatcgatcgatcgatcgatcg TTTTCTCTGGAGACTCAAGT & 49 & G & A & 3 \\
\hline rs3857080 & NR3C2 & gatcgatcgatcgatcgatcgatcgatcgatcgaGTTTTCCAGAGAACTGAGTGTC & 56 & G & A & 3 \\
\hline rs5522 & $N R 3 C 2$ & gatcgatcgatcgatcgatcgatcgatcgatcgatcgatcgTGAATGGTGGCGTCATGCGCGCC & 64 & G & A & 3 \\
\hline rs3021284 & WNK3 & gatcgatcgatcgatcgatcgatcgatcgatcgatcgatcgatcGATAACCCAATTTACCTCTGTACAAA & 70 & $\mathbf{T}$ & A & 3 \\
\hline rs11737660 & $N R 3 C 2$ & ATCACACCACCTTTCATGCC & 20 & G & A & 4 \\
\hline rs5534 & $N R 3 C 2$ & CTTTCCAAGATCAGAAGGGAA & 21 & C & $\mathbf{T}$ & 4 \\
\hline rs10519963 & $N R 3 C 2$ & gatGAGCTCTCTCTTACCCTTTTAAAGA & 28 & C & $\mathbf{T}$ & 4 \\
\hline rs4835493 & $N R 3 C 2$ & gatcgaTGAGGGATATGGAGATATTAGG & 28 & G & A & 4 \\
\hline rs1040288 & $N R 3 C 2$ & gatcgatcgatcgaTGTGTGCCAAGCTGAGTAAT & 34 & G & C & 4 \\
\hline rs6810951 & $N R 3 C 2$ & gatcgatcgGACCTCATCCTCTACTCTGGAATAAGTCAA & 39 & C & A & 4 \\
\hline rs11099680 & NR3C2 & gatcgatcgatcgatcgatcgatcTGAGGCATATGGCAACATAG & 44 & C & $\mathbf{T}$ & 4 \\
\hline
\end{tabular}


rs3846329 NR3C2 gatcgatcgatcgatcgatcgatcgatcgGGCTGCTCACCTCCACAGAT rs11099681 NR3C2 gatcgatcgatcgatcgatcgatcgatcgatGTGTAAGATTGCTGGTGTTTCTTT

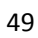

55

Y refers to C or T as the IUPAC codes (in the SNaPShot primer for rs2277869)

\subsubsection{Dideoxy chain termination (Sanger) sequencing}

The chain termination sequencing using capillary sequencer is derived originally from the work of Sanger and Coulson in 1975. The difference here is the use of fluorescently labeled ddNTPs in one reaction only. Each of the ddNTPs can give specific color which leads to recognize the end of the sequence. The reaction mix should contain also dNTPs to extend the DNA strand through the sequencing PCR reaction. On each extension procedure, there is a chance to add one of the fluorescent ddNTPs and end the extension. The differently sized DNA fragments could be separated by capillary electrophoresis. The end of each DNA fragment sequence could be detected by laser detector supplied with the sequencer. The huge number of extended DNA fragments with different sizes through the sequencing PCR reaction will lead to distinguish all the probable nucleotides through the sequenced DNA fragment. This method is efficient to sequence DNA fragments between 60 base pairs and maximum several hundreds of base pairs in one run.

In details, DNA from mini-prep directly [2.5.2.1] or after purification step of previous PCR reaction [2.5.7.1] is treated with the sequencing master mix and sequencing PCR is performed in a 384-well PCR Plate (FrameStar ${ }^{\circledR} ;$ 4titude, Dorking, UK) as the following (Table 16):

Table 16: Sequencing PCR reaction and conditions

\section{Sequencing PCR Mastermix}

$\mathrm{ddH}_{2} \mathrm{O}$

DMSO (Dimethyl sulfoxide)

Primer $(10 \mu \mathrm{M})$

BigDye ${ }^{\circledR}$ terminator v1.1 (Applied

Biosystems, Darmstadt)

\section{Volume per sample $[\mu \mathrm{l}]$}

\section{2,25}

0,25

0,5

1

Total 4

DNA 


\section{Sequencing PCR conditions}

\begin{tabular}{lcc|l} 
& Temperature & \multicolumn{2}{c}{ Duration } \\
\cline { 2 - 3 } Initial Denaturation & $94^{\circ} \mathrm{C}$ & $2 \mathrm{Min}$ & \\
Denaturation & $96^{\circ} \mathrm{C}$ & $15 \mathrm{sec}$ & $26 \mathrm{Cycles}$ \\
Primers annealing & $56.5^{\circ} \mathrm{C}$ & $15 \mathrm{sec}$ & $2 \mathrm{~min}$ \\
Elongation & $60^{\circ} \mathrm{C}$ & $7 \mathrm{~min}$ & \\
Final end-terminal elongation & $72^{\circ} \mathrm{C}$ & Forever
\end{tabular}

To remove the unincorporated dNTPs and ddNTPs from the reaction mix, the samples should undergo a purification step through Sephadex G50 superfine (Amersham Bioscience, Freiburg). For that, $35 \mathrm{mg}$ of sephadex is transferred to a 96-well filter plate (MAHV-N45, Millipore, Schwalbach) and incubated at room temperature after adding $300 \mu \mathrm{ddH} 2 \mathrm{O}$ for three hours. After that, the excess water was removed by centrifuging for 5 minutes at $700 \mathrm{rpm}$ (Centrifuge $5810 \mathrm{R}$; Eppendorf, Hamburg). Again, $150 \mu \mathrm{l}$ of $\mathrm{ddH} 2 \mathrm{O}$ was added and the sephadex was incubated at room temperature for half an hour. The excess water was removed by centrifuging also (700 rpm; RT). Finally, the sephadex plate was placed over a sequencing plate and the samples were transferred to the sephadex wells. The samples were collected in the sequencing plate after centrifuging for $5 \mathrm{~min}$ at $700 \mathrm{rpm}$ and room temperature. Samples were sequenced using the 3130xl Genetic Analyser (Applied Biosystems, Darmstadt) and data were analyzed using Sequencing Analysis Version 5.2 software $^{\circledR}$ (Applied Biosystems, Darmstadt) then with Staden Package v4.0 (Cambridge, UK) or DNASTAR ${ }^{\circledR}$ v11.2 (Madison WI, USA).

Primers which were used to sequence the vectors in this research (pGL3promoter, pOTB7 and pcDNA3.1) and to check the insertions are listed in Table 17. 
Table 17: Primers used for sequencing the clones

\begin{tabular}{ll}
\hline Primer & Sequence \\
\hline pGL3prom_f & GAATCGATAGTACTAACATA \\
M13_f & TGTAAAACGACGGCCAGT \\
T7_universal & TAATACGACTCACTATAGGG \\
LHX4_f_1 & CCGCAAGGCCCAGGACTTTGTCTAC \\
LHX4_f_2 & GAGGGAGCAGCTGTCCTCAGAGACA \\
LHX4_f_3 & GGACGGGACAGGACAATCCTATCAG \\
LHX4_f_4 & GCCCCCCTGGCTTGAGAGAATATCT \\
LHX4_f_5 & TTTGCTCCAACTGGTGTGTCTCACA \\
\hline
\end{tabular}

\subsubsection{Massive parallel sequencing (Next generation sequencing)}

The massive parallel sequencing (also called Next generation sequencing NGS, High-throughput sequencing or Deep sequencing) is a method where one can sequence the DNA in mega base pairs scale, giving the possibility to scan a number of genes for a number of participants and pooling all the samples from different participants in one run without the need to treat them separately alike the capillary sequencing. The difference in the number of the read bp per run differs between the instruments and techniques, but in general it ranges between $100 \mathrm{Mbp}$ and $600000 \mathrm{Mbp}$.

As a new technique in the institute of clinical pharmacology, the Ion Personal Genome Machine $^{\mathrm{TM}}$ Sequencer (PGM ${ }^{\mathrm{TM}}$; Life technologies, Darmstadt) was used in this work to sequence all the exon regions in the WNK4 gene for all the participants in both clinical studies. The Ion $\mathrm{PGM}^{\mathrm{TM}}$ Sequencer (Ion Torrent) chemistry is based on ion semiconductor sequencing. The ion semiconductor sequencing is based on the detection of hydrogen ions that are released after each incorporation of a new dNTP that is complementary to the template DNA.

The typical workflow in the massive parallel sequencing usually includes: target enrichment, library preparation, template preparation, sequencing and data analysis. 


\subsubsection{Target enrichment}

First of all, the idea was to use the advantage of the high read numbers of the technique to sequence all the DNA samples from both clinical studies together. The pooling criteria was set as the Sodium and Chloride excretion between 0 and 24 hours. For that, each clinical study was divided into two groups; low and high sodium and chloride eliminators. To have these two groups in the first clinical study on loop diuretics, the excretion of sodium and chloride under each drug was given a sorting code, then the participants were sorted upon the median numbers coming from the sorting codes for each of the three drugs. The same was applied for the second clinical study but with the numbers coming only from hydrochlorothiazide 25 and $100 \mathrm{mg}$ days. The DNA samples were normalized using QIAgility ${ }^{\circledR}$ pipetting machine (QIAGEN $\left.{ }^{\circledR}\right)$ then pooled as defined into four final samples (each contains DNA which is coming from around 50 participants).

One of the limitations of the ion torrent sequencing techniques is that the amplicons' length should not exceed $300 \mathrm{bp}$ as maximum. For that it was necessary to amplify the exons of WNK4 in two separate pools for each sample to cover the whole wanted area. Primers were designed using Ion AmpliSeq ${ }^{\mathrm{TM}}$ Designer webtool from life technologies. A total of 50 amplicons divided into two pools for each group of the four pooled sample groups were covering finally the 19 exons of the WNK4 gene (Figure 11).

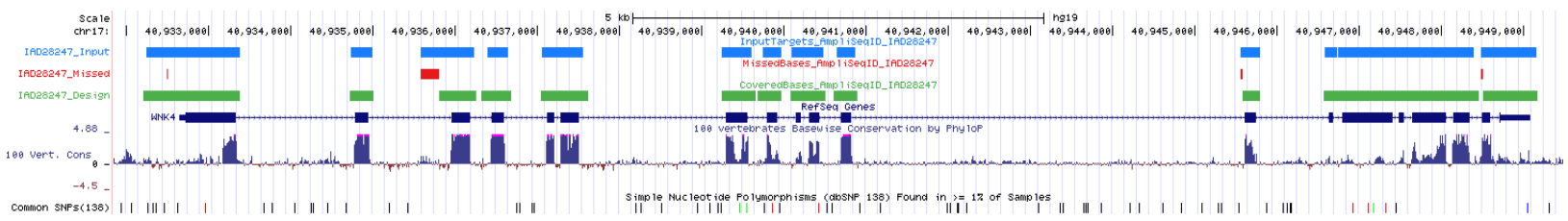

Figure 11: WNK4 gene with the covered regions by the target enrichment.

The upper blue panel is the final covered regions. The red one is the missing regions from the originally designed and wanted regions (in green). The WNK4 19 exons reference is on dark blue under the three last panels. The figure was produced using the "loading custom track" function in the UCSC genome browser (http://genome-euro.ucsc.edu/index.html). 
The final 8 pools were normalized to have $10 \mathrm{ng}$ of total DNA for library preparation. An overview of the pooling procedure and target enrichment are depicted in (Figure 12):

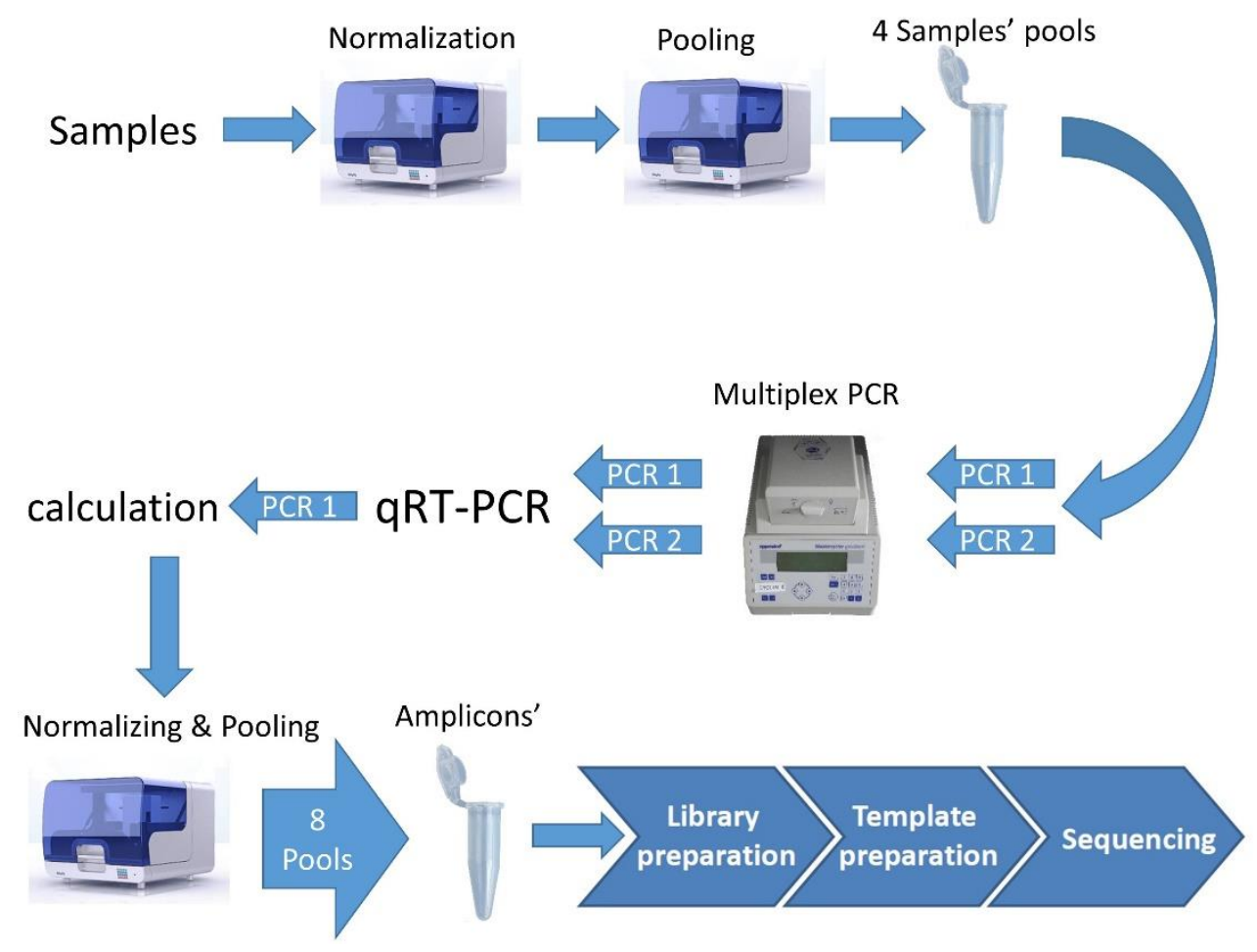

Figure 12: Target enrichment for the NGS workflow

The pipetting machine icon was taken from the company website (Qiagility; Qiagen, Hilden) (http://www.qiagen.com/products/catalog/automated-solutions/assay-setup/qiagility)

\subsubsection{Library preparation}

Library preparation was performed according to the manufacturer's user guide for lon AmpliSeq $^{\text {TM }}$ Library Kit 2.0 (Life technologies), catalog numbers 4475345, 4478378, 4478379, publication part Number MAN0006735 and revision date 8 June 2012. The final quantification of the prepared libraries was performed according to the manufacturer's user guide for lon Library Quantitation Kit (Life technologies), catalog number 4468802, publication part number 4468986 Rev. C and revision date August 2011.

In general the library preparation implements several enzymatic steps after the target enrichment for end repair, adapter ligation, nick repair and PCR amplification. In between there 
is also a number of purification steps mostly using the magnetic beads and quality control steps by regular quantification of the libraries.

After preparing the libraries, the barcodes and adapters would be ligated to the DNA fragments. The 8 different pools from the four sample groups were pooled together for further treatment for the template preparation.

\subsubsection{Template preparation}

Template preparation was performed according to the manufacturer's quick reference for lon OneTouch $^{\mathrm{TM}} 200$ Template Kit v2 (Life technologies), publication part number 4478371 Rev. B and revision date 13 June 2012.

In general, the template preparation begins with generating an emulsion from the pooled library products. In this step, on average in each emulsion drop only one DNA molecule should be trapped with one Ion OneTouch ${ }^{\mathrm{TM}} 200$ Ion Sphere ${ }^{\mathrm{TM}}$ Particle (ISP). Then performing emulsion PCR using the OneTouch ${ }^{\mathrm{TM}}$ instrument for preparing template-positive ISPs. The next step would be to recover the positive ISPs through enrichment procedure using lon OneTouch ${ }^{\mathrm{TM}} \mathrm{ES}$. The enrichment involves using magnetic beads which have streptavidin and bind to the positive ISPS (biotin-streptavidin bind) then isolating them using a magnet. After that, the magnet beads would be washed out leaving the positive ISPs with single strands DNA.

\subsubsection{Sequencing and data analysis}

Sequencing was performed according to the manufacturer's quick reference for lon PGM ${ }^{\mathrm{TM}} 200$ Sequencing kit (Life technologies), publication part number 4474596 Rev. A and revision date 17 February 2012. The used chip was Ion $316^{\mathrm{TM}}$. Data were analyzed mainly by two software: DNASTAR $^{\circledR}$ V11.2 (Madison WI, USA) and Integrative Genomics Viewer v3.4.51874 (Broad institute, Cambridge MA, USA) with Torrent Variant Caller Plugin v3.4.

\subsection{DNA-protein binding}

\subsubsection{Electrophoretic mobility shift assay (EMSA)}

Nuclear protein extracts from HEK293 cells were obtained by the Dignam method (Dignam et al., 1983) followed by a purification step with ammonium sulfate (kindly provided by Dr. Kristin 
Bokelmann). The extraction was done at $4^{\circ} \mathrm{C}$ under $\mathrm{pH}=7.9$ to prevent denaturation of the proteins. Quantification of the protein amount was done by the Bicinchoninic Acid Assay (BCA).

The required short double strand DNA segments were obtained by placing the mixture of the complementary oligonucleotides in Table 18 inside $1.5 \mathrm{ml}$ Eppendorf tube at $95^{\circ} \mathrm{C}$ water and leaving it cooling down to the room temperature.

Electrophoretic mobility shift assay (EMSA) was performed as the following. $2 \mathrm{pmol} / \mu \mathrm{L}$ of the annealed oligonucleotides were radiolabeled by incubation with Klenow-Fragment (MBIFermantas, St. Leon-Roth) at $37^{\circ} \mathrm{C}$ for 1 hour with $\left[\alpha^{32} \mathrm{P}\right] \mathrm{dCTP}$ (Hartmann Analytic GmbH, Braunschweig) and the other three dNTPs (each $1 \mu \mathrm{M}$ ) (Table 19). For purification from the unbound $\left[\alpha^{32} \mathrm{P}\right] \mathrm{dCTP}$, mini Quick Spin Oligo Columns (Roche, Germany) were incubated first for one hour at room temperature, then homogenized by vortexing and centrifuged to remove the excess water at $3200 \mathrm{~g}$ for two minutes at room temperature (Biofuge $15 \mathrm{R}$; Heraeus, Hanau). The labeled samples were added to the columns and centrifuged again ( $3200 \mathrm{~g}, 4$ minutes, RT) (Biofuge $15 \mathrm{R}$; Heraeus, Hanau). For the binding reaction, an amount of $20 \mu \mathrm{g}$ from the nuclear protein extracts was pre-incubated for $10 \mathrm{~min}$ on ice with $18 \mu \mathrm{l}$ reaction mixture consisting of binding buffer, poly $\mathrm{dl}-\mathrm{dC} 1 \mu \mathrm{g} / \mu \mathrm{L}$ (poly deoxyinosinic-deoxycytidylic) and $\mathrm{ddH}_{2} \mathrm{O}$. The radioactive probes (30000 CPM) were added and incubated with the mixture for 10 minutes (Table 20). The samples were mixed with $6 x$ loading buffer (Table 20) before running the samples on a $5 \%$ native non-denaturing polyacrylamide gel equilibrated in $0.5 \%$ TBE-buffer at 180 Volt for one hour (Table 21). The gel was dried by placing it on Whatman papers (Nr. 2668, Schleicher und Schüll, Dassel) over the gel-drying-system at $80^{\circ} \mathrm{C}$ for one hour (DrygelSr; Hoffer scientific instruments, San Francisco, USA). The dried gel was incubated overnight with Fujifilm BAS1500 plate and the radioactive signals were visualized using Phosphor Imager (Raytest, Sprockhövel) and the software BASreader and AIDA (Version 4.15.025, Raytest, Sprockhövel).

To determine the exact amount of radioactivity in the labeled samples, $1 \mu$ l of the sample was mixed with $4 \mathrm{ml}$ of safety scintillator solution (Aquasafe 500 Plus; Zinsser Analytic, Berkshire) and measured by the scintillation counter LS1801 (Beckman, München). 
Table 18: Annealing mixture for oligonucleotides used in EMSA

\begin{tabular}{lc}
\hline Reagent & Volume $[\mu \mathrm{\mu l}]$ \\
\hline Oligo_f $(100 \mu \mathrm{M})$ & 1 \\
Oligo_r $(100 \mu \mathrm{M})$ & 1 \\
$\mathrm{NaCl}(0.5 \mathrm{M})$ & 1 \\
$\mathrm{ddH}_{2} \mathrm{O}$ & to 50 \\
\hline
\end{tabular}

Table 19: Labeling mixture with $\left[\alpha^{32} P\right] d C T P$

\begin{tabular}{|c|c|c|}
\hline Reagent & Volume per sample $[\mu \mathrm{l}]$ & \\
\hline ds-Oligonukleotide (2 pmol/ $\mu \mathrm{l})$ & 1 & \\
\hline dNTPs (A, G, T each 1 mM) & 1 & \\
\hline 10x Klenow-Buffer & 2 & \\
\hline $\mathrm{ddH}_{2} \mathrm{O}$ & 12 & \multirow{3}{*}{ Add in the radioactive area } \\
\hline$\left[\alpha-{ }^{32} \mathrm{P}\right] \mathrm{dCTP}(10 \mu \mathrm{Ci} / \mu \mathrm{l})$ & 2 & \\
\hline Klenow-Fragment (1 u/ $\mu \mathrm{l})$ & 2 & \\
\hline
\end{tabular}

Table 20: EMSA binding reaction and buffers

\section{4x Binding buffer $\mathrm{pH} 7.9$ :}

Store at $4^{\circ} \mathrm{C}$

$\begin{array}{lr}\text { HEPES pH 7.8 } & 80 \mathrm{mM} \\ \text { EDTA pH 8 } & 4 \mathrm{mM} \\ \text { DTT } & 2 \mathrm{mM} \\ \text { Glycerol } & 40 \% \\ \mathrm{KCl} & 560 \mathrm{mM}\end{array}$




\section{Binding reaction:}

On ice

$\begin{array}{lr}\text { 4x Binding buffer } & 5 \mu \mathrm{l} \\ \text { Nuclear protein extracts } & 20 \mu \mathrm{g} \\ \text { Poly dl-dC }(1 \mu \mathrm{g} / \mu \mathrm{l}) & 2 \mu \mathrm{l} \\ \mathrm{dd}_{2} \mathrm{O} & \text { To } 18 \mu \mathrm{l}\end{array}$

\section{6x Loading buffer:}

Store at $-20^{\circ} \mathrm{C}$

$\begin{array}{lr}\text { Glycerol 87\% } & 30 \%(\mathrm{v} / \mathrm{v}) \\ \text { Bromphenol Blue } & 0.25 \%(\mathrm{w} / \mathrm{v}) \\ \text { Xylene Cyanol FF } & 0.25 \%(\mathrm{w} / \mathrm{v})\end{array}$

Table 21: 5\% native non-denaturing polyacrylamide gel

\section{5\% Polyacrylamide gel:}

40\% (w/v) Acrylamide/Mix 37:5:1 $4.4 \mathrm{ml}$

5x TBE $\quad 3.5 \mathrm{ml}$

$\mathrm{ddH}_{2} \mathrm{O} \quad 27 \mathrm{ml}$

$\begin{array}{lr}\text { APS } 10 \%(w / v) & 350 \mu \mathrm{l} \\ \text { TEMED } & 35 \mu \mathrm{l}\end{array}$ Gel forming reagents

\section{5x TBE Buffer pH 8:}

$450 \mathrm{mM}$

Boric acid

$450 \mathrm{mM}$

EDTA

$10 \mathrm{mM}$ 


\subsubsection{Cold competition}

Cold competition was performed either to define the specific binding pattern between the different alleles of the polymorphism, or to check the competition with the known consensus (binding sites' sequences) of some transcription factors. For that, 10- to 50-fold of the unlabeled competitor probe was added. Quantification of the signals was done using Quantity One v4.2.1 software (Bio-Rad, München). Cold competition was done with the known consensus for the most probable transcription factors suggested with TRANSFAC $^{\circledR}$ database $(A P 1, B A R X 1$, GBX2, LHX4, MSX1, SOX4, and TBX5). In case of the competition, either the intensity of the band could be decreased or the band itself might disappear.

\subsubsection{Super shift assay}

For the super shift assay we used $2 \mu \mathrm{L}$ anti-LHX4 antibody which provided as a suspension in 50\% ammonium sulfate and phosphate buffered saline (Product number L 5042, Sigma-Aldrich, St. Louis, USA). When the determined transcription factor binds to its specific antibody, either the intensity of the band could decrease or the band itself might be shifted up.

All the oligonucleotides in this work (Eurofins MWG Synthesis GmbH, Ebersberg) which were used in EMSA experiments, cold competition and super shift are listed in Table 22.

Table 22: Oligonucleotides used for electrophoretic mobility shift assays (EMSA)

Oligo Name

$\underline{\text { rs3857080 }}$

rs3857080 major allele $(G)-f^{*}$

rs3857080 major allele $(G)-r^{* *}$

rs3857080 minor allele (A) - f

rs3857080 minor allele (A) - r

rs3857080 Mutated minor allele (A) - f sequence

gatcCAGAGAACTGAGTGTC-G-ATTTTAATGTTTTTTTC

gatcGAAAAAAACATTAAAAT-C-GACACTCAGTTCTCTG

gatcCAGAGAACTGAGTGTC-A-ATTTTAATGTTTTTTTC

gatcGAAAAAAACATTAAAAT-T-GACACTCAGTTCTCTG

gatcCAGAGAACTGAGTGTC-A-GGGG-TAATGTTTTTTTC 
rs3857080 Mutated minor allele (A) - r

$\underline{\mathrm{LHX} 4}$

Lhx4 Consensus - $f$

Lhx4 Consensus - $r$

Lhx4 Mutated - $f$

Lhx4 Mutated - $r$

rs11099680 as negative control

rs11099680 major allele (T) - $f$

rs11099680 major allele (T) - r

rs11099680 minor allele (C) - $f$

rs11099680 minor allele (C) - r
gatcGAAAAAAACATTA-CCCC-T-GACACTCAGTTCTCTG

\author{
gatcGTATGAATC-AT-TAAT-TG-ACAACATAT \\ gatcATATGTTGT-CA-ATTA-AT-GATTCATAC \\ gatcGTATGAATCAT-CCCC-TGACAACATAT \\ gatcATATGTTGTCA-GGGG-ATGATTCATAC
}

gatcGCATATGGCAACATAG-T-GTAATACTTGGAAGAC

gatcGTCTTCCAAGTATTAC-A-CTATGTTGCCATATGC

gatcGCATATGGCAACATAG-C-GTAATACTTGGAAGAC

gatcGTCTTCCAAGTATTAC-G-CTATGTTGCCATATGC

${ }^{*} \mathrm{f}=$ forward, ${ }^{* *} \mathrm{r}=$ reverse

\subsection{Working with bacteria}

\subsubsection{Bacteria growth medium}

Luria-Bertani (LB) complex medium was used as a growth medium for the Escherichia coli bacteria strain One Shot ${ }^{\circledast}$ TOP10 Electrocomp ${ }^{T M}$ E. coli (Invitrogen, Karlsruhe). For preparation of the LB-solution, $10 \mathrm{~g}$ Tryptone, $5 \mathrm{~g}$ Yeast extract and $5 \mathrm{~g} \mathrm{NaCl}$ were dissolved in $\mathrm{dd}_{2} \mathrm{O}$ to a final volume of one liter. For preparation of solid LB-medium, $14 \mathrm{~g}$ agar (AppliChem, Darmstadt) could be added. The last mixture should be autoclaved and stored either at $4^{\circ} \mathrm{C}$ as solution or till it reaches $\sim 50^{\circ} \mathrm{C}$, then it could be distributed under sterile conditions into the petri dishes. When necessary, an antibiotic as a selection marker could be added after the autoclaving step as the following (Table 23): 
Table 23: Concentrations of the used antibiotics

\begin{tabular}{llc}
\hline Antibiotic & $\begin{array}{l}\text { Concentration in the stock solution } \\
\text { stored } \text { at }-20^{\circ} \mathrm{C}\end{array}$ & Working concentration (Dilution) \\
\hline $\begin{array}{l}\text { Ampicillin } \\
\text { (Sodium salt) }\end{array}$ & $50 \mathrm{mg} / \mathrm{ml}$ in water & $100 \mu \mathrm{g} / \mathrm{ml} \mathrm{(1/500)}$ \\
Chloramphenicol & $34 \mathrm{mg} / \mathrm{ml}$ in ethanol & $170 \mu \mathrm{g} / \mathrm{ml}(1 / 200)$
\end{tabular}

\subsubsection{Bacteria cultivation on agar plates}

This cultivation was usually done after transformation by electroporation [2.8.4] or for propagation of the clones (e.g. from bacteria suspension before starting mini-prep for making midi-prep). For that the bacteria suspension was distributed on the agar plate in petri dish, which could be supplied with the corresponding antibiotic as selection marker. For the distribution, a sterile Pasteur pipet treated with the flame was used. The agar plates were incubated at $37^{\circ} \mathrm{C}$ with the cover facing down overnight. Next day, the plates could be sealed using Parafilm (Brand; Wertheim) and stored at $4^{\circ} \mathrm{C}$ for maximum one month.

\subsubsection{Bacteria cultivation in solution}

This cultivation was usually done to get the bacteria suspension necessary for mini-prep [2.5.2.1] or midi-prep [2.5.2.2]. For mini-prep, a picked up clone from an agar plate was suspended in $5 \mathrm{ml}$ LB-medium supplied with the corresponding antibiotic into $15 \mathrm{ml}$ sterile tube (Greiner, Frickenhausen) and incubated at $37^{\circ} \mathrm{C}$ overnight with $250 \mathrm{rpm}$ shaking using $\mathrm{K} 2260$ basic-shaker for bacteria (Ika, Staufen). The tube should be placed on a slant position to increase the surface for oxygen exchange and the cap should not be tightened for the exchange of the air also. For midi-prep, $30 \mathrm{ml}$ of LB-medium in special $500 \mathrm{ml}$ autoclaved bottle could be used as described above. Sometimes it was better to start cultivating the bacteria in $5 \mathrm{ml}$ LBmedium for some hours before transferring a small amount of the suspension to the $30 \mathrm{ml}$ in the bottle for midi-prep. 


\subsubsection{Transformation by electroporation}

This procedure was done to insert a certain plasmid into the bacteria cells so they can reproduce this plasmid again and again. The circular plasmid DNA with the insertion should be prepared first by a number of steps explained previously like preparative digestion [2.5.7.3], ligation [2.5.8] and dialysis [2.5.9]. Electroporation mix should be prepared by adding $30 \mu l$ $\mathrm{ddH}_{2} \mathrm{O}, 10 \mu \mathrm{l}$ from the One Shot ${ }^{\circledast}$ TOP10 Electrocomp ${ }^{T M}$ E. coli (Invitrogen, Karlsruhe). The mix was transferred into pre cooled Electroporation cuvette (PeqLab, Erlangen), then 0.8-1 $\mu$ l of the final prepared dialyzed plasmid was mixed by pipetting. The electroporation was performed using Gene Pulser II (Bio-Rad, Hercules, USA) under the following conditions: $2.5 \mathrm{kV}, 25 \mu \mathrm{F}$ and $200 \Omega$ for about 5 milliseconds. If the electroporation was successful with no electric shock-sign, $800 \mu \mathrm{l}$ of pre-warmed LB-medium was added and incubated at $37^{\circ} \mathrm{C}$ for one hour. Finally, a volume of 50 - and $200 \mu \mathrm{l}$ of the suspension was cultivated on two agar plates with the suitable selection marker [2.8.2].

\subsubsection{Making bacteria reservoir (Stock)}

After getting positive clones with the required insertion, a stock solution from the generated bacteria was prepared for long-term storage. For that, $600 \mu \mathrm{l}$ from a fresh-5 $\mathrm{ml}$ bacteria suspension overnight-cultured should be mixed with $600 \mu \mathrm{l}$ of sterile $50 \%$ glycerol solution. The stock should be transferred immediately to $-80^{\circ} \mathrm{C}$ where bacteria could be stored for several years into it.

\subsection{HEK293 cells workflow}

\subsubsection{Culturing conditions}

HEK293 Cell Line (DMSZ, Braunschweig) is derived from the human embryonic kidney cells and was used in this research for performing the luciferase reporter gene assay. Cells were cultured in DMEM medium supplied with $10 \%$ FCS (fetal calf serum) and 1\% penicillin/Streptomycin (100 $\mathrm{u} / \mathrm{ml}$ and $100 \mu \mathrm{g} / \mathrm{ml}$ solved in distilled water respectively). The medium was always pre-warmed in a water bath at $37^{\circ} \mathrm{C}$ (CO2-Incubator BBD 6220; Heraeus, Hanau). The cells were sub-cultured every 3-4 days upon reaching $\sim 80 \%$ confluence in the $75 \mathrm{~cm}^{2}$ culture flask. The cells were 
visually examined using the microscope (Axiovert 40 CFL; Zeiss, Jena). The ratio of sub-cultured cells transferred to the new culturing flask was 1:5. All the cell related work was done under the sterile bench.

\subsubsection{Thawing the cells}

The first steps in defrosting the cells should be performed as fast as possible to eliminate the DMSO from the freezing cells medium ( $90 \%$ FCS and 10\% DMSO). For that, $10 \mathrm{ml}$ from the prewarmed DMEM medium (with FCS and P/S) was transferred to $15 \mathrm{ml}$ falcon tube. The Cryo tube (Nunc $^{\mathrm{TM}}$ Thermo Scientific, Schwerte) which contains the frozen cells was taken out from the liquid nitrogen tank $\left(-170^{\circ} \mathrm{C}\right)$ and thawed by hand or in a $37^{\circ} \mathrm{C}$ water bath. Immediately when thawed, the cells were transferred to the $10 \mathrm{ml}$ DMEM medium and centrifuged at $300 \mathrm{~g}$ and room temperature (Laborfuge 400R; Heraeus, Hanau). The supernatant was discarded and the cells were re-suspended in $5 \mathrm{ml}$ DMEM medium (with FCS and P/S), then transferred to a $25 \mathrm{~cm}^{2}$ flask. Further sub-culturing was done as described before. The cells were used for the experiments after the third passage to ensure they reach a stable vital condition.

\subsubsection{Counting the cells with Neubauer-cell chamber}

To count the HEK293 cells before sub-culturing them or plating them into the experimental plates, the old medium was discarded, then the cells were re-suspended in $10 \mathrm{ml}$ DMEM (with FCS and $\mathrm{P} / \mathrm{S}$ ) and transferred to $50 \mathrm{ml}$ falcon tube. $15 \mu \mathrm{l}$ of the cell suspension was mixed (1:1) with $15 \mu$ l Trypan Blue (Sigma-Aldrich, Deisenhofen) by pipetting up and down. After mixing, $15 \mu \mathrm{l}$ of the staining mixture was transferred to the Neubauer-Cell Chamber which was covered with a cover slip. Cells' concentration per $\mathrm{ml}$ was calculated using the following equation:

$$
\text { cells per } m l=\text { the number of cells in the four big squares } \times \frac{2}{4} \times 10^{4}
$$

Where 2 is coming from the $15 \mu$ l taken from the $30 \mu \mathrm{l}$ staining mix (the dilution ratio), 4 is to have the average number of cells per one big square in the chamber and $10^{4}$ is the glass factor. 


\subsubsection{Transient transfection and luciferase reporter gene assay}

\subsubsection{Generating the intron 3 polymorphism region (rs3857080) into pGL3-promoter vector} (Luciferase reporter vector)

pGL3-promoter vector was digested by the restriction enzymes KpnI and Bg/II [2.5.7.3]. Samples were run after each digestion on $0.8 \%$ agarose gel [2.5.5]. DNA was extracted from the gel by QiaCube ${ }^{\oplus}$ machine (Qiagen, Hilden) using the QIAquick Gel Extraction Kit (Qiagen, Hilden) [2.5.3]. Oligonucleotides were ordered to have compatible ends with the cutting sites of $K p n l$ and Bg/II (Eurofins MWG Synthesis GmbH, Ebersberg) (Table 24). To ligate the oligonucleotides with the digested vector, the ratio 13:2 vector:oligonucleotide was used with $4 \mu$ ligase buffer and $1 \mu \mathrm{l}$ ligase enzyme (Ligate-ITTM Rapid Ligation Kit, USB, Staufen) [2.5.8]. Control was prepared in the last step with $\mathrm{ddH} 2 \mathrm{O}$ instead of the inserted oligonucleotide. The ligation solutions got dialyzed [2.5.9] before the electroporation. Transforming the vector into the bacteria cells should be done after [2.8.4].

Bacteria were cultured overnight on solid agar containing ampicillin and then clones were picked for mini-prep [2.5.2.1] and sequenced to confirm the insertion [2.6.2]. Midi-prep [2.5.2.2] was performed to prepare more DNA from the successful clones and transfect those to the HEK293 cells [2.9.4].

\subsubsection{Generating pcDNA3.1::LHX4 vector}

To assess the effects of the intron 3 polymorphism region on the luciferase assay with or without LHX4 protein, The same last HEK293 cells were transfected with pcDNA3.1 containing the open reading frame (ORF) of the transcription factor LHX4. The LHX4 was obtained from Source BioScience (Nottingham, UK) in pOTB7 vector. The LHX4-ORF was amplified by PCR using the modified oligonucleotides in Table 17 which included the restriction sites for HindIII and Kpnl restriction enzymes. pcDNA3.1 (Invitrogen, Karlsruhe) was digested by the same restriction enzymes [2.5.7.3]. Ligation [2.5.8], dialysis [2.5.9] and the next steps were done as described previously.

\subsubsection{Luciferase assay (Reporter gene assay)}

HEK293 cells were cultured in DMEM medium containing 10\% fetal bovine serum and 1\% penicillin/streptomycin $(100 \mathrm{u} / \mathrm{ml}$ and $100 \mu \mathrm{g} / \mathrm{ml}$ solved in distilled water respectively). In order 
to do the transfection, a total number of $3 \times 10^{5}$ cells/well was plated into each well of a twelvewell plate. The wells were covered first with poly-D lysine and incubated at $37^{\circ} \mathrm{C}$ for 15 minutes, then the solution has been removed and the wells left to dry before plating the cells. A total amount of $0.8 \mu \mathrm{g} /$ well of the DNA was transfected. When two vectors were transfected, the total DNA amount was $1.05 \mu \mathrm{g} /$ well and divided like 3:1 (where 3 is for the pGL3-promoter and 1 is for the expression vector pcDNA3.1 or pcDNA3.1::LHX4). FuGene6 (Roche, Mannheim) was used as transfection reagent $\left(2.4 \mu \mathrm{l} /\right.$ well). The $\mathrm{pCMV}$-Renilla-luciferase plasmid $\left(1.7 \mathrm{ng} / \mathrm{cm}^{2}\right)$ was used as an internal standard for transfection efficacy. The activity of the Firefly and Renilla reniformis luciferase reporter genes was assessed using the Dual-Luciferase Reporter Assay System (Promega, Manheim, Germany) according to the manufacturer instructions. Briefly, the cells were washed after 48 hours from transfection with 1X PBS, then lysed with 1X Passive Lysis Buffer (provided with the kit), then three cycles of freezing and thawing in liquid nitrogen. The samples were centrifuged at $13000 \mathrm{rpm}$ for 5 minutes. The luciferase activity in the supernatant was measured by GloMax plate luminometer (Promega).

Table 24: Oligonucleotides used in the different cloning procedures and luciferase assay

\begin{tabular}{ll}
\hline Oligonucleotide & sequence \\
\hline rs3857080 Major G-allele forward & CAGAGAACTGAGTGTCGATTTTAATGTTTTTTTCa \\
rs3857080 Major G-allele reverse & gatctGAAAAAAACATTAAAATCGACACTCAGTTCTCTGgtac \\
rs3857080 Minor A-allele forward & CAGAGAACTGAGTGTCAATTTTAATGTTTTTTTCa \\
rs3857080 Minor A-allele reverse & gatctGAAAAAAACATTAAAATTGACACTCAGTTCTCTGgtac \\
rs3857080 Minor A-allele forward Mutated & CAGAGAACTGAGTGTCAGGGGTAATGTTTTTTTCa \\
rs3857080 Minor A-allele reverse Mutated & gatctGAAAAAAACATTACCCCTGACACTCAGTTCTCTGgtac \\
\hline
\end{tabular}




\subsection{Bioinformatics}

\subsubsection{Calculating the linkage disequilibrium using HaploView ${ }^{\circledR}$ v4.2}

\subsubsection{From the two clinical studies}

The linkage disequilibrium of the polymorphisms within the studied volunteers of our two clinical studies was calculated and compared with the linkage disequilibrium from the genotyped population of the international HapMap project or 1000 genomes project. Two different files for the software should be prepared. The files' extensions should be ".ped" and ".info" generated from a text tab-delimited files and have the exact same file name. the first ".ped" file has the first column for the subject ID, second is a serial number then four columns has the same values as the following " $0,0,1,0$ " which refer to "Family ID, individual ID, paternal ID, maternal ID" respectively. After the last six columns, the genotyped polymorphisms are placed in column in the same order in the ".info" file (Figure 13, part A). In the ".info" file, the polymorphisms IDs should be placed in vertical way (rows) with second column for their positions in the chromosome or as a relative position also (Figure 13, part B). The genotyped polymorphisms should be coded as the following: 0 as not determined, 1 for $A, 2$ for $C, 3$ for $G$ and 4 for T with a space between each two numbers for the genotype (e.g. GC would be 32 , Figure 13). The file could be opened using the first option from the open panel "Linkage format".

(A)

\begin{tabular}{|l|c|c|c|c|c|c|c|c|c|c|}
\hline Subject 1 & 1 & 0 & 0 & 1 & 0 & 32 & 11 & 23 & 12 & 14 \\
\hline Subject 2 & 2 & 0 & 0 & 1 & 0 & 22 & 41 & 22 & 12 & 44 \\
\hline Subject 3 & 3 & 0 & 0 & 1 & 0 & 22 & 44 & 20 & 11 & 44 \\
\hline
\end{tabular}

(B)

\begin{tabular}{|l|l|}
\hline P1 & Position1 \\
\hline P2 & Position2 \\
\hline P3 & Position3 \\
\hline P4 & Position4 \\
\hline P5 & Position5 \\
\hline
\end{tabular}

Figure 13: Preparing the (.ped) and (.info) files for HaploView ${ }^{\circledR}$ v4.2

$(A)$ is an example of the (.ped) file. (B) is an example of the (.info) file. $P 1, P 2, \ldots$ are poylmorphism1, polymorphism $2, \ldots$ 


\subsubsection{From the international HapMap Project}

Linkage data for genotyped polymorphisms from the international HapMap project could be downloaded directly from the software using "Download HapMap info track" command. The last option was not so useful because one could not choose the exact population. For that, the SNP genotype data file could be downloaded as ".txt" file from the website after choosing the required population http://hapmap.ncbi.nlm.nih.gov/cgi-perl/gbrowse/hapmap28 B36/, the file could be opened using the third option from the open panel "HapMap format".

\subsubsection{From 1000 genomes project}

The detailed region information file was downloaded from the 1000 genomes project browser http://browser.1000genomes.org/index.html using their slicing tool for the exact position on the chromosome. The ".vcf" data file was opened by Microsoft excel and treated finally to get two separated files ready to be analyzed using HaploView software as described above [2.10.1.1].

\subsubsection{Calculating the haplotypes using PHASE $^{\circledR}$ v2.1}

The program PHASE $^{\circledR}$ implements methods for calculating haplotypes from population genotype. The software also incorporates methods for predicting recombination rates. Phase program doesn't have user interface (UI) and it needs to be run after preparing all the required files and placing them in one directory with the same path level on the PC. Four major steps have been done to prepare the data for further genotype phenotype analysis using SPSS ${ }^{\circledR}$ v20. As shown in Figure 14 (part A), genotyping data should be arranged first in a way that the polymorphisms are placed in column (P1, P2, P3....). All unavailable genotypes could be substituted with (?) sign. The fo type of inputting the data file (.inp) was used (refer to the program manual for more file types), meaning two lines for each genotyped Individual (Figure 14 , part B). The first three lines of the input file should be on this exact order: $1^{\text {st }}$ the number of individuals, $2^{\text {nd }}$ the number of loci (genotyped polymorphisms) and $3^{\text {rd }}$ the type of the entered polymorphism (e.g. SNP or Ins/Del). The results' shape is shown in part C of Figure 14. The allele frequencies are calculated and the genotype for each participant is predicted. Finally, the file could be prepared in a way ready for statistical analysis by coding 0,1 or 2 depending on the number of alleles for the exact haplotype which was predicted by the software (Figure 14, 
part D). To run the software after preparing the input file, one needs to edit multiple_seed.bad file and place this command into it: start/wait PHASE -f0 -x10 file_name.inp file_name.out, then double click.

(A)

(B)

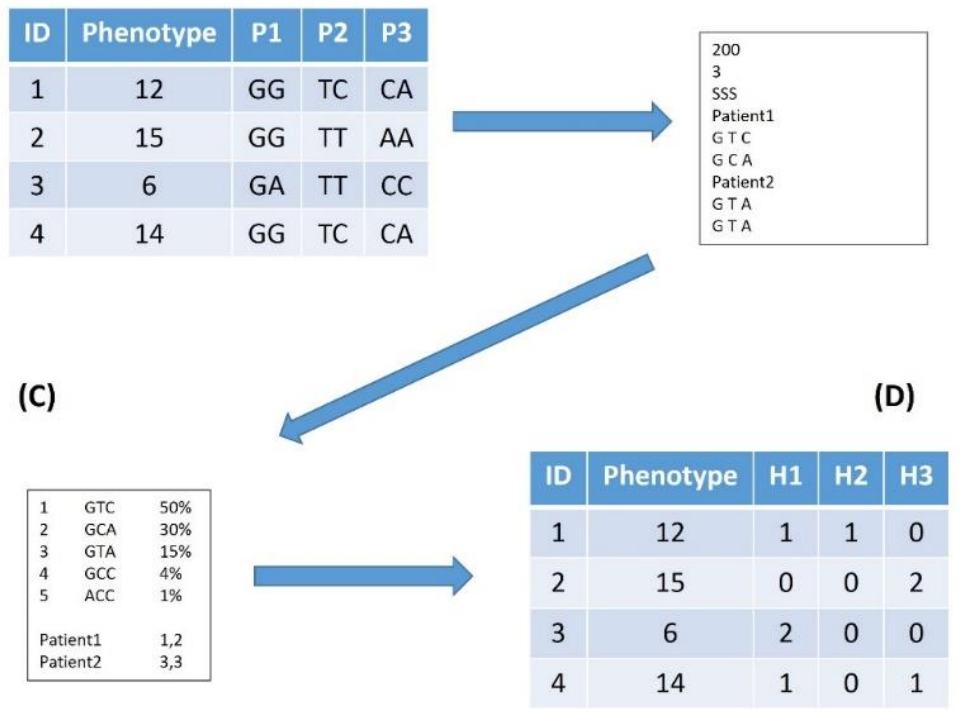

Figure 14: Calculating haplotypes using Phase ${ }^{\circledR}$ program v2.1

\subsubsection{Protein function prediction tools}

These tools were used to predict the effects of the non-synonymous SNPs on the coded protein functionality. The tools are using different algorithms to predict changed functionality. Most of them were trained upon known In Vitro proofed data. Some tools are predicting depending on the expected changes in the 3D structure of the protein, while other tools predict depending on the difference coming from the change in the alignments of the amino acids. The tools used in this work are shown in Table 25. 
Table 25: Protein prediction tools

Prediction tool

Webpage

PROVEAN (Protein Variation Effect Analyzer) v1.1.3

http://provean.jcvi.org/genome submit.php

SIFT (Sort Intolerant from Tolerant amino acid

substitutions) v1.0.3

http://provean.jcvi.org/genome submit.php

SNAP (Effects of single amino acid substitutions on

protein function) (Bromberg and Rost, 2007)

https://rostlab.org/services/snap/

PolyPhen-2 (PPH2) (Polymorphism Phenotyping v2) v2.2.2 http://genetics.bwh.harvard.edu/pph2/bgi.shtml

nsSNPAnalyzer (predicting disease-associated non-

synonymous single nucleotide polymorphisms)

http://snpanalyzer.uthsc.edu/

MutPred v1.2 (Li et al., 2009)

http://mutpred.mutdb.org/

Mutation t@sting (Schwarz et al., 2010)

http://www.mutationtaster.org/

PhD SNP (Predictor of human Deleterious Single

Nucleotide Polymorphisms)

http://snps.biofold.org/phd-snp/phd-snp.html

SNPs\&Go (Calabrese et al., 2009)

http://snps-and-go.biocomp.unibo.it/snps-and-

go/index.html

\subsubsection{Transcription factor prediction (TRANSFAC ${ }^{\circledR}$ )}

TRANSFAC $^{\circledR}$ database 2013.1 was used to predict the possible transcript factors binding sites (Wingender, 2008) for the sequence around the region of the intron 3 polymorphism rs3857080 in the aldosterone receptor gene $N R 3 C 2$. The list was sorted to give the transcription factors with higher hit number for the minor A-allele than the major G-allele of the last polymorphism. 


\section{Results}

\subsection{Renal regulation candidate genes}

Earlier studies in the institute of clinical pharmacology have extensively searched for polymorphisms in the known renal ion transporter genes (e.g. SLC12A3 for the NCC, SLC12A1 for NKCC2, SCNN1A, SCNN1B and SCNN1G for the three ENaC subunits $\alpha, \beta$ and $\gamma$ ). Nevertheless, genomic variation in genes regulating expression or activity of these transporters had not yet been studied. By the systematic study of current literature, eleven possible candidate genes were identified to be scanned by predefined rules (see also Methods [2.3Selecting polymorphisms 2.3]): 6 coding kinases, one phosphatase, three co-transporters and the mineralocorticoid receptor gene (aldosterone receptor gene). Genes coding kinases were WNK1, WNK3, WNK4, STK39, OXSR1 and SGK1. The phosphatase gene was NEDD4L. The cotransporters' genes were $K C N J 1, C L C K A$ and $C L C N K B$ and the aldosterone receptor gene was NR3C2 (Table 26).

Table 26: Renal regulation candidate genes

\begin{tabular}{|c|c|c|c|c|c|c|}
\hline Gene & Protein & Chr & $\begin{array}{l}\text { Nr. Of } \\
\text { Exons }\end{array}$ & $\begin{array}{l}\text { Nr. Of Amino } \\
\text { Acids }\end{array}$ & $\begin{array}{l}\text { Position on chromosome } \\
\text { (GRCh37/hg19) }\end{array}$ & Size $[b p]$ \\
\hline WNK1 & WNK1 & 12 & 28 & 2382 & $862089 . .1020618$ & 158530 \\
\hline WNK3 & WNK3 & $x$ & 24 & 1743 & $54219256 . .54384438$ & 165183 \\
\hline WNK4 & WNK4 & 17 & 19 & 1243 & $40932649 . .40949084$ & 16436 \\
\hline STK39 & SPAK & 2 & 18 & 545 & 168810530..169104105 & 293576 \\
\hline OXSR1 & OSR1 & 3 & 18 & 527 & $38207026 . .38296979$ & 89954 \\
\hline$S G K 1$ & SGK1 & 6 & 17 & 431 & $134490384 . .134639196$ & 148813 \\
\hline NEDD4L & NEDD4L & 18 & 31 & 975 & $55711619 . .56068772$ & 357154 \\
\hline KCNJ1 & ROMK & 11 & 5 & 391 & 128707915..128737268 & 29354 \\
\hline CLCKA & $\mathrm{ClC}-\mathrm{Ka}$ & 1 & 20 & 687 & $16348486 . .16360545$ & 12060 \\
\hline$C L C K B$ & $\mathrm{ClC}-\mathrm{Kb}$ & 1 & 20 & 687 & $16370247 . .16383803$ & 13557 \\
\hline$N R 3 C 2$ & NR3C2 & 4 & 9 & 984 & 148999915..149363672 & 363758 \\
\hline
\end{tabular}




\subsection{Selected and genotyped polymorphisms}

Applying the criteria for selecting polymorphisms in the candidate genes revealed 45 polymorphisms to be genotyped (Table 27). Six polymorphisms out of the 45 selected ones could not be genotyped for technical reasons, because of the highly homologous regions where no specific primers could be designed. 39 polymorphisms were genotyped successfully. 31 SNPs out of the 39 genotyped polymorphisms in the 11 genes were polymorphic in our clinical studies' participants. Randomly selected $20 \%$ of the samples were genotyped in duplicate with a $100 \%$ match. $10 \%$ of the genotyped polymorphisms were checked for the possibility of typing errors by the technical assistant.

For the exact numbers of the genotyped SNPs with the calculations of Hardy-Weinberg equilibrium using Chi square test $\left(\chi^{2}\right)$ refer to supplementary materials [6.1.1].

Table 27: Selected and genotyped polymorphisms

\begin{tabular}{|c|c|c|c|c|c|c|c|c|}
\hline rs-number & Gene & $\begin{array}{l}\text { Functional } \\
\text { localization }\end{array}$ & amino-acid & $\begin{array}{c}\text { MAF } \\
\text { (dbSNP 137) }\end{array}$ & $\begin{array}{l}\text { MAF } \\
(1+2)\end{array}$ & $\begin{array}{c}\text { HWE } \\
\text { (Study 1) }\end{array}$ & $\begin{array}{c}\text { HWE } \\
\text { (Study 2) }\end{array}$ & $\begin{array}{l}\text { HWE } \\
(1+2)\end{array}$ \\
\hline rs3088353 & WNK1 & 5'UTR & 0 & 0.217 & 0.474 & - & 0.047 & 0.039 \\
\hline rs2107614 & WNK1 & Intron 1 & 0 & 0.341 & 0.29 & - & - & - \\
\hline rs765250 & WNK1 & Intron 1 & 0 & 0.345 & 0.295 & - & - & - \\
\hline rs1159744 & WNK1 & Intron 2 & 0 & 0.258 & 0.238 & - & - & - \\
\hline rs2277869 & WNK1 & Intron 26 & 0 & 0.142 & 0.183 & - & - & - \\
\hline rs2495801 & $\begin{array}{l}\text { FAM120C } \\
==> \\
\text { WNK3 }\end{array}$ & Intronic & 0 & 0.142 & 0.109 & Chr X & ChrX & Chr X \\
\hline rs3021280 & WNK3 & Intron 7 & 0 & 0.035 & 0.022 & ChrX & Chr X & Chr X \\
\hline rs3021285 & WNK3 & Intron 11 & 0 & 0.067 & 0.092 & Chr X & Chr X & Chr X \\
\hline rs3021284 & WNK3 & Intron 13 & 0 & 0.067 & 0.092 & Chr X & ChrX & Chr X \\
\hline rs2516040 & WNK3 & Intron 22 & 0 & 0.15 & & & & \\
\hline rs7880501 & WNK3 & 3'UTR & 0 & 0.048 & 0.022 & Chr X & ChrX & Chr X \\
\hline rs74932519 & WNK4 & Promoter & 0 & 0.181 & & & & \\
\hline rs77879367 & WNK4 & Promoter & 0 & 0.125 & NP & NP & NP & NP \\
\hline rs75596106 & WNK4 & Exon 2 & $\begin{array}{c}\text { missense } \\
L[\text { Leu }] \Rightarrow V[\text { Val }]\end{array}$ & Watson 0.5 & NP & NP & NP & NP \\
\hline rs78645838 & WNK4 & Intron 6 & 0 & 0.067 & 0.048 & - & - & - \\
\hline rs61755606 & WNK4 & Intron 10 & 0 & 0.133 & 0.083 & - & - & - \\
\hline rs77012584 & WNK4 & Intron 15 & 0 & 0.097 & NP & NP & NP & NP \\
\hline rs9493857 & SGK1 & Intron 2 & 0 & 0.183 & 0.192 & - & - & - \\
\hline
\end{tabular}




\begin{tabular}{|c|c|c|c|c|c|c|c|c|}
\hline rs-number & Gene & $\begin{array}{l}\text { Functional } \\
\text { localization }\end{array}$ & amino-acid & $\begin{array}{c}\text { MAF } \\
\text { (dbSNP 137) }\end{array}$ & $\begin{array}{l}\text { MAF } \\
(1+2)\end{array}$ & $\begin{array}{c}\text { HWE } \\
\text { (Study 1) }\end{array}$ & $\begin{array}{c}\text { HWE } \\
\text { (Study 2) }\end{array}$ & $\begin{array}{l}\text { HWE } \\
(1+2)\end{array}$ \\
\hline rs1057293 & SGK1 & Exon 13 & $\begin{array}{c}\text { synonymous } \\
D[\text { Asp }] \Rightarrow D[\text { Asp }]\end{array}$ & 0.098 & 0.122 & - & - & - \\
\hline rs457661 & OXSR1 & Exon 1 & $\begin{array}{c}\text { synonymous } \\
\mathrm{E}[\mathrm{Glu}] \Rightarrow \mathrm{E}[\mathrm{Glu}]\end{array}$ & $\begin{array}{l}0.02 \text { only in } \\
\text { CEPH }\end{array}$ & NP & NP & NP & NP \\
\hline rs6599079 & OXSR1 & Exon 10 & $\begin{array}{c}\text { missense } \\
\mathrm{T}[\mathrm{Thr}] \Rightarrow \mathrm{I}[\mathrm{lle}]\end{array}$ & 0.117 & 0.105 & - & - & - \\
\hline rs113919536 & OXSR1 & Exon 13 & $\begin{array}{c}\text { missense } \\
A[\text { Ala }] \Rightarrow S[\text { Ser }]\end{array}$ & $\begin{array}{c}0.5 \text { Single } \\
\text { Caucasian } \\
\text { Male }\end{array}$ & NP & NP & NP & NP \\
\hline rs35295772 & OXSR1 & Exon 14 & $\begin{array}{c}\text { missense } \\
\mathrm{S}[\mathrm{Ser}] \Rightarrow \mathrm{T}[\mathrm{Thr}]\end{array}$ & 0.023 & NP & NP & NP & NP \\
\hline rs4149601 & NEDD4L & $\begin{array}{l}5^{\prime} \text { UTR } \\
\text { Exon } 1\end{array}$ & $\mathrm{Q}[\mathrm{Gln}] \Rightarrow \mathrm{Q}[\mathrm{Gln}]$ & 0.358 & 0.334 & 0.012 & - & - \\
\hline rs2288774 & NEDD4L & Intron 6 & 0 & 0.491 & 0.467 & - & - & - \\
\hline rs2846679 & KCNJ1 & Intron 2 & 0 & 0.133 & 0.14 & - & - & - \\
\hline rs76640813 & KCNJ1 & Exon 5 & $\begin{array}{c}\text { synonymous } \\
\mathrm{V}[\mathrm{Val}] \Rightarrow \mathrm{V}[\mathrm{Val}]\end{array}$ & 0.01 & NP & NP & NP & NP \\
\hline rs76937254 & KCNJ1 & Exon 5 & $\begin{array}{c}\text { missense } \\
\mathrm{V}[\mathrm{Val}] \Rightarrow \mathrm{A}[\mathrm{Ala}]\end{array}$ & Watson 0.5 & NP & NP & NP & NP \\
\hline rs10927887 & CLCNKA & Exon 4 & $\begin{array}{c}\text { missense } \\
\mathrm{R}[\mathrm{Arg}] \Rightarrow \mathrm{G}[\mathrm{Gly}]\end{array}$ & $\begin{array}{l}\text { Watson is } A / A \\
\text { Venter is } \mathrm{G} / \mathrm{G}\end{array}$ & & & & \\
\hline rs1010069 & CLCNKA & Intron 5 & 0 & 0.486 & 0.469 & - & - & - \\
\hline rs1805152 & CLCNKA & Exon 14 & $\begin{array}{c}\text { missense } \\
\mathrm{A}[\text { Ala }] \Rightarrow \mathrm{T}[\mathrm{Thr}]\end{array}$ & 0.456 & & & & \\
\hline rs12140311 & CLCNKB & Exon 15 & $\begin{array}{c}\text { missense } \\
\mathrm{T}[\mathrm{Thr}] \Rightarrow \mathrm{S}[\mathrm{Ser}]\end{array}$ & $\begin{array}{c}0.5 \text { in } \\
\text { Bushman }\end{array}$ & & & & \\
\hline rs2297727 & CLCNKB & Intron 17 & 0 & 0.45 & & & & \\
\hline rs2070951 & NR3C2 & 5'UTR & 0 & 0.433 & 0.487 & - & - & - \\
\hline rs5522 & NR3C2 & Exon 2 & $\begin{array}{c}\text { missense } \\
\mathrm{V}[\mathrm{Val}] \Rightarrow \mathrm{I}[\mathrm{lle}]\end{array}$ & 0.102 & 0.098 & - & - & - \\
\hline rs10519963 & NR3C2 & Intron 2 & 0 & 0.15 & 0.135 & - & - & - \\
\hline rs3846329 & NR3C2 & Intron 2 & 0 & 0.212 & 0.216 & - & - & - \\
\hline rs3857080 & NR3C2 & Intron 3 & 0 & 0.115 & 0.111 & - & - & - \\
\hline rs11099681 & NR3C2 & Intron 4 & 0 & 0.281 & 0.290 & - & - & - \\
\hline rs11099680 & NR3C2 & Intron 4 & 0 & 0.292 & 0.288 & - & - & - \\
\hline rs4835493 & NR3C2 & Intron 4 & 0 & 0.281 & 0.286 & - & - & - \\
\hline rs6810951 & NR3C2 & Intron 4 & 0 & 0.408 & 0.389 & - & - & - \\
\hline rs1040288 & NR3C2 & Intron 6 & 0 & 0.434 & 0.426 & - & - & - \\
\hline rs11737660 & NR3C2 & Intron 8 & 0 & 0.212 & 0.236 & - & - & - \\
\hline rs5534 & NR3C2 & 3'UTR & 0 & 0.42 & 0.410 & 0.034 & - & - \\
\hline
\end{tabular}

Marked polymorphisms could not be genotyped for technical reasons. MAF minor allele frequency. dbSNP 137 Single Nucleotides Polymorphisms database build version 137. HWE is referring to Chi square test $\left(x^{2}\right)$ for Hardy-Weinberg disequilibrium. Study 1 and 2 are the clinical study 1 on loop diuretics and clinical study 2 on hydrochlorothiazide and triamterene. NP was not polymorphic in our clinical studies' participants. (-) means not significant $(P>0.05)$. 


\subsection{Selecting genes for further investigations}

The repetitive analyze of covariance has been done in three statistical models [2.4.1]. The first statistical model included the excretion on the diuretic drugs as covariate, the second included all the previously known affecting polymorphisms and the third didn't include any other than the studied polymorphism. The model of our interest was always the first statistical model which has the excretion of the diuretic drug into consideration as covariate only. First analysis has been done for all polymorphic polymorphisms (Table 28). The two clinical studies were divided to be analyzed depending on the diuretics' mechanism of action.

As documented in Table 28, under monovariate statistics not taking multiple testing into account, a number of polymorphisms were associated with the relevant phenotypes. However, when focusing on the most significant associations, the polymorphisms in aldosterone receptor appeared most promising. As illustrated by the color highlighting, the polymorphisms and haplotypes in the aldosterone receptor gene were significantly associated with numerous phenotypes. The p-values were rather small for number of associations in different genes, although by strict adjustment for multiple testing, where $p$-value should be less than 0.0001 , the aldosterone receptor gene arose as strong candidate for more investigation. 
Table 28: P-values from repetitive analyze of covariance (RANCOVA) of studied polymorphisms and haplotypes

\begin{tabular}{|c|c|c|c|c|c|c|c|c|c|c|c|c|c|c|}
\hline & & & & & & & \multicolumn{2}{|c|}{ BFT } & \multicolumn{2}{|c|}{ HCT } & \multicolumn{2}{|c|}{ TRIA } & \multirow[b]{3}{*}{$\begin{array}{c}\text { MAF / } \\
\text { AF }\end{array}$} & \multirow[b]{3}{*}{$\begin{array}{l}\text { Functional } \\
\text { localization }\end{array}$} \\
\hline & & & & & & & $\mathrm{NaCl}$ & K & $\mathrm{NaCl}$ & K & $\mathrm{NaCl}$ & K & & \\
\hline & \multicolumn{6}{|c|}{ major $>$ minor } & & & & & & & & \\
\hline \multicolumn{15}{|l|}{ WNK1 } \\
\hline rs3088353 & $\mathrm{T}$ & $>$ & G & & & & - & - & - & - & - & - & $47 \%$ & 5'UTR \\
\hline rs2107614 & G & $>$ & A & & & & - & . 010 & - & - & - & - & $29 \%$ & Intron 1 \\
\hline rs765250 & A & $>$ & G & & & & - & .024 & - & - & - & - & $30 \%$ & Intron 1 \\
\hline rs1159744 & C & $>$ & G & & & & - & .007 & - & - & - & - & $24 \%$ & Intron 2 \\
\hline rs2277869 & T & $>$ & C & & & & - & .040 & - & - & - & - & $18 \%$ & Intron 26 \\
\hline H1_1 & & G & G & A & C & $\mathrm{T}$ & - & - & - & - & - & - & $38 \%$ & 5'UTR_i26 \\
\hline H1_2 & & $\mathrm{T}$ & A & G & G & $\mathrm{T}$ & - & .002 & - & - & - & - & $20 \%$ & \\
\hline H1_3 & & T & G & A & c & C & - & .029 & - & - & - & - & $18 \%$ & \\
\hline H1_4 & & T & G & A & c & T & - & .052 & - & - & - & - & $14 \%$ & \\
\hline H1_5 & & G & A & G & C & $\mathrm{T}$ & - & - & .029 & .041 & - & - & $6 \%$ & \\
\hline H1_6 & & G & A & G & G & T & .033 & - & - & - & - & - & $3 \%$ & \\
\hline $\mathrm{H} 1 \_7$ & & T & G & A & G & T & .076 & - & - & - & - & - & $1 \%$ & \\
\hline H2_1 & & & G & A & C & & - & .018 & - & - & - & - & $69 \%$ & i1_i2 \\
\hline $\mathrm{H} 2 \_2$ & & & A & G & G & & - & .004 & - & - & - & - & $22 \%$ & \\
\hline $\mathrm{H} 2 \_3$ & & & A & G & c & & .095 & - & - & .070 & - & - & $7 \%$ & \\
\hline $\mathrm{H} 2 \_4$ & & & G & A & G & & .076 & - & - & - & - & .069 & $1 \%$ & \\
\hline H3_1 & & & G & A & c & T & - & - & - & - & - & - & $51 \%$ & i1_i26 \\
\hline H3_2 & & & A & G & G & T & - & .009 & - & - & - & - & $22 \%$ & \\
\hline H3_3 & & & G & A & C & C & - & .080 & - & - & - & - & $18 \%$ & \\
\hline H3_4 & & & A & G & C & $\mathrm{T}$ & - & & - & .070 & - & - & $7 \%$ & \\
\hline H3_5 & & & G & A & G & T & .076 & & - & - & - & .069 & $1 \%$ & \\
\hline
\end{tabular}

\begin{tabular}{|c|c|c|c|c|c|c|c|c|c|c|c|c|c|c|}
\hline \multicolumn{15}{|l|}{ WNK3 } \\
\hline rs3021280 & G & $>$ & $\mathrm{T}$ & & & & - & - & - & - & - & - & $2 \%$ & Intron 7 \\
\hline rs3021285 & $\mathrm{T}$ & $>$ & C & & & & .065 & - & .026 & - & - & - & $9 \%$ & Intron 11 \\
\hline rs3021284 & $A$ & $>$ & $\mathrm{T}$ & & & & .065 & - & .026 & - & - & - & $9 \%$ & Intron 13 \\
\hline rs7880501 & $\mathrm{T}$ & $>$ & C & & & & - & - & - & - & - & - & $2 \%$ & 3'UTR \\
\hline rs2495801 & $C$ & $>$ & $\mathrm{T}$ & & & & .034 & - & .025 & - & - & - & $11 \%$ & Intronic \\
\hline $\mathrm{H} 1 \_1$ & & G & $\mathrm{T}$ & A & T & C & .034 & - & .028 & - & - & - & $89 \%$ & all \\
\hline $\mathrm{H} 1$ _2 & & G & C & $\mathrm{T}$ & $\mathrm{T}$ & $\mathrm{T}$ & .065 & - & .023 & .042 & - & - & $9 \%$ & \\
\hline H1_3 & & $T$ & $\mathrm{~T}$ & $A$ & C & $T$ & - & - & - & - & - & - & $2 \%$ & \\
\hline
\end{tabular}

\begin{tabular}{|c|c|c|c|c|c|c|c|c|c|c|c|}
\hline \\
\hline \multicolumn{12}{|l|}{$\begin{array}{l}\text { WNK4 } \\
\text { rs78645838 }\end{array}$} \\
\hline rs61755606 & G & $>$ & $A$ & - & .024 & - & - & - & - & $8 \%$ & Inton 10 \\
\hline H1_1 & & G & G & - & - & - & - & - & - & $87 \%$ & all \\
\hline H1_2 & & G & $A$ & - & .024 & - & - & - & - & $8 \%$ & \\
\hline H1_3 & & $A$ & G & - & .014 & - & - & - & - & $5 \%$ & \\
\hline
\end{tabular}

\begin{tabular}{|c|c|c|c|c|c|c|c|c|c|c|c|}
\hline \multicolumn{12}{|l|}{ NEDD4L } \\
\hline rs4149601 & C & $>$ & $\mathrm{T}$ & - & - & - & - & - & - & $33 \%$ & 5'UTR Exon 1 \\
\hline rs2288774 & $A$ & $>$ & G & - & .038 & - & - & - & - & $47 \%$ & Intron 6 \\
\hline H1_1 & & C & G & .002 & - & - & - & - & - & $38 \%$ & all \\
\hline $\mathrm{H} 1 \_2$ & & C & A & .001 & - & - & - & - & - & $28 \%$ & \\
\hline H1_3 & & $T$ & A & .084 & .022 & - & .038 & - & - & $25 \%$ & \\
\hline H1_4 & & T & G & - & .001 & .093 & - & - & - & $9 \%$ & \\
\hline
\end{tabular}




\begin{tabular}{|c|c|c|c|c|c|c|c|c|c|c|c|c|}
\hline \multicolumn{13}{|c|}{ OXSR1 (OSR1) } \\
\hline rs6599079 & G & $>$ & A & & - & - & - & - & - & - & $11 \%$ & Exon 10 \\
\hline \multicolumn{13}{|l|}{ SGK1 } \\
\hline rs9493857 & C & $>$ & $T$ & & - & - & - & - & - & - & $19 \%$ & Intron 2 \\
\hline rs3215438 & - & $>$ & G & & - & .018 & $\mathrm{~N}$ & $\mathrm{~N}$ & $\mathrm{~N}$ & $\mathrm{~N}$ & $45 \%$ & Intron 5 \\
\hline rs1743966 & $\mathrm{T}$ & $>$ & C & & - & .073 & $\mathrm{~N}$ & $\mathrm{~N}$ & $\mathrm{~N}$ & $\mathrm{~N}$ & $23 \%$ & Intron 9 \\
\hline rs1057293 & C & $>$ & $T$ & & - & .085 & - & .039 & - & .047 & $12 \%$ & Exon 13 \\
\hline H1_1 & & C & G & & - & .058 & $\mathrm{~N}$ & $\mathrm{~N}$ & $\mathrm{~N}$ & $N$ & $42 \%$ & i2_i5 \\
\hline $\mathrm{H} 1 \_2$ & & C & - & & - & - & $\mathrm{N}$ & $\mathrm{N}$ & $\mathrm{N}$ & $\mathrm{N}$ & $40 \%$ & \\
\hline H1_3 & & $T$ & - & & - & - & $\mathrm{N}$ & $\mathrm{N}$ & $\mathrm{N}$ & $\mathrm{N}$ & $16 \%$ & \\
\hline $\mathrm{H} 1 \_4$ & & $\mathrm{~T}$ & G & & .028 & - & $\mathrm{N}$ & $\mathrm{N}$ & $\mathrm{N}$ & $\mathrm{N}$ & $3 \%$ & \\
\hline $\mathrm{H} 2 \_1$ & & C & G & $\mathrm{T}$ & - & .082 & $\mathrm{~N}$ & $\mathrm{~N}$ & $\mathrm{~N}$ & $\mathrm{~N}$ & $41 \%$ & i2_i9 \\
\hline $\mathrm{H} 2 \_2$ & & C & - & $\mathrm{T}$ & - & - & $\mathrm{N}$ & $\mathrm{N}$ & $\mathrm{N}$ & $\mathrm{N}$ & $28 \%$ & \\
\hline $\mathrm{H} 2 \_3$ & & $C$ & - & C & - & - & $\mathrm{N}$ & $\mathrm{N}$ & $\mathrm{N}$ & $\mathrm{N}$ & $12 \%$ & \\
\hline $\mathrm{H} 2 \_4$ & & $\mathrm{~T}$ & - & C & - & .038 & $\mathrm{~N}$ & $\mathrm{~N}$ & $\mathrm{~N}$ & $\mathrm{~N}$ & $10 \%$ & \\
\hline $\mathrm{H} 2 \_5$ & & $T$ & - & $T$ & - & - & $\mathrm{N}$ & $\mathrm{N}$ & $\mathrm{N}$ & $\mathrm{N}$ & $6 \%$ & \\
\hline $\mathrm{H} 2 \_6$ & & $T$ & G & $T$ & .028 & - & $\mathrm{N}$ & $\mathrm{N}$ & $\mathrm{N}$ & $\mathrm{N}$ & $3 \%$ & \\
\hline $\mathrm{H} 2 \_7$ & & C & G & C & - & - & $\mathrm{N}$ & $\mathrm{N}$ & $\mathrm{N}$ & $\mathrm{N}$ & $1 \%$ & \\
\hline H3_1 & & C & C & & - & - & - & .002 & - & - & $74 \%$ & i2_e13 \\
\hline H3_2 & & $T$ & C & & - & - & - & - & - & - & $14 \%$ & \\
\hline H3_3 & & C & $T$ & & - & - & .099 & .013 & - & .068 & $7 \%$ & \\
\hline H3_4 & & $T$ & $\mathrm{~T}$ & & - & - & - & - & - & - & $5 \%$ & \\
\hline
\end{tabular}

\begin{tabular}{|c|c|c|c|c|c|c|c|c|c|c|c|c|}
\hline \multicolumn{13}{|l|}{ CLCNKa } \\
\hline rs1010069 & G & $>$ & A & & - & .024 & .086 & - & - & - & $47 \%$ & Intron 5 \\
\hline \multicolumn{13}{|c|}{ KCNJ1 (ROMK) } \\
\hline rs2846679 & $\mathrm{C}$ & $>$ & $\mathrm{T}$ & & - & - & .013 & - & .092 & .033 & $14 \%$ & Intron 2 \\
\hline \multicolumn{13}{|c|}{ NR3C2 (aldosterone receptor) } \\
\hline rs2070951 & & G & $>$ & $\mathrm{C}$ & .030 & - & - & - & - & - & $49 \%$ & 5'UTR \\
\hline rs5522 & & $A$ & $>$ & G & .062 & - & - & - & .051 & .024 & $10 \%$ & Exon 2 \\
\hline rs3857080 & & G & $>$ & A & .000 & .067 & - & .004 & - & .026 & $11 \%$ & Intron 3 \\
\hline H1_1 & & C & A & & .030 & - & - & - & - & - & $49 \%$ & 5'UTR_e2 \\
\hline H1_2 & & G & $A$ & & - & - & - & - & - & - & $41 \%$ & \\
\hline H1_3 & & G & G & & .062 & - & - & - & .051 & .024 & $10 \%$ & \\
\hline H2_1 & & C & A & G & - & - & - & .010 & - & - & $40 \%$ & all \\
\hline $\mathrm{H} 2 \_2$ & & G & A & G & - & - & - & - & - & - & $40 \%$ & \\
\hline $\mathrm{H} 2 \_3$ & & G & G & G & .062 & - & - & - & .051 & .024 & $10 \%$ & \\
\hline $\mathrm{H} 2 \_4$ & & C & A & $A$ & .000 & .002 & - & .026 & - & - & $9 \%$ & \\
\hline $\mathrm{H} 2 \_5$ & & G & $A$ & A & - & - & - & .037 & - & .000 & $2 \%$ & \\
\hline H3_1 & & & $A$ & G & - & - & - & .005 & - & .000 & $79 \%$ & e2_i3 \\
\hline H3_2 & & & A & A & .000 & .067 & - & .004 & - & .026 & $11 \%$ & \\
\hline H3_3 & & & G & G & .062 & - & - & - & .051 & .024 & $10 \%$ & \\
\hline
\end{tabular}

$P<0.1$ yellow. $P<0.05$ red cells. $P<0.01$ red cells with bold black font. BFT loop diuretics study days from clinical study 1. HCT hydrochlorothiazide study days from the clinical study 2. TRIA triamterene study day from the clinical study 2. Nucleotides in grey are the minor alleles. UTR untranslated region. The (e) prefix in the haplotype functional localization is for exons. The (i) prefix in the haplotype functional localization is for introns. Haplotypes are named as Haplotype number_allele number. NaCl is the association with sodium and chloride excretion as composite endpoint. $K$ is the association with potassium excretion. All the association of $\mathrm{NaCl}$ and $\mathrm{K}$ excretion in this table were for the time between $\mathrm{O}$ and 24 hours. (-) refers to no significance. ( $\mathrm{N}$ ) was for two SNPs in the SGK1 gene which were only genotyped in the first clinical study. The statistical model included the diuretic drugs excretion but not the previously known affecting polymorphisms (first statistical model). 


\subsection{Aldosterone receptor polymorphisms}

\subsubsection{Phenotype-genotype association}

Twelve polymorphisms in the aldosterone receptor gene (NR3C2) in both clinical studies were investigated. 229 participants of the two clinical studies were genotyped for twelve NR3C2 polymorphisms formerly identified to be associated with clinical phenotypes (Table 3).

Urinary ion excretion was associated mainly with only one of the twelve polymorphisms, the intron-3 polymorphism (rs3857080). The significance of the genotype-phenotype associations for the 12 studied polymorphisms and calculated haplotypes are presented in Table 29.

\subsubsection{Linkage disequilibrium}

The linkage disequilibrium among the polymorphisms was similar in our population from both clinical studies and in the Caucasian chromosomes of the 1000-Genomes project (www.1000genomes.org/) (Figure 15). The SNP found in our study to be significantly associated with renal salt handling (rs3857080) was between two major linkage blocks and not linked more than $36 \%$ on a range of $180 \mathrm{~kb}$ right and left with any other polymorphisms. Calculating haplotype-phenotype associations did not give additional information over polymorphismbased phenotype associations. 
Table 29: P-values from analyze of covariance (ANCOVA) of studied polymorphisms and haplotypes in the aldosterone receptor gene NR3C2

\begin{tabular}{|c|c|c|c|c|c|c|c|c|c|c|c|c|c|c|c|c|c|c|}
\hline & & & & & & & & & & & B & & $\mathrm{H}$ & & TR & & & \\
\hline & & & & & & & & & & & $\mathrm{NaCl}$ & K & $\mathrm{NaCl}$ & K & $\mathrm{NaCl}$ & K & & \\
\hline & & & & & & & & & & & & & & & & & MAF / & Functional \\
\hline & majo & $r>m i$ & inor & & & & & & & & & & & & & & $\mathrm{AF}$ & Localization \\
\hline rs2070951 & G & $>C$ & $\mathrm{C}$ & & & & & & & & .030 & - & - & - & - & - & $49 \%$ & 5'UTR \\
\hline rs5522 & $A$ & $>C$ & G & & & & & & & & .062 & - & - & - & .051 & .024 & $10 \%$ & Exon 2 \\
\hline rs10519963 & $\mathrm{C}$ & $>T$ & $\mathrm{~T}$ & & & & & & & & - & - & - & - & - & - & $14 \%$ & Intron 2 \\
\hline rs3846329 & $\mathrm{C}$ & $>A$ & $A$ & & & & & & & & - & - & .011 & - & - & - & $22 \%$ & Intron 2 \\
\hline rs3857080 & G & $>A$ & $A$ & & & & & & & & .000 & .067 & - & .004 & - & .026 & $11 \%$ & Intron 3 \\
\hline rs11099681 & $\mathrm{T}$ & $>C$ & C & & & & & & & & .023 & .092 & - & - & - & - & $29 \%$ & Intron 4 \\
\hline rs11099680 & $\mathrm{T}$ & $>C$ & C & & & & & & & & .023 & .092 & - & - & - & - & $29 \%$ & Intron 4 \\
\hline rs4835493 & G & $>A$ & $A$ & & & & & & & & .036 & - & - & - & - & - & $29 \%$ & Intron 4 \\
\hline rs6810951 & $\mathrm{C}$ & $>A$ & $A$ & & & & & & & & .092 & .001 & - & .068 & - & - & $39 \%$ & Intron 4 \\
\hline rs1040288 & C & $>C$ & G & & & & & & & & - & .044 & - & - & - & - & $43 \%$ & Intron 6 \\
\hline rs11737660 & G & $>A$ & $A$ & & & & & & & & .075 & - & - & - & - & - & $24 \%$ & Intron 8 \\
\hline rs5534 & C & $>T$ & $\mathrm{~T}$ & & & & & & & & - & - & - & - & - & - & $41 \%$ & 3'UTR \\
\hline Haplotypes & & & & & & & & & & & & & & & & & & \\
\hline H1_1 & C & $A$ & & & & & & & & & .030 & - & - & - & - & - & $49 \%$ & 5'UTR_e2 \\
\hline H1_2 & G & $A$ & & & & & & & & & - & - & - & - & - & - & $41 \%$ & \\
\hline H1_3 & G & G & & & & & & & & & .062 & - & - & - & .051 & .024 & $10 \%$ & \\
\hline & & & & & & & & & & & - & - & & & & & & \\
\hline $\mathrm{H} 2 \_1$ & & & C C & & & & & & & & - & - & .010 & - & - & - & $75 \%$ & i2 \\
\hline $\mathrm{H} 2 \_2$ & & & C A & & & & & & & & - & .088 & .069 & - & - & - & $11 \%$ & \\
\hline $\mathrm{H} 2 \_3$ & & & $\mathrm{~T} \quad \mathrm{~A}$ & & & & & & & & - & - & - & - & - & - & $10 \%$ & \\
\hline $\mathrm{H} 2 \_4$ & & $T$ & T $\mathrm{C}$ & & & & & & & & - & - & - & - & - & .077 & $3 \%$ & \\
\hline H3_1 & & & & $\mathrm{T}$ & $\mathrm{T}$ & G & $\mathrm{C}$ & C & G & $\mathrm{T}$ & - & - & - & - & - & - & $26 \%$ & i4_3'UTR \\
\hline H3_2 & & & & C & C & A & $C$ & G & G & C & - & - & .082 & - & - & - & $11 \%$ & \\
\hline H3_3 & & & & $\mathrm{T}$ & $\mathrm{T}$ & G & A & C & A & C & .048 & .019 & - & .025 & - & - & $11 \%$ & \\
\hline H3_4 & & & & $\mathrm{T}$ & $T$ & G & A & G & G & C & .091 & - & - & - & - & - & $10 \%$ & \\
\hline H3_5 & & & & $\mathrm{T}$ & $\mathrm{T}$ & G & A & C & G & C & .024 & - & - & - & - & - & $10 \%$ & \\
\hline H3_6 & & & & C & $C$ & A & $C$ & G & G & $\mathrm{T}$ & .052 & - & - & - & - & - & $8 \%$ & \\
\hline H3_7 & & & & C & C & A & C & G & A & C & - & - & - & - & - & - & $7 \%$ & \\
\hline H3_8 & & & & $\mathrm{T}$ & $\mathrm{T}$ & G & A & C & G & $\mathrm{T}$ & - & - & - & - & - & - & $5 \%$ & \\
\hline H3_9 & & & & $\mathrm{T}$ & $\mathrm{T}$ & G & $C$ & C & G & C & - & .083 & .006 & - & .061 & - & $3 \%$ & \\
\hline H3_10 & & & & C & C & A & A & C & A & C & .088 & - & - & - & - & - & $2 \%$ & \\
\hline H3_11 & & & & $\mathrm{T}$ & $\mathrm{T}$ & G & $C$ & G & G & $\mathrm{T}$ & - & .001 & .036 & - & .061 & - & $2 \%$ & \\
\hline H3_12 & & & & $\mathrm{T}$ & $T$ & G & $C$ & G & A & C & - & - & .017 & - & .020 & - & $2 \%$ & \\
\hline H3_13 & & & & $\mathrm{T}$ & $\mathrm{T}$ & G & $C$ & G & G & C & - & - & - & - & .071 & - & $1 \%$ & \\
\hline H3_14 & & & & $\mathrm{T}$ & $T$ & G & $C$ & C & A & C & - & - & - & - & - & - & $1 \%$ & \\
\hline H3_15 & & & & $\mathrm{T}$ & $T$ & G & $A$ & $\mathrm{G}$ & $A$ & C & - & - & - & .002 & - & - & $1 \%$ & \\
\hline
\end{tabular}

$P<0.1$ yellow. $P<0.05$ red cells. $P<0.01$ red cells with bold black font. BFT loop diuretics study days from clinical study 1 . HCT hydrochlorothiazide study days from the clinical study 2. TRIA triamterene study day from the clinical study 2. Nucleotides in grey are the minor alleles. UTR untranslated region. The (e) prefix in the haplotype functional localization is for (exon). The (i) prefix in the haplotype functional localization is for (intron). Haplotypes are named as Haplotype number_allele number. NaCl is the association with sodium and chloride excretion as composite endpoint. $K$ is the association with potassium excretion. All the association of $\mathrm{NaCl}$ and $\mathrm{K}$ excretion in this table were for the time between 0 and 24 hours. (-) refers to no significance. The statistical model included the diuretic drugs excretion but not the previously known affecting polymorphisms (first statistical model). 

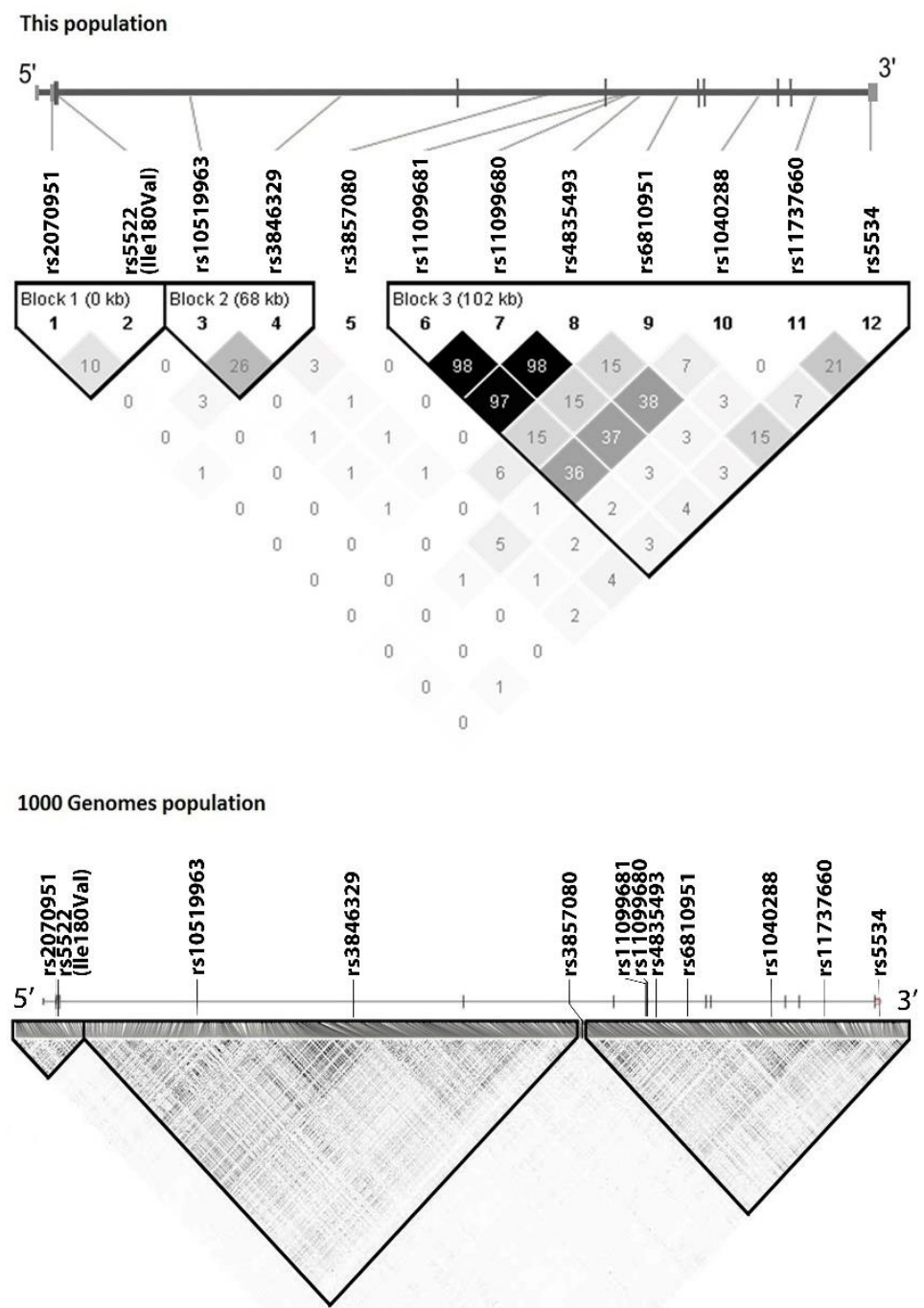

Figure 15: Linkage disequilibrium among the investigated polymorphisms

The figure depicts the linkage disequilibrium among the investigated polymorphisms. The upper part depicts the approximate position of the polymorphisms in relation to the exon-intron structure of the aldosterone receptor gene and the linkage disequilibrium in the pooled two populations of our two clinical studies ("This population"). The lower part depicts the linkage disequilibrium in the Caucasian chromosomes of the 1000-genomes project (www.1000genomes.org/). The darker the shading of the diamonds, the stronger the linkage disequilibrium; the numbers in the diamonds (in the upper part) are the respective $r^{2}-$ values. The three big black triangles in both parts demark the three corresponding linkage disequilibrium blocks (also called haplotype blocks), which we used for the calculation of haplotypes (see Table 29 for more details about the calculated haplotypes). 


\subsubsection{Effects on sodium and chloride excretion and potassium excretion}

Higher sodium and chloride excretion after bumetanide and furosemide, and higher potassium excretion under most circumstances were associated with minor A-allele of rs3857080 (Figure 16, Figure 17, Table 30). Sodium and chloride excretion was evaluated as a combined endpoint (Na\&Cl). Single regression analyses without further predictors in the model revealed near three gram higher sodium\&chloride excretion over $24 \mathrm{~h}$ per A-allele after bumetanide or furosemide (Table 30) corresponding to about five to six gram higher sodium\&chloride excretion per day in carriers of two A-alleles compared to two G-alleles. Five to six grams were one fourth of the mean sodium \&chloride excretion after bumetanide or furosemide (Table 30).

Higher potassium excretion was associated with the minor A-allele under most conditions (Figure 16, Figure 17 and Table 30). Regression analyses without adjustment revealed about half a gram higher potassium excretion over $24 \mathrm{~h}$ per A-allele under these circumstances (Table 30). Volume excretion was associated with rs3857080 similar to potassium but statistically weaker. The statistical model was extended to test the stability of the associations (compare Figure 17 with Table 30). The excreted drug amounts and the eight polymorphisms earlier reported to be implicated with urinary electrolyte excretion in the study populations were stepwise included (Vormfelde and Brockmoller, 2012; Vormfelde et al., 2006; Vormfelde et al., 2007; Vormfelde et al., 2010). The above mentioned associations, especially the effect sizes, remained stable.

Torsemide is a loop diuretic similar to bumetanide and furosemide, nonetheless torsemide additionally blocks the aldosterone receptor, and this difference is highly relevant to the interpretation of our study. The complete pattern of associations after torsemide appeared different from those after bumetanide and furosemide (Figure 17, Table 30). Furosemide appeared similar to bumetanide rather than to torsemide in terms of comparable effects' sizes with potassium and similar associations with sodium plus chloride and volume excretion (Figure 17, Table 30). Calculating the phenotype-genotype associations separately for intervals of 0-6 $\mathrm{h}$ and 6-24 $\mathrm{h}$ showed that the differences between the genotypes were apparent in both intervals (Figure 18). 
$\mathrm{Na} \& \mathrm{Cl}$ after furosemide

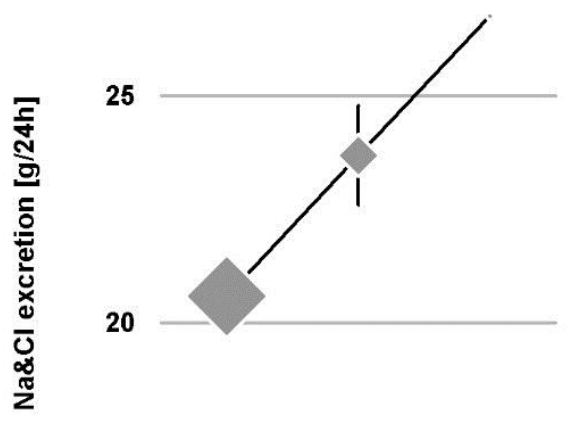

15

GG
GA

\section{$\mathrm{K}+$ on $\mathrm{NaCl}$ restriction}

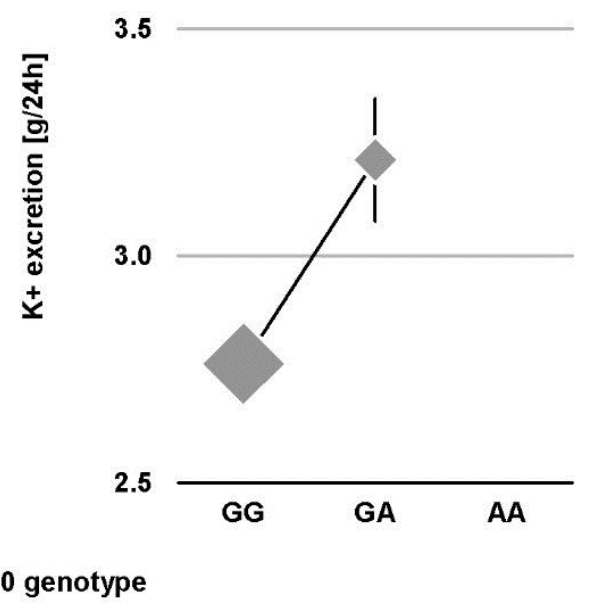

Figure 16: Sodium and Chloride, and potassium excretion by rs3857080 genotypes

The figure depicts the $24 \mathrm{~h}$ excretion of Sodium and chloride (Na\&Cl) after furosemide intake (left) and of potassium on moderate sodium chloride restriction (right) in relation to the genotype of rs3857080. Sodium and chloride excretion was evaluated as a combined endpoint Na\&Cl. Data are mean/SEM. Symbol sizes are proportional to the group sizes. Number of participants in the genotypic groups are GG:72, GA:19, AA:1 for Na\&Cl after furosemide, and GG:76, GA:23, AA:0 for potassium on moderate sodium chloride restriction. Concerning this polymorphism (rs3857080), there was 87, 22 and 1 carriers of the GG, GA and AA genotypes in the first study and 93, 25 and 1 carriers of GG, GA and AA in the second study (the AA carrier in the second study did not complete any study day) (see 6.1.1 for more details on the genotyped numbers). 


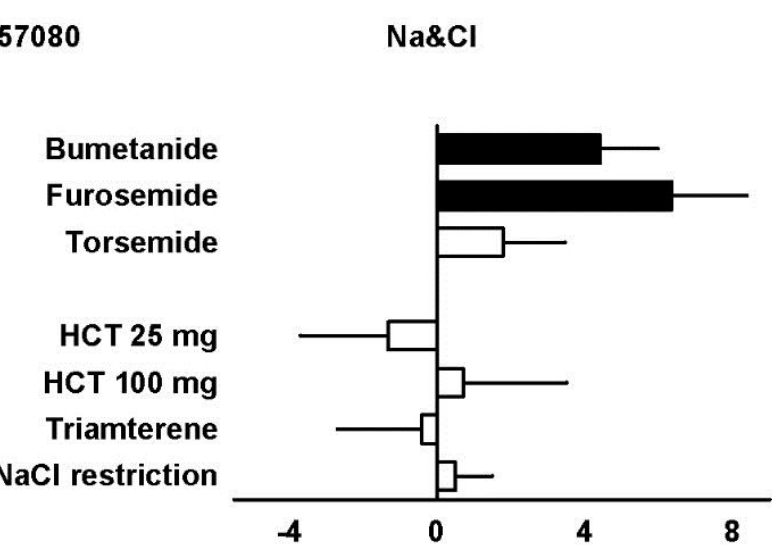

Ile180Val (rs5522)
$\mathrm{Na \& Cl}$

8

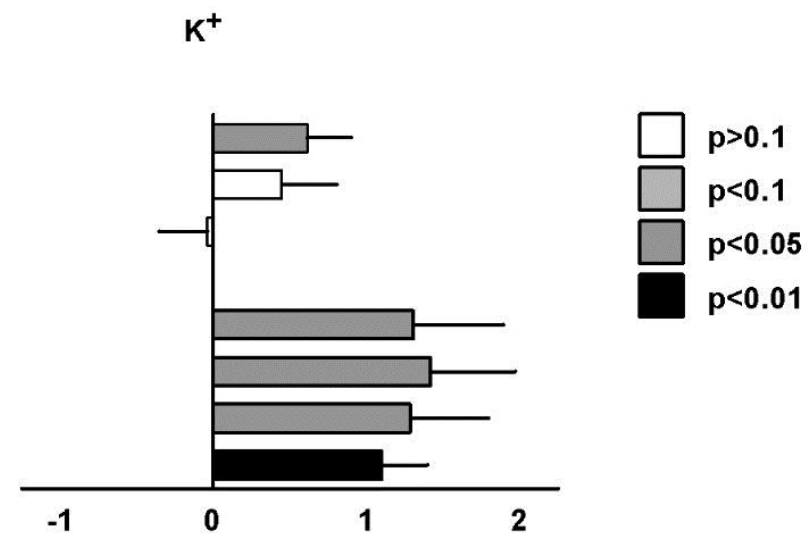

$<0.1$

$<0.01$

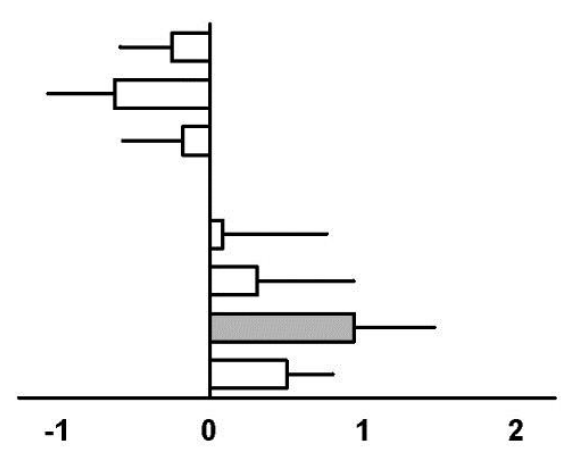

Difference in the urinary electrolyte excretion over $24 \mathrm{~h}$ per two minor alleles [g]

Figure 17: Differences in urinary sodium\&chloride, and potassium excretion with rs3857080 and lle180Val (rs5522)

The figure depicts the mean differences in the $24 \mathrm{~h}$ excretion of sodium and chloride ( $\mathrm{Na \& Cl}$ ) and of potassium $\left(\mathrm{K}^{+}\right)$associated with the two polymorphisms rs3857080 and lle180Val (rs5522). Data are mean differences ( \pm SEM). Predictors included in the statistical model were the two NR3C2 polymorphisms, urinary drug excretion and the eight polymorphisms formerly published to affect urinary excretion in our studies (Vormfelde and Brockmoller, 2012; Vormfelde et al., 2006; Vormfelde et al., 2007; Vormfelde et al., 2010) (for more details see paragraph [2.4.1] in the methods for the second statistical model). Data are presented per two alleles for two reasons: To reflect the natural bi-allelic situation and to allow sensible comparison with cohort means. Numbers give the differences associated with two minor alleles (A-or valine-alleles) compared to two major alleles (G-or isoleucine-alleles). NaCl sodium chloride. HCT hydrochlorothiazide. 


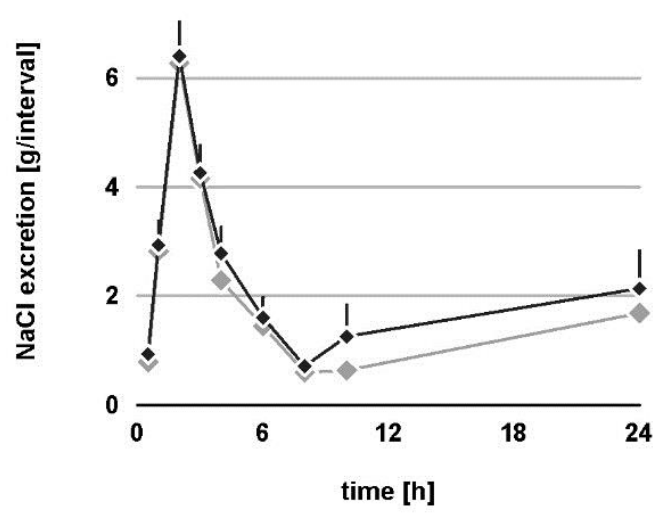

C

$\mathrm{K}+$ after Triamterene

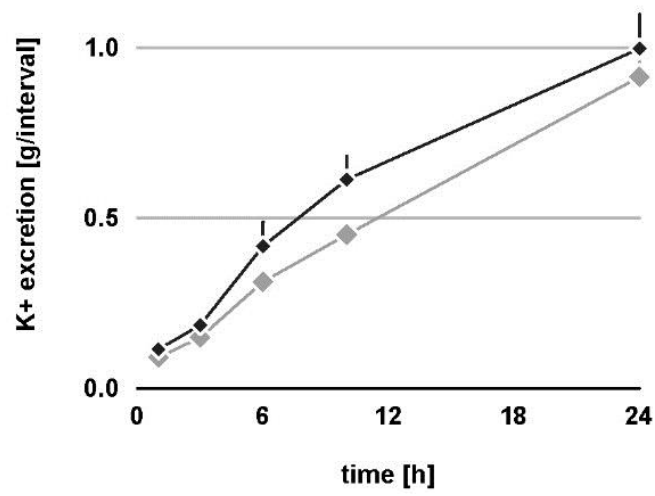

B

K+ after HCT

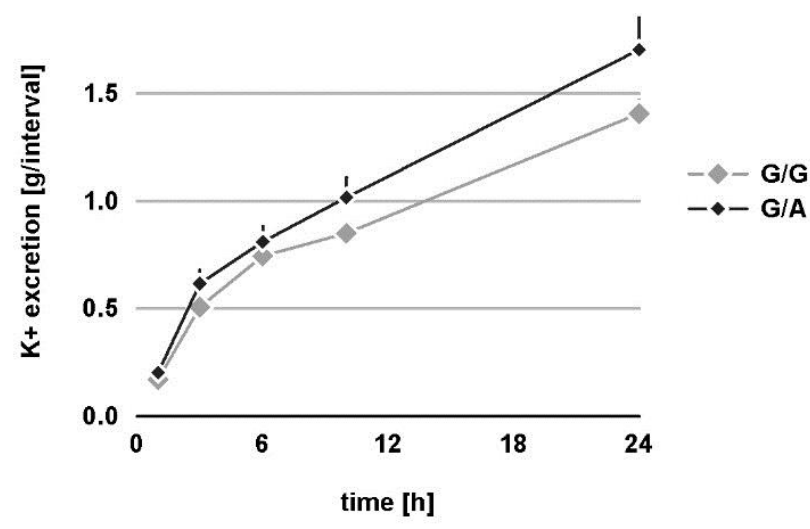

D

$\mathrm{K}+$ after $\mathrm{NaCl}-$ restriction

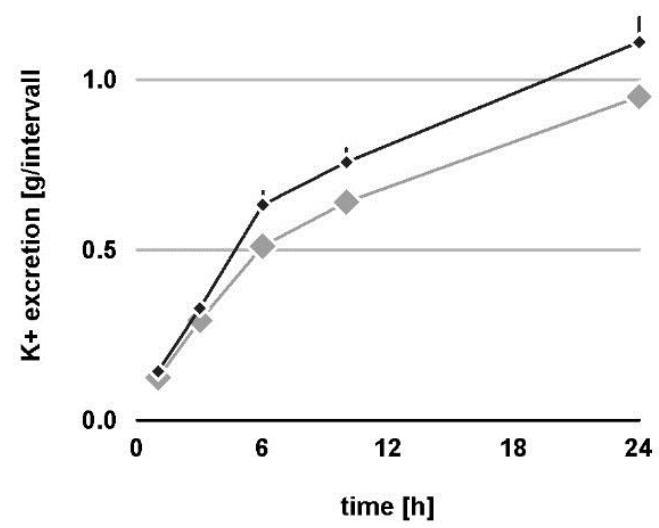

Figure 18: Time course of potassium and sodium\&chloride excretion by rs3857080 genotype

The figure depicts the electrolyte excretion over 24 h separately for homozygous G-allele carriers of rs3857080 (grey diamonds) and heterozygous $\mathrm{G} / \mathrm{A}$-carriers (black diamonds). The figure depicts the time courses of sodium and chloride excretion (Na\&Cl) after furosemide in part $A$ and the time course of potassium $\left(K^{+}\right)$excretion after $100 \mathrm{mg}$ hydrochlorothiazide in part $B$, after triamterene in part $C$, and after moderate sodium chloride restriction in part $D$. Data are given as means and SEM. Symbols sizes are proportional to the genotyped numbers. Repeated measures analysis of variance with time as within-participants variable and rs3857080 genotype as the between-participants factor has been performed. Differences between the genotypes were significant $(p<0.05)$ in case of potassium excretion after hydrochlorothiazide $100 \mathrm{mg}$, triamterene and moderate sodium restriction. 
Table 30: Mean urinary $24 \mathrm{~h}$ excretion and differences in $24 \mathrm{~h}$ excretion of volume and electrolytes in relation to rs3857080 and lle180Val

\begin{tabular}{|c|c|c|c|c|c|c|c|}
\hline & \multicolumn{3}{|l|}{ Study 1} & \multicolumn{4}{|l|}{ Study 2} \\
\hline & Bumetanide & Furosemide & Torsemide & $\overline{H C T} 25 \mathrm{mg}^{a}$ & HCT $100 \mathrm{mg}$ & Triamterene & $\mathrm{NaCl}^{- \text {restriction }}{ }^{b}$ \\
\hline Volume $(\mathrm{l} / \mathrm{d})^{\mathrm{c}}$ & $4.9 \pm 0.2$ & $4.9 \pm 0.2$ & $4.5 \pm 0.2$ & $3.5 \pm 0.1$ & $3.8 \pm 0.1$ & $3.0 \pm 0.1$ & $3.0 \pm 0.1$ \\
\hline $\operatorname{rs} 3857080^{d}$ & $0.5 \pm 0.8$ & $0.5 \pm 0.8$ & $-0.2 \pm 0.7$ & $1.2 \pm 0.6 *$ & $0.8 \pm 0.6$ & $1.5 \pm 0.6 *$ & $0.7 \pm 0.3 *$ \\
\hline Ile180Val ${ }^{d}$ & $-0.9 \pm 0.9$ & $-1.8 \pm 0.9 *$ & $-0.9 \pm 0.9$ & $0.5 \pm 0.6$ & $0.3 \pm 0.6$ & $0.3 \pm 0.6$ & $-0.2 \pm 0.3$ \\
\hline $\mathrm{Na \& Cl}(\mathrm{g} / \mathrm{d})^{\mathrm{e}}$ & $21.5 \pm 0.4$ & $21.3 \pm 0.5$ & $17.4 \pm 0.4$ & $12.8 \pm 0.5$ & $17.9 \pm 0.5$ & $8.7 \pm 0.4$ & $7.7 \pm 0.2$ \\
\hline rs3857080 & $4.7 \pm 2.0 *$ & $6.2 \pm 2.0 * *$ & $1.7 \pm 1.7$ & $-0.7 \pm 2.4$ & $0.3 \pm 2.4$ & $-0.3 \pm 1.9$ & $0.4 \pm 1.0$ \\
\hline Ile180Val & $-3.6 \pm 2.4$ & $-2.7 \pm 2.4$ & $-1.9 \pm 2.0$ & $2.3 \pm 2.3$ & $0.4 \pm 2.3$ & $3.7 \pm 1.7 *$ & $0.5 \pm 0.9$ \\
\hline $\mathrm{K}^{+}(\mathrm{g} / \mathrm{d})$ & $2.9 \pm 0.1$ & $3.1 \pm 0.1$ & $2.6 \pm 0.1$ & $3.8 \pm 0.1$ & $4.3 \pm 0.1$ & $2.3 \pm 0.1$ & $2.9 \pm 0.1$ \\
\hline rs3857080 & $0.7 \pm 0.3 *$ & $0.4 \pm 0.3$ & $-0.1 \pm 0.3$ & $1.1 \pm 0.6(*)$ & $1.3 \pm 0.6 *$ & $1.1 \pm 0.5 *$ & $0.9 \pm 0.3 * *$ \\
\hline Ile180Val & $-0.3 \pm 0.4$ & $-0.7 \pm 0.4\left(^{*}\right)$ & $-0.2 \pm 0.4$ & $1.0 \pm 0.6$ & $0.6 \pm 0.6$ & $1.0 \pm 0.4 *$ & $0.5 \pm 0.3 *$ \\
\hline
\end{tabular}

a $\quad H C T=$ Hydrochlorothiazide.

b $\quad \mathrm{NaCl}$-restriction $=$ moderate sodium chloride restriction (mean $7.7 \pm 3.4,7.3 \pm 3.3$ and $8.0 \pm 3.4 \mathrm{~g}$ per $24 \mathrm{~h}$ on the three placebo days before $25 \mathrm{mg} \mathrm{HCT}, 100 \mathrm{mg} \mathrm{HCT}$ and triamterene, respectively)

c data are mean \pm SEM of the entire study cohort

d data are mean differences ( \pm SEM). They were calculated with single linear regression analyses with no further potential predictor included in the model. Data are presented per two alleles to reflect the natural biallelic situation, which is also the basis for the means of the entire study cohort. Numbers give the differences associated with two minor alleles (A- or valinealleles) compared to two major alleles (G-or isoleucine-alleles).

e $\quad \mathrm{Na \& Cl}=$ sodium\&chloride as composite endpoint

$(*), * * *\left(^{*}\right)$ indicates $p=0.1-0.05, *$ indicates $p<0.05$, and ** indicates $p<0.01$ as $p$-values from single linear regression analyses with no further potential predictor included in the model. 


\subsubsection{Comparing the effects of the polymorphisms with the pharmacokinetic effects}

Large fractions of variation were attributed to rs3857080 (Figure 4). rs3857080 explained relevant percentages of variation in sodium and chloride excretion after bumetanide and furosemide and in potassium excretion after most conditions (Figure 19). Taken together, the ten investigated polymorphisms (eight previously and two from $N R 3 C 2$ ) explained $34.2 \%$ in the urinary sodium and chloride excretion after bumetanide or furosemide and $23.2 \%, 19.3 \%$ and $11.0 \%$ in the urinary potassium excretion after hydrochlorothiazide, after triamterene and on moderate sodium chloride restriction, respectively. These fractions were larger than those explained by the respective urinary drug excretion. As Figure 19 shows, rs3857080 explained more variation under these conditions than the other polymorphisms. 
A

$\mathrm{Na} \& \mathrm{Cl}$ after bumetanide and furosemide

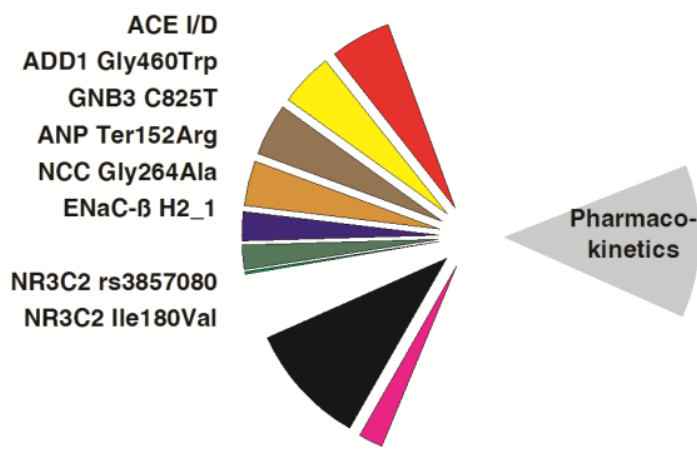

C

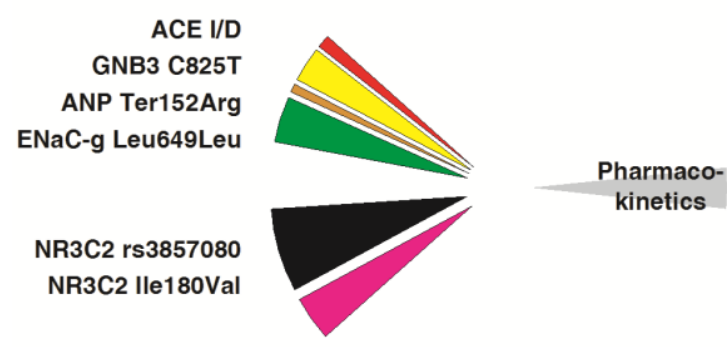

B

$\mathrm{K}+$ after HCT

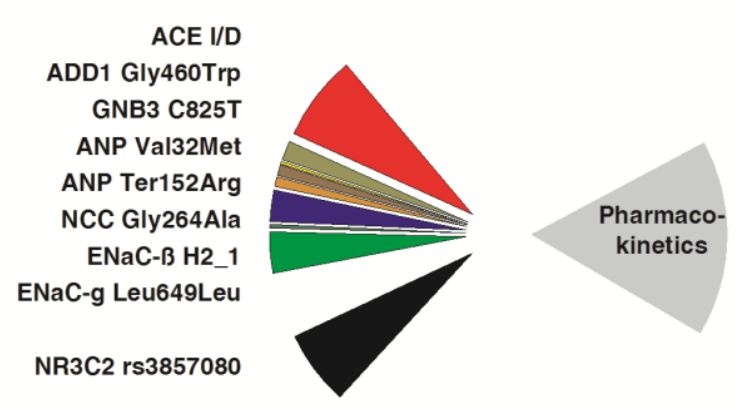

D

$\mathrm{K}+$ after $\mathrm{NaCl}$ restriction

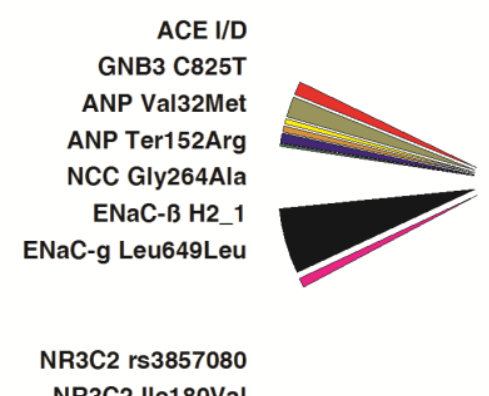

Figure 19: Variation in 24 h electrolyte excretion explained by ten genetic polymorphisms and urinary drug excretion

The figure depicts the fractions of the variation in urinary electrolyte excretion, which were attributed to ten genetic polymorphisms and to urinary drug excretion. Shown are the fractions of variation in the $24 \mathrm{~h}$ excretion of sodium plus chloride (Na\&Cl) after bumetanide and furosemide in part $A$ and of potassium $(\mathrm{K}+$ ) after $25 \mathrm{mg}$ and $100 \mathrm{mg}$ hydrochlorothiazide (HCT) in part $B$, after triamterene in part $C$ and after moderate sodium chloride restriction in part $D$. Data are from four covariance analyses. We analyzed the bumetanide and the furosemide study days together and the two hydrochlorothiazide study days (HCT 25 and $100 \mathrm{mg}$ ) also together.

Predictors included in the model besides urinary drug excretion were as follows: $A C E I / D$, the insertion/deletion polymorphism rs1799752 in the angiotensin l-converting enzyme; ADD1 Gly460Trp (also referred to as rs4961) in alpha-adducin; GNB3 C825T (rs5443) in the G protein subunit beta 3; ANP Val32Met (rs5063) in the atrial natriuretic peptide precursor; ANP Ter152Arg ( $r$ 5065), which is a termination to arginine exchange; NCC Gly264Ala ( $r$ 1529927) in the sodium-chloride cotransporters; ENaC- $\beta$ H2_1, a frequent haplotype in the beta subunit of the epithelial sodium channels composed by the T, C and A alleles of rs 152728 , rs238547 and rs152745 (Vormfelde et al., 2007); ENaC-g Leu649Leu (rs5723) in the gamma subunit of the epithelial sodium channel; NR3C2 rs3857080, the intron 3 polymorphism in the aldosterone receptor gene and NR3C2 Ile180Leu (rs5522) in the aldosterone receptor gene.

Bumetanide and furosemide excretion explained $12.7 \%$ of the variation in sodium plus chloride excretion after their intake in a common analysis (part D). In that analysis, NR3C2 rs3857080 explained 10.1\% ( $p<0.001)$ and NR3C2 Ile180Leu explained $2.0 \%$ $(p=0.069)$.

After hydrochlorothiazide (part B, $25 \mathrm{mg}$ and $100 \mathrm{mg}$ analyzed together), urinary hydrochlorothiazide excretion explained 16.3\% of the variation in potassium excretion ( $p<0.001)$, NR3C2 rs3857080 explained $6.2 \%(p<0.001)$, NR3C2 Ile180Val was negligible (0.1\%).

Urinary triamterene excretion explained $3.4 \%(p=0.086)$ of the variation in potassium excretion after triamterene (part $C)$ compared to NR3C2 rs3857080: 6.9\% ( $p=0.014)$.

The most considerable predictor of the variation in potassium excretion during moderate sodium chloride restriction (part D) was NR3C2 rs3857080: 5.4\% ( $p<0.001)$. 
Among all other aldosterone receptor polymorphisms studied, only the lle180Val polymorphism appeared to be functionally relevant. Potassium and sodium\&chloride excretion were weaker associated with the polymorphism lle180Val (rs5522) with and without controlling for drug excretion and other polymorphisms (Figure 17, Table 30). After triamterene, the size of the differences was comparable to those observed with rs3857080 with one gram potassium and four gram sodium and chloride on the study day (Figure 17). The pattern of associations with Ile180Val differed from that with rs3857080 but both were also not genetically linked at all (Figure 15).

\subsection{Functional study of the intron 3 polymorphism (rs3857080) in the aldosterone receptor gene (NR3C2)}

The A-allele of rs3857080 does not change protein structure but may enhance the binding of transcription factors. For that the Electrophoretic mobility shift assay (EMSA) was performed first to detect any DNA-protein binding possibility before going further into the investigation of the intronic polymorphism.

\subsubsection{DNA-protein binding (EMSA)}

In electrophoretic mobility shift assay (EMSA), several types of evidence indicated that the intron 3 polymorphism ( $\mathrm{s} 3857080$ ) affects transcription factor binding. The region around the polymorphism showed strong nuclear protein binding (Figure $21 \mathrm{~B}$, lane 2). Both major and minor alleles had shown DNA-protein binding bands with more intense second band for the minor-A allele of rs3857050. A possible negative control was selected from the set of already genotyped SNP as a self-testing for the statistical analysis. The negative control was selected to be an intronic SNP also from the same aldosterone receptor gene $N R 3 C 2$ which showed no significant association to the studied phenotypes ( $r$ 11099680). The positive control was CAMPresponsive-Element (CRE) (Figure 20). 


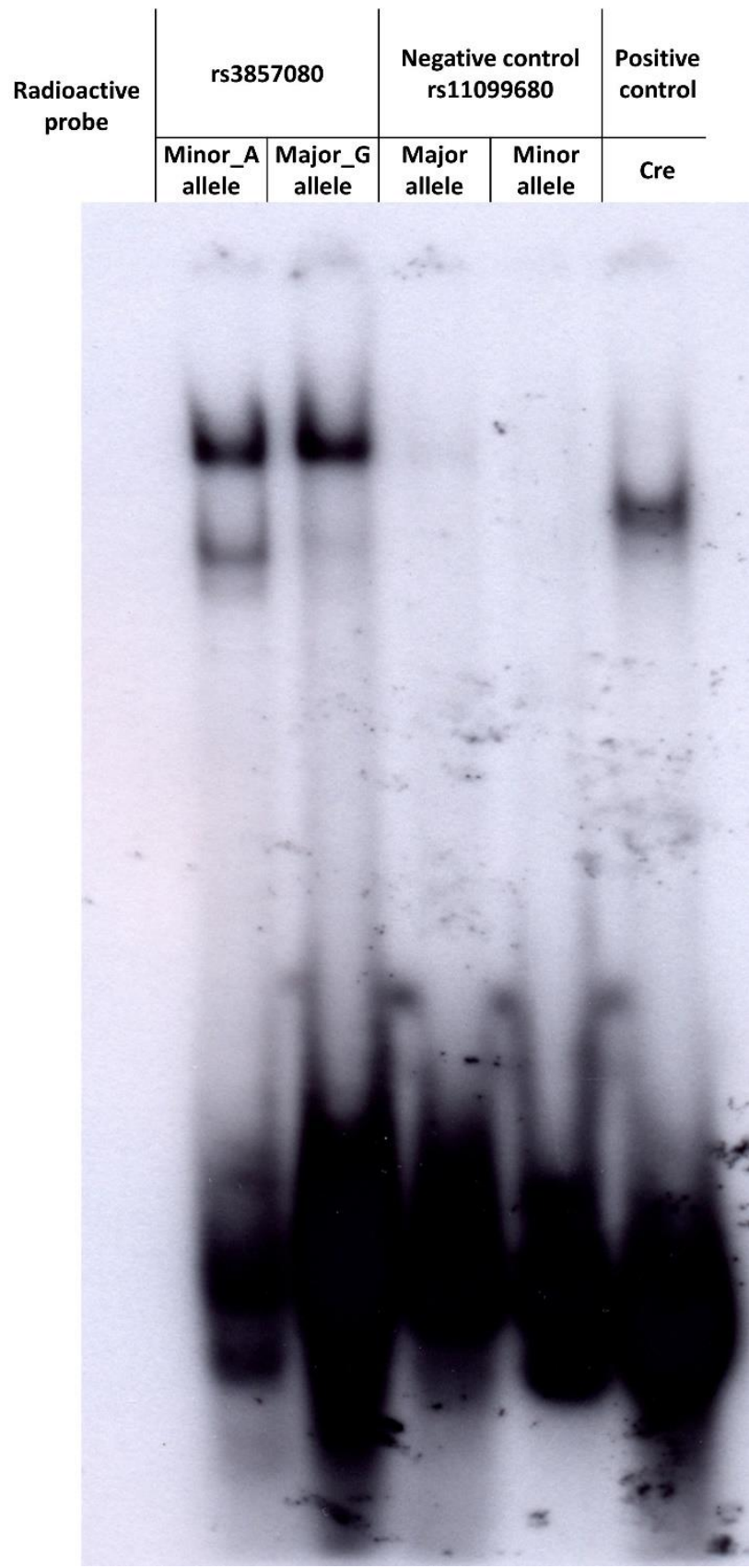

Figure 20: Electrophoretic mobility shift assay for minor-A and major-G alleles of rs3857080

Nuclear cell extract was from the HEK293 cells. Negative control (rs11099680) was selected from the genotyped SNPs in the aldosterone receptor gene with no significance. Positive control was the CAMP-responsive-Element (CRE) 
A

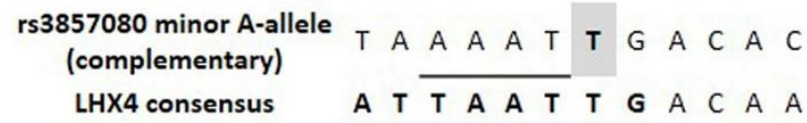

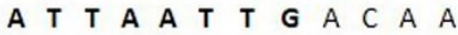

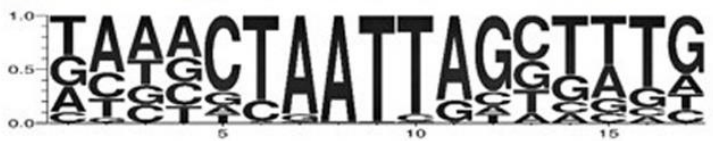

C

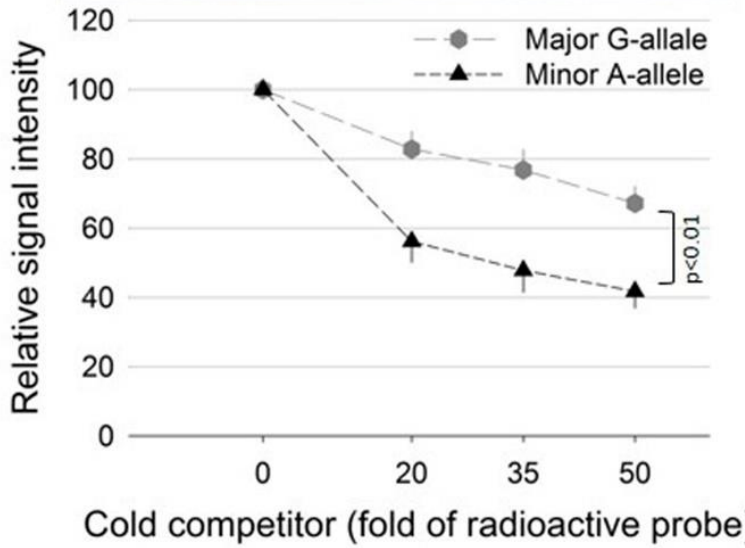

Figure 21: Electrophoretic Mobility Shift Assay for rs3857080 with HEK293 nuclear cell extracts

Electrophoretic mobility shift assay shows the binding of nuclear protein extracts of HEK293 cells to the rs3857080 DNA region. (A) Sequence of the minor A-allele of rs3857080. Underlined are the four mutated nucleotides of the minor A-allele. The sequence of the LHX4 consensus shows the binding site (underlined) (Machinis and Amselem, 2005) with the expected weight matrix created with WebLogo 3.3 using the position dependent probabilities from TRANSFAC ${ }^{\circledR}$ (This analysis was kindly provided by Mr. Martin Haubrock, department of bioinformatics, Göttingen University). (B) Radioactive probe was always the oligonucleotide of the minor-A-allele of rs3857080 DNA region (Table 22). Two bands were always detected by this binding. The cold competition shows allele-specific differences in DNA-protein binding between the major-G- and minor-A-allele. The unlabeled cold competitors were given in 10X- to 50X-fold molar excess of the labeled probe. The use of the anti-LHX4 antibody resulted in reduction of the signal compared to the IgG as a control. (C) Quantification of the cold competition signals for the lower band from five independent experiments (mean $\pm S E M)$. There was significant difference in relation to the type of cold competitor or in relation to how many folds molar excess were used ( $p<0.01)$. Significances were calculated using two-way ANOVA (SigmaPlot 11.0) taking into consideration the type of the cold competitor and the folds of mole excess. 


\subsubsection{Allele specific binding (Cold competition)}

The binding of the nuclear proteins was stronger with the minor A-allele compared to the Gallele (Figure 21 B, lanes 3 to 8), a difference, which was statistically significant [ $<<0.001$ (lower band)], (Figure $21 \mathrm{C}$ ).

\subsubsection{Transcription factors prediction using TRANSFAC ${ }^{\circledR}$}

Bioinformatics analysis suggested a list of possible transcription factors that might bind to the region of rs3857080 [for the complete list and details see the supplementary materials 6.1.2]. The list was sorted from the higher hit numbers to the lower (Supplementary table 4). The transcription factors with higher hit numbers in the WT-frequency column than the Variantfrequency column were excluded from being tested. The corresponding consensus for the tested transcription factors are presented in Table 31.

Table 31: consensus for the seven tested transcription factors

\begin{tabular}{lll}
\hline $\begin{array}{l}\text { Protein } \\
\text { Name }\end{array}$ & Consensus & Source (citation) \\
\hline Msx1 & ATCCATTGCACACTAATTGGAGGCTGTAG & (Catron et al., 1993) \\
Sox4 & AGACTGAGAACAAAGCGCTCTCACAC & $\begin{array}{l}\text { (van de Wetering et al., } \\
\text { 1993) } \\
\text { http://jaspar.binf.ku.dk/ }\end{array}$ \\
Barx1 & AAAGTAATTGACACAT & $\frac{\text { cgi-bin/jaspar db.pl }}{\text { (Machinis and }}$ \\
LHX4 & GTATGAATCATTAATTGACAACATAT & Amselem, 2005) \\
TBX5 & GGATCCTGTCGCCCGGTGCTAGTTGTGACACCTAACTGAGGC & (Ghosh et al., 2001) \\
Gbx2 & ACTCATTC & (Roeseler et al., 2012) \\
AP1 & CGCTTGATGATTTATGGTTGCATAGTA & SANTA CRUZ \\
& & BIOTECHNOLOGY, \\
\hline
\end{tabular}

Two possible relevant transcription factors were identified. Among the 7 most promising candidates suggested by bioinformatics analysis, we identified the transcription factor LHX4 and Barx1 to bind to the rs3857080 region. Cold competition with unlabeled LHX4 and Barx1 consensus oligonucleotide eliminated the lower band (Figure 22). 


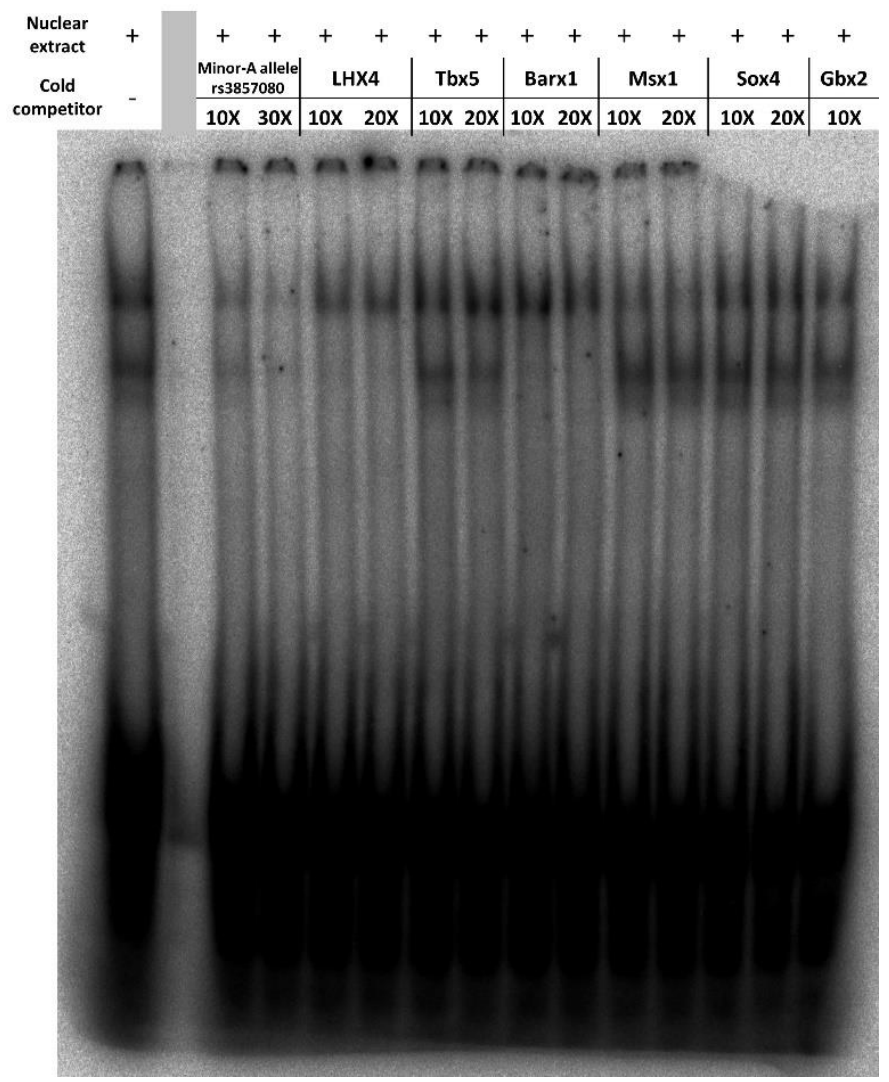

Figure 22: Cold competition with transcription factors' consensus

Cold competition with the consensus of predicted transcription factors by the TRANSFAC database. The nuclear extract was from HEK293 cells. The radioactive probe was always the labeled minor-A allele of rs3857080. The mole excess of the unlabeled probes ranged between 10X to 30X. Both LHX4 and Barx1 could compete with the labeled probe to eliminate the second band (lanes 5, 6, 9 and 10).

Aligning the sequences for the rs3857080 region with the LHX4 and Barx1 used consensus revealed into shared binding core between all (Figure 23, blue cells).

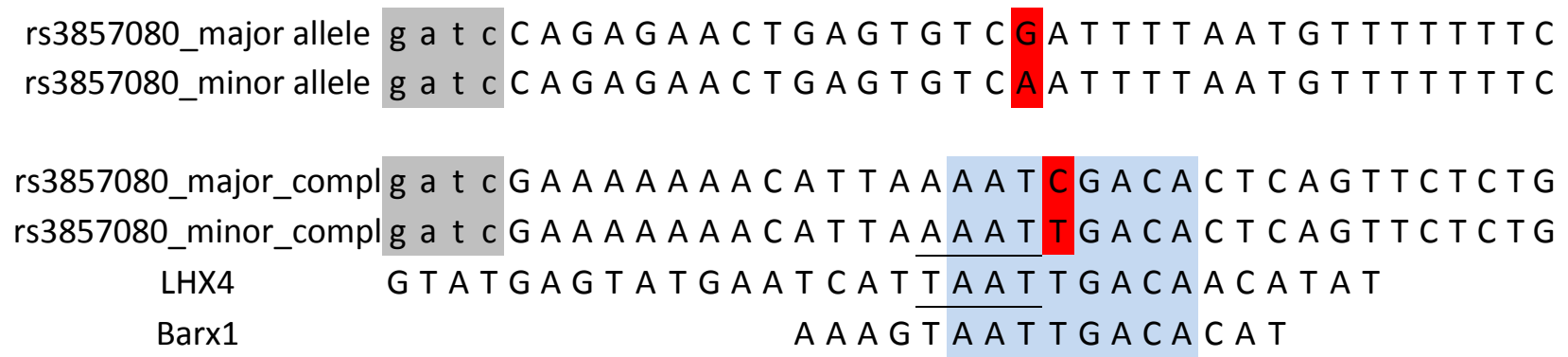

Figure 23: Aligned sequences of the rs3857080 region with LHX4 and Barx1 consensus.

rs3857080 polymorphism in red. Blue barked nucleotides are the shared region between all. Compl referes to the complimentary sequence (reversed). The underlined four nucleotides are the mutated ones [see Mutating the possible binding site 3.5.1.4] 


\subsubsection{Super shift assay - determining the predicted transcription factor}

The Anti-LHX4 antibody clearly reduced the intensity of both bands (Figure $21 \mathrm{~B}$, lanes 9 and 10). While the Anti Barx1 didn't affect the binding affinity to the labeled probe of the minor-A allele of the rs3857080 polymorphism.

\subsubsection{Mutating the possible binding site}

As one more step of confirming the specificity of LHX4 binding to the rs3857080 region, four nucleotides in the LHX4 consensus oligonucleotide were mutated as in (Machinis and Amselem, 2005 ) and in the same corresponding nucleotides in the minor A-allele oligonucleotide. EMSA revealed no DNA-protein interaction with both mutated sequences when mutated (Figure 24, Table 22). 


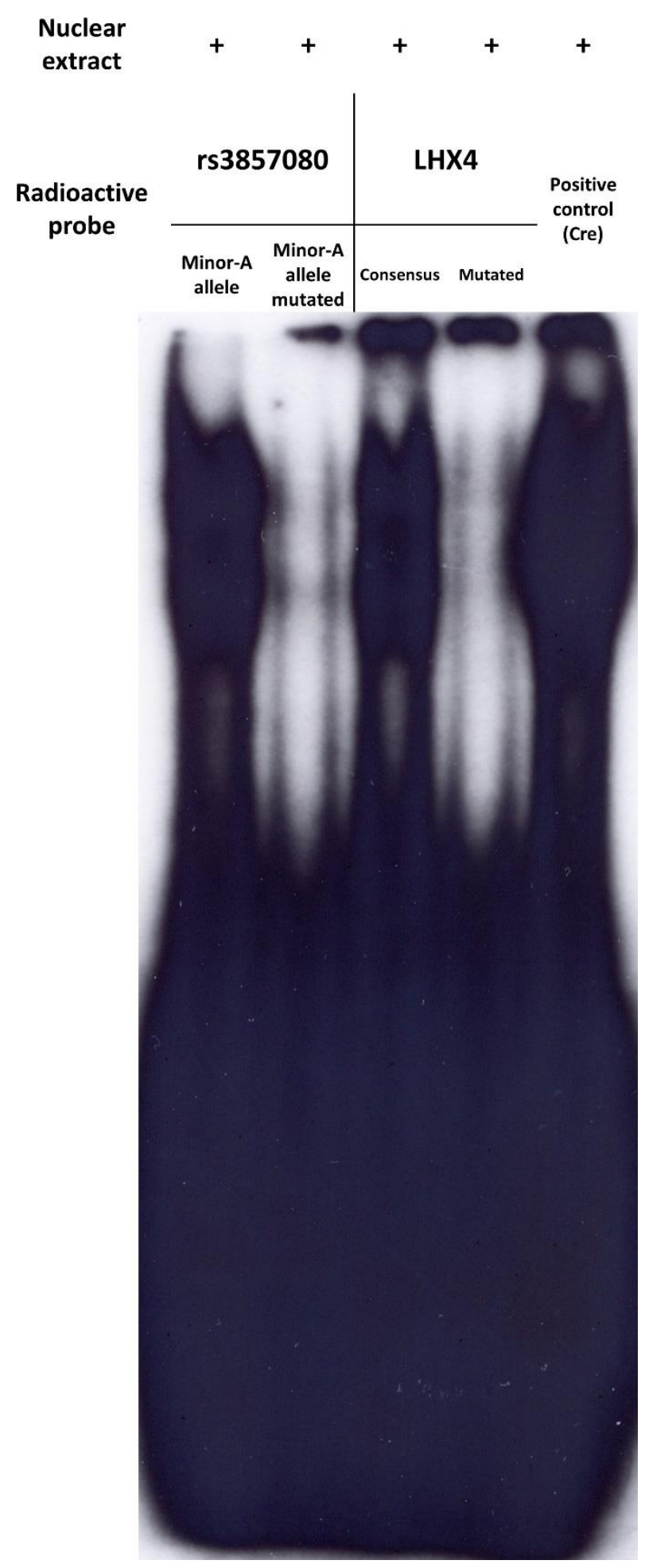

Figure 24: EMSA for rs3857080 and LHX4 consensus and their mutated sequences

Mutating four nucleotides in the expected binding core for the minor-A allele of rs3857080 and LHX4 consensus revealed into no DNA-protein binding by EMSA. 


\subsubsection{Reporter gene assay}

\subsubsection{Generating plasmids with the major-G-, minor-A-, and minor-mutated-alleles}

Three different plasmids were generated, each of them from two different clones. All plasmids contained the rs3857080 region inserted before both the promoter and the firefly luciferase sequences (Figure 25). The first plasmid contains the major-G allele of the rs3857080, the second contains the minor-A allele and the third contains the same mutated allele of rs 3857080 which was used in the EMSA experiments. The insertion was done by using the restriction enzymes Kpnl and Bg/II [2.9.4.1].
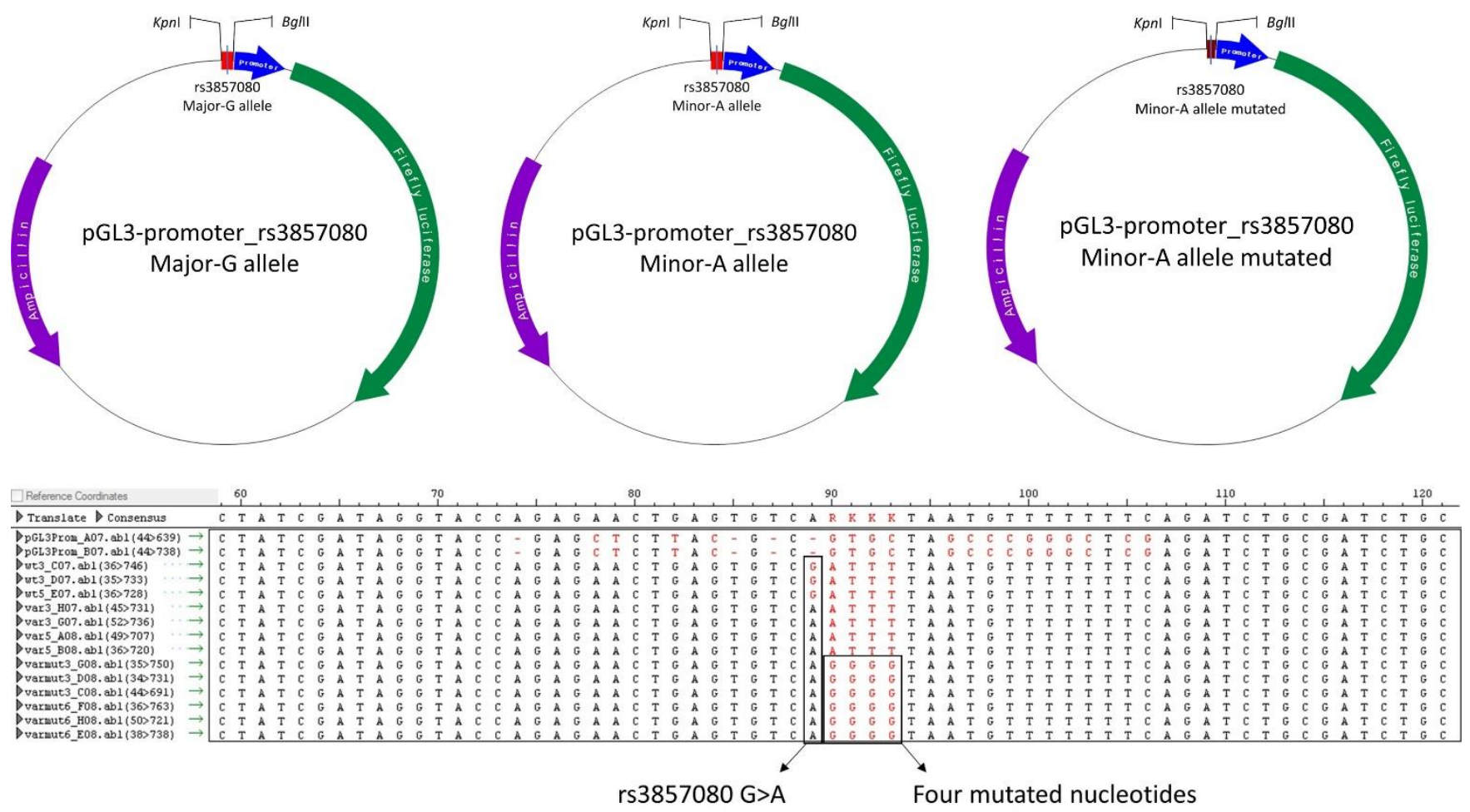

Figure 25: rs3857080 region inserted in the pGL3-promoter vector 


\subsubsection{Effects of the constructs on luciferase assay}

The previous plasmids with the major-G, minor-A and mutated alleles were transfected into HEK293 cells. The pCMV-Renilla-luciferase plasmid was transfected also into the same HEK293 cells for normalization as an internal standard. Luciferase assay was performed as described in [method 2.9.4.3]. The results for each construct are coming from two different clones with more than three repetitions. The average of the firefly luciferase activity was calculated after normalizing the measurements to the renilla luciferase acitivity (Figure 26). The activity increased by almost 1.7 folds for the three transfected clones.

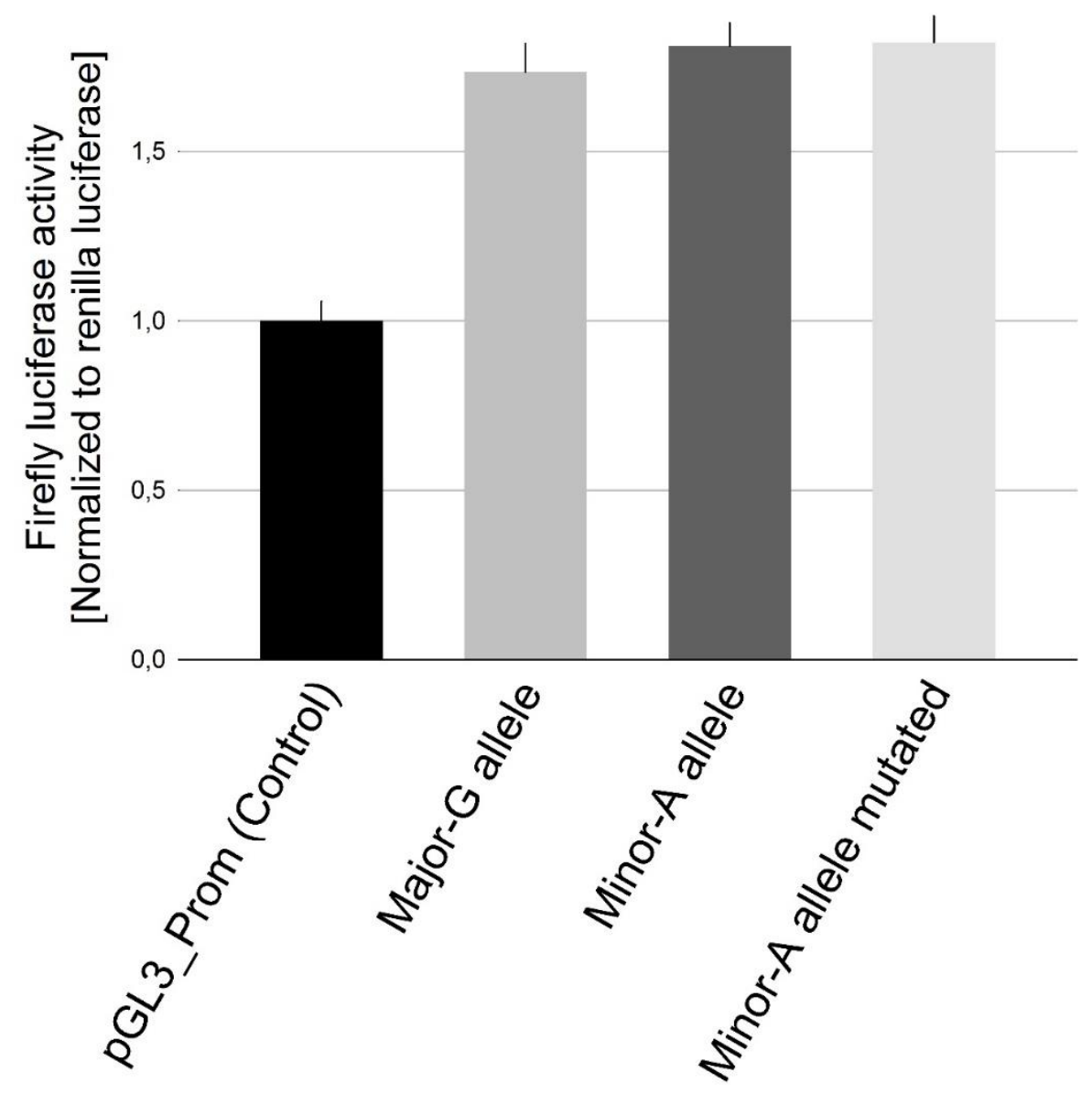

Figure 26: Reporter gene assay for the rs3857080 major-G, minor-A and mutated alleles

The figure depicts the firefly luciferase activity after normalizing the measurements to the renilla luciferase activity. The figure shows the increased fold activity in comparison to the empty transfected vector. Data are presented as the average \pm SEM. 


\subsubsection{Generating expression plasmid with LHX4 (pCDNA3.1::LHX4)}

The possible coding sequence for the LHX4 protein was delivered in pOTB7 vector. The pOTB7 vector is not an expression vector, for that it was necessary to re-clone the open reading frame (ORF) of the LHX4 into an expression vector (e.g. pcDNA3.1). First, the sequence of the LHX4 in the pOTB7 vector was checked by sequencing one of the selected clones using 7 primers to cover the whole sequence (Table 17). The sequencing was done to check if there is any mutation that might cause a stop codon in the LHX4 sequence. After proofing the correct sequence, the LHX4-ORF was amplified using two designed primers with a specific restriction enzyme sites included (Table 10). The restriction enzymes were HindIII and Kpnl. pcDNA3.1 was double digested using the same restriction enzymes for end compatibility before ligation. The general steps of re-cloning LHX4-ORF from pOTB7 vector into pcDNA3.1 are explained in Figure 27.

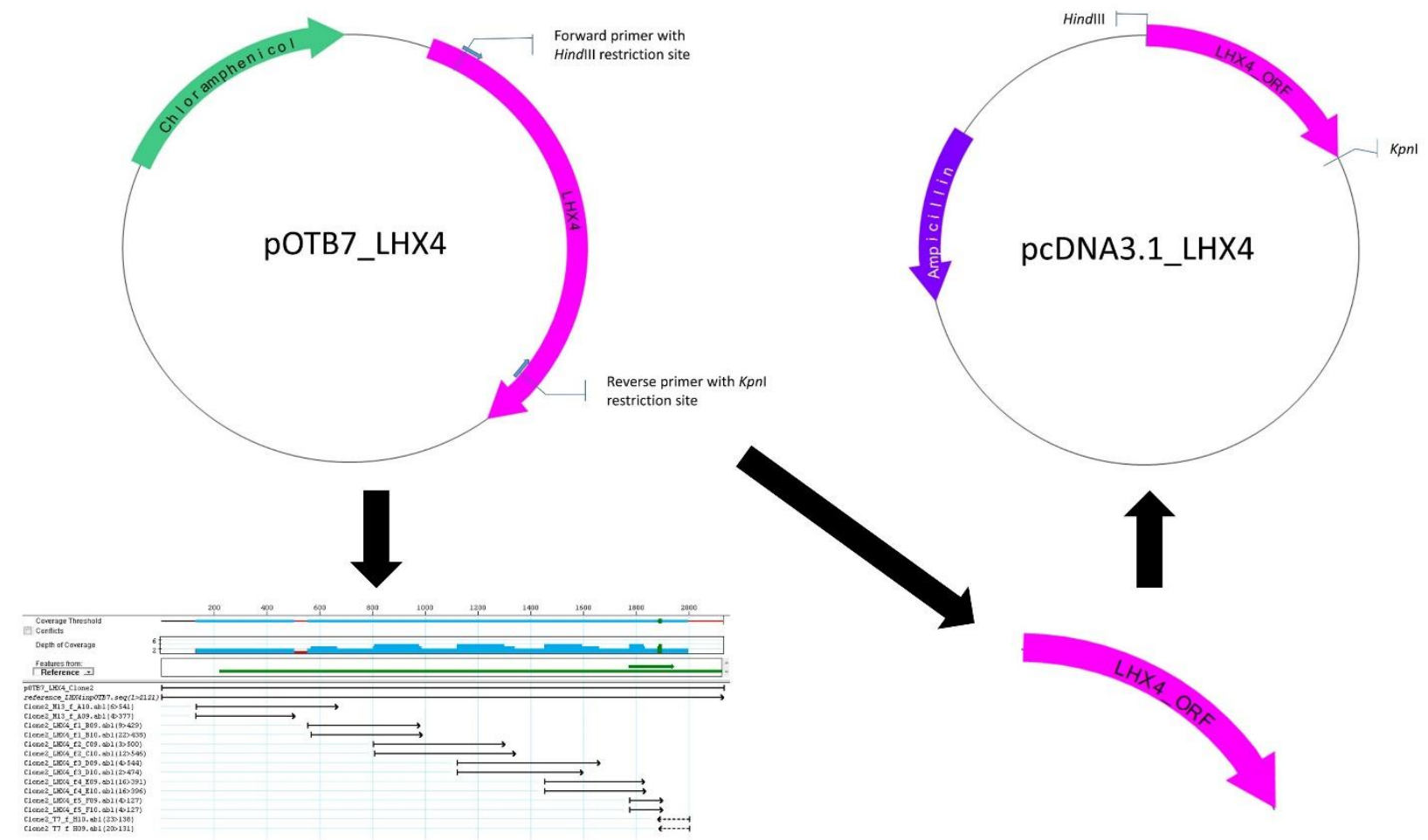

Figure 27: re-cloning LHX4-ORF from pOTB7 into pcDNA3.1 vector.

The figure depicts the general performed steps to re-clone the LHX4-ORF from the non-expression vector pOTB7 into the pcDNA3.1 vector for further transfection into the HEK293 cells. 


\subsubsection{Effects of the constructs on luciferase assay when LHX4 is expressed}

The same reporter gene assay experiments were repeated in the presence or absence of the LHX4. Firefly luciferase showed higher activity in the presence of LHX4 in the all constructs with a little less activity with the mutated allele of the rs3857080 (Figure 28)

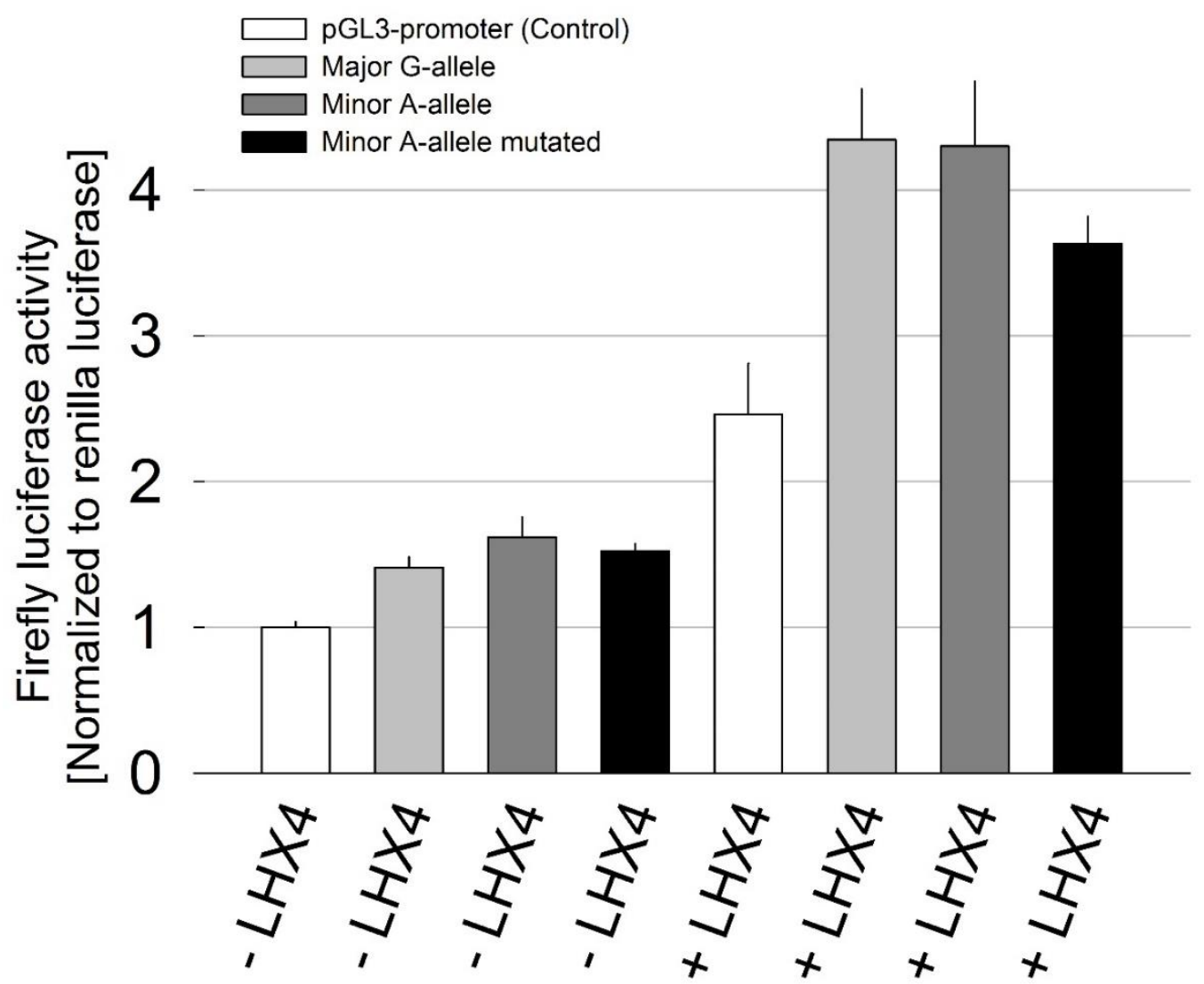

Figure 28: Reporter gene assay for the rs 3857080 major-G, minor-A and mutated alleles in the presence or absence of LHX4

The figure depicts the firefly luciferase activity after normalizing the measurements to the renilla luciferase activity. The figure shows the increased fold activity in comparison to the empty transfected vector in the presence or absence of the LHX4. Data are presented as the average \pm SEM. 


\subsection{WNK4 results}

\subsubsection{Pooling the samples}

Samples from each clinical study were divided into two groups. The criterion was sodium and chloride excretion between 0 and 24 hours ( $\left.N a C l \_0 \_24\right)$. The used phenotype was adjusted for the creatinine clearance first as explained in the methods [2.2.3]. The DNA concentration of the samples was measured using the PicoGreen ${ }^{\circledR}$ assay [2.5.6.2], then normalized by Qiagility ${ }^{\circledR}$ pipetting machine to $10 \mathrm{ng}$ of DNA per sample. Table 32 Shows the four different groups with the corresponding barcodes which were used in the next generation sequencing:

Table 32: Pooled DNA samples into four different groups from two clinical studies

\begin{tabular}{lllcc}
\hline Clinical Study & Term & Phenotype & Nr. Samples & Barcode for sequencing \\
\hline Loop diuretics study & Diu1_1 & High sodium and chloride excreters & 47 & 7 \\
& Diu1_2 & Low sodium and chloride excreters & 48 & 8 \\
Hydrochlorothiazide and & Diu2_1 & High sodium and chloride excreters & 51 & 9 \\
Triamterene study & Diu2_2 & Low sodium and chloride excreters & 52 & 10 \\
\hline
\end{tabular}

\subsubsection{Confirming and validating the detected polymorphisms}

Many parameters could affect the detected polymorphisms by the bioinformatics tools. The coverage was one of the most interesting parameters that should be adjusted in addition to the allele frequency (number of reads). With 100X coverage of the exon regions of WNK4 gene, there were 163 detected possible polymorphisms. The list was further filtered by choosing polymorphisms that had more than $0.7 \%$ minor allele frequency (almost one read per 100, meaning almost one read per divided groups). The list was reduced to 126 polymorphisms. Choosing the non-synonymous SNPs only reduced the number of polymorphisms to 69 SNPs. As the technique is known of its false positive detection of polymorphisms when they are in homopolymere region, all polymorphisms within such regions were sorted out manually. Finally, 25 possible non-synonymous SNPs were validated further by genotyping using SNaPShot ${ }^{\circledR}$ [2.6.1] or capillary sequencing [2.6.2]. There were only five true SNPs out of the validated 25 SNPs, two of them were novel (Table 33). 
Table 33: Detected and validated SNPs in the WNK4 gene

\begin{tabular}{|c|c|c|c|c|c|c|}
\hline Amino acid change & $\begin{array}{c}\text { Position } \\
\text { (GRCh37/hg19) }\end{array}$ & Ref allele & Alt allele & dbSNP 137 & Genotypes & MAF \\
\hline S239W & 40934873 & C & G & NOVEL & $1 \mathrm{Het}^{*}$ pool 9 DIU2_1 & 0.009 \\
\hline V358A & 40936500 & $\mathrm{~T}$ & C & NOVEL & $\begin{array}{l}1 \text { Het Pool } 8 \text { DIU1_2 } \\
1 \text { Het Pool } 10 \text { DIU2_2 }\end{array}$ & 0.01 \\
\hline P1025L & 40947694 & C & $\mathrm{T}$ & rs56099549 & $\begin{array}{c}3 \text { Het Pool } 7 \text { DIU1_1 } \\
1 \text { Het Pool } 9 \text { DIU2_1 } \\
2 \text { Het Pool } 10 \text { DIU2_2 }\end{array}$ & 0.01 \\
\hline V1084A & 40947871 & $\mathrm{~T}$ & C & rs148648427 & 1 Het Pool 7 DIU1_1 & 0.01 \\
\hline R1204C & 40948319 & C & $\mathrm{T}$ & rs56116165 & 1 Het pool 10 DIU2_2 & 0.009 \\
\hline
\end{tabular}

* Het refers to heterozygous. $S$ serine, $W$ tryptophan, $V$ valine, $A$ alanine, $P$ proline, $L$ leucine, $R$ arginine and $C$ cysteine.

The five SNPs were applied for nine protein prediction tools [2.10.3]. One of the two novel validated SNPs was predicted to be deleterious by all protein prediction tools. The final results of the five detected and validated SNPs with the functional predictions on the protein function are presented in Table 34. The used primers in validating the five SNPs are presented in Supplementary materials [6.1.4].

Table 34: protein function predictions for the five validated polymorphisms in the WNK4 gene

\begin{tabular}{cccccccccccc}
\hline Amino acid change & dbSNP 137 & PROVEAN & SIFT SNAP PPH2 & nsSNPAnalyzer & MutPred & Mutation & @sting PhD SNP SNPs\&Go No.D \\
\hline S239W & NOVEL & D & D & D & D & D & D & D & $\mathrm{n}$ & D & 8 \\
V358A & NOVEL & D & D & D & D & D & D & D & D & D & 9 \\
P1025L & rs56099549 & D & D & $\mathrm{n}$ & D & D & $\mathrm{n}$ & D & $\mathrm{n}$ & $\mathrm{n}$ & 5 \\
V1084A & rs148648427 & $\mathrm{n}$ & $\mathrm{n}$ & $\mathrm{n}$ & $\mathrm{n}$ & $\mathrm{D}$ & $\mathrm{n}$ & $\mathrm{n}$ & $\mathrm{n}$ & $\mathrm{n}$ & 1 \\
R1204C & rs56116165 & D & D & D & D & D & $\mathrm{n}$ & D & $\mathrm{n}$ & $\mathrm{n}$ & 6 \\
\hline
\end{tabular}

$D$ deleterious. $n$ Neutral. No.D number of deleterious prediction 


\section{Discussion}

\subsection{Overview}

The analyses are based on two clinical studies. In the first clinical study, we studied the effects of three loop diuretic drugs in about 100 healthy volunteers. In the second clinical study, we studied the effects of moderate sodium restriction, hydrochlorothiazide and triamterene in about 100 volunteers also. The purpose of this pharmacogenomics study was to identify inherited polymorphisms which had an impact on renal handling of salt and water excretion. The healthy volunteers were genotyped systematically for 39 polymorphisms in 11 genes responsible for regulation of the activity of renal salt transporters. During the analysis, two genes arose as candidates for further investigation, the mineralocorticoid receptor gene $N R 3 C 2$ and the with-no-lysine 4 kinase gene WNK4. The NR3C2 gene arose as a most promising candidate gene since the intron 3 polymorphism ( $\mathrm{s} 3857080$ ) in that gene was of high impact mostly on potassium excretion under most conditions in both clinical studies. In silico and in vitro studies showed that the intron 3 polymorphism region has a possible binding site with the LHX4 transcription factor which was confirmed to some extent by in vitro cell biology studies. The WNK4 gene got into our special focus, because on one hand it is considered relevant for several functions and diseases but on the other hand in the databases there were only very few polymorphisms recorded. I performed massive parallel sequencing of the whole exon regions of the WNK4 gene in the volunteers from both clinical studies but found only five polymorphisms which could be confirmed by other methods. Two novel non-synonymous polymorphisms in the kinase region of the WNK4 (S239W and V358A) were predicted to have deleterious effect on the protein function.

\subsubsection{Why different diuretic drugs?}

We analyzed different diuretic drugs in the two clinical studies for two reasons: First, to study the molecular genetic basis of inter-individual variation in pharmacokinetics of each drug. Second, to study the molecular genetic reasons behind variation in pharmacodynamics. Concerning the pharmacokinetic variation, the loop diuretic drugs and the thiazide were studied in dependence of organic anion transporters (e.g. OAT1, OAT3, OAT4, and OATP1B1). 
Concerning pharmacodynamics variation, the loop diuretic drugs were already studied in relation to polymorphisms in NKCC2, the thiazide in relation to NCC and triamterene was studied in relation to ENAC polymorphism. In this work, we focused on the regulation of the mentioned pharmacodynamics candidate genes.

\subsection{Phenotype-genotype analysis of the renal regulation candidate genes}

After having developed, performed and validated the genotyping of the 39 polymorphisms, we firstly performed an extensive exploratory screening to identify which of the promising polymorphisms may be associated with the tested renal functions before then focusing on the major possible finding. To study the association between the phenotypes and the 39 genotyped polymorphisms in Table 27, we had to take into account the multiple testing problem. Without adjusting for multiple testing, numerous significant associations were found (Table 28). On the other hand, many of these associations were not significant by adjusting for multiple testing at the appropriate calculated type-I-error margin $(P<0.0001)$. At this level only the intronic SNP in the NR2C3 gene was significant, but in addition to the SNP-wise significance we took into account how consistent the associations with the other polymorphisms with p-values between 0.01 and 0.0001 were. Consistent here means whether they appeared in both studies (independent unrelated volunteers) and with the same renal functions (e.g. K or $\mathrm{Na}$ excretion). For example, the five selected polymorphisms in the WNK1 gene were associated with differences in urine potassium, systolic blood pressure (SBP) and diastolic blood pressure (DBP) in the literature (Newhouse et al., 2009; Turner et al., 2005). In one of the studies, WNK1 polymorphisms were also significantly associated with the relevant phenotypes after four weeks on hydrochlorothiazide (Turner et al., 2005). Nevertheless, in our studies the associations with WNK1 polymorphisms were only found in one of the clinical studies, and the associations were quantitatively weak and disappeared after adjusting for multiple testing (Table 28). In the aldosterone receptor gene, the associations were more consistent and the associations of one polymorphism were still significant, even after adjustment. 


\subsection{Aldosterone receptor polymorphisms}

Twelve polymorphisms in the aldosterone receptor were selected for genotyping. The selection was based on a literature review. Only polymorphisms in NR3C2 were selected which were known to have an association with specific biological or medical phenotypes. Surprisingly, an intronic polymorphism (rs3857080) had more effects than the well-studied non-synonymous polymorphism lle180Val (rs5522). In this work, only known polymorphisms in the NR3C2 were genotyped for the volunteers from both clinical studies, but in a future perspective, it may be very promising to have a full exon sequence of this gene for the volunteers for two reasons: First, variation may be associated with several other more rare polymorphisms which may have escaped out of attention. Second, to check the linkage with the most prominent finding in my research, the intron 3 polymorphism, with all detected polymorphisms in the exon regions. The linkage to any polymorphism in the exon region may provide a more conclusive explanation why the polymorphism was associated with functional phenotypes. Only exon regions are suggested for sequencing because of the big gene size (almost $370 \mathrm{~kb}$ ).

\subsubsection{Effects on ion excretion}

\subsubsection{The intron 3 polymorphism (rs3857080) effects on in vivo salt and fluid homeostasis with and without diuretic drugs}

Sodium and chloride excretion after the loop diuretics bumetanide and furosemide, and potassium excretion under most circumstances were higher in carriers of the A-allele of the rs3857080 polymorphism. The difference was quantitatively significant and the aldosterone receptor polymorphism explained more variation (Figure 19) than other polymorphisms studied in this context (Vormfelde and Brockmoller, 2012). Torsemide was less affected by rs3857080 than other loop diuretics but torsemide is also different from the others since it also has an antialdosteronergic effect (Uchida et al., 1991). However, data concerning the antialdosteronergic effects of torsemide to our knowledge only came from studies in rats (Uchida et al., 1991).

High aldosterone receptor expression associated with the A-allele of rs3857080 may be derived from the predominant finding that high potassium excretion was associated with the A-allele 
under most conditions (Figure 17). Only after torsemide, which is a loop diuretic similar to bumetanide and furosemide which may additionally block the aldosterone receptor, potassium excretion was similar between the A- and the G-allele of rs3857080. One study showed that torsemide may inhibit the secretion of aldosterone (Goodfriend et al., 1998). The finding that an antialdosteronergic drug reduced or abolished the association of kaliuresis with the aldosterone receptor polymorphism may confirm our hypothesis that the polymorphism modulates aldosterone receptor expression and function.

In this work, the urinary excretion under true steady state conditions was not measured. Nevertheless, in another study [Table S6 in (Tobin et al., 2008)], no association of $24 \mathrm{~h}$ urinary sodium, chloride and potassium excretion with rs3857080 was observed under steady state conditions. However, upon stimulation of aldosterone secretion by salt depletion and diuresis in this study, one can assume that participants had elevated aldosterone concentrations. Under this condition higher aldosterone receptor expression may be particularly functional resulting in higher aldosterone receptor function.

rs3867080 appears to primarily affect the kaliuretic function of the aldosterone receptor (Figure 17). While aldosterone is better known for sodium retention, it has two distinct functions; this has been termed the "aldosterone paradox" [1.5.2]. While sodium retention predominates in hypovolemia, kaliuresis predominates in normovolemia (Seva Pessoa et al., 2013), and in our studies, normovolemia was ensured by allowing the volunteers to drink as much water as they requested.

\subsubsection{Ile180Val polymorphism (rs5522) effects on in vivo salt and fluid homeostasis with and} without diuretic drugs

As a secondary finding of this research, lle180Val (rs5522), which has earlier been studied by several authors (Derijk et al., 2008; Klok et al., 2011; Martinez et al., 2009; van Leeuwen et al., 2011), may modulate the urinary excretion of electrolytes in some instances. This polymorphism is located in exon 2, coding the amino acid number 180 in the aldosterone receptor. The change from isoleucine to valine is in the $\mathrm{N}$-terminal domain of the protein. This domain controls the transcriptional activity of the aldosterone receptor (MR) by recruiting a number of coregulators. It is suggested that this change may attenuate the activity of MR as the amino acid change is located in a central inhibitory domain (residues 163-437) (Viengchareun et al., 2007). 
Comparatively high aldosterone receptor function may be associated with the valine allele of Ile180Val as observed in this work. High sodium\&chloride excretion was associated with the valine allele after triamterene intake (Table 30, Figure 17). As triamterene blocks ENaC, a comparatively strong triamterene effect refers to high ENaC activity before the blocking. This suggests comparatively high aldosterone receptor function associated with the valine allele as the aldosterone receptor increases $\mathrm{ENaC}$ expression.

Earlier findings about Ile180Val are inconclusive (Cavallari et al., 2010; DeRijk et al., 2006; Kortmann et al., 2013; Rovaris et al., 2013). At least, protection from hypertension has been related to a haplotype including the valine allele (Martinez et al., 2009). The large effect sizes potentially associated with Ile180Val, however worth its further investigation in kidney-related phenotypes.

\subsubsection{Functional characterization of the intron 3 polymorphism (rs3857080)}

As the primary finding of this research, the intronic aldosterone receptor polymorphism rs3857080 appeared to be a functional polymorphism with a considerable effect on the renal functions. There are several approaches to investigate an intronic polymorphism. First is to define any possible transcription factor binding site around this polymorphism. Second is to transfect the polymorphism region into selected cells and assess effects by the reporter gene assay. Third is to study the effect of the polymorphism on the gene expression in different tissues where the gene is highly expressed (e.g. the small intestine, colon, lungs, thyroid and kidneys) (Supplementary figure 5). Forth is to define any transcript variants splicing sites around the polymorphism region. The possibility of this polymorphism to be in a splicing region is low, although not excluded, because it is not close to any of the near exons, where the donor or receiver regions are usually located.

\subsubsection{Effects on protein binding - transcription factor binding site}

My in vitro experiments provided several types of evidence that the polymorphism is located at a LHX4 binding site (e.g. Figure 21) and that the transcription factor LHX4 binds with higher affinity to the minor A-allele than to the major G-allele (Figure 21). LHX4 is a member of the LIM homeodomain transcription factors known for its effects on pituitary gland differentiation and development (Mullen et al., 2007). To the best of our knowledge, no studies have previously 
linked LHX4 to the aldosterone receptor expression or diuretic drugs' efficacy; however, considering the impact of LHX4 on the pituitary gland which regulates cortisol biosynthesis may give some clues. Nevertheless, no final explanation on the molecular basis can be given other than its possible effect on transcription.

\subsubsection{Reportergene assay}

\subsection{Effects of rs3857080 region on the luciferase activity}

The activity of firefly luciferase was increased by about 1.7 fold compared to the control with the major-G and minor-A alleles of rs3857080. Surprisingly, this activity was not reduced or abolished when the mutated allele from the rs3857080 was transfected. The mutated allele of the rs3857080 showed completely no binding band with the EMSA experiments, and was expected to have no effect on the firefly luciferase alike the control. Another unexplained observation was that no clear difference in the luciferase activity between the major-G and minor-A alleles of rs3857080 was observed. It was expected then, that the co-transfection of the LHX4 factor with the major and minor alleles' clones of rs3857080 would amplify the effect besides the difference.

\subsection{Effects of rs3857080 region on the luciferase activity when LHX4 is co-expressed}

The activity of firefly luciferase was clearly amplified when LHX4 was co-expressed compared to the last experiment without co-expressing the LHX4 (Figure 28). There was some increase in the activity of the luciferase when LHX4 was co-expressed even with the control. The increased activity in the control could be explained. The empty pGL3-promoter plasmid (the control) contained already possible binding sites for LHX4. The effect of the mutated allele of rs3857080 on the luciferase was less than the major and minor allele but still not as low as the negative control. It is suggested to repeat the reporter gene assays with the same inserted regions but in different luciferase vectors. The vectors should be checked prior to exclude any possible binding site for the LHX4.

\subsubsection{Possible clinical consequences of the minor A-allele carriers of the intron 3 polymorphism (rs3857080)}

Clinically potentially relevant, the intron-3 polymorphism ( $r$ 3857080) affected electrolyte excretion stronger than other polymorphisms (Figure 19). Particularly, potassium excretion may 
lead to hypokalemia and its devastating consequences. Clinically, one may speculate that carriers of the minor A-allele of rs3857080 are at higher risk of hypokalemia and consequently may have less favorable outcomes of diuretic therapy. The possibility to match this polymorphism with available antialdosteronergic drugs such as torsemide, spironolactone or eplerenone suggests the possibility of differential pharmacotherapy. Taken together, rs3857080 appears interesting for future research in heart diseases, blood pressure and pharmacotherapy. Also antialdosteronergic drugs (e.g. spironolactone, eplerenone and torsemide) may be especially beneficial in A-allele carriers.

\subsection{WNK4 polymorphisms}

The WNK4 gene appears to be located in a non-polymorphic region of chromosome 17 (Table 35). The last impression arises because genotyping the 19 exons of WNK4 in 229 healthy Caucasian men resulted only in 5 confirmed single nucleotide polymorphisms with a minor allele frequencies all around 1\%. All detected and confirmed polymorphisms were heterozygous.

Table 35: percentage of the polymorphisms through the studied genes

\begin{tabular}{lcccc}
\hline Gene & Nr. SNPs $>$ 1\% MAF & Nr. non-synonym SNPs $>$ 1\% MAF $^{* *}$ & Gene size $^{* * *}$ & $\begin{array}{c}\text { Ratio }^{* * * *} \\
\text { [per thousand bp] }\end{array}$ \\
\hline WNK1 & 555 & 5 & 158530 & 3.501 \\
WNK3 & 129 & 1 & 165183 & 0.781 \\
WNK4 & 20 & 1 & 16436 & 1.217 \\
STK39 & 921 & 4 & 293576 & 3.137 \\
OXSR1 & 188 & 1 & 89954 & 2.09 \\
SGK1 & 613 & 2 & 148813 & 4.119 \\
NEDD4L & 1573 & 0 & 357154 & 4.404 \\
KCNJ1 & 102 & 0 & 29354 & 3.475 \\
CLCKA & 78 & 9 & 12060 & 6.468 \\
CLCKB & 145 & 7 & 13557 & 10.696 \\
NR3C2 & 1351 & 1 & 363758 & 3.714 \\
\hline
\end{tabular}

* The number of SNPs through the gene (Exon-intron) with minor allele frequency higher than 1\%. The numbers were extracted from the 1000 genomes project. ${ }^{* *}$ The number of the non-synonymous SNPs in the European American population from the NHLBI Exome Sequencing Project (ESP) with minor allele frequency higher than 1\%. ${ }^{* * *}$ Genes' sizes were calculated from the genes' positions from GRCh37/hg19 (Table 26). ${ }^{* * *}$ The ratio is for the total number of SNPs $>1 \%$ through the gene divided by the gene size. 
Two polymorphisms (S239 and V358A) were predicted to be deleterious by almost all tools used to evaluate the functional consequences from amino acid substitutions [See methods 2.10.3] (8 and 9 deleterious out of 9 predictions respectively, Table 34). Both of the polymorphisms were found in the kinase region of the WNK4. The kinase region is a highly conserved region between the four WNKs, and they share about $84 \%$ sequence identity of this region (McCormick and Ellison, 2011). Figure 29 shows the relative positions of the polymorphisms in the WNK4 kinase with the number of deleterious predictions. Further in vitro experiments should follow to illustrate the actual role of these polymorphisms on the function and activity of the WNK4. A direct idea would be to study the kinase activity of the protein (Ahlstrom and Yu, 2009). In general, two approaches could be applicable: The first classical approach for such an experiment is to get a considerable purified amount of the kinase (WNK4) and to incubate it with radioactive ATP and a substrate (SPAK or OSR1), followed by kinase activity measurement. The second suggested approach is to measure the phosphorylated substrate of the kinase with a method like western blot. Both of the last mentioned approaches are not perfectly established yet and there could be a lot of difficulties and weak points in between. Difficulties and weak points could be: Getting the purified WNK4, getting a specific anti-phospho-substrate of the kinase and choosing the best specific activator of the WNK4 alone.

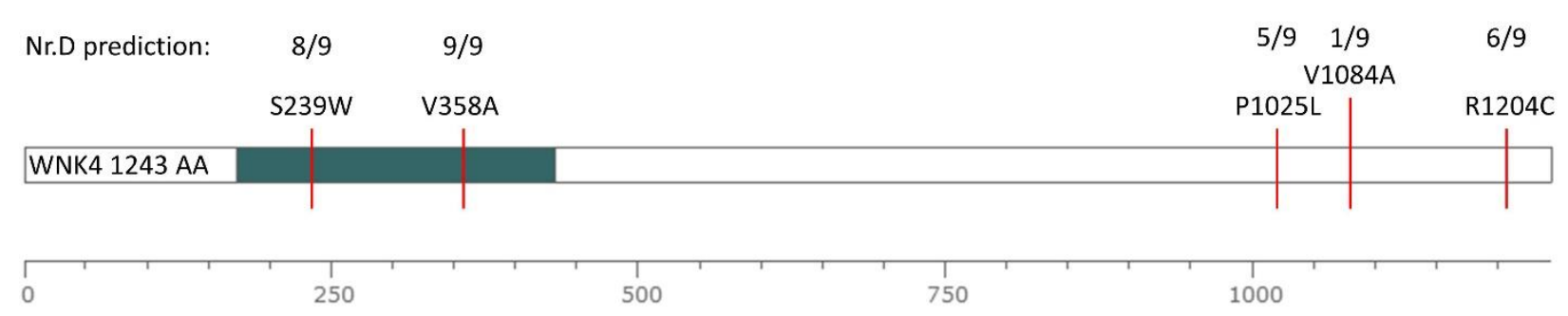

Figure 29: WNK4 detected polymorphisms

Nr. D prediction is the number of deleterious predictions by the used tools for the corresponding polymorphism. The kinase region is marked with dark green where two detected polymorphisms are predicted to have a deleterious effects on the protein. 


\subsection{Conclusion}

Two aldosterone receptor polymorphisms, rs3857080 more strongly than Ile180Val, appeared to affect renal electrolyte handling under moderate salt restriction and diuretic intake. In particular, carriers of the A-allele of rs3857080 may be more prone to hypokalemia from diuretic therapy and its devastating consequences than carriers of the major G-allele. The Aallele of rs3857080 may predict a sub-optimal outcome from diuretic therapy and heart diseases. Interestingly, the possible antialdosteronergic effect of torsemide may counteract genotype-dependent potassium excretion and torsemide may thus be indicated in carriers of the A-allele. One may hypothesize that spironolactone or eplerenone similarly attenuate or abolish the effect of rs3857080. Most of the work on NR3C2 was focused on its posttranslational role as transcription factor, but non as known have reported the effects on NR3C2 gene pre-translational (Rogerson et al., 2004). In vitro results indicate that rs3857080 may affect the binding of the transcription factor LHX4 and may thus itself be a functional rather than a marker polymorphism. The effects of lle180Val appeared less consistent. However, given the considerable effect sizes after triamterene, further research appears warranted. Hypertensive valine carriers may e.g. profit from triamterene more than expected. In conclusion, rs3857080, more than lle180Val, is a new, highly promising candidate for further in vitro studies and clinical research.

WNK4 is considered as disease gene, and seems to be not polymorphic. Genotyping all the exons for 229 healthy volunteers from two clinical studies revealed five polymorphisms. Two of these polymorphisms were novel and located in the kinase region. Both polymorphisms were predicted by the bioinformatics tools to have a deleterious effect on the protein function. In Vitro studies should follow to confirm the consistency with the bioinformatics findings. 


\section{References}

Adrogue, H.J., and Madias, N.E. (2007). Sodium and potassium in the pathogenesis of hypertension. N Engl J Med 356, 1966-1978.

Ahlstrom, R., and Yu, A.S. (2009). Characterization of the kinase activity of a WNK4 protein complex. American journal of physiology Renal physiology 297, F685-692.

Arroyo, J.P., Ronzaud, C., Lagnaz, D., Staub, O., and Gamba, G. (2011). Aldosterone paradox: differential regulation of ion transport in distal nephron. Physiology (Bethesda) 26, 115123.

Barlassina, C., Dal Fiume, C., Lanzani, C., Manunta, P., Guffanti, G., Ruello, A., Bianchi, G., Del Vecchio, L., Macciardi, F., and Cusi, D. (2007). Common genetic variants and haplotypes in renal CLCNKA gene are associated to salt-sensitive hypertension. Hum Mol Genet 16, 1630-1638.

Berger, S., Bleich, M., Schmid, W., Cole, T.J., Peters, J., Watanabe, H., Kriz, W., Warth, R., Greger, R., and Schutz, G. (1998). Mineralocorticoid receptor knockout mice: pathophysiology of $\mathrm{Na}+$ metabolism. Proceedings of the National Academy of Sciences of the United States of America 95, 9424-9429.

Binart, N., Lombes, M., Rafestin-Oblin, M.E., and Baulieu, E.E. (1991). Characterization of human mineralocorticosteroid receptor expressed in the baculovirus system. Proceedings of the National Academy of Sciences of the United States of America 88, 10681-10685.

Boron, W.F., and Boulpaep, E.L. (2012). Medical physiology : a cellular and molecular approach, 2nd edn (Philadelphia, Pa.: Saunders/Elsevier).

Bromberg, Y., and Rost, B. (2007). SNAP: predict effect of non-synonymous polymorphisms on function. Nucleic acids research 35, 3823-3835.

Calabrese, R., Capriotti, E., Fariselli, P., Martelli, P.L., and Casadio, R. (2009). Functional annotations improve the predictive score of human disease-related mutations in proteins. Human mutation 30, 1237-1244.

Castaneda-Bueno, M., Arroyo, J.P., and Gamba, G. (2012). Independent regulation of Na+ and $\mathrm{K}+$ balance by the kidney. Medical principles and practice : international journal of the Kuwait University, Health Science Centre 21, 101-114.

Catron, K.M., Iler, N., and Abate, C. (1993). Nucleotides flanking a conserved TAAT core dictate the DNA binding specificity of three murine homeodomain proteins. Molecular and cellular biology 13, 2354-2365.

Cavallari, L.H., Groo, V.L., Viana, M.A., Dai, Y., Patel, S.R., and Stamos, T.D. (2010). Association of aldosterone concentration and mineralocorticoid receptor genotype with potassium response to spironolactone in patients with heart failure. Pharmacotherapy 30, 1-9.

Chobanian, A.V., Bakris, G.L., Black, H.R., Cushman, W.C., Green, L.A., Izzo, J.L., Jr., Jones, D.W., Materson, B.J., Oparil, S., Wright, J.T., Jr., et al. (2003). The Seventh Report of the Joint National Committee on Prevention, Detection, Evaluation, and Treatment of High Blood Pressure: the JNC 7 report. JAMA 289, 2560-2572.

Chun, T.Y., Bankir, L., Eckert, G.J., Bichet, D.G., Saha, C., Zaidi, S.A., Wagner, M.A., and Pratt, J.H. (2008). Ethnic differences in renal responses to furosemide. Hypertension 52, 241-248.

Committee, J.F. (2013). British National Formulary (Pharmaceutical Press). 
Derijk, R.H., van Leeuwen, N., Klok, M.D., and Zitman, F.G. (2008). Corticosteroid receptor-gene variants: modulators of the stress-response and implications for mental health. Eur J Pharmacol 585, 492-501.

DeRijk, R.H., Wust, S., Meijer, O.C., Zennaro, M.C., Federenko, I.S., Hellhammer, D.H., Giacchetti, G., Vreugdenhil, E., Zitman, F.G., and de Kloet, E.R. (2006). A common polymorphism in the mineralocorticoid receptor modulates stress responsiveness. J Clin Endocrinol Metab 91, 5083-5089.

Dignam, J.D., Lebovitz, R.M., and Roeder, R.G. (1983). Accurate transcription initiation by RNA polymerase II in a soluble extract from isolated mammalian nuclei. Nucleic Acids Res 11, 1475-1489.

Erlich, P.M., Cui, J., Chazaro, I., Farrer, L.A., Baldwin, C.T., Gavras, H., and DeStefano, A.L. (2003). Genetic variants of WNK4 in whites and African Americans with hypertension. Hypertension 41, 1191-1195.

Flatman, P.W. (2007). Cotransporters, WNKs and hypertension: important leads from the study of monogenetic disorders of blood pressure regulation. Clin Sci (Lond) 112, 203-216.

Fodstad, H., Gonzalez-Rodriguez, E., Bron, S., Gaeggeler, H., Guisan, B., Rossier, B.C., and Horisberger, J.D. (2009). Effects of mineralocorticoid and $\mathrm{K}+$ concentration on $\mathrm{K}+$ secretion and ROMK channel expression in a mouse cortical collecting duct cell line. American journal of physiology Renal physiology 296, F966-975.

Frisoli, T.M., Schmieder, R.E., Grodzicki, T., and Messerli, F.H. (2012). Salt and hypertension: is salt dietary reduction worth the effort? Am J Med 125, 433-439.

Funder, J.W. (2005). The nongenomic actions of aldosterone. Endocrine reviews 26, 313-321.

Ghosh, T.K., Packham, E.A., Bonser, A.J., Robinson, T.E., Cross, S.J., and Brook, J.D. (2001). Characterization of the TBX5 binding site and analysis of mutations that cause Holt-Oram syndrome. Hum Mol Genet 10, 1983-1994.

Goodfriend, T.L., Ball, D.L., Oelkers, W., and Bahr, V. (1998). Torsemide inhibits aldosterone secretion in vitro. Life sciences 63, PL45-50.

Halperin, M.L., Cheema-Dhadli, S., Lin, S.H., and Kamel, K.S. (2006). Control of potassium excretion: a Paleolithic perspective. Curr Opin Nephrol Hypertens 15, 430-436.

Hanks, S.K., Quinn, A.M., and Hunter, T. (1988). The protein kinase family: conserved features and deduced phylogeny of the catalytic domains. Science $241,42-52$.

Holden, S., Cox, J., and Raymond, F.L. (2004). Cloning, genomic organization, alternative splicing and expression analysis of the human gene WNK3 (PRKWNK3). Gene 335, 109-119.

Hoorn, E.J., Nelson, J.H., McCormick, J.A., and Ellison, D.H. (2011). The WNK kinase network regulating sodium, potassium, and blood pressure. J Am Soc Nephrol 22, 605-614.

Huang, C.-L., Yang, S.-S., and Lin, S.-H. (2008). Mechanism of regulation of renal ion transport by WNK kinases. Current Opinion in Nephrology and Hypertension 17, 519-525 510.1097/MNH.1090b1013e32830dd32580.

Iwai, N., Tago, N., Yasui, N., Kokubo, Y., Inamoto, N., Tomoike, H., and Shioji, K. (2004). Genetic analysis of 22 candidate genes for hypertension in the Japanese population. J Hypertens 22, 1119-1126.

Kahle, K.T., Gimenez, I., Hassan, H., Wilson, F.H., Wong, R.D., Forbush, B., Aronson, P.S., and Lifton, R.P. (2004). WNK4 regulates apical and basolateral Cl- flux in extrarenal epithelia. 
Proceedings of the National Academy of Sciences of the United States of America 101, 2064-2069.

Klok, M.D., Vreeburg, S.A., Penninx, B.W., Zitman, F.G., de Kloet, E.R., and DeRijk, R.H. (2011). Common functional mineralocorticoid receptor polymorphisms modulate the cortisol awakening response: Interaction with SSRIs. Psychoneuroendocrinology 36, 484-494.

Knighton, D.R., Zheng, J.H., Ten Eyck, L.F., Ashford, V.A., Xuong, N.H., Taylor, S.S., and Sowadski, J.M. (1991). Crystal structure of the catalytic subunit of cyclic adenosine monophosphatedependent protein kinase. Science 253, 407-414.

Kortmann, G.L., Contini, V., Bertuzzi, G.P., Mota, N.R., Rovaris, D.L., Paixao-Cortes, V.R., de Lima, L.L., Grevet, E.H., Salgado, C.A., Vitola, E.S., et al. (2013). The role of a mineralocorticoid receptor gene functional polymorphism in the symptom dimensions of persistent ADHD. Eur Arch Psychiatry Clin Neurosci 263, 181-188.

Lalioti, M.D., Zhang, J., Volkman, H.M., Kahle, K.T., Hoffmann, K.E., Toka, H.R., Nelson-Williams, C., Ellison, D.H., Flavell, R., Booth, C.J., et al. (2006). Wnk4 controls blood pressure and potassium homeostasis via regulation of mass and activity of the distal convoluted tubule. Nat Genet 38, 1124-1132.

Lang, F., Capasso, G., Schwab, M., and Waldegger, S. (2005). Renal tubular transport and the genetic basis of hypertensive disease. Clin Exp Nephrol 9, 91-99.

Le Moellic, C., Ouvrard-Pascaud, A., Capurro, C., Cluzeaud, F., Fay, M., Jaisser, F., Farman, N., and Blot-Chabaud, M. (2004). Early nongenomic events in aldosterone action in renal collecting duct cells: PKCalpha activation, mineralocorticoid receptor phosphorylation, and cross-talk with the genomic response. J Am Soc Nephrol 15, 1145-1160.

Li, B., Krishnan, V.G., Mort, M.E., Xin, F., Kamati, K.K., Cooper, D.N., Mooney, S.D., and Radivojac, P. (2009). Automated inference of molecular mechanisms of disease from amino acid substitutions. Bioinformatics 25, 2744-2750.

Lifton, R.P., Gharavi, A.G., and Geller, D.S. (2001). Molecular mechanisms of human hypertension. Cell 104, 545-556.

Lombes, M., Binart, N., Delahaye, F., Baulieu, E.E., and Rafestin-Oblin, M.E. (1994). Differential intracellular localization of human mineralocorticosteroid receptor on binding of agonists and antagonists. The Biochemical journal 302 ( Pt 1), 191-197.

Machinis, K., and Amselem, S. (2005). Functional relationship between LHX4 and POU1F1 in light of the LHX4 mutation identified in patients with pituitary defects. J Clin Endocrinol Metab 90, 5456-5462.

Machnik, A., Neuhofer, W., Jantsch, J., Dahlmann, A., Tammela, T., Machura, K., Park, J.K., Beck, F.X., Muller, D.N., Derer, W., et al. (2009). Macrophages regulate salt-dependent volume and blood pressure by a vascular endothelial growth factor-C-dependent buffering mechanism. Nat Med 15, 545-552.

Mancia, G., Fagard, R., Narkiewicz, K., Redon, J., Zanchetti, A., Bohm, M., Christiaens, T., Cifkova, R., De Backer, G., Dominiczak, A., et al. (2013). 2013 ESH/ESC Guidelines for the management of arterial hypertension: The Task Force for the management of arterial hypertension of the European Society of Hypertension (ESH) and of the European Society of Cardiology (ESC). J Hypertens 31, 1281-1357. 
Martinez, F., Mansego, M.L., Escudero, J.C., Redon, J., and Chaves, F.J. (2009). Association of a mineralocorticoid receptor gene polymorphism with hypertension in a Spanish population. Am J Hypertens 22, 649-655.

Matayoshi, T., Kamide, K., Takiuchi, S., Yoshii, M., Miwa, Y., Takami, Y., Tanaka, C., Banno, M., Horio, T., Nakamura, S., et al. (2004). The thiazide-sensitive $\mathrm{Na}(+)-\mathrm{Cl}(-)$ cotransporter gene, C1784T, and adrenergic receptor-beta3 gene, T727C, may be gene polymorphisms susceptible to the antihypertensive effect of thiazide diuretics. Hypertens Res 27, 821-833.

Mayan, H., Vered, I., Mouallem, M., Tzadok-Witkon, M., Pauzner, R., and Farfel, Z. (2002). Pseudohypoaldosteronism type II: marked sensitivity to thiazides, hypercalciuria, normomagnesemia, and low bone mineral density. J Clin Endocrinol Metab 87, 3248-3254.

McCormick, J.A., and Ellison, D.H. (2011). The WNKs: atypical protein kinases with pleiotropic actions. Physiol Rev 91, 177-219.

McMurray, J.J., Adamopoulos, S., Anker, S.D., Auricchio, A., Bohm, M., Dickstein, K., Falk, V., Filippatos, G., Fonseca, C., Gomez-Sanchez, M.A., et al. (2012). ESC Guidelines for the diagnosis and treatment of acute and chronic heart failure 2012: The Task Force for the Diagnosis and Treatment of Acute and Chronic Heart Failure 2012 of the European Society of Cardiology. Developed in collaboration with the Heart Failure Association (HFA) of the ESC. European heart journal 33, 1787-1847.

Mick, V.E., Itani, O.A., Loftus, R.W., Husted, R.F., Schmidt, T.J., and Thomas, C.P. (2001). The alpha-subunit of the epithelial sodium channel is an aldosterone-induced transcript in mammalian collecting ducts, and this transcriptional response is mediated via distinct ciselements in the 5'-flanking region of the gene. Molecular endocrinology 15, 575-588.

Montasser, M.E., Gu, D., Chen, J., Shimmin, L.C., Gu, C., Kelly, T.N., Jaquish, C.E., Rice, T., Rao, D.C., Cao, J., et al. (2011). Interactions of genetic variants with physical activity are associated with blood pressure in Chinese: the GenSalt study. Am J Hypertens 24, 10351040.

Morales-Suarez-Varela, M.M., Mansego, M.L., Vicedo-Cabrera, A.M., Pineda-Alonso, M., LlopisGonzalez, A., Martin-Moreno, J.M., Martin-Escudero, J.C., and Chaves, F.J. (2011). Inefficient arterial hypertension control in patients with metabolic syndrome and its link to renin-angiotensin-aldosterone system polymorphisms. Hypertens Res 34, 758-766.

Morrison, N., Harrap, S.B., Arriza, J.L., Boyd, E., and Connor, J.M. (1990). Regional chromosomal assignment of the human mineralocorticoid receptor gene to $4 q 31.1$. Hum Genet 85,130 132.

Mullen, R.D., Colvin, S.C., Hunter, C.S., Savage, J.J., Walvoord, E.C., Bhangoo, A.P., Ten, S., Weigel, J., Pfaffle, R.W., and Rhodes, S.J. (2007). Roles of the LHX3 and LHX4 LIMhomeodomain factors in pituitary development. Mol Cell Endocrinol 265-266, 190-195.

Newhouse, S., Farrall, M., Wallace, C., Hoti, M., Burke, B., Howard, P., Onipinla, A., Lee, K., Shaw-Hawkins, S., Dobson, R., et al. (2009). Polymorphisms in the WNK1 gene are associated with blood pressure variation and urinary potassium excretion. PLoS One 4, e5003.

Nossent, A.Y., Hansen, J.L., Doggen, C., Quax, P.H., Sheikh, S.P., and Rosendaal, F.R. (2011). SNPs in microRNA binding sites in 3'-UTRs of RAAS genes influence arterial blood pressure and risk of myocardial infarction. Am J Hypertens 24, 999-1006. 
O'Reilly, M., Marshall, E., Speirs, H.J., and Brown, R.W. (2003). WNK1, a gene within a novel blood pressure control pathway, tissue-specifically generates radically different isoforms with and without a kinase domain. J Am Soc Nephrol 14, 2447-2456.

O'Shaughnessy, K.M., and Karet, F.E. (2006). Salt handling and hypertension. Annual review of nutrition 26, 343-365.

Pan, Y., Wang, K.S., and Aragam, N. (2011). NTM and NR3C2 polymorphisms influencing intelligence: family-based association studies. Prog Neuropsychopharmacol Biol Psychiatry 35, 154-160.

Pearce, D., and Kleyman, T.R. (2007). Salt, sodium channels, and SGK1. J Clin Invest 117, 592595.

Richardson, C., and Alessi, D.R. (2008). The regulation of salt transport and blood pressure by the WNK-SPAK/OSR1 signalling pathway. J Cell Sci 121, 3293-3304.

Roeseler, D.A., Sachdev, S., Buckley, D.M., Joshi, T., Wu, D.K., Xu, D., Hannink, M., and Waters, S.T. (2012). Elongation factor 1 alpha1 and genes associated with Usher syndromes are downstream targets of GBX2. PLoS One 7, e47366.

Rogerson, F.M., Brennan, F.E., and Fuller, P.J. (2004). Mineralocorticoid receptor binding, structure and function. Mol Cell Endocrinol 217, 203-212.

Rovaris, D.L., Mota, N.R., de Azeredo, L.A., Cupertino, R.B., Bertuzzi, G.P., Polina, E.R., Contini, V., Kortmann, G.L., Vitola, E.S., Grevet, E.H., et al. (2013). MR and GR functional SNPs may modulate tobacco smoking susceptibility. J Neural Transm.

Rudy, D.W., Gehr, T.W., Matzke, G.R., Kramer, W.G., Sica, D.A., and Brater, D.C. (1994). The pharmacodynamics of intravenous and oral torsemide in patients with chronic renal insufficiency. Clin Pharmacol Ther 56, 39-47.

Schwarz, J.M., Rodelsperger, C., Schuelke, M., and Seelow, D. (2010). MutationTaster evaluates disease-causing potential of sequence alterations. Nature methods 7, 575-576.

Seva Pessoa, B., van der Lubbe, N., Verdonk, K., Roks, A.J., Hoorn, E.J., and Danser, A.H. (2013). Key developments in renin-angiotensin-aldosterone system inhibition. Nature reviews Nephrology 9, 26-36.

Song, S.B., Jin, H.S., Hong, K.W., Lim, J.E., Moon, J.Y., Jeong, K.H., Ihm, C.G., Lee, T.W., Oh, B., and Lee, S.H. (2011). Association between renin-angiotensin-aldosterone system-related genes and blood pressure in a Korean population. Blood Press 20, 204-210.

Svensson-Farbom, P., Wahlstrand, B., Almgren, P., Dahlberg, J., Fava, C., Kjeldsen, S., Hedner, T., and Melander, O. (2011). A functional variant of the NEDD4L gene is associated with beneficial treatment response with beta-blockers and diuretics in hypertensive patients. J Hypertens 29, 388-395.

Tobin, M.D., Raleigh, S.M., Newhouse, S., Braund, P., Bodycote, C., Ogleby, J., Cross, D., Gracey, J., Hayes, S., Smith, T., et al. (2005). Association of WNK1 gene polymorphisms and haplotypes with ambulatory blood pressure in the general population. Circulation 112, 3423-3429.

Tobin, M.D., Tomaszewski, M., Braund, P.S., Hajat, C., Raleigh, S.M., Palmer, T.M., Caulfield, M., Burton, P.R., and Samani, N.J. (2008). Common variants in genes underlying monogenic hypertension and hypotension and blood pressure in the general population. Hypertension 51, 1658-1664. 
Turner, S.T., Schwartz, G.L., Chapman, A.B., and Boerwinkle, E. (2005). WNK1 kinase polymorphism and blood pressure response to a thiazide diuretic. Hypertension 46, 758765.

Uchida, T., Yamanaga, K., Nishikawa, M., Ohtaki, Y., Kido, H., and Watanabe, M. (1991). Antialdosteronergic effect of torasemide. Eur J Pharmacol 205, 145-150.

van de Wetering, M., Oosterwegel, M., van Norren, K., and Clevers, H. (1993). Sox-4, an Sry-like HMG box protein, is a transcriptional activator in lymphocytes. The EMBO journal 12, 3847-3854.

van Leeuwen, N., Bellingrath, S., de Kloet, E.R., Zitman, F.G., DeRijk, R.H., Kudielka, B.M., and Wust, S. (2011). Human mineralocorticoid receptor (MR) gene haplotypes modulate MR expression and transactivation: implication for the stress response. Psychoneuroendocrinology 36, 699-709.

van Leeuwen, N., Caprio, M., Blaya, C., Fumeron, F., Sartorato, P., Ronconi, V., Giacchetti, G., Mantero, F., Fernandes-Rosa, F.L., Simian, C., et al. (2010). The functional C.-2G>C variant of the mineralocorticoid receptor modulates blood pressure, renin, and aldosterone levels. Hypertension 56, 995-1002.

Vargo, D.L., Kramer, W.G., Black, P.K., Smith, W.B., Serpas, T., and Brater, D.C. (1995). Bioavailability, pharmacokinetics, and pharmacodynamics of torsemide and furosemide in patients with congestive heart failure. Clin Pharmacol Ther 57, 601-609.

Verissimo, F., and Jordan, P. (2001). WNK kinases, a novel protein kinase subfamily in multicellular organisms. Oncogene 20, 5562-5569.

Viengchareun, S., Le Menuet, D., Martinerie, L., Munier, M., Pascual-Le Tallec, L., and Lombes, M. (2007). The mineralocorticoid receptor: insights into its molecular and (patho)physiological biology. Nucl Recept Signal 5, e012.

Vormfelde, S.V., and Brockmoller, J. (2012). The genetics of loop diuretic effects. Pharmacogenomics J 12, 45-53.

Vormfelde, S.V., Sehrt, D., Bolte, D., Pahl, S., Tzvetkov, M., and Brockmoller, J. (2006). Hydrochlorothiazide efficacy and polymorphisms in ACE, ADD1 and GNB3 in healthy, male volunteers. Eur J Clin Pharmacol 62, 195-201.

Vormfelde, S.V., Sehrt, D., Toliat, M.R., Schirmer, M., Meineke, I., Tzvetkov, M., Nurnberg, P., and Brockmoller, J. (2007). Genetic variation in the renal sodium transporters NKCC2, NCC, and $\mathrm{ENaC}$ in relation to the effects of loop diuretic drugs. Clin Pharmacol Ther 82, 300-309.

Vormfelde, S.V., Toliat, M.R., Nurnberg, P., and Brockmoller, J. (2010). Atrial natriuretic peptide polymorphisms, hydrochlorothiazide and urinary potassium excretion. International journal of cardiology 144, 72-74.

Welling, P.A., Chang, Y.P., Delpire, E., and Wade, J.B. (2010). Multigene kinase network, kidney transport, and salt in essential hypertension. Kidney Int 77, 1063-1069.

Wilson, F.H., Disse-Nicodeme, S., Choate, K.A., Ishikawa, K., Nelson-Williams, C., Desitter, I., Gunel, M., Milford, D.V., Lipkin, G.W., Achard, J.M., et al. (2001). Human hypertension caused by mutations in WNK kinases. Science 293, 1107-1112.

Wingender, E. (2008). The TRANSFAC project as an example of framework technology that supports the analysis of genomic regulation. Briefings in bioinformatics 9, 326-332. 
Xu, B., English, J.M., Wilsbacher, J.L., Stippec, S., Goldsmith, E.J., and Cobb, M.H. (2000). WNK1, a novel mammalian serine/threonine protein kinase lacking the catalytic lysine in subdomain II. The Journal of biological chemistry 275, 16795-16801.

Xu, Q., Modrek, B., and Lee, C. (2002). Genome-wide detection of tissue-specific alternative splicing in the human transcriptome. Nucleic Acids Res 30, 3754-3766.

Yancy, C.W., Jessup, M., Bozkurt, B., Butler, J., Casey, D.E., Jr., Drazner, M.H., Fonarow, G.C., Geraci, S.A., Horwich, T., Januzzi, J.L., et al. (2013). 2013 ACCF/AHA Guideline for the Management of Heart Failure: A Report of the American College of Cardiology Foundation/American Heart Association Task Force on Practice Guidelines. Circulation. 


\section{Supplementary materials}

\subsubsection{Genotyped polymorphisms, allele frequencies and Chi square calculations for Hardy-}

Weinberg disequilibrium

The total number of genotyped participants was 229. 110 were from the first clinical study, and 119 from the second one. Calculations were done as the following:

$$
\text { Allele frequency }(A F)=\frac{(2 \times N r . \text { homozygous subjects })+N r . \text { heterozygous subjects }}{2 \times N r . \text { genotyped subjects }}
$$

$$
\begin{gathered}
\text { Expected }(A / A \text { or } B / B) \text { genotypes }=\text { Allele frequency } A(\text { or } B) \\
\times \text { Allele frequency } A(\text { or } B) \times N r \text {.genotyped subjects } \\
\text { Equation 2: Expected }(A) / A \text { or } B / B) \text { genotypes }
\end{gathered}
$$

Expected $(A / B)$ genotypes $=$ Allele frequency $A \times$ Allele frequency $B$ $\times N r$ genotyped subjects

Equation 3:Expected $(A / B)$ genotypes

The numbers in the following tables in the observed and expected columns are referring to the number of genotyped people (not the number of alleles).

\subsubsection{Clinical study 1 (loop diuretics)}

Supplementary table 1: Genotyped polymorphisms, allele frequencies and Chi square for the first clinical study

\begin{tabular}{lccccccccccc}
\hline \multicolumn{1}{c}{ Polymorphism } & \multicolumn{3}{c}{ Observed } & \multicolumn{3}{c}{ Expected } & \multicolumn{3}{c}{ Allele Frequency } \\
& A/A & A/B & B/B & A/A & A/B & B/B & & A & B & \\
\hline CLCNKa_rs1010069_G/A & 23 & 65 & 22 & 28 & 55 & 27 & 110 & 0.505 & 0.495 & 0.162 \\
KCNJ1_rs2846679_C/T & 86 & 24 & 0 & 87 & 21 & 1 & 110 & 0.891 & 0.109 & 0.438 \\
KCNJ1_rs76640813_G/A & NP & NP & NP & NP & NP & NP & NP & NP & NP & NP \\
KCNJ1_rs76937254_C/T & NP & NP & NP & NP & NP & NP & NP & NP & NP & NP \\
NEDD4L_rs2288774_G/A & 28 & 48 & 34 & 25 & 55 & 31 & 110 & 0.473 & 0.527 & 0.425 \\
NEDD4L_rs4149601_C/T & 38 & 65 & 7 & 45 & 51 & 14 & 110 & 0.641 & 0.359 & 0.012 \\
NR3C2_rs1040288_G/C & 38 & 57 & 15 & 40 & 53 & 17 & 110 & 0.605 & 0.395 & 0.680 \\
NR3C2_rs10519963_C/T & 86 & 21 & 3 & 85 & 24 & 2 & 110 & 0.877 & 0.123 & 0.493 \\
NR3C2_rs11099680_C/T & 52 & 52 & 6 & 55 & 45 & 9 & 110 & 0.709 & 0.291 & 0.310
\end{tabular}




\begin{tabular}{|c|c|c|c|c|c|c|c|c|c|c|}
\hline NR3C2_rs11099681_C/T & 52 & 52 & 6 & 55 & 45 & 9 & 110 & 0.709 & 0.291 & 0.310 \\
\hline NR3C2_rs11737660_G/A & 66 & 36 & 8 & 64 & 40 & 6 & 110 & 0.764 & 0.236 & 0.619 \\
\hline NR3C2_rs2070951_G/C & 28 & 56 & 26 & 29 & 55 & 27 & 110 & 0.509 & 0.491 & 0.981 \\
\hline NR3C2_rs3846329_C/A & 71 & 32 & 7 & 69 & 36 & 5 & 110 & 0.791 & 0.209 & 0.450 \\
\hline NR3C2_rs3857080_G/A & 87 & 22 & 1 & 87 & 21 & 1 & 110 & 0.891 & 0.109 & 0.955 \\
\hline NR3C2_rs4835493_G/A & 53 & 51 & 6 & 56 & 45 & 9 & 110 & 0.714 & 0.286 & 0.370 \\
\hline NR3C2_rs5522_G/A & 0 & 19 & 91 & 1 & 17 & 92 & 110 & 0.086 & 0.914 & 0.612 \\
\hline NR3C2_rs5534_C/T & 45 & 40 & 25 & 38 & 53 & 18 & 110 & 0.591 & 0.409 & 0.034 \\
\hline NR3C2_rs6810951_C/A & 37 & 59 & 14 & 40 & 53 & 17 & 110 & 0.605 & 0.395 & 0.442 \\
\hline OXSR1_rs113919536_C/A & NP & NP & NP & NP & NP & NP & NP & NP & NP & NP \\
\hline OXSR1_rs35295772_A/T & NP & NP & NP & NP & NP & NP & NP & NP & NP & NP \\
\hline OXSR1_rs457661_G/A & NP & NP & NP & NP & NP & NP & NP & NP & NP & NP \\
\hline OXSR1_rs6599079_G/A & 86 & 23 & 1 & 86 & 22 & 1 & 110 & 0.886 & 0.114 & 0.924 \\
\hline SGK1_rs1057293_C/T & 83 & 27 & 0 & 85 & 24 & 2 & 110 & 0.877 & 0.123 & 0.341 \\
\hline SGK1_rs9493857_C/T & 74 & 31 & 5 & 73 & 33 & 4 & 110 & 0.814 & 0.186 & 0.760 \\
\hline WNK1_rs1159744_G/C & 8 & 44 & 58 & 8 & 44 & 58 & 110 & 0.273 & 0.727 & 0.996 \\
\hline WNK1_rs2107614_G/A & 47 & 51 & 12 & 48 & 49 & 13 & 110 & 0.659 & 0.341 & 0.946 \\
\hline WNK1_rs2277869_C/T & 5 & 28 & 77 & 3 & 31 & 75 & 110 & 0.173 & 0.827 & 0.518 \\
\hline WNK1_rs3088353_G/T & 25 & 49 & 36 & 22 & 54 & 33 & 110 & 0.450 & 0.550 & 0.576 \\
\hline WNK1_rs765250_G/A & 13 & 50 & 47 & 13 & 50 & 47 & 110 & 0.345 & 0.655 & 0.999 \\
\hline FAM120C_rs2495801_C/T & 97 & $\operatorname{chr} X$ & 13 & $\operatorname{chr} \mathrm{X}$ & $\operatorname{chr} X$ & $\operatorname{chr} \mathrm{X}$ & 110 & 0.882 & 0.118 & $\operatorname{chr} X$ \\
\hline WNK3_rs3021280_G/T & 107 & $\operatorname{chr} X$ & 3 & $\operatorname{chr} X$ & $\operatorname{chr} X$ & $\operatorname{chr} X$ & 110 & 0.973 & 0.027 & $\operatorname{chr} X$ \\
\hline WNK3_rs3021284_A/T & 100 & $\operatorname{chr} X$ & 10 & $\operatorname{chr} X$ & $\operatorname{chr} X$ & $\operatorname{chr} X$ & 110 & 0.909 & 0.091 & $\operatorname{chr} X$ \\
\hline WNK3_rs3021285_C/T & 100 & $\operatorname{chr} X$ & 10 & $\operatorname{chr} X$ & $\operatorname{chr} X$ & $\operatorname{chr} X$ & 110 & 0.909 & 0.091 & $\operatorname{chr} \mathrm{X}$ \\
\hline WNK3_rs7880501_C/T & 107 & $\operatorname{chr} X$ & 3 & $\operatorname{chr} X$ & $\operatorname{chr} X$ & $\operatorname{chr} X$ & 110 & 0.973 & 0.027 & $\operatorname{chr} \mathrm{X}$ \\
\hline WNK4_rs61755606_G/A & 91 & 18 & 1 & 91 & 18 & 1 & 110 & 0.909 & 0.091 & 0.995 \\
\hline WNK4_rs75596106_G/C & NP & NP & NP & NP & NP & NP & NP & NP & NP & $\mathrm{NP}$ \\
\hline WNK4_rs77012584_C/T & NP & NP & NP & NP & NP & NP & NP & NP & NP & NP \\
\hline WNK4_rs77879367_G/T & NP & NP & NP & NP & NP & NP & NP & NP & NP & NP \\
\hline WNK4_rs78645838_G/A & 99 & 11 & 0 & 99 & 10 & 0 & 110 & 0.950 & 0.050 & 0.859 \\
\hline
\end{tabular}

NP not polymorphic

\subsubsection{Clinical study 2 (Thiazide and Triamterene)}

Supplementary table 2: Genotyped polymorphisms, allele frequencies and Chi square for the second clinical study

\begin{tabular}{lcccccccccc}
\hline Polymorphism & \multicolumn{3}{c}{ Observed } & \multicolumn{3}{c}{ Expected } & \multicolumn{3}{c}{ Allele Frequency Chi Sqr } \\
& A/A & A/B & B/B & A/A & A/B & B/B & & Total & B \\
\hline CLCNKa_rs1010069_G/A & 36 & 60 & 23 & 37 & 59 & 24 & 119 & 0.555 & 0.445 & 0.975 \\
KCNJ1_rs2846679_C/T & 83 & 32 & 4 & 82 & 33 & 3 & 119 & 0.832 & 0.168 & 0.916 \\
KCNJ1_rs76640813_G/A & NP & NP & NP & NP & NP & NP & NP & NP & NP & NP \\
KCNJ1_rs76937254_C/T & NP & NP & NP & NP & NP & NP & NP & NP & NP & NP \\
NEDD4L_rs2288774_G/A & 25 & 60 & 34 & 25 & 59 & 34 & 119 & 0.462 & 0.538 & 0.988 \\
NEDD4L_rs4149601_C/T & 57 & 50 & 12 & 57 & 51 & 12 & 119 & 0.689 & 0.311 & 0.978
\end{tabular}




\begin{tabular}{|c|c|c|c|c|c|c|c|c|c|c|}
\hline NR3C2_rs1040288_G/C & 37 & 56 & 26 & 36 & 59 & 25 & 119 & 0.55 & 0.45 & 0.858 \\
\hline NR3C2_rs10519963_C/T & 89 & 25 & 5 & 87 & 30 & 3 & 119 & 0.85 & 0.15 & 0.208 \\
\hline NR3C2_rs11099680_C/T & 63 & 44 & 12 & 61 & 49 & 10 & 119 & 0.71 & 0.29 & 0.590 \\
\hline NR3C2_rs11099681_C/T & 62 & 45 & 12 & 60 & 49 & 10 & 119 & 0.71 & 0.29 & 0.673 \\
\hline NR3C2_rs11737660_G/A & 72 & 38 & 9 & 70 & 43 & 7 & 119 & 0.76 & 0.24 & 0.470 \\
\hline NR3C2_rs2070951_G/C & 33 & 57 & 29 & 32 & 59 & 28 & 119 & 0.517 & 0.483 & 0.905 \\
\hline NR3C2_rs3846329_C/A & 73 & 39 & 7 & 72 & 41 & 6 & 119 & 0.78 & 0.22 & 0.844 \\
\hline NR3C2_rs3857080_G/A & 93 & 25 & 1 & 94 & 24 & 2 & 119 & 0.887 & 0.113 & 0.889 \\
\hline NR3C2_rs4835493_G/A & 63 & 44 & 12 & 61 & 49 & 10 & 119 & 0.71 & 0.29 & 0.590 \\
\hline NR3C2_rs5522_G/A & 1 & 24 & 94 & 1 & 23 & 94 & 119 & 0.109 & 0.891 & 0.925 \\
\hline NR3C2_rs5534_C/T & 43 & 54 & 22 & 41 & 58 & 20 & 119 & 0.59 & 0.41 & 0.788 \\
\hline NR3C2_rs6810951_C/A & 43 & 61 & 15 & 45 & 56 & 17 & 119 & 0.62 & 0.38 & 0.649 \\
\hline OXSR1_rs113919536_C/A & NP & NP & NP & NP & NP & NP & NP & NP & NP & NP \\
\hline OXSR1_rs35295772_A/T & NP & NP & NP & NP & NP & NP & NP & NP & NP & NP \\
\hline OXSR1_rs457661_G/A & NP & NP & NP & NP & NP & NP & NP & NP & NP & NP \\
\hline OXSR1_rs6599079_G/A & 98 & 19 & 2 & 97 & 21 & 1 & 119 & 0.903 & 0.097 & 0.647 \\
\hline SGK1_rs1057293_C/T & 92 & 25 & 2 & 92 & 25 & 2 & 119 & 0.878 & 0.122 & 0.980 \\
\hline SGK1_rs9493857_C/T & 74 & 43 & 2 & 77 & 38 & 5 & 119 & 0.803 & 0.197 & 0.311 \\
\hline WNK1_rs1159744_G/C & 2 & 45 & 72 & 5 & 39 & 75 & 119 & 0.206 & 0.794 & 0.233 \\
\hline WNK1_rs2107614_G/A & 65 & 50 & 4 & 68 & 44 & 7 & 119 & 0.756 & 0.244 & 0.312 \\
\hline WNK1_rs2277869_C/T & 7 & 32 & 80 & 4 & 37 & 77 & 119 & 0.193 & 0.807 & 0.324 \\
\hline WNK1_rs3088353_G/T & 36 & 46 & 37 & 29 & 59 & 30 & 119 & 0.496 & 0.504 & 0.047 \\
\hline WNK1_rs765250_G/A & 4 & 51 & 64 & 7 & 44 & 67 & 119 & 0.248 & 0.752 & 0.265 \\
\hline FAM120C_rs2495801_C/T & 107 & $\operatorname{chr} X$ & 12 & $\operatorname{chr} X$ & $\operatorname{chr} X$ & $\operatorname{chr} X$ & 119 & 0.899 & 0.101 & $\operatorname{chr} \mathrm{X}$ \\
\hline WNK3_rs3021280_G/T & 117 & $\operatorname{chr} X$ & 2 & $\operatorname{chr} X$ & $\operatorname{chr} X$ & $\operatorname{chr} X$ & 119 & 0.983 & 0.017 & $\operatorname{chr} X$ \\
\hline WNK3_rs3021284_A/T & 108 & $\operatorname{chr} X$ & 11 & $\operatorname{chr} X$ & $\operatorname{chr} X$ & $\operatorname{chr} X$ & 119 & 0.908 & 0.092 & $\operatorname{chr} X$ \\
\hline WNK3_rs3021285_C/T & 108 & $\operatorname{chr} X$ & 11 & $\operatorname{chr} X$ & $\operatorname{chr} X$ & $\operatorname{chr} X$ & 119 & 0.908 & 0.092 & $\operatorname{chr} X$ \\
\hline WNK3_rs7880501_C/T & 117 & $\operatorname{chr} X$ & 2 & $\operatorname{chr} X$ & $\operatorname{chr} X$ & $\operatorname{chr} X$ & 119 & 0.983 & 0.017 & $\operatorname{chr} X$ \\
\hline WNK4_rs61755606_G/A & 102 & 16 & 1 & 102 & 17 & 1 & 119 & 0.924 & 0.076 & 0.916 \\
\hline WNK4_rs75596106_G/C & NP & NP & NP & NP & NP & NP & NP & NP & NP & NP \\
\hline WNK4_rs77012584_C/T & NP & NP & NP & NP & NP & NP & NP & NP & NP & NP \\
\hline WNK4_rs77879367_G/T & NP & NP & NP & NP & NP & NP & NP & NP & NP & NP \\
\hline WNK4_rs78645838_G/A & 109 & 9 & 1 & 108 & 10 & 0 & 119 & 0.954 & 0.046 & 0.300 \\
\hline
\end{tabular}

NP not polymorphic

\subsubsection{Both clinical studies}

Supplementary table 3: Genotyped polymorphisms, allele frequencies and Chi square for the both clinical studies

\begin{tabular}{lcccccccccc}
\hline Polymorphism & \multicolumn{3}{c}{ Observed } & \multicolumn{3}{c}{ Expected } & \multicolumn{3}{c}{ Allele Frequency Chi Sqr } \\
& A/A & A/B & B/B & A/A & A/B & B/B & & A & B \\
\hline CLCNKa_rs1010069_G/A & 59 & 125 & 45 & 64 & 114 & 50 & 229 & 0.531 & 0.469 & 0.350 \\
KCNJ1_rs2846679_C/T & 169 & 56 & 4 & 169 & 55 & 4 & 229 & 0.860 & 0.140 & 0.967 \\
KCNJ1_rs76640813_G/A & NP & NP & NP & NP & NP & NP & NP & NP & NP & NP
\end{tabular}




\begin{tabular}{|c|c|c|c|c|c|c|c|c|c|c|}
\hline KCNJ1_rs76937254_C/T & NP & NP & NP & NP & NP & NP & NP & NP & NP & NP \\
\hline NEDD4L_rs2288774_G/A & 68 & 108 & 53 & 65 & 114 & 50 & 229 & 0.533 & 0.467 & 0.728 \\
\hline NEDD4L_rs4149601_C/T & 95 & 115 & 19 & 102 & 102 & 26 & 229 & 0.666 & 0.334 & 0.150 \\
\hline NR3C2_rs1040288_G/C & 75 & 113 & 41 & 76 & 112 & 42 & 229 & 0.574 & 0.426 & 0.990 \\
\hline NR3C2_rs10519963_C/T & 175 & 46 & 8 & 171 & 54 & 4 & 229 & 0.865 & 0.135 & 0.100 \\
\hline NR3C2_rs11099680_C/T & 115 & 96 & 18 & 116 & 94 & 19 & 229 & 0.712 & 0.288 & 0.947 \\
\hline NR3C2_rs11099681_C/T & 114 & 97 & 18 & 115 & 94 & 19 & 229 & 0.710 & 0.290 & 0.915 \\
\hline NR3C2_rs11737660_G/A & 138 & 74 & 17 & 134 & 83 & 13 & 229 & 0.764 & 0.236 & 0.294 \\
\hline NR3C2_rs2070951_G/C & 61 & 113 & 55 & 60 & 114 & 54 & 229 & 0.513 & 0.487 & 0.982 \\
\hline NR3C2_rs3846329_C/A & 144 & 71 & 14 & 141 & 78 & 11 & 229 & 0.784 & 0.216 & 0.437 \\
\hline NR3C2_rs3857080_G/A & 180 & 47 & 2 & 181 & 45 & 3 & 229 & 0.889 & 0.111 & 0.855 \\
\hline NR3C2_rs4835493_G/A & 116 & 95 & 18 & 117 & 94 & 19 & 229 & 0.714 & 0.286 & 0.972 \\
\hline NR3C2_rs5522_G/A & 185 & 43 & 1 & 186 & 41 & 2 & 229 & 0.902 & 0.098 & 0.665 \\
\hline NR3C2_rs5534_C/T & 88 & 94 & 47 & 80 & 111 & 39 & 229 & 0.590 & 0.410 & 0.071 \\
\hline NR3C2_rs6810951_C/A & 80 & 120 & 29 & 86 & 109 & 35 & 229 & 0.611 & 0.389 & 0.299 \\
\hline OXSR1_rs113919536_C/A & NP & NP & NP & NP & NP & NP & NP & NP & NP & NP \\
\hline OXSR1_rs35295772_A/T & NP & NP & NP & NP & NP & NP & NP & NP & NP & NP \\
\hline OXSR1_rs457661_G/A & NP & NP & NP & NP & NP & NP & NP & NP & NP & NP \\
\hline OXSR1_rs6599079_G/A & 184 & 42 & 3 & 184 & 43 & 3 & 229 & 0.895 & 0.105 & 0.943 \\
\hline SGK1_rs1057293_C/T & 175 & 52 & 2 & 176 & 49 & 3 & 229 & 0.878 & 0.122 & 0.681 \\
\hline SGK1_rs9493857_C/T & 148 & 74 & 7 & 149 & 71 & 8 & 229 & 0.808 & 0.192 & 0.826 \\
\hline WNK1_rs1159744_G/C & 130 & 89 & 10 & 133 & 83 & 13 & 229 & 0.762 & 0.238 & 0.557 \\
\hline WNK1_rs2107614_G/A & 112 & 101 & 16 & 115 & 94 & 19 & 229 & 0.710 & 0.290 & 0.569 \\
\hline WNK1_rs2277869_C/T & 157 & 60 & 12 & 153 & 69 & 8 & 229 & 0.817 & 0.183 & 0.166 \\
\hline WNK1_rs3088353_G/T & 73 & 95 & 61 & 63 & 114 & 51 & 229 & 0.526 & 0.474 & 0.039 \\
\hline WNK1_rs765250_G/A & 111 & 101 & 17 & 114 & 95 & 20 & 229 & 0.705 & 0.295 & 0.655 \\
\hline FAM120C_rs2495801_C/T & 204 & $\operatorname{chr} X$ & 25 & $\operatorname{chr} X$ & $\operatorname{chr} X$ & $\operatorname{chr} X$ & 229 & 0.891 & 0.109 & $\operatorname{chr} \mathrm{X}$ \\
\hline WNK3_rs3021280_G/T & 224 & $\operatorname{chr} X$ & 5 & $\operatorname{chr} \mathrm{X}$ & $\operatorname{chr} \mathrm{X}$ & $\operatorname{chr} X$ & 229 & 0.978 & 0.022 & $\operatorname{chr} \mathrm{X}$ \\
\hline WNK3_rs3021284_A/T & 208 & $\operatorname{chr} X$ & 21 & $\operatorname{chr} \mathrm{X}$ & $\operatorname{chr} \mathrm{X}$ & $\operatorname{chr} X$ & 229 & 0.908 & 0.092 & $\operatorname{chr} \mathrm{X}$ \\
\hline WNK3_rs3021285_C/T & 208 & $\operatorname{chr} X$ & 21 & $\operatorname{chr} X$ & $\operatorname{chr} X$ & $\operatorname{chr} X$ & 229 & 0.908 & 0.092 & $\operatorname{chr} \mathrm{X}$ \\
\hline WNK3_rs7880501_C/T & 224 & $\operatorname{chr} X$ & 5 & $\operatorname{chr} \mathrm{X}$ & $\operatorname{chr} \mathrm{X}$ & $\operatorname{chr} X$ & 229 & 0.978 & 0.022 & $\operatorname{chr} \mathrm{X}$ \\
\hline WNK4_rs61755606_G/A & 193 & 34 & 2 & 193 & 35 & 2 & 229 & 0.917 & 0.083 & 0.935 \\
\hline WNK4_rs75596106_G/C & NP & NP & NP & NP & NP & NP & NP & NP & NP & NP \\
\hline WNK4_rs77012584_C/T & NP & NP & NP & NP & NP & NP & NP & NP & NP & NP \\
\hline WNK4_rs77879367_G/T & NP & NP & NP & NP & NP & NP & NP & NP & NP & NP \\
\hline WNK4_rs78645838_G/A & 208 & 20 & 1 & 208 & 21 & 1 & 229 & 0.952 & 0.048 & 0.793 \\
\hline
\end{tabular}

NP not polymorphic 


\subsubsection{Effects of the twelve selected polymorphisms in $\mathrm{NR3C2}$ gene on $\mathrm{NaCl}$ and $\mathrm{K}^{+}$excretion} between 0 and $24 \mathrm{~h}$

To calculate the mean effect of the minor allele for each SNP, new compliment variable for each SNP was coded using SPSS ${ }^{\circledR}$ v20.0. The univariate command in SPSS ${ }^{\circledR}$ was used on both variables (SNP and its complimentary) using the main effect model and the "estimate parameters" option. The effects of one minor allele was calculated, after that the effect of one minor allele was multiplied by 2 to mimic the 2 minor allele effects.

The impact of 12 SNPs on potassium excretion after administration of bumetanide and torsemide. The figure depicts the difference in $\mathrm{K}+$ excretion between the participants carrying two minor alleles from each SNP. Each rhombus reflects the mean amount of K+ excreted in $24 \mathrm{~h}$ and the area of it reflects the number on the minor allele carriers in our clinical studies. Figures from other used diuretics are looking almost the same as the one of bumetanide. 


\subsubsection{After moderate sodium chloride restriction}

\section{Sodium and chloride excretion per two alleles between 0 and $24 \mathrm{~h}$ after moderate sodium chloride restriction}

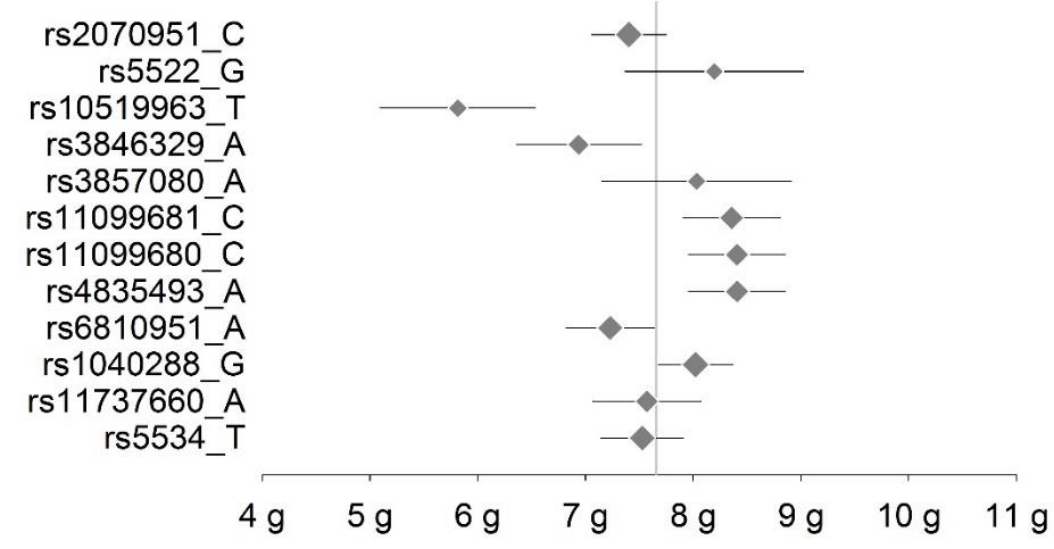

\section{Potassium excretion per two alleles between 0 and $24 \mathrm{~h}$ after moderate sodium chloride restriction}

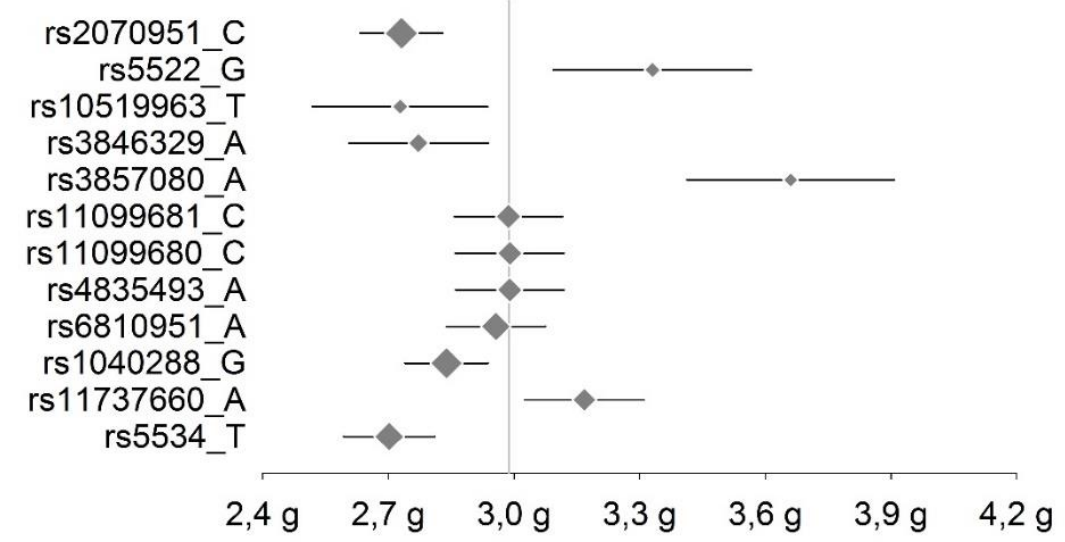

Supplementary figure 1: The impact of 12 SNPs on sodium chloride and potassium excretion after moderate sodium chloride restriction

The figure depicts the difference in $\mathrm{NaCl}$ and $\mathrm{K}+$ excretion between the participants carrying 2 minor alleles for each SNP. Each rhombus reflects the mean amount of $\mathrm{K}+$ excreted in $24 \mathrm{~h}$ and the area of it reflects the number on the minor allele carriers in our clinical studies. The middle line is the mean excretion of all 2 minor alleles groups. 


\subsubsection{After bumetanide, furosemide and torsemide}

Sodium and chloride excretion per two alleles between 0 and $24 \mathrm{~h}$

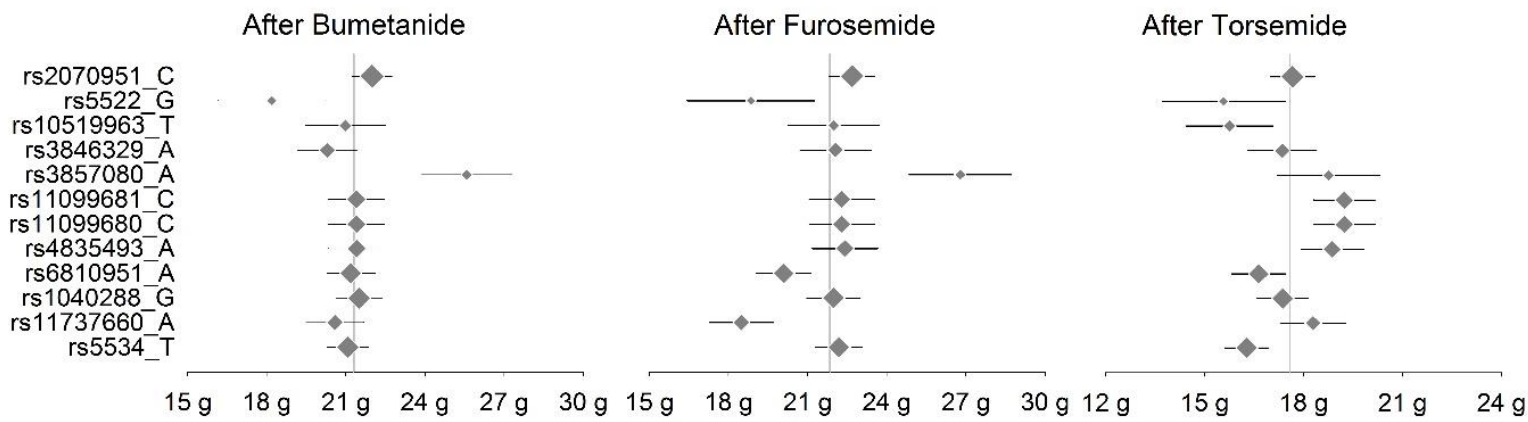

Potassium excretion per two alleles between 0 and $24 \mathrm{~h}$

After Bumetanide

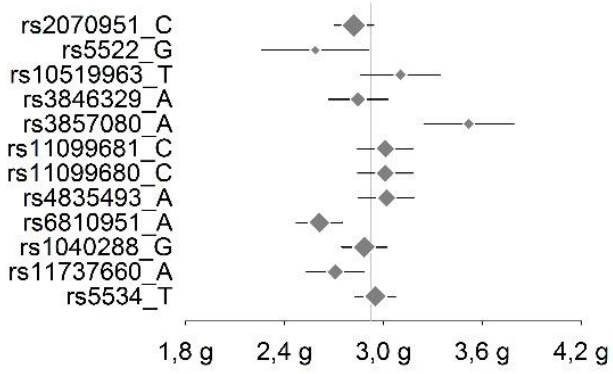

After Furosemide

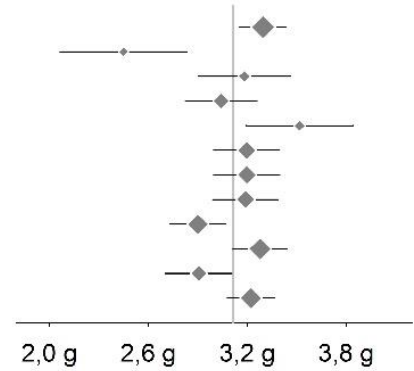

After Torsemide

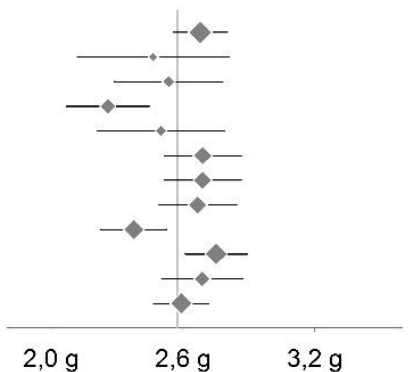

Supplementary figure 2: The impact of 12 SNPs on sodium chloride and potassium excretion after bumetanide, furosemide and torsemide

The figure depicts the difference in $\mathrm{NaCl}$ and $\mathrm{K}+$ excretion between the participants carrying 2 minor alleles for each SNP. Each rhombus reflects the mean amount of $K+$ excreted in $24 \mathrm{~h}$ and the area of it reflects the number on the minor allele carriers in our clinical studies. The middle line is the mean excretion of all 2 minor alleles groups. 


\subsubsection{After hydrochlorothiazide}

Sodium and chloride excretion per two alleles between 0 and $24 \mathrm{~h}$ After Hydrochlorothiazide $100 \mathrm{mg}$

After Hydrochlorothiazide $25 \mathrm{mg}$

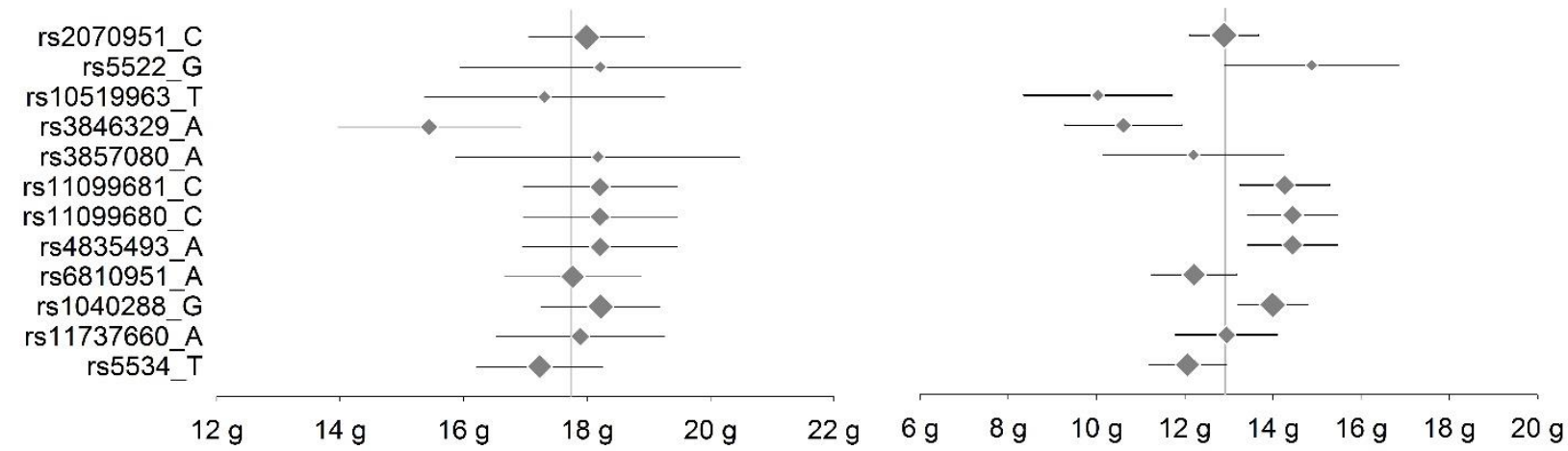

Potassium excretion per two alleles between 0 and $24 \mathrm{~h}$

After Hydrochlorothiazide $100 \mathrm{mg}$

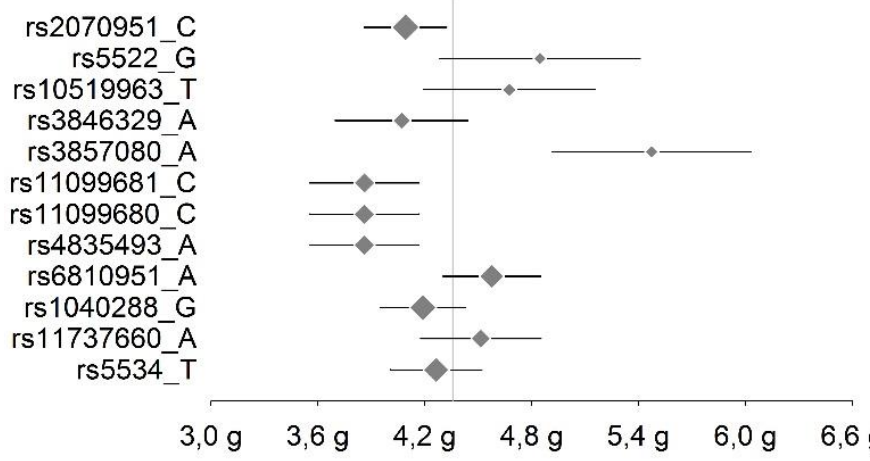

After Hydrochlorothiazide $25 \mathrm{mg}$

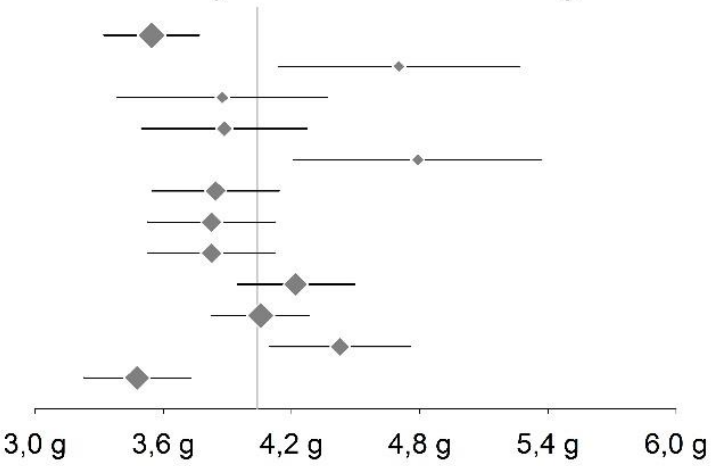

Supplementary figure 3: The impact of 12 SNPs on sodium chloride and potassium excretion after hydrochlorothiazide 25 and $100 \mathrm{mg}$

The figure depicts the difference in $\mathrm{NaCl}$ and $\mathrm{K}+$ excretion between the participants carrying 2 minor alleles for each SNP. Each rhombus reflects the mean amount of $K+$ excreted in $24 \mathrm{~h}$ and the area of it reflects the number on the minor allele carriers in our clinical studies. The middle line is the mean excretion of all 2 minor alleles groups. 


\subsubsection{After triamterene}

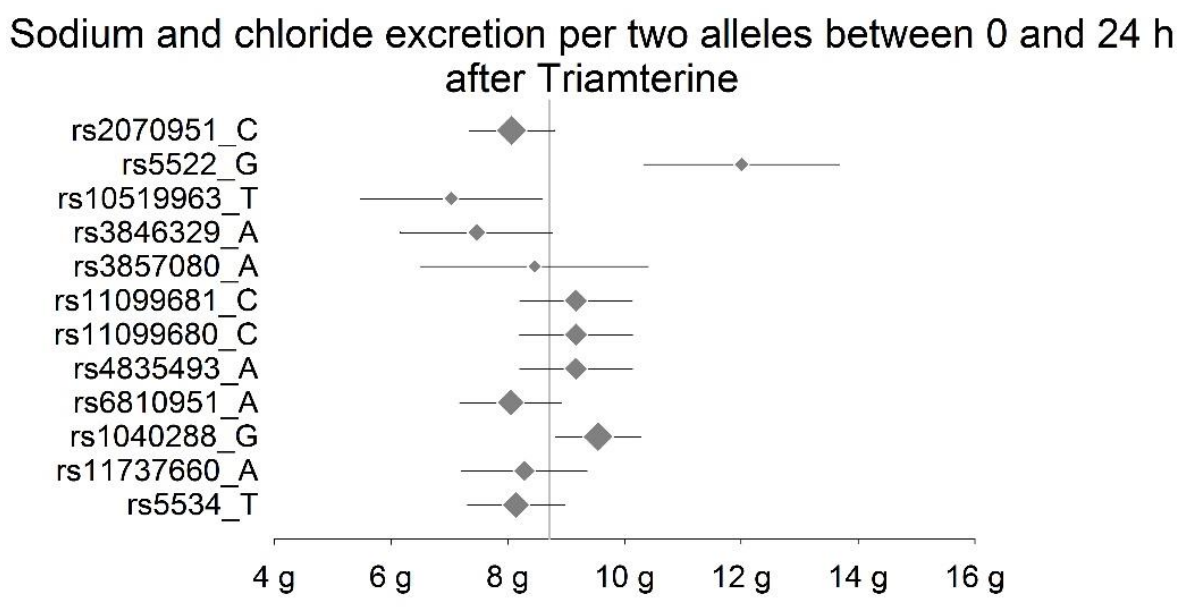

\section{Potassium excretion per two alleles between 0 and $24 \mathrm{~h}$ after Triamterine}

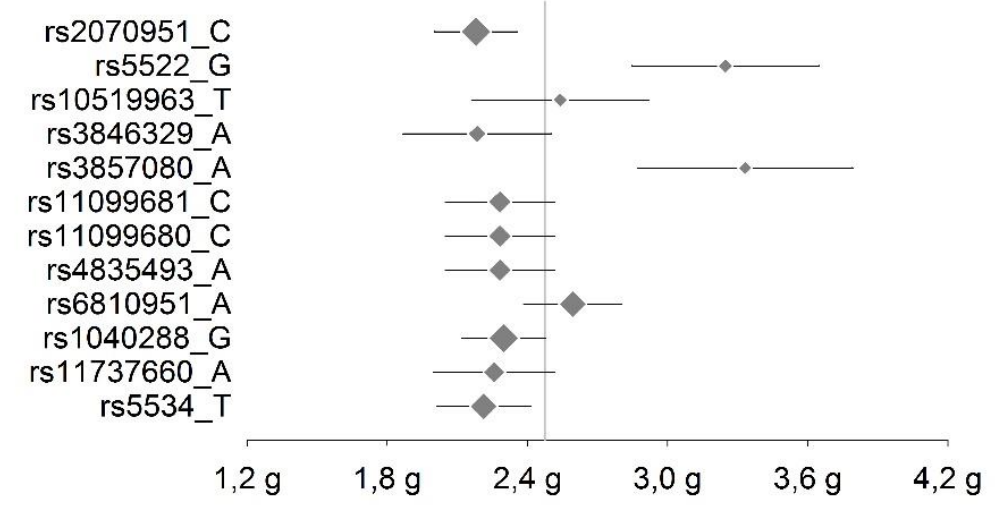

Supplementary figure 4: The impact of 12 SNPs on sodium chloride and potassium excretion after triamterene

The figure depicts the difference in $\mathrm{NaCl}$ and $\mathrm{K}+$ excretion between the participants carrying 2 minor alleles for each SNP. Each rhombus reflects the mean amount of $K+$ excreted in $24 \mathrm{~h}$ and the area of it reflects the number on the minor allele carriers in our clinical studies. The middle line is the mean excretion of all 2 minor alleles groups. 


\subsubsection{Predicted transcription factors by TRANSFAC ${ }^{\circledR}$}

The next table is summarizing the different transcription factors binding sites behavior (TFBS) of the transcription factors that have a known Position Weight Matrix (PWM) in TRANSFAC. The last two columns in the table are describing the frequencies for which these used PWM was found in the major-G allele of rs3857080 (WT) sequence or in the minor-A allele of rs3857080 (variant). When 0 appears in the WT frequency column, it means no hit for that PWM in WT but a hit in the variant sequence. Some hits are found only or more frequently in the WT-sequence compared to the variant. This explains the different number in non-zero entries.

Supplementary table 4: Prediction of transcription factors binding sites to the rs3857080 region by TRANSFAC

\begin{tabular}{|c|c|c|c|c|c|c|c|}
\hline $\begin{array}{l}\text { Transfac Matrix } \\
\text { Identifier }\end{array}$ & Protein Name & $\begin{array}{c}\text { WT } \\
\text { frequency }\end{array}$ & $\begin{array}{c}\text { Variant } \\
\text { frequency }\end{array}$ & $\begin{array}{l}\text { Transfac Matrix } \\
\text { Identifier }\end{array}$ & Protein Name & $\begin{array}{c}\text { WT } \\
\text { frequency }\end{array}$ & $\begin{array}{c}\text { Variant } \\
\text { frequency }\end{array}$ \\
\hline V\$MSX1_02 & Msx-1 & 14 & 15 & V\$PITX3_01 & Pitx3 & 2 & 1 \\
\hline V\$SOX4_01 & Sox4 & 13 & 15 & V\$TCF1_07 & Tcf1 & 2 & 1 \\
\hline V\$NKX12_01 & Nkx1-2 & 13 & 12 & V\$CDP_02 & CDP & 2 & 0 \\
\hline V\$BARX1_01 & Barx1 & 10 & 11 & V\$SOX5_04 & Sox5 & 2 & 0 \\
\hline V\$LHX4_01 & Lhx4 & 10 & 11 & V\$HMGIY_01 & HMGIY & 1 & 3 \\
\hline V\$NKX11_01 & Nkx1-1 & 10 & 9 & V\$OCT1_07 & Oct-1 & 1 & 3 \\
\hline V\$RAX_01 & $\operatorname{rax}$ & 10 & 9 & V\$PAX6_01 & Pax-6 & 1 & 3 \\
\hline V\$TBX5_Q5 & TBX5 & 9 & 11 & V\$SRY_02 & SRY & 1 & 3 \\
\hline V\$E2F1_01 & $\mathrm{E} 2 \mathrm{~F}-1$ & 9 & 8 & V\$AP1_01 & $\mathrm{AP}-1$ & 1 & 2 \\
\hline V\$GBX2_01 & Gbx2 & 8 & 10 & V\$AP1_02 & AP1 & 1 & 2 \\
\hline V\$HOXC6_01 & HOXC6 & 8 & 7 & V\$AP1_Q6_02 & $\mathrm{AP}-1$ & 1 & 2 \\
\hline V\$NKX24_01 & Nkx2-4 & 7 & 8 & V\$CDX2_Q5 & Cdx-2 & 1 & 2 \\
\hline V\$PMX2A_01 & PMX2A & 7 & 8 & V\$CREBP1CJUN_01 & ATF2:C-Jun & 1 & 2 \\
\hline V\$ALX3_01 & Alx3 & 6 & 8 & V\$ELF4_04 & Elf3 & 1 & 2 \\
\hline V\$BARHL1_01 & Barhl-1 & 6 & 8 & V\$FOXD3_01 & FOXD3 & 1 & 2 \\
\hline V\$HOXA10_01 & HOXA10 & 6 & 8 & V\$FXR_Q3 & FXR/RXR-alpha & 1 & 2 \\
\hline V\$HOXD10_01 & HOXD10 & 6 & 8 & V\$HOXA9_01 & hoxa9 & 1 & 2 \\
\hline V\$ISGF4G_04 & Isgf3g & 6 & 8 & V\$IPF1_05 & IPF1 & 1 & 2 \\
\hline V\$NKX26_01 & Nkx2-6 & 6 & 8 & V\$MAFB_01 & MAFB & 1 & 2 \\
\hline V\$ESX1_01 & Esx1 & 6 & 7 & V\$OCT1_Q6 & Oct-1 & 1 & 2 \\
\hline V\$HMX3_02 & Nkx5-1 & 6 & 7 & V\$OCTAMER_02 & Octamer & 1 & 2 \\
\hline V\$HOXA3_02 & HOXA3 & 6 & 7 & V\$PAX8_01 & Pax-8 & 1 & 2 \\
\hline V\$HOXC4_01 & HOXC4 & 6 & 7 & V\$PBX1_04 & $\mathrm{Pbx} 1$ & 1 & 2 \\
\hline V\$ISL2_01 & $|s| 2$ & 6 & 7 & V\$PBX1_05 & $\mathrm{Pbx}$ & 1 & 2 \\
\hline V\$LMX1_01 & $\operatorname{Lmx}-1$ & 6 & 7 & V\$SOX1_03 & Sox1 & 1 & 2 \\
\hline V\$LMX1B_01 & $\operatorname{Im} \times 1 b$ & 6 & 7 & V\$SOX7_04 & Sox7 & 1 & 2 \\
\hline V\$NKX52_01 & Nkx5-2 & 6 & 7 & V\$SOX8_04 & Sox8 & 1 & 2 \\
\hline V\$PMX2B_01 & PMX2B & 6 & 7 & V\$SOX9_B1 & SoX9 & 1 & 2 \\
\hline V\$UNCX4.1_01 & Uncx-4.1 & 6 & 7 & V\$XFD1_01 & XFD-1 & 1 & 2 \\
\hline V\$SRF_06 & Srf & 6 & 5 & V\$XFD2_01 & XFD-2 & 1 & 2 \\
\hline V\$BRN4_01 & Brn-4 & 5 & 7 & V\$ZIC2_05 & Zic2 & 1 & 2 \\
\hline V\$DBX2_01 & $\mathrm{Db} \times 2$ & 5 & 7 & V\$ARID3A_02 & Arid3a & 1 & 0 \\
\hline
\end{tabular}




\begin{tabular}{|c|c|c|c|c|c|c|}
\hline V\$K2B_01 & $K-2 b$ & 5 & 7 & V\$CACD_01 & CACD & 1 \\
\hline V\$BARHL2_01 & Barhl2 & 5 & 6 & V\$CDPCR3HD_01 & CDP CR3+HD & 1 \\
\hline V\$LHX61_01 & Ihx6.1 & 5 & 6 & V\$CLOX_01 & Clox & 1 \\
\hline V\$LHX8_01 & Lhx8 & 5 & 6 & V\$CMAF_01 & c-Maf & 1 \\
\hline V\$PROP1_02 & Prop-1 & 5 & 6 & V\$CREBATF_Q6 & CREB, ATF & 1 \\
\hline V\$CDP_04 & CDP & 5 & 4 & V\$GATA1_01 & GATA-1 & 1 \\
\hline V\$HOXA2_01 & HoxA2 & 5 & 4 & V\$GATA2_03 & GATA-2 & 1 \\
\hline V\$HOXA6_01 & HOXA6 & 5 & 4 & V\$GATA3_03 & GATA-3 & 1 \\
\hline V\$HOXD11_01 & HOXD11 & 5 & 4 & V\$GATA6_05 & Gata-6 & 1 \\
\hline V\$SRY_01 & SRY & 5 & 4 & V\$GFI1B_01 & Gfi1b & 1 \\
\hline V\$VAX1_01 & Vax-1 & 5 & 4 & V\$GMEB1_04 & Gmeb1 & 1 \\
\hline V\$EN1_02 & En-1 & 4 & 6 & V\$IRF5_03 & IRF-5 & 1 \\
\hline V\$EVX1_01 & Evx-1 & 4 & 6 & V\$IRF6_03 & IRF-6 & 1 \\
\hline V\$HDX_01 & $\mathrm{Hdx}$ & 4 & 6 & V\$IRF7_01 & IRF-7 & 1 \\
\hline V\$HMGIY_Q3 & HMGIY & 4 & 6 & V\$ISGF3G_03 & IRF-9 & 1 \\
\hline V\$HOXD8_01 & HOXD8 & 4 & 6 & V\$MINI19_B & $\begin{array}{l}\text { Muscle initiator } \\
\text { sequences-19 }\end{array}$ & 1 \\
\hline V\$MSX3_01 & Msx-3 & 4 & 6 & V\$MUSCLEINI_B & Muscle initiator & 1 \\
\hline V\$NKX63_01 & Nkx6-3 & 4 & 6 & V\$NRF2_Q4 & Nrf-2 & 1 \\
\hline V\$TST1_02 & Oct-6 & 4 & 6 & V\$OTX_Q1 & OTX & 1 \\
\hline V\$EMX2_01 & EMX2 & 4 & 5 & V\$PAX5_02 & Pax-5 & 1 \\
\hline V\$FOXJ2_02 & FOXJ2 & 4 & 5 & V\$PITX1_Q6 & PITX1 & 1 \\
\hline V\$GTF2IRD1_01 & $\begin{array}{l}\text { GTF2IRD1- } \\
\text { isoform2 }\end{array}$ & 4 & 5 & V\$SMAD_Q6 & SMAD & 1 \\
\hline V\$HOXA1_01 & HOXA1 & 4 & 5 & V\$SP100_04 & Sp100 & 1 \\
\hline V\$HOXB6_01 & HOXB6 & 4 & 5 & V\$AP1_Q2 & AP-1 & 0 \\
\hline V\$HOXB7_01 & HOXB7 & 4 & 5 & V\$ARID5A_03 & Arid5a & 0 \\
\hline V\$MEIS2_01 & Meis2 & 4 & 5 & V\$BRN2_01 & Brn-2 & 0 \\
\hline V\$NKX25_02 & Nkx2-5 & 4 & 5 & V\$CART1_02 & CART1 & 0 \\
\hline V\$OTP_01 & OTP & 4 & 5 & V\$CEBPG_Q6 & C/EBPgamma & 0 \\
\hline V\$RHOX11_01 & Rhox11 & 4 & 3 & V\$OG2_02 & OG-2 & 0 \\
\hline V\$RHOX11_02 & Rhox11 & 4 & 3 & V\$PAX4_05 & Pax-4 & 0 \\
\hline V\$SIX3_01 & Six-3 & 4 & 3 & V\$SOX11_04 & Sox11 & 0 \\
\hline V\$SIX6_02 & Six-6 & 4 & 3 & V\$SOX5_07 & Sox4 & 0 \\
\hline V\$SIX1_01 & Six-1 & 4 & 2 & V\$AHR_01 & AhR & 0 \\
\hline V\$HOXB9_01 & HOXB9 & 3 & 5 & V\$AP1FJ_Q2 & AP-1 & 0 \\
\hline V\$HOXC9_01 & HOXC9 & 3 & 5 & V\$AP1_Q2_01 & AP-1 & 0 \\
\hline V\$MSX2_01 & Msx-2 & 3 & 5 & V\$AP1_Q4 & AP-1 & 0 \\
\hline V\$PAX6_02 & pax6 & 3 & 5 & V\$AP1_Q4_01 & AP-1 & 0 \\
\hline V\$SOX15_04 & Sox15 & 3 & 5 & V\$AP1_Q6 & AP-1 & 0 \\
\hline V\$CAP_01 & cap & 3 & 4 & V\$AP1_Q6_01 & $A P-1$ & 0 \\
\hline V\$GEN_INI2_B & GEN_INI & 3 & 4 & V\$CFOS_Q6 & c-Fos & 0 \\
\hline V\$GEN_INI3_B & GEN_INI & 3 & 4 & V\$CJUN_Q6 & C-Jun & 0 \\
\hline V\$GEN_INI_B & GEN_INI & 3 & 4 & V\$CREB1_Q6 & CREB1 & 0 \\
\hline V\$HOXA4_Q2 & HOXA4 & 3 & 4 & V\$CREB_Q3 & CREB & 0 \\
\hline V\$HOXD13_01 & HOXD13 & 3 & 4 & V\$DMRT4_01 & DMRT4 & 0 \\
\hline V\$LEF1_03 & Lef1 & 3 & 4 & V\$ERALPHA_Q6_01 & ER-alpha & 0 \\
\hline V\$NKX25_03 & NKX25 & 3 & 4 & V\$ERALPHA_Q6_02 & ER-alpha & 0 \\
\hline V\$SOX17_04 & Sox17 & 3 & 4 & V\$ER_Q6 & ER & 0 \\
\hline V\$SOX5_01 & SOX5 & 3 & 4 & V\$ESR1_01 & ESR1 & 0 \\
\hline V\$SRY_Q6 & SRY & 3 & 4 & V\$FOXA2_04 & HNF3-beta & 0 \\
\hline V\$VAX2_01 & Vax-2 & 3 & 4 & V\$HBP1_Q2 & hbp1 & 0 \\
\hline
\end{tabular}




\begin{tabular}{|c|c|c|c|c|c|c|c|}
\hline V\$HNF4A_02 & $\mathrm{Hnf} 4 \mathrm{a}$ & 3 & 2 & V\$HMEF2_Q6 & MEF-2 & 0 & 1 \\
\hline V\$OBOX3_01 & Obox3 & 3 & 2 & V\$HNF1_Q6 & HNF1 & 0 & 1 \\
\hline V\$OTX3_01 & Otx3 & 3 & 2 & V\$HNF4A_04 & HNF4-alpha & 0 & 1 \\
\hline V\$SIX4_01 & six 4 & 3 & 2 & V\$HNF6_Q4 & HNF-6 & 0 & 1 \\
\hline V\$SIX6_01 & Six-6 & 3 & 2 & V\$ICSBP_Q6 & ICSBP & 0 & 1 \\
\hline V\$CPHX_01 & Cphx & 3 & 1 & V\$JUNB_Q6 & JunB & 0 & 1 \\
\hline V\$GATA1_03 & GATA-1 & 3 & 1 & V\$JUND_Q6 & JunD & 0 & 1 \\
\hline V\$OBOX2_01 & Obox2 & 3 & 1 & V\$LXR_Q6 & LXR; FXR & 0 & 1 \\
\hline V\$OBOX5_02 & Obox5 & 3 & 1 & V\$MAFK_04 & Mafk & 0 & 1 \\
\hline V\$TST1_01 & Tst-1 & 2 & 6 & V\$MAF_Q6_01 & MAF & 0 & 1 \\
\hline V\$CART1_03 & CART1 & 2 & 4 & V\$MEF2_01 & MEF-2 & 0 & 1 \\
\hline V\$DLX5_Q3 & dlx5 & 2 & 4 & V\$MEF2C_Q4 & MEF-2C & 0 & 1 \\
\hline V\$EVX2_01 & Evx2 & 2 & 4 & V\$MEIS1_01 & MEIS1 & 0 & 1 \\
\hline V\$HB9_01 & HB9 & 2 & 4 & V\$MEIS1AHOXA9_01 & MEIS1A:HOXA9 & 0 & 1 \\
\hline V\$HOX13_02 & HOXA5 & 2 & 4 & V\$MYOGNF1_01 & myogenin / NF-1 & 0 & 1 \\
\hline V\$OCT1_08 & Oct-1 & 2 & 4 & V\$NKX25_Q5 & Nkx2-5 & 0 & 1 \\
\hline V\$POU4F1_Q6 & POU4F1 & 2 & 4 & V\$OC2_Q3 & OC-2 & 0 & 1 \\
\hline V\$PSX1_01 & PSX1 & 2 & 4 & V\$PAX4_01 & Pax-4 & 0 & 1 \\
\hline V\$BRN1_Q6 & BRN1 & 2 & 3 & V\$PAX_Q6 & Pax & 0 & 1 \\
\hline V\$BRN3C_01 & Brn-3c & 2 & 3 & V\$PBX1_02 & $P b x-1 b$ & 0 & 1 \\
\hline V\$CMAF_02 & C-MAF & 2 & 3 & V\$PBX1_03 & $\mathrm{Pbx}-1$ & 0 & 1 \\
\hline V\$FOXA2_02 & Foxa2 & 2 & 3 & V\$PLZF_02 & PLZF & 0 & 1 \\
\hline V\$FOXM1_01 & FOXM1 & 2 & 3 & V\$PPARG_01 & PPARgamma:RXRalpha & 0 & 1 \\
\hline V\$ISL2_03 & $|s| 2$ & 2 & 3 & V\$PPARG_02 & $\begin{array}{l}\text { PPARgamma:RXRalpha, } \\
\text { PPARgamma }\end{array}$ & 0 & 1 \\
\hline V\$NCX_01 & Ncx & 2 & 3 & V\$RARA_04 & Rara & 0 & 1 \\
\hline V\$NCX_02 & Ncx & 2 & 3 & V\$RBPJK_01 & RBP-Jkappa & 0 & 1 \\
\hline V\$NFE2_01 & NF-E2 & 2 & 3 & V\$SOX15_03 & Sox15 & 0 & 1 \\
\hline V\$NKX25_01 & Nkx2-5 & 2 & 3 & V\$SOX18_03 & Sox18 & 0 & 1 \\
\hline V\$NKX25_Q6 & Nkx-2.5 & 2 & 3 & V\$TBR2_01 & TBR2 & 0 & 1 \\
\hline V\$PAX4_02 & Pax-4 & 2 & 3 & V\$TCF11_01 & TCF11 & 0 & 1 \\
\hline V\$PIT1_01 & Pit-1 & 2 & 3 & V\$TCF7L2_04 & Tcf7l2 & 0 & 1 \\
\hline V\$PRX2_Q2 & Prx2 & 2 & 3 & V\$TITF1_Q3 & TTF1 (Nkx2-1) & 0 & 1 \\
\hline V\$SRY_05 & Sry & 2 & 3 & V\$XFD3_01 & XFD-3 & 0 & 1 \\
\hline V\$FOX01_04 & FOXO1 & 2 & 1 & V\$YB1_Q4 & YB-1 & 0 & 1 \\
\hline V\$IRF4_04 & Irf4 & 2 & 1 & V\$YY1_01 & YY1 & 0 & 1 \\
\hline V\$MSX2_Q3 & Msx-2 & 2 & 1 & V\$ZFP105_04 & Zfp105 & 0 & 1 \\
\hline V\$OBOX1_01 & Obox1 & 2 & 1 & & & & \\
\hline
\end{tabular}




\subsubsection{Validating WNK4 polymorphisms}

The 5 detected and validated SNPs were genotyped in two batches among the $25^{\text {th }}$ possible detected polymorphisms. The used primers for making the PCR and SNaPShot ${ }^{\circledR}$ reactions are listed in the following tables:

Supplementary table 5: PCR primers for validating 5 SNPs in the WNK4 gene

\begin{tabular}{llcc}
\hline Primer name & Sequence & Amplicon lenght & Batch \\
\hline V358A_F & GGCCAGAGTGCCCAGCAATCTGATC & 218 & 1 \\
V358A_r & GCCCCATCCCTCTCACCGAAGTGAC & 218 & 1 \\
S239W_f & TGGGTGTCCTGGGCCTGACATGACA & 213 & 1 \\
S239W_r & TGAGCGTGCCCGAGGTCATGAGTTC & 213 & 1 \\
P1025L_f & GCTGGCGCCCATCTCTGAAGGTAAG & 289 & 1 \\
P1025L_r & CCGCCTCCAGCACTGTCCTCTGTAT & 289 & 1 \\
R1204C_f & CCGTGCATCCTCAGGCACTTGTCAG & 412 & 2 \\
R1204C_r & CCGGTGCTGCTGCCACTCAGAGAGT & 412 & 2 \\
S1073G_V1084A_f & TTGGGCGTTTCCAAGTGACTTCATC & 373 & 2 \\
S1073G_V1084A_r & AGCTCAGCCCAGAACTCCTCATCTT & 373 & 2 \\
\hline
\end{tabular}

Supplementary table 6: SNaPShot primers for validating 5 SNPs in the WNK4 gene

\begin{tabular}{llcc|cc}
\hline Primer & Sequence & \multicolumn{3}{c}{ Alle 1 Allele 2 Primer Length Batch } \\
\hline V358A & TGCACATGCCGAACGCGTAC & $\mathrm{A}$ & $\mathrm{G}$ & 20 & 1 \\
S239W & gatcgatcCATCGTCCGCTTCTATGATT & $\mathrm{C}$ & $\mathrm{G}$ & 28 & 1 \\
P1025L_2 & gatcgatcgatcgatcgatcTCCAAGTGACTTCATCCAAGGAAC & $\mathrm{C}$ & $\mathrm{T}$ & 44 & 1 \\
V1084A & gatcgatcTGAGGGTCTGGGGGCTGGAG & $\mathrm{T}$ & $\mathrm{C}$ & 28 & 2 \\
R1204C & gatcgatcgatcgatcgatcgTCTCACCAGGGCCTGGGGGCTCAGAGC & $\mathrm{G}$ & $\mathrm{A}$ & 48 & 2 \\
\hline
\end{tabular}




\subsubsection{Gene expression in 20 tissues panel (NR3C2 - WNK4)}

Complimentary DNA was synthesized from mRNA of 20 tissues panel [methods 6.10]. Quantitative PCR was performed for both genes NR3C2 (the aldosterone receptor) and WNK4 (With no Lysine kinase 4) with the house keeping gene TBP (TATA box binding protein). Comparing the expression of both genes showed that WNK4 is expressed more than the $N R 3 C 2$ in some tissues while $N R 3 C 2$ is widely expressed over the different tissues.

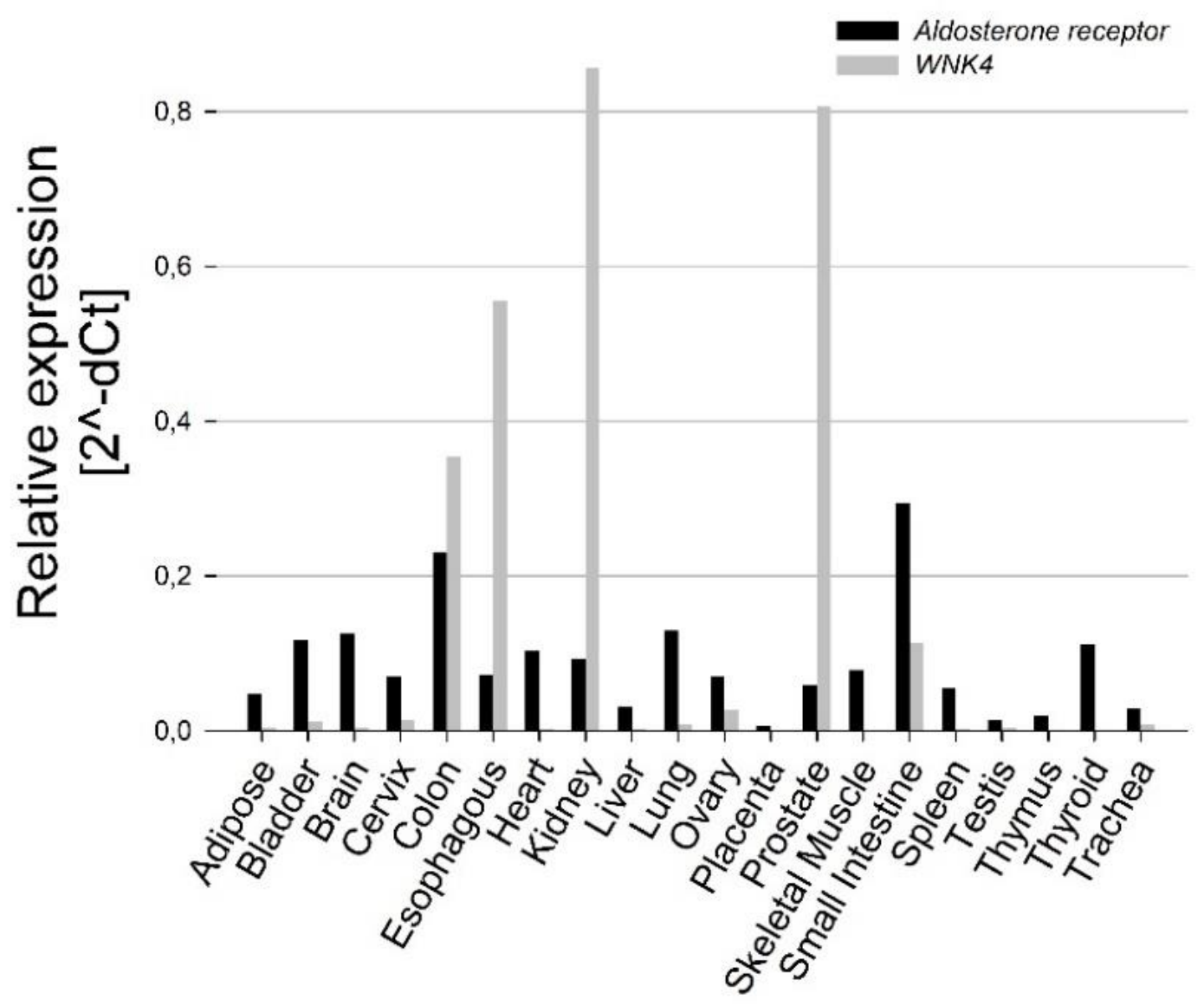

Supplementary figure 5: Expression of NR3C2 and WNK4 genes in 20 tissues panel 


\section{CURRICULUM VITAE}

Name : $\quad$ Nawar Dalila

Place and Date of Birth: Lattakia 03/03/1982

Nationality:

Syrian

Address:

Am Vogelsang 3, app121

37075, Göttingen

Germany

E-mail: nawar82@gmail.com

\section{Education}

2011-2014

$\mathrm{PhD}$ in the molecular medicine study program, institute of clinical pharmacology, University medical centre, Göttingen, Germany.

Research: Genetic polymorphisms in genes regulating renal ion excretion and diuretic drug effects

$2006-2008$

Master degree in Pharmaceutical sciences, Faculty of Pharmacy, Damascus University, Syria,

Research: Study on the Interaction of Clopidogrel with Statins in Test Animals

$2005-2006$

Diploma in Pharmaceutical sciences, Faculty of Pharmacy,

Damascus University, Syria.

$2000-2005$

Bachelor Degree in Pharmacy \& Pharmaceutical Chemistry Faculty of Pharmacy, Damascus University (with grade of "very good")

2000

Syrian Baccalaureate/Scientific section, Damascus-Syria

\section{$\underline{\text { Experiences }}$}

Sep 07 -Jan 11

Teaching assistant in practical courses of Biopharmaceutics \& Drug kinetics and Clinical \& Hospital Pharmacy at Kalamoon UniversityFaculty of Pharmacy, Syria.

Sep 07 -Sep 08 Teaching assistant in practical courses of Clinical \& Hospital Pharmacy at Damascus University - Faculty of Pharmacy, Syria.

Sep 07 - Jan 08 Teaching assistant in practical courses Analytical Chemistry at Kalamoon University- Faculty of Pharmacy, Syria.

Feb 06 - Aug 07 Medical Advisor, Barakat Pharmaceutical Industries, Damascus, Syria. (Recommendation letter available)

- Training responsible for new medical representatives in the company

- Providing the medical representatives in the company with the most up to date clinical information about the produced drugs

- Representing the company in scientific conferences by giving talks or presenting posters 
- Arranging scientific meetings with physicians

July 05 - Jan 06 Medical Representative, Barakat Pharmaceutical Industries, Damascus, Syria.

- Brief introduction to new drugs produced

- doctors' inquiries about the company's drug portfolio

March 04 - Aug 04 Medical Representative at Sandi-Pharma, Damascus, Syria.

July 02 - March 04 Training at Al-Anwar (private drug store), Damascus, Syria.

\section{Languages}

- Arabic: Mother tongue

- English: Fluent

- German: Good

- Swedish: Basic

\section{Other Experiences}

- $\quad$ MBTI Certificate (Myers-Briggs Types Indicator)

- NLP DIPLOMA from AMERICAN BOARD of NEURO - LIGNUSTIC PROGRAMMING

- Certificate First Aids from Syrian Red Crescent

\section{$\underline{\text { Publications }}$}

- Dalila N, Pharmacogenetics from discovery to patient care, Drug Information Journal, second volume (September2010), Damascus University publications.

\section{$\underline{\text { Scholarships }}$}

- Young scientists' scholarship in the European Association of Clinical Pharmacology and Therapeutics (EACPT 2013) in Geneva. 